UNIVERSIDADE DE SÃO PAULO

INSTITUTO DE PSICOLOGIA

JULIANA CRISTINA DONADONE

\title{
ANÁLISE DE CONTINGÊNCIAS DE ORIENTAÇÕES E AUTO-ORIENTAÇÕES EM INTERVENÇÕES CLÍNICAS COMPORTAMENTAIS
}

SÃO PAULO

2009 
UNIVERSIDADE DE SÃO PAULO

INSTITUTO DE PSICOLOGIA

JULIANA CRISTINA DONADONE

\section{ANÁLISE DE CONTINGÊNCIAS DE ORIENTAÇÕES E AUTO-ORIENTAÇÕES EM INTERVENÇÕES CLÍNICAS COMPORTAMENTAIS}

Trabalho apresentado ao Instituto de Psicologia da Universidade de São Paulo para obtenção do título de Doutor em Psicologia.

Área de concentração: Psicologia Clínica.

Orientadora: Prof. ${ }^{\text {a }}$ Dr. ${ }^{a}$ Sonia Beatriz Meyer

Bolsista Capes doutorado (março de 2005 a março de 2009)

São Paulo

2009 


\section{AUTORIZO A REPRODUÇÃO E DIVULGAÇÃO TOTAL OU PARCIAL DESTE TRABALHO, POR QUALQUER MEIO CONVENCIONAL OU ELETRÔNICO, PARA FINS DE ESTUDO E PESQUISA, DESDE QUE CITADA A FONTE.}

Catalogação na publicação

Biblioteca Dante Moreira Leite

Instituto de Psicologia da Universidade de São Paulo

Donadone, Juliana Cristina.

Análise de contingências de orientações e auto-orientações em intervenções clínicas comportamentais / Juliana Cristina Donadone; orientadora Sônia Beatriz Meyer. -- São Paulo, 2009.

$290 \mathrm{p}$.

Tese (Doutorado - Programa de Pós-Graduação em Psicologia. Área de Concentração: Psicologia Clínica) - Instituto de Psicologia da Universidade de São Paulo.

1. Comportamento governado por regras 2. Terapia comportamental 3. Análise de contingências 4. Aconselhamento I. Título.

RC489.B4 


\section{FOLHA DE APROVAÇÃO}

Juliana Cristina Donadone

Análise de Contingências de Orientações e Auto-orientações em Intervenções Clínicas Comportamentais

Tese apresentada ao Instituto de Psicologia da Universidade de São Paulo para obtenção do título de Doutor em Psicologia

Área de concentração: Psicologia Clínica

Orientadora: Prof. ${ }^{a}$ Dr. ${ }^{\text {a }}$ Sonia Beatriz Meyer

Aprovada em:

\section{Banca Examinadora}

Prof. Dr. a Sonia Beatriz Meyer Universidade de São Paulo 


\section{DEDICATÓRIA}

Dedico este trabalho aos meus pais Élio e Maria Lucia, a quem agradeço pela vida, pelo cuidado, pelo carinho e pelo apoio incondicional por toda minha vida. 


\section{AGRADECIMENTOS}

A minha querida orientadora Sonia Beatriz Meyer pelas contribuições a este trabalho e orientação cuidadosa durante todos esses anos, além do excelente modelo de pesquisadora.

À Capes, pelo vital apoio financeiro.

A meus pais, pelo apoio financeiro, intelectual e pelo carinho e compreensão sem os quais seria muito difícil realizar esta pesquisa.

Aos meus irmãos Fábio e Julio, pelo exemplo de profissionais e pesquisadores.

Aos terapeutas e clientes participantes desta pesquisa, em especial às terapeutas Clarissa Giani Cabral Maragno e Silmare Bertolani, pelo empenho e contribuições valiosos.

A Fernanda Pallone pelo aceite da difícil tarefa de ser juiz desta pesquisa.

Aos amigos de São Carlos: Juliana Teodoro, Giuliana Romano, Heloisa Bandini, Sandra Brockson e em especial a Camila Muchon, Naiene Pimentel e Carmem Bandini pela leitura atenta desta tese e pelas discussões animadas.

Às amigas Lili Monteiro e Carol Marcideli, pela impecável hospedagem em São Paulo, além das conversas divertidíssimas.

Aos meninos da informática Rafael e Julio, pela dedicação ao trabalho, paciência, compreensão e carinho.

E a todos os amigos que passaram por minha vida e que, de uma forma ou de outra, contribuíram para a realização deste trabalho.

\section{MUITO OBRIGADA!}


"Enquanto homens conversarem entre si sempre haverá uma hipótese implícita de que afguma correspondência existe entre conversar e fazer. "( $(\mathcal{L}$ oyd, 1984, pág.14,3) 


\section{RESUMO}

Donadone, J.C. (2009). Análise de Contingências de Orientações e Auto-orientações em Intervenções Clínicas Comportamentais. Tese de Doutorado. Instituto de Psicologia, Universidade de São Paulo.

Há debates sobre quais são os mecanismos responsáveis por mudanças ocorridas em psicoterapias. Pergunta-se se são as técnicas específicas ou as variáveis da relação terapêutica que propiciam os efeitos da terapia. Também tem sido questionado se mudanças comportamentais produzidas pela terapia são modeladas por contingências da relação terapêutica ou são governadas por novas regras produzidas na terapia. Nas pesquisas sobre emissão de regras (orientação) e autorregras (auto-orientação) anteriores a esta pesquisa não foram encontradas variáveis responsáveis por sua emissão. A determinação da utilização da estratégia de orientação ora parecia ser o cliente, ora o terapeuta, ora nenhum deles, ora o tema abordado, e possivelmente uma complexa combinação destas e de outras variáveis. O estudo detalhado das orientações e auto-orientações de 81 sessões de terapia analítico-comportamental foi realizado nesta pesquisa com o objetivo de verificar quais as variáveis responsáveis pela emissão de orientação e auto-orientação em intervenções clínicas comportamentais. Os resultados indicaram que a maioria dos terapeutas emitiu de 40 a 60 orientações nas nove sessões analisadas. Os clientes dos terapeutas independente da experiência apresentaram poucas auto-orientações. O número de orientações diminuiu para menos da metade quando se contaram apenas orientações com conteúdos e funções diferentes, indicando que os terapeutas tendem a 'repetir' funcionalmente a orientação. Para as auto-orientações houve diminuição de um quarto ao se contarem aquelas com conteúdo e função diferente. $\mathrm{O}$ conjunto de terapeutas emitiu mais orientações para ação específica e genérica; e de forma similar os clientes destes terapeutas emitiram mais autoorientações para ação específica e auto-orientações para ação genérica. Episódios de orientação/auto-orientação foram identificados nas 81 sessões, ocupando em média um terço das sessões dos terapeutas experientes e um quarto das sessões dos terapeutas pouco experientes. E nesses episódios havia diversos tipos de intervenção do terapeuta além da orientação. Orientações são emitidas de modo geral no seguinte contexto: clientes relatam uma situação vivenciada e algumas intervenções do terapeuta ocorrem. Quando clientes mostram dificuldade em assumir responsabilidade, enfrentar e avaliar seus comportamentos há fornecimento de regras pelo terapeuta. Os clientes na maioria das vezes concordam com as orientações recebidas, em um quarto das ocasiões se opõem a ela e em um sexto recebem novas orientações. Dois terços das auto-orientações foram seguidos de aprovação do terapeuta, mas ocorreram também reprovações. As variáveis intervenientes "temas", "motivação" e "escolaridade" foram consideradas e correlacionadas: existe pouca relação entre tema abordado e presença de orientação/auto-orientação; clientes motivados receberam mais orientações que os desmotivados e resistentes; quanto maior a escolaridade do cliente maior o número de auto-orientações. $10 \%$ da amostra foram avaliados por um juiz, com índices de concordância juiz-pesquisador satisfatórios indicando confiabilidade. Futuras pesquisas devem ser realizadas para correlacionar o uso de regras e os resultados das intervenções clínicas comportamentais.

Palavras Chave: regras; terapia analítico-comportamental, análise de contingências; orientação; auto-orientação. 


\begin{abstract}
Donadone, J.C. (2009). Contingency Analysis of Orientation and Self-orientation in Behavioral Clinical Interventions. Doctoral Thesis. Institute of Psychology, University of São Paulo.
\end{abstract}

Mechanisms responsible for changes that occur in psychotherapy are subject to debate. The question is whether specific techniques or variables of the therapeutic relationship promote the effects of the therapy. Another question is whether behavioral changes produced by therapy are shaped by contingencies of the therapeutic relationship or if they are governed by new rules produced in therapy. In researches about emission of rules (orientation) and self emitted rules (self-orientation) prior to this research, no variables responsible for their emission were found. The use of the orientation strategy seemed to be determined either by the client, or by the therapist, sometimes by neither, and at times by the theme, and possibly by a complex combination of these and other variables. A detailed study of orientations and self-orientations in 81 sessions of behavior analytic therapy was carried out in this research to ascertain which variables were responsible for the emission of orientation and self-orientation in behavioral clinical interventions. The findings indicated that each therapist issued an average of 40 to 60 orientations during their nine sessions. The clients of both experienced and inexperienced therapists presented few self-orientations. The number of orientations decreased to less than half when only rules with different contents and functions were counted, indicating that therapists tend to functionally 'repeat' the rule. The selforientations decreased one quarter when those with different content and function were considered. The group of therapists issued more orientations for specific and generic action; similarly, the clients of these therapists issued more self-orientations for specific and generic action. Episodes of orientation/self-orientation were identified in the 81 sessions, occupying an average of one third of the sessions of experienced therapists, and one quarter of the sessions of inexperienced therapists. These episodes involved several types of intervention by the therapist besides orientation. Orientations were generally issued within the following context: clients report a situation they have experienced and the therapist makes some interventions. When clients show difficulty in assuming responsibility, facing and evaluating their behavior, the therapist provides rules. Clients usually agree with the rules they receive, but on one quarter of occasions they oppose them and, and in one sixth of occasions they receive new orientations. Two thirds of self-orientations were approved by the therapist, but there were also disapprovals. There was little correlation between the theme and the presence of orientation/self-orientation. Motivated clients received more orientation than unmotivated and resistant clients; the higher the client's level of education the greater the number of self-orientation. Ten percent of the sessions were evaluated by a judge, with satisfactory indices of judge-researcher agreement indicating external validity. Future researches should be conducted to correlate the use of rules and the results of behavioral clinical interventions.

Keywords: rules; behavior analytic therapy; contingency analysis; orientation; selforientation 


\section{Sumário}

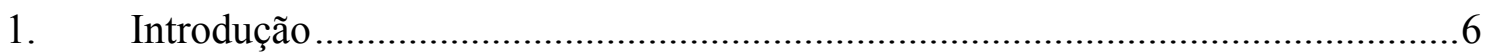

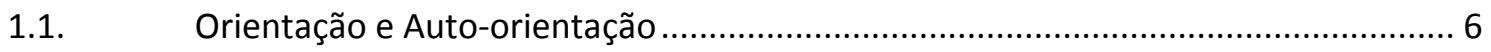

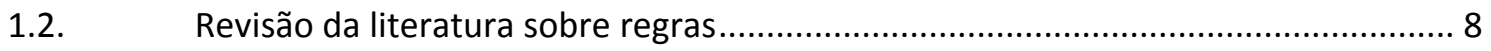

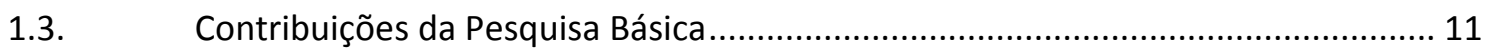

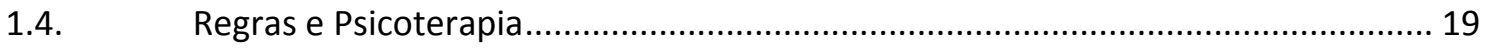

1.5. Revisão da literatura sobre o uso de orientação.................................................... 22

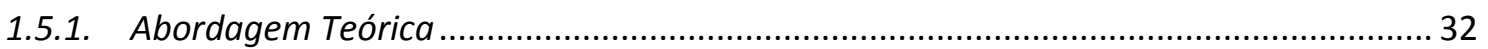

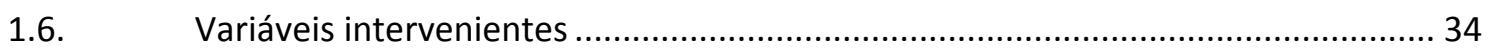

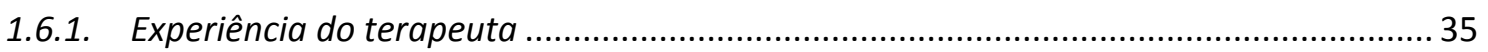

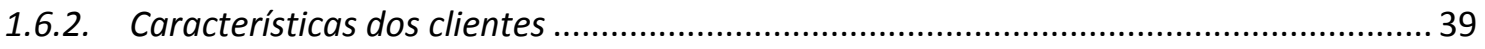

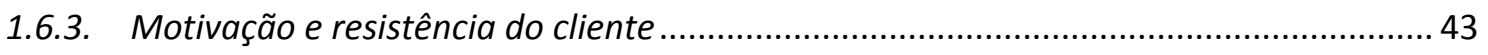

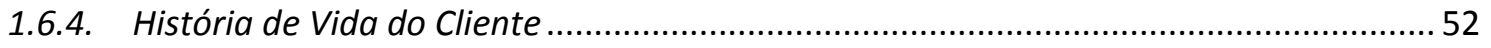

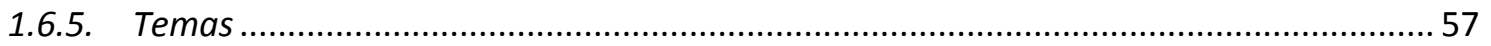

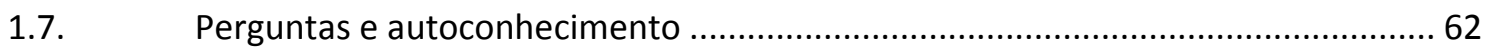

1.8. Alcances e limites de análises baseadas no governo por regras ............................. 72

1.9. Análise de verbalizações e análise de episódios ...................................................... 76

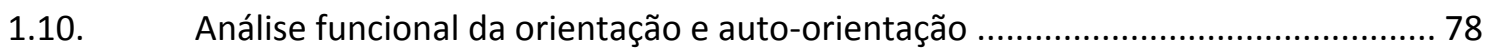

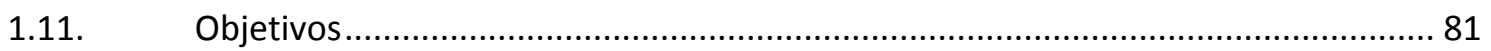

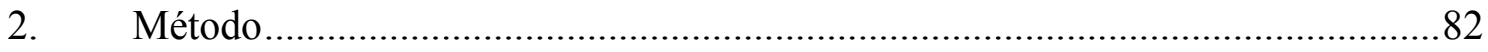

2.1. Descrição dos participantes da pesquisa de Donadone (2004)............................... 82

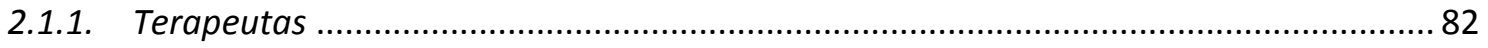

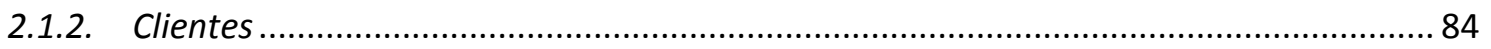

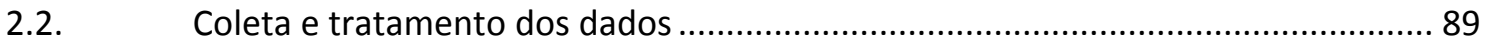

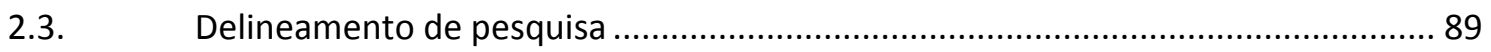

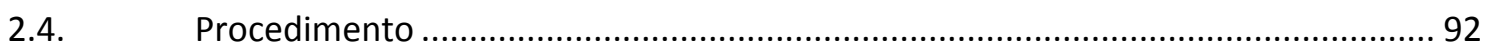

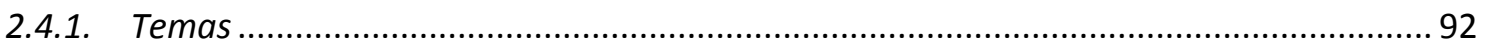

2.4.2. Análise das perguntas realizadas durante os episódios de $O / A O$....................................94

2.4.3. Análise das respostas a cada pergunta realizada nos episódios de orientação e

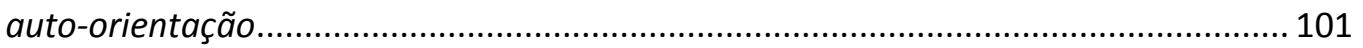

2.4.4. Análise de contingências das orientações e auto-orientações ..................................... 108

2.4.5. Correlação entre escolaridade-orientação/auto-orientação; queixaorientação/auto-orientação; perfil do cliente-orientação/auto-orientação; idade 
do cliente-orientação/auto-orientação; tempo de terapia-orientação/auto-

orientação e situação financeira-orientação/auto-orientação. 126

2.4.6. Criação de banco de dados IACON (instrumento de análise de contingências)............ 128

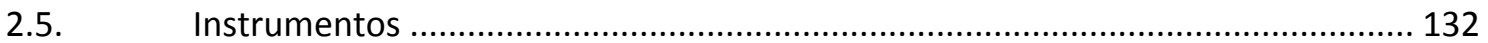

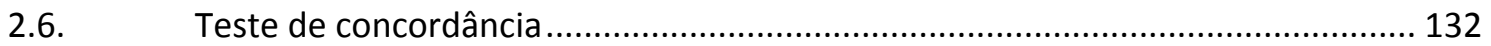

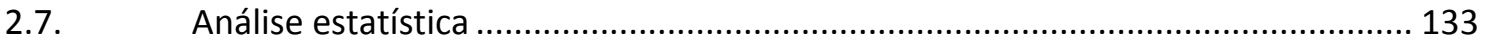

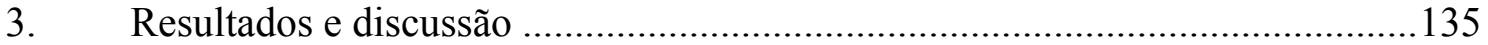

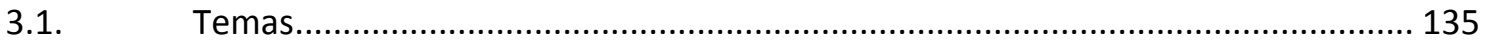

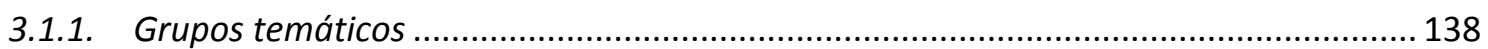

3.1.2. Grupos temáticos e subtipos de orientação/auto-orientação ...................................... 139

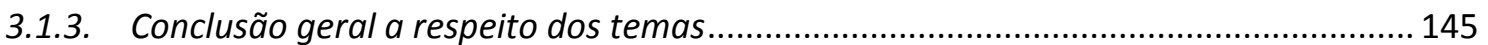

3.2. Episódios de orientação/auto-orientação ............................................................ 147

3.3. Análise das perguntas realizadas durante os episódios de O/AO .......................... 148

3.4. Análise de cada pergunta realizada durante os episódios de O/AO ...................... 151

3.5. Análise de contingências das orientações e auto-orientações ............................... 158

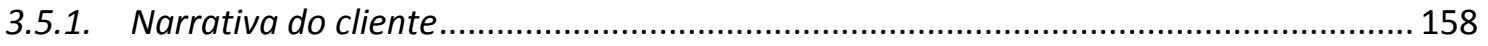

3.5.2. Intervenções do terapeuta que antecedem a emissão de orientação ou autoorientação

3.5.3. Antecedente (Comportamentos do cliente anteriores à apresentação de

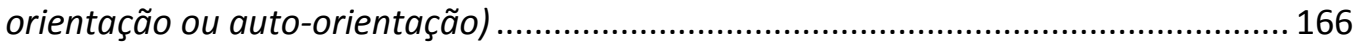

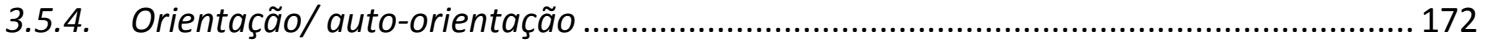

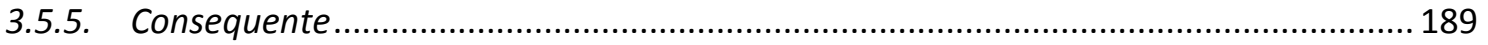

3.6. Correlação entre perfil do cliente e orientação ................................................. 192

3.7. Correlação entre escolaridade e auto-orientação; queixa e orientação, idade, tempo de terapia, situação financeira e emissão de auto-orientação....... 196

3.8. Concordância entre pesquisador e juiz ............................................................ 198

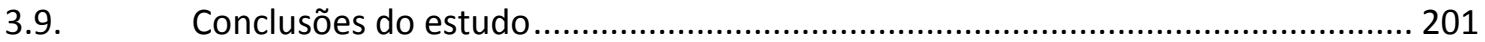

4. Considerações Finais ............................................Erro! Indicador não definido. 


\section{Lista de Figuras}

Figura 1. Número de temas na sessão, número de temas sobre os quais ocorrem orientações, número de temas sobre os quais ocorrem auto-orientações nas sessões dos diferentes terapeutas. $\mathrm{O}$ eixo $\mathrm{X}$ apresenta os diferentes terapeutas e o eixo $\mathrm{Y}$ apresenta o número de ocorrências.

Figura 2. Porcentagem de temas nos quais ocorreram orientação e auto-orientação dentro de cada grupo temático. O Eixo $\mathrm{X}$ apresenta os diferentes grupos temáticos e o eixo $\mathrm{Y}$ a porcentagem de ocorrências.

Figura 3. Número médio de orientações e de auto-orientações para cada grupamento de perfil de clientes.

Erro! Indicador não definido.

Figura 4. Número médio de subtipos orientações e de auto-orientações para cada grupamento de perfil de clientes.

Erro! Indicador não definido.

Figura 5. Média do número de cada subtipo de orientação em relação aos diferentes graus de escolaridade.

Erro! Indicador não definido.

Figura 6. Média do número de cada subtipo de auto-orientação em relação aos diferentes graus de escolaridade.

Erro! Indicador não definido. 


\section{Lista de Tabelas}

Tabela 1 - Descrição dos terapeutas considerando-se as seguintes variáveis: anos de experiência, graduação, pós-graduação, $\mathrm{n}^{0}$ total de casos atendidos $\left(\mathrm{n}^{\mathrm{o}}\right.$ de casos de crianças, adolescentes e adultos atendidos)

Tabela 2 - Descrição dos clientes participantes dessa pesquisa. Cada bloco (A, B,C) era constituído por dois terapeutas pouco experientes formados na mesma universidade.

Cada terapeuta coletou dados de três clientes diferentes. 86

Tabela 3 - Grupos temáticos

Tabela 4 - Categorias de respostas emitidas pelos clientes à pergunta: "Por que ocorreu a situação?".

Tabela 5 - Categorias de respostas emitidas pelos clientes à pergunta: "Como o cliente lidou com a situação-problema?"

Tabela 6 - Grupo de possibilidades de respostas emitidas pelos clientes à pergunta:

"Qual é a avaliação do cliente sobre a forma como lidou com a situação?”................. 104

Tabela 7 - Esquema básico de palavras emocionais (adaptado de Shaver et al. 1987 readaptado por Donadone \& Meyer, 2009)

Tabela 8 - Categorias de respostas emitidas pelos clientes à pergunta: "Passada a situação o cliente é capaz de verbalizar o que deveria fazer em situações similares ou emitiu a reação pretendida?"

Tabela 9 - Adaptação das categorias de comportamento verbal vocal do terapeuta de Zamignani e Meyer (2007) e exemplos.

Tabela 10 - Adaptação das categorias de comportamento verbal vocal do cliente de Zamignani e Meyer (2007) e exemplos

Tabela 11 - Definição de orientação e auto-orientação e seus respectivos exemplos . 118 Tabela 12 - Exemplos de orientações e auto-orientações, enfatizando conteúdo explícito e função

Tabela 13 - Categorias de consequentes ao comportamento de orientar, adaptadas das categorias de comportamento verbal vocal do terapeuta e do cliente (Zamignani e Meyer, 2007) e exemplos

Tabela 14 - Categorias de consequentes ao comportamento de auto-orientar, adaptadas das categorias de comportamento verbal vocal do terapeuta e do cliente (Zamignani e Meyer, 2007) e exemplos

Tabela 18 - Frequência média de orientação e auto-orientação dos diferentes terapeutas nos grupos temáticos.

Tabela 19. Média e porcentagem do número de falas em episódios de orientação/ autoorientação nas sessões dos terapeutas experientes e pouco experientes.

Tabela 20. Ocorrências e frequência relativa percentil (apresentada em porcentagem) de perguntas realizadas pelos terapeutas e respostas dos clientes durante os episódios de orientação e auto-orientação.

Tabela 21. Número médio de respostas emitidas pelos diferentes clientes aos terapeutas e frequência relativa percentil; respostas emitidas pelos clientes dos terapeutas experientes e pouco experientes tanto na orientação quanto na auto-orientação para a pergunta: "Quando ocorreu a situação relatada pelo cliente?".

Tabela 22. Ocorrências e frequência relativa percentil de resposta à pergunta: "Por que ocorreu aquela situação?" dos diferentes clientes nos episódios de orientação e autoorientação. 
Tabela 23. Ocorrências e frequência relativa percentil de respostas à pergunta: "Como o cliente lidou com a situação problema?" dos clientes dos terapeutas experientes (TE) e pouco experientes (TPE) nos episódios de orientação e auto-orientação...................... 154 Tabela 24. Ocorrências e frequência relativa percentil de resposta à pergunta: "Qual é a avaliação do cliente sobre a forma como lidou com a situação?" dos clientes dos diferentes terapeutas nos episódios de orientação e auto-orientação.

Tabela 25. Número de ocorrência e frequência relativa percentil (apresentada em porcentagem) das emoções nos episódios de orientação e auto-orientação.

Tabela 26. Número médio de respostas emitidas pelos diferentes clientes aos terapeutas e frequência relativa percentil (apresentada em porcentagem); respostas emitidas pelos clientes dos terapeutas experientes e pouco experientes tanto na orientação quanto na auto-orientação para a pergunta: "Passada a situação o cliente é capaz de verbalizar o que deveria fazer em situações similares ou se emitiu a reação pretendida?".

Tabela 27. Ocorrência/não ocorrência de narrativa do cliente nos episódios de orientação/auto-orientação.

Tabela 28. Ocorrência/não-ocorrência de intervenções do terapeuta que antecedem a emissão de orientação/auto-orientação.

Tabela 29. Número médio de intervenções dos diferentes terapeutas nos episódios de orientação e frequência relativa percentil (apresentada em porcentagem); número médio (e frequência relativa percentil) de intervenções emitidas pelos terapeutas experientes e pouco experientes que antecediam a emissão de orientação de acordo com a adaptação das categorias de comportamento verbal vocal do terapeuta de Zamignani e Meyer (2007)

Tabela 30. Número médio de intervenções dos diferentes terapeutas nos episódios de auto-orientação e frequência relativa percentil (apresentada em porcentagem); número médio (e frequência relativa percentil) de intervenções emitidas pelos terapeutas experientes e pouco experientes que antecediam a emissão de auto-orientação de acordo com a adaptação das categorias de comportamento verbal vocal do terapeuta de Zamignani e Meyer (2007). Erro! Indicador não definido. Tabela 31. Número médio e frequência relativa percentil de categorias de antecedentes às orientações emitidas pelos diferentes clientes; número médio (e frequência relativa percentil) de categorias de antecedentes à emissão de orientação dos clientes dos terapeutas experientes e pouco experientes de acordo com a adaptação das categorias de comportamento verbal vocal do cliente de Zamignani e Meyer (2007)..Erro! Indicador não definido.

Tabela 32. Número médio e frequência relativa percentil de categorias de antecedentes às auto-orientações emitidas pelos diferentes clientes; número médio (e frequência relativa percentil) de categorias de antecedentes à emissão de auto-orientações dos clientes dos terapeutas experientes e pouco experientes de acordo com a adaptação das categorias de comportamento verbal vocal do cliente de Zamignani e Meyer (2007)

Erro! Indicador não definido.

Tabela 33. Distribuição de orientação e auto-orientação entre os diferentes terapeutas

Tabela 34. Ocorrências e frequência relativa percentil (apresentada em porcentagem) de subtipos de orientação/auto-orientação ................................................................... 175 Tabela 35. Conteúdo e função das orientações e auto-orientações para cada terapeuta183 Tabela 36. Emissão de auto-orientação dos clientes terapeutas experientes e pouco experientes....

Tabela 37. Número médio e frequência relativa percentil de categorias de consequentes às orientações emitidas pelos diferentes clientes; número médio (e frequência relativa 
percentil) de categorias de consequentes à emissão de orientações dos clientes dos terapeutas experientes e pouco experientes de acordo com a adaptação das categorias de comportamento verbal vocal do terapeuta e do cliente de Zamignani e Meyer (2007)

Erro! Indicador não definido.

Tabela 38. Número médio e frequência relativa percentil de categorias de consequentes às auto-orientações emitidas pelos diferentes clientes de acordo com a adaptação das categorias de comportamento verbal vocal do terapeuta e do cliente de Zamignani e Meyer (2007)

Erro! Indicador não definido. Tabela 39. Correlação entre o número de Orientação e auto-orientação e o perfil do cliente.

Tabela 40. Perfis dos clientes e subtipos de orientação e auto-orientação. 196

Tabela 41. Legenda de escolaridade.... Erro! Indicador não definido. Tabela 42. Legenda de queixas. Erro! Indicador não definido. Tabela 43. Legenda de perfil do cliente Erro! Indicador não definido. Tabela 44. Correlações de fala com orientação (FO) e auto-orientação (FAO) versus escolaridade e queixa.

Erro! Indicador não definido. Tabela 45. Idade, tempo de terapia e situação financeira dos clientes que emitiram autoorientação.

Erro! Indicador não definido. 


\section{Lista de Anexos}

1. CD auto-explicativo e sistema com banco de dados (IACON)

2. Termo de consentimento do cliente

3. Termo de consentimento do terapeuta

4. Questionário entregue aos terapeutas

5. Manual de instrução para o juiz e modelo de folha de resposta

6. Metodologia Estatística 


\section{PREFÁCIO}

Em 1968, Ferster afirmou que conhecer as razões do sucesso de intervenções clínicas era extremamente necessário e útil. Necessário, pois, ao se conhecer os determinantes de um comportamento, assim como conhecer melhor a relação entre as ações eficazes do terapeuta e o conjunto de circunstâncias (contingências) que as controla, seria possível contribuir para descrever maneiras de produzir alterações comportamentais relevantes. Útil, pois o conhecimento das razões do sucesso de determinada intervenção poderia facilitar a formação de terapeutas mais efetivos e inventivos, além de criar subsídios para a proposição de novos desafios teóricos.

Até hoje ocorrem debates sobre quais são os mecanismos responsáveis por mudanças ocorridas em intervenções clínicas comportamentais. Pergunta-se se são as técnicas específicas ou as variáveis da relação terapêutica que propiciam os efeitos da terapia. Também tem sido questionado se mudanças comportamentais produzidas pela terapia são modeladas por contingências da relação terapêutica ou são governadas por novas regras produzidas na terapia. Skinner (1966) aponta que muitas mudanças ocorridas em terapia se dão através de procedimentos estruturados e do controle por regras. Já autores como Hayes, Kohlenberg e Melacon (1989), e Follette, Naugle e Callaghan (1996) afirmam que a história de aprendizagem e a modelagem adquirida na interação com o terapeuta são um importante mecanismo de mudança.

$\mathrm{Na}$ tentativa de responder a essa questão, em 2004, Donadone desenvolveu um estudo onde se buscava verificar se procedimentos de mudança ocorridos em processos psicoterápicos ocorriam por formulação (e seguimento) de novas regras.

O foco de análise do estudo era a estratégia de orientação, uma vez que é claramente uma estratégia de controle por regras tanto em sua topografia como em sua 
função. Assim, apoiada no arcabouço teórico da pesquisa básica sobre regras, categorias de orientação e auto-orientação foram formuladas. Vinte e sete sessões de terapeutas experientes e cinquenta e quatro sessões de terapeutas pouco experientes foram analisadas, controlando-se a variável experiência (nove terapeutas, sendo três experientes e seis pouco experientes) e parcialmente a variável formação (todos os terapeutas participantes da pesquisa se autodenominavam terapeutas analíticocomportamentais), clientes (cada terapeuta gravava sessões com três diferentes clientes com queixas aleatórias), e flutuações intrassessões (cada terapeuta gravou três diferentes sessões consecutivas com três diferentes clientes a partir da $12^{\mathrm{a}}$ sessão, pois haveria pequena probabilidade de ocorrerem orientações nas primeiras sessões).

Os resultados encontrados sugeriram que as variáveis eleitas na dissertação de Donadone (2004) (experiência, formação, clientes e flutuações intrassessões) não eram determinantes do comportamento de orientar. Os terapeutas variaram o número de falas e o número de falas com orientação por sessão com todos os clientes. A flutuação de falas dos terapeutas não pareceu ser controlada por diferenças entre clientes, já que houve variações entre sessões de um mesmo cliente para todos os terapeutas. Para os nove terapeutas que participaram da pesquisa (três terapeutas experientes e seis terapeutas pouco experientes) foi baixa a proporção de falas com orientação, indicando não ser esta uma estratégia muito usada por nenhum dos terapeutas comportamentais experientes e pouco experientes. Observaram-se também grandes flutuações entre sessões e entre clientes de cada terapeuta quanto ao número de falas contendo orientação e auto-orientação, não sendo estas, portanto, variáveis de controle relevantes. Quando os terapeutas usavam orientações, estas tendiam a ser específicas e poucas vezes genéricas. Quando orientou, o primeiro terapeuta experiente tanto indicou ações quanto reflexões para seus clientes; já o segundo e o terceiro terapeuta experientes 
indicaram ações específicas a serem realizadas por seus clientes no cotidiano, na maioria das vezes. Os terapeutas pouco experientes maciçamente indicaram orientações para ação específica e genérica. A prescrição de tarefas, tipo de orientação que mais se esperaria dos terapeutas comportamentais de acordo com a literatura, não ocorreu nas sessões dos terapeutas experientes; já nas sessões dos terapeutas pouco experientes, esta não ocorreu em todas as sessões, tampouco foi apresentada a todos os clientes. Tanto os clientes dos terapeutas experientes como os dos terapeutas pouco experientes emitiram poucas auto-orientações nas sessões analisadas; com exceção de apenas um cliente de um terapeuta experiente. O resultado mais expressivo foi que os terapeutas comportamentais experientes tiveram uma média de orientação mais alta que os terapeutas pouco experientes $(17,5 \%$ e $9,6 \%$ respectivamente) e que também a variação entre as sessões foi maior (desvio-padrão de $16 \%$ e $9,8 \%$ respectivamente).

Uma série de hipóteses sobre os possíveis determinantes da estratégia de orientação foram levantadas a partir do estudo de Donadone (2004). Em alguns momentos a orientação parece estar relacionada a diferentes características dos clientes, em outros a diferentes características dos terapeutas e ainda a nenhuma das duas variáveis, e sim a outras, como o tema abordado. Pode-se supor também que a estratégia de orientação é determinada por uma mistura de todos esses elementos. Diante deste quadro, considerou-se válido prosseguir na investigação das variáveis responsáveis pela utilização de tal estratégia.

Assim, na presente pesquisa não foram selecionadas variáveis específicas. Foi feita a verificação de algumas variáveis observadas de forma assistemática no estudo de Donadone (2004), investigando outras possíveis variáveis que fazem parte da determinação do comportamento de orientar. 
O caminho percorrido nesta pesquisa foi sendo desenvolvido a partir do contato direto com os dados. A cada questão levantada, ao debruçar-se sobre os dados, buscavase na literatura sustentação teórica. Tal forma de análise produziu um longo itinerário que será detalhado nos tópicos a seguir. Assim, inicialmente as definições de orientação e auto-orientação serão apresentadas. Como as categorias de orientação e autoorientação definidas no estudo de Donadone (2004) foram baseadas na revisão da literatura sobre regras, tal revisão também será apresentada assim como as contribuições da pesquisa básica. No tópico regras e psicoterapia, será apresentada a transposição dos conhecimentos da pesquisa básica sobre regras para a prática clínica. Também será apresentada uma revisão da literatura sobre o uso de orientação, considerando como terapeutas de diferentes abordagens discutem o uso de tal estratégia.

Como mencionado acima, na presente pesquisa variáveis que foram observadas de forma assistemática no estudo de Donadone (2004) serão também consideradas. Assim, algumas variáveis correlacionadas serão apresentadas na introdução. Entre elas destacam-se: a correlação entre experiência do terapeuta e emissão de regras; a motivação/resistência do cliente correlacionada à emissão de regras; o próprio cliente (incluindo história de vida do cliente), e a correlação entre temas discutidos na sessão e emissão de regras.

Através da revisão da literatura, serão apresentados alguns estudos que abordam a utilização de perguntas em sessões de psicoterapia. Também será destacado como perguntas podem promover autoconhecimento. Após esta revisão de estudos, alcances e limites de análises baseadas no governo por regras serão apresentados. Ferramentas teóricas serão apresentadas para esboçar a estratégia de análise da presente pesquisa. Como na dissertação de Donadone (2004) a análise descritiva do comportamento de orientar não trouxe resultados satisfatórios sobre as variáveis determinantes de tal 
comportamento, nesta pesquisa será realizada análise de verbalizações e análises de episódio de orientação. Análises de episódios levam em consideração o contexto em que o comportamento ocorre. Por fim, uma tentativa de análise funcional do comportamento de orientar e auto-orientar será apresentada.

A partir do arcabouço teórico apresentado nesta pesquisa, pretende-se apontar quais variáveis são responsáveis pelos comportamentos de orientar e auto-orientar nas sessões dos terapeutas experientes e pouco experientes. 


\section{Introdução}

\subsection{Orientação e auto-orientação}

Para Skinner (1974/1982), orientação pode ser entendida como uma descrição, feita pelo falante, do comportamento a ser executado pelo ouvinte. Essa descrição contempla, implícita ou explicitamente, as consequências da ação do ouvinte. Com base nesta definição é possível afirmar que auto-orientação seria uma descrição do comportamento feita pelo falante a ser executado por ele mesmo, com descrição explícita ou implícita das consequências da ação. A diferença entre a orientação e a auto-orientação é que, no segundo caso, a pessoa descreve o comportamento que ela mesma deverá executar.

As orientações englobam ordens, avisos e conselhos, que são diferentes formas de regras (Skinner, 1974/1982). Segundo o autor:

"Uma das primeiras práticas verbais deste tipo deve ter sido a de dar ordens. "Vá andando!" descreve um ato e implica uma conseqüência: o ouvinte deve mover-se - senão! O falante diz ao ouvinte o que este deve fazer e organiza conseqüências aversivas em que ele aprende a fazê-lo e a fazê-lo uma e outra vez, sempre que a ordem seja repetida. Um aviso difere habitualmente de uma ordem porque as conseqüências aversivas não são organizadas pela pessoa que o emitiu: "Preste atenção!" descreve um ato e implica uma consequência, tal como evitar uma rocha prestes a cair, mas esta é antes um resultado natural do comportamento do que um resultado planejado pelo falante. Um conselho ("Vá pra o Oeste, rapaz!") especifica um comportamento e implica consequências 
positivamente reforçadoras que também não foram ideadas pelo conselheiro (“... e você ficará rico”).” (Skinner, 1974/1982, p. 105)

Uma pessoa que esteja seguindo uma orientação, aceitando um conselho, prestando atenção a um aviso, obedecendo a leis e regras, não se comporta exatamente da mesma maneira que outra que tenha sido exposta diretamente às contingências que mantêm a ação descrita pela regra. Isto porque uma descrição das contingências nunca é completa ou exata (usualmente, é simplificada para poder ser ensinada ou compreendida com facilidade) e porque as contingências de apoio raras vezes são mantidas plenamente. O controle exercido por orientações, conselhos, regras ou leis é mais ostensivo do que o exercido pelas próprias contingências, em parte porque este é menos sutil, enquanto aquele, por isso mesmo, parece significar maior contribuição pessoal e valor interno (Skinner, 1974/1982).

Na pesquisa de mestrado e na atual pesquisa, orientação foi entendida como uma descrição do comportamento a ser executado pelo cliente fora das sessões de terapia, com indicação explícita ou implícita das consequências desta ação. Já auto-orientação foi entendida como uma descrição do comportamento feita pelo cliente a ser executado por ele mesmo fora das sessões de terapia, com descrição explícita ou implícita das consequências da ação. As seguintes subcategorias baseadas em estudos experimentais (o tópico a seguir apresenta a revisão da literatura sobre os estudos experimentais) foram selecionadas para a análise: orientações para ação específica, ação genérica, tarefa e encobertos, auto-orientação para ação específica, para ação genérica, encobertos e tarefas.

Orientação para ação específica (OAE) é a orientação para que o cliente se comporte, em seu cotidiano, da forma indicada, com especificação da topografia do comportamento a ser desenvolvido; orientação para ação genérica (OAG) é a 
orientação para que o cliente se comporte da forma indicada, em seu cotidiano, sem indicação da ação que deve ser executada, e sim qual o resultado a ser atingido com qualquer topografia de comportamento; orientação para tarefa (OT) é a orientação para que o cliente execute uma tarefa terapêutica e orientação para encobertos (OE) é uma orientação para que o cliente reflita sobre um tema proposto ou observe suas ações e pensamentos.

Estes quatro subtipos de orientação também se aplicam ao caso da autoorientação. Assim, por auto-orientação para ação específica (AOAE) entende-se a autoorientação feita pelo cliente para que se comporte da forma indicada, em seu cotidiano, com especificação da topografia do comportamento a ser desenvolvido. Por autoorientação para ação genérica (AOAG) entende-se a auto-orientação feita pelo cliente para que se comporte da forma indicada, em seu cotidiano, porém não indicando a ação que deve ser executada, e sim qual o resultado a ser atingido com qualquer topografia de comportamento. Por auto-orientação para tarefa (AOT) entende-se a auto-orientação emitida pelo cliente para que execute uma tarefa terapêutica e por auto-orientação para encobertos (AOE) entende-se uma auto-orientação feita pelo cliente para que reflita sobre um tema proposto ou observe suas ações e pensamentos.

A estratégia de orientação/auto-orientação é claramente uma estratégia de controle por regras tanto em sua topografia como em sua função. Dessa forma, faz-se necessária a revisão da literatura sobre regras.

\subsection{Revisão da literatura sobre regras ${ }^{1}$}

Skinner (1974/1982) definiu comportamento modelado por contingências como comportamento modelado e mantido diretamente por consequências relativamente

\footnotetext{
${ }^{1}$ Baseado em Meyer, S. B. (2005). Regras e auto-regras no laboratório e na clínica. In J. Abreu-Rodrigues e M. M. Ribeiro (Orgs), Análise do comportamento: pesquisa, teoria e aplicação, (pp. 211-229). Porto Alegre: Artmed.
} 
imediatas. Já regras foram definidas como estímulo discriminativo verbal que descreve uma contingência. A distinção entre comportamentos modelados por contingências e comportamentos governados por regras ou, conforme Catania (1998/1999), comportamentos governados verbalmente, encontra-se no fato de que o comportamento governado por regras depende do comportamento verbal de outra pessoa (o falante), ou seja, está sob controle de antecedentes verbais que descrevem contingências (Baum, 1994/1999), o que não ocorre no caso do comportamento modelado por contingências.

Regras são úteis quando substituem procedimentos de modelagem de uma resposta em seres humanos. Segundo Skinner (1974/1982) “... homens podem, utilizando descrições verbais, induzir uns aos outros a se comportarem de modo efetivo sem que haja necessidade de exposição, geralmente longa, às consequências descritas". Há, portanto, diferenças entre comportamentos governados por regras e o modelado por contingências. Tais diferenças foram descritas por Skinner (1974/1982) em seu livro Sobre o Behaviorismo (pp.109-111). São elas:

- Regras podem ser aprendidas mais rapidamente que o comportamento modelado pelas contingências que as regras descrevem;

- Quando há semelhanças entre contingências, o aproveitamento via regras é mais fácil, todavia o processo de generalização pode prover uma resposta fraca;

- Enquanto o comportamento modelado por contingências demanda maior tempo de aprendizagem, ou pode nem mesmo ser aprendido, regras são úteis quando as contingências são pouco claras, complexas ou pouco efetivas;

- Por meio das regras - da gramática e do dicionário - é possível aprender um novo idioma quando o indivíduo não foi exposto a uma comunidade verbal adequada, necessária para modelar a fala correta; 
- O controle exercido por orientações, conselhos, regras e leis é evidente, não é sutil, já o controle pelas contingências é bem menos evidente. Nesta última forma de controle é comum que a comunidade considere que o indivíduo tenha maior contribuição pessoal e mérito interno. Fazer o bem porque recebe o reforço social por ter feito o bem é considerado mais virtuoso do que fazer o bem porque a lei assim o determina. Já o indivíduo que realiza uma obra planejada pode sofrer das reservas associadas aos comportamentos emitidos de forma calculada;

- Os sentimentos associados ao comportamento governado por regras também são diferentes dos sentimentos associados ao comportamento modelado por contingências (mas os sentimentos não explicam as diferenças entre esses comportamentos). Há diversas ocasiões em que o sentimento associado ao seguimento de regras é apenas o de medo de punição, enquanto aquele associado ao comportamento modelado pelas contingências consiste em alegria e em entusiasmo.

Após a distinção entre comportamento governado por regras e modelado por contingências feita por Skinner, Hayes, em conjunto com outros pesquisadores (e.g., Hayes \& Ju, 1998; Hayes, Zettle, \& Rosenfarb, 1989) apresentou uma nova distinção entre tipos de comportamentos governados por regras. Para esses autores comportamentos governados por regras poderiam ser de dois tipos: aquiescência (em inglês pliance) e rastreamento (em inglês tracking).

Um comportamento aquiescente seria aquele que essencialmente depende de contingências sociais (o reforço é contingente diretamente ligado ao comportamento de fazer o que a regra diz); um comportamento de rastreamento depende essencialmente de correspondência entre a regra e os eventos ambientais. Uma norma, uma lei ou um costume controlam comportamentos de aquiescer; uma instrução ou uma descrição de um trajeto controlam comportamentos de rastrear. Ou seja, as consequências que 
mantêm o comportamento governado por regras são de dois tipos: a obediência à regra (aquiescência) é mantida por contingências sociais; a execução do comportamento especificado pela regra (rastreamento) é, em geral, um desempenho motor modelado por contingências naturais (Matos, 2001).

Holmes, Hayes e Dymond (2001) apontam que seres humanos não apenas seguem regras apresentadas por outros como também formulam e seguem suas próprias regras. Quando estas são formuladas ou reformuladas pelo indivíduo cujo comportamento passam a controlar, dizemos que são autorregras. Neste caso, uma parte do repertório do indivíduo afeta outra parte deste repertório. As autorregras podem ser explicitadas publicamente ou podem ocorrer de forma encoberta quando o indivíduo pensa (Jonas, 1997).

A distinção proposta por Skinner, entre o comportamento modelado por contingências e o governado por regras, foi submetida a estudos experimentais, e o corpo de conhecimentos resultante tem implicações diretas para trabalhos aplicados. A seguir, as contribuições da pesquisa básica para a clínica, serão analisadas, bem como algumas contribuições da pesquisa clínica a respeito do uso de regras, conselhos e intervenções chamadas diretivas. Será discutido, ainda, qual tipo de controle - por regras ou por modelagem pelas contingências - pode ser considerado responsável pelas mudanças clínicas.

\subsection{Contribuições da Pesquisa Básica}

No item anterior foi mencionado que regras facilitam a aquisição de novos comportamentos, principalmente quando as contingências são complexas, imprecisas ou aversivas. Por outro lado, um dos resultados mais salientes das pesquisas desenvolvidas na área tem sido a constatação de que regras podem produzir redução na sensibilidade comportamental às contingências (Abreu-Rodrigues \& Sanabio, 2004). O termo 
sensibilidade pode ser definido como mudanças sistemáticas no comportamento diante de mudanças nas contingências de reforço. Dessa forma, quando as contingências mudam e o comportamento não se altera, diz-se que o comportamento é insensível às contingências (Madden, Chase \& Joyce, 1998). Este fenômeno foi observado em investigações sobre controle instrucional. Nesse tipo de investigação criam-se situações experimentais em que instruções para o desempenho podem ser coincidentes ou discrepantes com os esquemas de reforçamento em vigor. Tipicamente, quando há discrepância, os participantes apresentam desempenhos em acordo com as instruções recebidas e insensíveis aos esquemas de reforçamento (Abreu-Rodrigues \& Sanabio, 2004).

Entretanto, alguns aspectos moduladores do controle instrucional devem ser levados em consideração antes de se afirmar que regras podem produzir redução na sensibilidade às contingências.

Um dos primeiros aspectos a ser considerado refere-se à extensão com que os comportamentos gerados pela instrução entram em contato com a discrepância entre instrução e contingência atual. Galizio (1979) realizou um experimento em que havia uma condição segundo a qual seguir as instruções não permitiria contato com a discrepância instruções-contingência e outra condição segundo a qual este contato ocorreria. A conclusão desse autor foi que o contato com a discrepância instruçãoesquema é necessário para a redução/eliminação do controle instrucional (ou aumento na sensibilidade comportamental), e não apenas a existência de tal discrepância. Outros estudos constataram o mesmo fenômeno (Buskist \& Miller, 1986; Hayes, Brownstein, Zettle, Rosenfarb, \& Korn, 1986, Experimento 1).

Um segundo aspecto considerado por Abreu-Rodrigues e Sanabio (2004) ao analisarem a insensibilidade às contingências no comportamento governado por regras, 
foi o conteúdo das instruções. Vários estudos foram citados (Danforth, Chase, Dolan, \& Joyce, 1990; Dixon \& Hayes, 1998; Otto, Torgrud, \& Holborn, 1999; Raia, Shillingford, Miller, \& Baier, 2000; Wulfert, Greenway, Farkas, Hayes, \& Dougher, 1994), nos quais, quando as instruções especificavam com exatidão a tarefa, ocorreram respostas estereotipadas e insensibilidade comportamental. Já instruções vagas favoreceram o desenvolvimento de controle pelas contingências.

Um terceiro aspecto que afeta a sensibilidade às contingências refere-se à variabilidade comportamental. LeFrancois, Chase e Joyce (1988) realizaram um estudo em que os participantes que foram expostos a apenas uma instrução e um esquema de reforçamento ficaram sob controle instrucional, enquanto aqueles que receberam várias instruções e vários esquemas de reforçamento apresentaram sensibilidade a mudanças nas contingências. A diferença foi discutida considerando a presença de alternativas comportamentais promovidas pela exposição à instrução e esquemas variados, o que favoreceria a sensibilidade às novas contingências.

A densidade de reforços contingentes ao comportamento instruído também afeta a sensibilidade à mudança. No estudo de Newman, Buffington e Hemmes (1995), observou-se controle instrucional quando o comportamento de seguir instruções sempre produzia reforços, tendo tal controle diminuído quando esse comportamento era reforçado apenas parcialmente e eliminado quando não havia reforços programados para seguir instruções. Esse resultado pode ser uma evidência adicional de que comportamento de seguir instruções é um operante mantido apenas quando reforçado.

Outra variável de controle da sensibilidade às contingências é a história de reforçamento do comportamento de seguir instruções. No estudo de Martinez e Ribes (1996), descrito por Abreu-Rodrigues e Sanabio (2004), os participantes foram submetidos a uma condição experimental de seguimento de instrução falsa (que não 
descrevia exatamente a relação resposta-consequência). Aqueles que haviam passado anteriormente pela condição de seguimento de instrução verdadeira seguiram muito mais as instruções falsas do que aqueles que não tiveram esta história prévia.

Outro aspecto que explica a persistência do controle instrucional em situações em que o comportamento de seguir instruções ocorre, mesmo havendo discrepância entre instrução e a relação resposta-consequência, ou mesmo quando há contanto com tal discrepância, é a história de reforços sociais para correspondência entre instrução e comportamento (Hayes et al., 1986).

Aspectos como história de vida foram abordados por Matos (2001) em uma descrição não experimental. Segundo esta autora:

“... na medida em que uma pessoa é 'deixada à vontade', ou é criada mais livremente, 'para se defender por si mesma', como dizemos, ela desenvolve estratégias para discriminar mais rapidamente as contingências importantes para sua sobrevivência, e também para discriminar mudanças nestas contingências. Ela se torna essencialmente controlada por procedimentos de modelagem sob contingências naturais e é especialmente sensível a mudanças nestas contingências. Uma pessoa a quem sempre foi dito para fazer isso ou aquilo, a quem não se deu a chance de entrar em contato com as contingências naturais senão com as suas descrições, torna-se especialmente dependente de contingências sociais e de regras sobre como agir (elas são seu único contato com os mecanismos de sobrevivência), torna-se extremamente dependente das correspondências descritas entre eventos sociais e 
naturais e do comportamento verbal de outro, e nesse sentido, ela se torna insensível a contingências naturais.” (Matos,2001,p.56-57)

O grau de discriminabilidade das contingências em vigor é outro aspecto que pode influenciar a sensibilidade as contingências. Newman, Buffington e Hemmes (1995) realizaram um estudo em que os esquemas de reforçamento intermitente geraram insensibilidade. Já o esquema de reforçamento contínuo produziu um desempenho sensível e houve relação direta entre seguir instruções e a densidade de reforços. Uma possível explicação para esse resultado seria o fato de que os esquemas intermitentes são mais difíceis de discriminar do que os esquemas contínuos.

Matos (2001) apresentou conclusões similares quanto ao grau de discriminabilidade das contingências. Esta autora afirma que, se as regras são ambíguas, mas as contingências são simples e fáceis de serem discriminadas, é provável que as pessoas passem a agir de acordo com tais contingências. Por outro lado, se são complexas e o desempenho exigido é elaborado, indivíduos podem apresentar um desempenho bastante variável inicialmente, até ficarem sob controle das contingências em vigor, ou até formularem autorregras a partir de experiências passadas com situações semelhantes.

Estudos sobre controle verbal têm investigado não somente os efeitos de estímulos verbais gerados por outra pessoa, mas também de estímulos verbais gerados pelo próprio indivíduo, sobre o comportamento não-verbal. Uma das formas de estudálas é verificar se há correspondência entre os comportamentos verbais e não verbais da mesma pessoa. Em tais estudos participantes são expostos a um determinado esquema de reforçamento e, após ou durante a sessão experimental, são questionados acerca de seus desempenhos não-verbais. Quando a correspondência entre relato e desempenho não-verbal é observada, é comum a conclusão (apesar de questionável) de que o 
desempenho do participante estava sob controle de autoinstruções formuladas durante o experimento (Abreu-Rodrigues \& Sanabio, 2004).

Os efeitos de relatos verbais modelados e instruídos sobre o responder nãoverbal foram estudados por Catania, Matthews e Shimoff (1982). Neste estudo, participantes deveriam trabalhar em um esquema de razão múltipla (na chave da esquerda) e de intervalo (na chave da direita). Periodicamente deveriam completar a frase: "o modo de ganhar pontos na chave da esquerda/direita é...". No grupo "instrução" os participantes recebiam dicas sobre o que escrever; no grupo "modelagem" os participantes recebiam pontos pelas descrições. Quando os relatos foram modelados, houve correspondência entre os comportamentos de relatar e pressionar a chave, mesmo na presença de discrepância entre os relatos e as contingências não-verbais programadas. Mas, quando os relatos eram instruídos, seu controle foi inconsistente sobre o comportamento de pressionar a chave. Os autores concluíram que é mais provável que o comportamento verbal controle comportamentos não-verbais quando o primeiro é modelado (e não instruído).

Nos estudos realizados por Cerutti (1991), Torgrud \& Holborn (1990) em que havia contingências não-verbais consistentes e previsíveis, o comportamento verbal e o não-verbal foram controlados por suas respectivas contingências. Já quando as contingências não-verbais programadas eram aleatórias e/ou incontroláveis, os relatos influenciaram o desempenho não-verbal. Estes estudos demonstraram que o controle verbal, tal como o observado no estudo de Catania et al. (1982), só ocorre quando as contingências não-verbais em vigor não estão exercendo controle discriminativo.

A história de reforçamento também influencia a correspondência entre o dizer e o fazer. Um exemplo ilustrativo é o estudo realizado por Amorim (2001). Neste estudo, quando o desempenho não-verbal foi reforçado diferencialmente, de modo a gerar taxas 
de respostas diversas ao longo das condições, foram observadas mudanças correspondentes nos relatos. Quando consequências diferenciais foram programadas para os relatos, selecionando relatos específicos no decorrer das condições, as taxas de respostas não verbais acompanharam os relatos. Quando essas manipulações foram efetuadas após o reforçamento da correspondência verbal - não-verbal, os relatos continuaram acompanhando as taxas de respostas e vice-versa; após o reforçamento da ausência de correspondência, por outro lado, foi observada uma discrepância entre taxas de respostas e relatos. Em conjunto, esses resultados sugerem que as relações de controle entre respostas verbais e não-verbais podem ocorrer nas duas direções e o tipo de relação de controle depende de uma história prévia de reforçamento para a correspondência ou não correspondência entre esses dois tipos de respostas.

Uma comparação entre instruções, autoinstruções e ausência de instruções foi realizada no estudo de Rosenfarb, Newland, Brannon e Howey (1992). Neste, três grupos foram formados: no grupo "autoinstruções" os participantes eram solicitados a relatar a melhor forma de obter reforços; no grupo "instruções externas" eram apresentados os relatos gerados pelo primeiro grupo; e no grupo "sem instruções", os participantes nem foram solicitados a emitir relatos e nem recebiam relatos externos. Ao final da fase de aquisição da resposta que estava sendo ensinada, os grupos "autoinstruções" e "instruções externas" apresentaram desempenhos mais apropriados aos esquemas em vigor do que o grupo "sem instruções". No entanto, após uma fase de extinção, o grupo "sem instrução" apresentou maior redução de respostas do que os outros dois grupos. Os autores concluíram que: (a) autoinstruções e instruções externas facilitam o controle exercido por contingências complexas; (b) instruções e autoinstruções retardam o processo de extinção, ou seja, reduzem sensibilidade à mudança; e (c) a formulação de instruções não é condição necessária para que as 
contingências exerçam controle sobre o comportamento. Quanto à comparação entre instruções e autoinstruções, a conclusão foi que seus efeitos são funcionalmente equivalentes, sendo ambas mantidas por reforçamento da comunidade verbal.

Meyer (2005) aponta que é importante considerar que quando há correspondência entre autorrelato e desempenho não-verbal é difícil afirmar se o desempenho não-verbal está sendo controlado pelo relato ou se as mesmas contingências controlam tanto a ação quanto a descrição da ação, sem que o relato participe da determinação da ação. É necessário então cautela ao interpretar relações entre eventos privados e públicos. Abreu-Rodrigues e Sanabio (2001) apontam algumas relações possíveis: (a) um evento ambiental observável produz o comportamento privado (neste caso a autorregra) e este, por meio de suas funções de estímulo, influencia o comportamento público (neste caso o desempenho não-verbal); (b) o comportamento público é afetado diretamente pelo evento ambiental, mas também é influenciado pelo comportamento privado produzido pelo mesmo evento ambiental; e (c) o evento ambiental gera tanto o comportamento privado quanto o comportamento público, mas não há relação entre esses dois comportamentos.

Meyer (2005) aponta outro aspecto a ser levado em consideração. Tal autora cita Skinner (1957/1992) ao afirmar que relatos podem não ser tatos puros, ou seja, não ser determinados apenas pelos estímulos que descrevem, mas também por outras variáveis ambientais. O relato de encobertos pode ser, por exemplo, uma forma de exprimir um sentimento, ou de se esquivar de um tema, ou mesmo uma forma de agredir o interlocutor ou testar seu nível de aceitação ou empatia (Delitti \& Meyer, 1995). Segundo Abreu-Rodrigues e Sanabio (2004), pesquisas têm indicado que vários fatores podem exercer influência sobre os autorrelatos: o limite de tempo para a resposta de escolha (Critchfield \& Perone, 1990), o número de estímulos-modelo (Critchfield \& 
Perone, 1993), o número de estímulos de comparação (Critchfield, 1993) e uma história de punição (Sanabio, 2000).

A análise das contribuições da pesquisa básica indica que a insensibilidade às contingências de reforçamento não é efeito inevitável do seguimento de regras. É, portanto, necessário que se levem em consideração aspectos como a densidade de reforços, o grau de contato com a discrepância entre instruções e contingências e o grau de discriminabilidade da contingência em vigor; a história de vida do indivíduo e o grau de variabilidade comportamental; o tipo de regra - se é modelada ou instruída e se descreve desempenho específico ou se é vaga.

\subsection{Regras e Psicoterapia}

As sessões de psicoterapia em consultório com adultos são na maioria das vezes baseadas em "conversas". Apesar de o terapeuta não ter controle direto sobre as contingências em vigor fora da sessão terapêutica, é a intervenção baseada em "conversas" durante a sessão que ajuda o cliente a lidar com problemas enfrentados fora dali, no dia-a-dia (Kohlenberg, Tsai, \& Dougher, 1993). O conceito de controle por regras pode ser um importante auxiliar no entendimento dos processos de mudança contemplados em terapia.

Skinner (1989/1991) afirmou, no seu livro Recent issues in the analysis of behavior (Questões recentes na análise comportamental), que terapeutas comportamentais, ao invés de organizarem novas contingências de reforçamento - tal como pode ser feito na escola, lar, local de trabalho ou hospital -, fornecem conselhos na forma de ordens ou descrição de contingências, ou seja, emitem regras. Para este autor "todo o problema pode ser resolvido mediante a aplicação de uma regra, e os terapeutas precisam ir um passo à frente e ensinar seus clientes a construir suas próprias regras. Isso significa ensinar-lhes algo sobre análise do comportamento" (p.112). 
Terapeutas cognitivo-comportamentais como Beck e Freeman (1990/1993) descrevem sua própria atuação como diretiva, por exemplo, ao instruir seus clientes a realizar diversas atividades fora do consultório. De maneira similar, Matos (2001) analisou que a habilidade de lidar com o comportamento humano verbal é a grande arma dos terapeutas e a garantia de sucesso de suas práticas. Quando os terapeutas orientam seus clientes a respeito de algo, estão muitas vezes verbalizando regras, as quais podem ou não ser seguidas.

Entretanto, há debates sobre quais são os mecanismos responsáveis por mudanças ocorridas em psicoterapias. Pergunta-se se são as técnicas específicas ou as variáveis da relação terapêutica que propiciam os efeitos da terapia. Também tem sido questionado se mudanças comportamentais produzidas pela terapia são modeladas por contingências da relação terapêutica ou são governadas por novas regras produzidas na terapia (Meyer, 2001; Meyer \& Vermes, 2001).

Meyer (2009) aponta que, atualmente, a importância da relação terapêutica é um consenso para os terapeutas comportamentais, porém há diferenças quanto ao papel desempenhado por esta relação (Raue \& Goldfried, 1994). Alguns autores como Rangé (1995) e Shinohara (2000) veem o vínculo terapêutico como um meio para facilitar outros aspectos importantes do processo de mudança, o que levaria a um maior engajamento na terapia. Por exemplo, Cahill, Carrigan e Evans (1998) consideram que à medida que a relação se desenvolve e a terapia entra numa fase de tratamento mais ativa, uma boa relação terapeuta-cliente torna o terapeuta mais eficaz, como um estímulo reforçador, e mais diretivo. Isto por sua vez, permitiria ao terapeuta ser consideravelmente mais influente em encorajar o cliente a tentar novas formas de pensamento e ação. Outros autores, no entanto, atribuem ao relacionamento que ocorre em terapia o principal mecanismo de mudança do cliente. Para estes terapeutas 
comportamentais, a relação terapêutica é uma oportunidade para o cliente emitir comportamentos que lhe têm trazido problemas e, a partir da interação com o terapeuta, aprender formas mais efetivas de respostas. Ou seja, o comportamento seria modelado pelas contingências da relação terapêutica mais do que governado por novas regras (Follette, Naugle, \& Callaghan, 1996; Kohlenberg \& Tsai, 1991/2001; Rosenfarb, 1992).

Aparentemente, mudanças podem ser promovidas em processos psicoterápicos tanto por alteração do controle por regras, quanto pela modelagem na relação terapêutica. Provavelmente os dois tipos de procedimento estão envolvidos nos processos de mudanças, em proporções diferentes, conforme o terapeuta e o cliente (Meyer, 2009). A pesquisa de Zamignani (2001) fornece apoio à noção de que terapeutas comportamentais podem usar, para promover mudanças, tanto procedimentos de modelagem por consequências (reforçamento diferencial), quanto controle por regras (sugestão de alternativas de resposta para solução de problemas, proposta de atividade incompatível com a resposta-queixa, orientação de exposição e/ou prevenção de respostas, ensino de procedimentos, solicitação de coleta de dados ou orientação ${ }^{2}$ (recomendação) para o cliente alterar pensamentos ou sentimentos. Foram comparados os desempenhos verbais de dois terapeutas. Cada um dos deles atendeu um cliente que apresentava diagnóstico de transtorno obsessivo-compulsivo (TOC) e outro cliente com outro tipo de queixa, de forma que cada terapeuta pudesse ser comparado com ele mesmo nas diferentes condições. Constatou-se que um dos terapeutas apresentou um percentual elevado de verbalizações de aprovação para ambos os clientes, apresentando verbalizações de aconselhamento praticamente só com o cliente com TOC, o qual tinha dificuldade em iniciar respostas de forma espontânea. Já o outro terapeuta apresentou

\footnotetext{
${ }^{2}$ Zamignani (2007) propõe o termo recomendação ao referir-se à orientação. Nesta pesquisa o termo utilizado será orientação (este termo foi utilizado por Skinner (1974/1982)). Orientação é entendida então como sinônimo de recomendação.
} 
predominantemente verbalizações de aconselhamento e explicação com ambos os clientes.

O uso da orientação, como uma das formas de produzir mudanças por regras, pode ter vários determinantes: a abordagem teórica comportamental, que tem produzido intervenções bem sucedidas com o uso de procedimentos padronizados envolvendo orientação; o cliente, que por vezes solicita conselhos; a experiência clínica, durante a qual pode ter havido reforço diferencial do emprego de estratégias diretivas; a história de vida pessoal, que poderia ter modelado, por exemplo, um estilo de interação pessoal mais controlador (Meyer \& Donadone, 2002).

\subsection{Revisão da literatura sobre o uso de orientação}

Estudos que abordam as estratégias de orientação em sessões de terapia são pouco frequentes. Quando encontrados, normalmente estão mesclados a outros comportamentos do terapeuta presentes na interação terapêutica e em alguns casos correlacionados aos resultados da terapia. Então, uma alternativa (ao estudo mesclado e à correlação/não correlação com resultados) utilizada em pesquisa clínica no intuito de aumentar o número de pesquisas que abordem determinados comportamentos dos terapeutas ou clientes é englobar pesquisas que avaliem a frequência de diferentes categorias de comportamento do terapeuta em intervenções, independentemente se tais intervenções alcançaram ou não os resultados pretendidos (Harwood, 2003; Orlinsky, Grawe \& Parks, 1994).

Apesar da escassez de estudos que abordam especificamente a orientação, Zamignani (2007) realizou uma revisão sobre os diferentes agrupamentos e definições das categorias de comportamento do terapeuta a partir dos sistemas de alguns pesquisadores como: Chamberlain e Ray (1988), Fiorini (1995), Hill (2004), Margotto (1998), Meyer e Vermes (2001), Schindler et al. (1989), Stiles (1992), Tourinho et al. 
(2003). Foi encontrada ao menos uma categoria equivalente à ‘orientação' em cada um dos sistemas de categorização, o que indica a concordância de terapeutas de diversas abordagens em diferentes épocas e países sobre ser esta uma forma de intervenção terapêutica, controversa ou não.

Silveira (2009) também apresentou uma revisão sobre alguns resultados de pesquisa que avaliam frequência de comportamentos presentes na interação terapêutica. Nesta revisão a autora citou alguns estudos que abordavam entre outros comportamentos a questão da orientação (foco principal da análise da presente pesquisa).

O primeiro estudo citado pela autora refere-se a um estudo de revisão realizado por Keijsers, Schaap e Hoogduin (2000). Neste estudo os autores verificaram que comparados a terapeutas de outras abordagens teóricas, os terapeutas comportamentais no geral falam mais, fazem mais questões, são mais diretivos, oferecem mais estruturação, informações e conselhos. De todas as verbalizações durante o tratamento cognitivo-comportamental, 12,4\% (Hardy \& Shapiro, 1996) e 7,0\% (Stiles et al., 1988) foram conselhos gerais, e 9\% (Kaimer et al., 1989) foram diretrizes e conselhos. Segundo Keijsers, Schaap, Hoogduin e Lammers (1995) na terapia cognitivocomportamental as intervenções diretivas aumentam de $4 \%$ na primeira sessão para $11 \%$ na terceira sessão, e diminuem $6 \%$ na décima sessão. Essas descobertas indicam que terapeutas cognitivo-comportamentais têm uma posição mais ativa e diretiva no tratamento do que terapeutas orientados para obtenção de insight, por exemplo. No entanto, afirmações diretivas e conselhos, comparados com outras formas de resposta do terapeuta, tais como afirmações empáticas e reconhecimento, ainda constituem uma pequena proporção de comportamentos verbais dos terapeutas durante o tratamento. 
Novamente, a questão que se levanta é se uma posição mais diretiva, ativa por parte do terapeuta promove resultados favoráveis de tratamentos. Dentro da literatura de processo psicoterápico há, porém, uns poucos estudos sobre o impacto do uso terapêutico de intervenções diretivas sobre os resultados de tratamentos. Já em 1986, Orlinsky e Howard concluíram que havia poucos estudos de pesquisa que foram conduzidos sobre a diretividade do terapeuta e os resultados de tratamento não permitiam que qualquer conclusão clara pudesse ser traçada.

Em estudos recentes (revisados por Silveira 2009), embora "diretividade" e “orientação" não fossem o foco das pesquisas, algumas conclusões acerca da efetividade de orientações diretivas puderam ser tiradas com base nos dados obtidos.

Orlinsky, Grawe e Parks (1994), ao examinarem intervenções bem e mal sucedidas, observaram que as categorias interpretação e apoio (parafrasear comentários do cliente e expressar empatia) ocorreram com frequência maior em intervenções que geraram resultados positivos. Já orientação ocorreu com maior frequência em intervenções que produziram mudanças discretas (apud Silveira 2009).

Harwood e Eyberg (2004) verificaram, ao revisarem intervenções com famílias, que confrontar e orientar geraram efeitos negativos somente nas primeiras sessões, com nenhum efeito prejudicial ao final da terapia. Portanto, oferecem resultados em parte contraditórios com os de Orlinsky, Grawe e Parks (1994) no que se refere aos efeitos do comportamento de orientar (apud Silveira, 2009).

Silveira (2009) apontou ainda que, de acordo com Harwood (2003), comportamentos de apoio são avaliados quanto à sua influência na produtividade na sessão assim como nos resultados. Comportamento empático pode ter como efeito que o cliente se sinta compreendido, aumentando, assim, as chances de este se engajar no processo terapêutico. Entretanto, também tem o potencial de levar o terapeuta, 
inadvertidamente, a reforçar e manter padrões que correspondam às dificuldades comportamentais que levaram o cliente a procurar terapia (Harwood, 2003). Patterson e Chamberlain (1994) constataram que uma alta frequência de comportamentos de empatia por parte do terapeuta produziu resultados desfavoráveis ao final da intervenção. Segundo os autores, o predomínio de apoio comparado às poucas ocorrências de orientação e interpretação produziu poucas mudanças terapêuticas ao final da intervenção.

Zamignani (2007) analisou três sessões (uma inicial, uma intermediária e uma final) de psicoterapia, com o objetivo de ilustrar a aplicação do seu sistema multidimensional de categorização dos comportamentos do terapeuta e cliente. Participaram do estudo, um terapeuta com vinte e cinco anos de experiência e uma cliente de 32 anos com queixas conjugais. Os resultados indicaram maior frequência e duração das seguintes categorias do terapeuta: Interpretação, Orientação (recomendação) e Aprovação, com aumento progressivo da fase inicial para a final. As categorias do cliente Relato e Concordância também se destacaram, com frequências constantes nas três sessões avaliadas, e Estabelece relações, da fase inicial para intermediária. As explicações do pesquisador para o aumento de Orientação (recomendação) e Interpretação na fase intermediária dizem respeito à etapa do processo terapêutico correspondente, em que já se prevê o levantamento de hipóteses e realização de intervenção, o que justificou também o aumento de Aprovação e Reprovação. A alta ocorrência e duração de Orientação (recomendação) e Interpretação na sessão final sugere uma preocupação do terapeuta em fornecer instruções, modelos de estratégias de ação devido à proximidade de interrupção dos atendimentos, ao invés de aplicar procedimentos de modelagem (Zamignani, 2007). 
Meyer (2009) realizou um estudo que teve por objetivo comparar os resultados encontrados em 18 pesquisas brasileiras. Todos os trabalhos selecionados possuíam uma categorização das verbalizações de terapeutas, feita a partir de transcrições e observações de sessões de terapia. Para isso, foi criado um banco de dados de sessões de terapia comportamental em que categorias semelhantes foram agrupadas de acordo com a proposta de Zamignani (2007). Quanto à categoria Orientação (recomendação), foram analisadas 622 sessões, conduzidas por 47 terapeutas. Os resultados encontrados neste estudo indicam que a porcentagem média de orientação das 35 sessões de número 1 foi de 5\%. Esta porcentagem quase dobra para as segundas sessões de terapia (média composta por 40 sessões), passando a ser de $10 \%$ das intervenções dos terapeutas em média. A porcentagem média continua subindo um pouco mais a cada sessão atingindo o valor máximo na $14^{\mathrm{a}}$ sessão, com $19 \%$ das intervenções dos terapeutas. A partir desse momento da terapia, aproximadamente no quarto mês, a porcentagem começa a diminuir. Considerando que em um ano de terapia ocorrem aproximadamente 40 sessões, verifica-se que próximo ao final do primeiro ano de terapia, na $31^{\mathrm{a}}$ sessão, a porcentagem média de orientação (recomendação) é de 14\%. Ao final do segundo ano de terapia (agrupamento das sessões 54 a 68) a porcentagem média cai para 7\%. No agrupamento das poucas sessões que encerram o terceiro ano de terapia (agrupamento das sessões 73 a 91), a porcentagem média de orientação é de apenas 3\%. Tais dados são similares aos encontrados por Keijsers et al. (1995) ao analisar interações diretivas na terapia cognitivo-comportamental. Em sua pesquisa, Keijsers encontrou que interações diretivas aumentavam de $4 \%$ na primeira sessão para $11 \%$ na terceira sessão, e diminuíam para 6\% na décima sessão.

Ao agrupar as sessões das 31 terapias conduzidas por terapeutas experientes com mais de oito anos de prática, Meyer (2009) observou que eles sistematicamente 
orientavam mais que os terapeutas com pouca experiência ou em formação. Na primeira sessão a média de orientação foi de $9,2 \%$, na segunda sessão eles já passaram a emitir $22 \%$ de orientação, na quinta chegaram a $31,6 \%$. A partir desse momento a porcentagem começou a flutuar para baixo, aparecendo ainda um pico de 34,3\% na altura da $21^{\mathrm{a}}$ sessão. O ponto mais baixo voltou a ocorrer no período que terminou com a $68^{\text {a }}$ sessão, com a média de 7\%. As 39 terapias conduzidas pelos terapeutas formados com até cinco anos de experiência clínica se iniciaram com 4\% de orientação e demoram duas sessões para triplicar essa porcentagem, subindo para $13 \%$ na terceira sessão. As 18 terapias conduzidas pelos terapeutas em formação levaram cinco sessões para passar dos 4,6\% da primeira sessão aos $7,8 \%$ na quinta sessão e aos $18 \%$ de orientação na sexta sessão. Em todos os níveis de experiência os terapeutas orientam pouco na primeira sessão e a porcentagem deste comportamento sobe mais rápido quanto maior a experiência. A partir da sexta sessão os terapeutas pouco experientes passam a orientar menos que aqueles em formação ${ }^{3}$. Estes só ultrapassam a marca dos $10 \%$ em média de orientação por sessão na terceira e quinta sessões. O banco de dados elaborado por Meyer (2009) permitiu encontrar regularidades no uso da estratégia de orientar de terapeutas comportamentais. Existe um aumento gradual e depois vai havendo uma redução desta forma de intervenção. Há também diferenças visíveis entre terapeutas com diferentes níveis de experiência clínica. Outras variáveis tais como diagnóstico do cliente, escolaridade, nível socioeconômico e idade podem ter determinado, em parte, os resultados. O pequeno número de atendimentos infantis presentes no banco de dados impede comparação por idade. Em outros casos, a falta de informação apresentadas nas pesquisas impediu algumas dessas análises.

\footnotetext{
${ }^{3}$ Nesta pesquisa, terapeutas em formação eram aqueles que realizavam atendimentos clínicos em estágios de graduação. Terapeutas pouco experientes eram aqueles que tinham no máximo cinco anos de atuação clínica e terapeutas experientes eram aqueles que tinham acima de oito anos de experiência clínica.
} 
Os estudos apresentados até o momento buscaram descrever comportamentos do terapeuta (especialmente o comportamento de orientar) em intervenções bem e mal sucedidas e suas possíveis relações com o sucesso da terapia. Concomitantemente, outras pesquisas chamam a atenção para os comportamentos do cliente (frente à orientação recebida) que facilitam ou prejudicam o processo.

Silveira (2009) aponta um estudo realizado por Bischoff e Tracey (1995). Nesse estudo os autores relacionaram a resistência dos clientes a intervenções do terapeuta ditas diretivas, como orientar, confrontar e interpretar, o que não ocorre com as não diretivas, como suporte, facilitação e informação.

Patterson e Forgatch (1985) examinaram o impacto do comportamento do terapeuta (variável independente) sobre a resistência do cliente (variável dependente). Os pesquisadores utilizaram um delineamento experimental $A B A B$ e observaram a frequência de comportamentos de resistência apresentada em uma intervenção com pais. Os comportamentos de resistência foram medidos por um sistema de categorias desenvolvido por Chamberlain, Patterson, Reid, Kavanagh, e Forgatch (1984). Conforme as hipóteses formuladas pelos autores, as intervenções diretivas no caso de confrontação e orientação levaram a um aumento nos comportamentos de resistência, já facilitação e suporte produziram uma diminuição em tais comportamentos. Os autores identificaram alguns possíveis efeitos que os comportamentos de resistência produzem em uma situação aplicada: (a) redução de comportamentos de orientar e confrontar; (b) aumento do número de sessões necessárias para produzir as mudanças terapêuticas almejadas; e (c) prejuízo no estabelecimento de uma relação de aceitação e de confiança com o cliente.

Patterson e Chamberlain (1994), ao analisarem resistência em terapias familiares, concluíram que ela pode nem chegar a aparecer se o terapeuta apresentar um 
nível ótimo de orientação e confrontação, que seja suficiente, mas não em excesso, para modificar os comportamentos desejados.

Silveira (2009) realizou uma análise da interação terapêutica em uma intervenção de grupo com cuidadoras. Para isso, a autora utilizou o sistema de categorização de Zamignani (2007). Os resultados encontrados em sua pesquisa demonstraram que as categorias de comportamento do terapeuta mais frequentemente encontradas foram as categorias Aprovação (37,9\%), Orientação ou recomendação $(19,2 \%)$ e Solicitação de relato (10,9\%). As categorias Reprovação $(1,1 \%)$ e Empatia $(5,9 \%)$ corresponderam aos menores percentuais de ocorrência no total das cinco sessões analisadas. A autora aponta que no estudo realizado resultados desejáveis foram encontrados, mesmo com a ocorrência elevada e constante da Orientação (recomendação) no decorrer das sessões analisadas. Tais resultados contradizem a posição de Alexander et al. (1976) e Keijsers et al. (1995), que estabeleceram associações entre a presença dessa categoria e prejuízos para o início da intervenção. A ocorrência expressiva de Orientação (Recomendação) pôde ser explicada através das características do próprio programa de intervenção (Bolsoni-Silva; Silveira; Ribeiro; 2008), isto é, dos procedimentos e temáticas planejados para cada sessão. Para cada uma das quatorze sessões, o planejamento explicitava as atividades a serem desenvolvidas e as habilidades sociais educativas a serem trabalhadas, cujas unidades comportamentais, representavam pré-requisitos para habilidades a serem abordadas em sessões posteriores. A autora apoiou-se nas afirmações de Meyer e Donadone (2002) que apontam que os terapeutas, ao orientarem os seus clientes, fornecem regras que podem ou não ser seguidas e que "um excesso de orientação, durante o processo terapêutico, dificultaria a aquisição de repertório por parte do cliente, que o conduzisse ao autocontrole e autonomia" (Meyer, 2004). Frente a estas considerações e a todos os 
achados teóricos e experimentais consistentes, referentes ao comportamento governado por regras ou comportamento governado verbalmente (Catania, 1999), Silveira (2009) levantou a hipótese de que em seu estudo ambos os procedimentos, Orientação (recomendação) e modelagem por aproximações sucessivas - devido à alta frequência de Aprovação e baixa frequência de Reprovação - foram empregados com igual ou similar frequência, igualando, portanto, as vantagens e desvantagens de cada um. Um aspecto considerado pela autora sobre a alta frequência de Orientação (recomendação) em seu estudo é a suposição de orientação ser um dos fatores que expliquem os relevantes resultados alcançados com a intervenção. A terapeuta ao apresentar Orientações (recomendações) ao grupo e não às clientes individualmente, pode ter minimizado os efeitos aversivos presentes nessa categoria, tão salientados na literatura (Orlinky, Grawe, \& Parks, 1994; Patterson \& Forgatch, 1985). Tal explicação encontra sustentação nos resultados obtidos por Barbera e Waldron (1994), que encontraram correlações positivas entre Ensinar (orientar) e a categoria do cliente Cooperação, resultado contrário ao esperado. Os autores justificaram o resultado, a partir da constatação de que o terapeuta, ao ensinar (orientar), se dirigia à família como um todo (adolescente infrator e pais), ou seja, ao grupo de clientes e não a um membro em específico, reduzindo, portanto, as propriedades aversivas e gerando cooperação.

Meyer (2009) aponta que, segundo Harwood (2003), tanto comportamentos ditos diretivos por parte do terapeuta (interpretação, orientação e confrontação) quanto os não diretivos (suporte e facilitação) são abordados na literatura, entretanto as conclusões a respeito de quais facilitam ou dificultam o processo terapêutico ainda são divergentes. Apesar da falta de esclarecimentos a respeito das condições em que tais comportamentos diretivos ou não são apresentados nos estudos citados (Harwood \& Eyberg, 2004; Orlinsky et al., 1994; Patterson \& Forgatch, 1985; Stoolmiller et al., 
1993) sugere-se com base em Harwood (2003) que a compreensão, aceitação do cliente e contexto de apresentação dos diferentes comportamentos são variáveis que podem ter determinado os resultados obtidos.

Keijsers et al. (1995) argumenta que a questão central não deve se limitar a se comportamentos diretivos do terapeuta possam ou não favorecer as mudanças terapêuticas almejadas, mas, sim, em qual momento ou sob quais condições são aceitas e seguidas pelos clientes.

Segundo Meyer (2009), ainda que algumas pesquisas (Harwood \& Eyberg, 2004; Patterson \& Forgatch, 1985) tenham demonstrado que diferentes comportamentos do terapeuta podem interferir de maneiras distintas nos comportamentos dos clientes, e como consequência, no andamento da terapia, constata-se a necessidade de mais pesquisas com descrições empíricas de categorias comportamentais do terapeuta.

Ainda, de acordo com Schaffer (1982), para o estudo não tangencial dos comportamentos do terapeuta são necessárias considerações a respeito de três dimensões: tipo de comportamento - refere-se aos objetivos, funções de determinado comportamento; perícia - a excelência com que esse comportamento é apresentado e, habilidade - a maneira como o terapeuta se relaciona com o cliente. Para o autor, comportamentos apresentados com frequência semelhante são analisados como tendo o mesmo impacto nos resultados, contudo, a desconsideração das dimensões de perícia e habilidade refletiria em conclusões discutíveis a respeito da qualidade da intervenção apresentada.

Assim, Schindler, Hohenberger-Sieber e Hahlweg (1989) sugerem a realização de observações sistemáticas e análises moleculares, identificando as interações momento-a-momento durante a sessão e por meio de análises intra e interssessões. 


\subsubsection{Abordagem Teórica}

Os estudos apresentados na revisão da literatura sobre orientação são em sua maioria estudos conduzidos na abordagem comportamental e cognitivocomportamental. Esta incidência de estudos nestas abordagens justifica-se pela forma como diferentes abordagens entendem a questão da diretividade (incluindo a emissão de orientação) em suas práticas.

A emissão de regras é uma das características das terapias cognitivas e comportamentais e é comum que terapeutas destas abordagens sejam descritos como diretivos, prescrevendo programas terapêuticos que compreendem procedimentos específicos, guiando e encorajando os esforços dos clientes nas sessões de tratamento e na vida diária (Frank \& Frank, 1993; Garfield, 1995). Por exemplo, terapeutas comportamentais podem dar instruções ao cliente de como relaxar, dar exercícios para serem praticados em casa, instruí-lo em como visualizar experiências particulares e ajudá-lo a construir uma hierarquia de situações temidas.

O estudo de Ablon e Jones (2002) fornece alguns dados empíricos para essa concepção. Os autores utilizaram um instrumento de 100 itens e analisaram o processo de interação terapeuta-cliente em 58 sessões de terapia cognitivo-comportamental para indivíduos deprimidos. Segundo eles, alguns dos itens mais característicos desta forma de terapia (e que se relacionam ao controle por regras) foram: discussão frequente sobre atividades e tarefas específicas para o cliente tentar fora da sessão, explicações e conselhos explícitos. Foi verificado que os clientes frequentemente concordavam com as colocações do terapeuta e as aceitavam, não iniciavam muitos tópicos de conversa em sessão, além de cumprir as solicitações feitas. A melhora foi associada, entre outros fatores, à obediência, admiração ou aprovação apresentadas pelos clientes em relação a seus terapeutas e ao desejo de maior proximidade e aceitação de suas intervenções sem 
ambivalência ou suspeita. É possível inferir que os procedimentos adotados funcionaram como regras e que seus efeitos foram obtidos através do reforçamento social fornecido pelo terapeuta. Esse efeito seria uma forma de comportamento aquiescente e não de rastreamento (Hayes \& Ju, 1998), ou seja, mais controlado por aprovação social do terapeuta do que pelas contingências naturais (fora da sessão) do comportamento instruído (apud Meyer, 2009).

Terapias psicodinâmicas são consideradas pouco diretivas. Terapeutas psicodinâmicos consideram que dar sugestões não seria uma atuação psicoterapêutica evocativa ou que propicie descobertas, objetivos que seriam alcançados por meio da autoexploração e busca de soluções pelo próprio cliente, estratégias que consideram mais intensas e desejáveis (Garfield, 1995). Muitas vezes, clientes que estão passando por um sofrimento chegam à sessão de terapia buscando ou até exigindo um conselho inteligente para tomar uma decisão ou que o terapeuta resolva um problema por eles. No entanto, segundo Corey (1983) a terapia não deve ser confundida com o ato de dar informação, orientação ou conselho. A tarefa do terapeuta consistiria em ajudar o cliente a descobrir suas próprias soluções e encontrar seu caminho, mas sem dizer como deveria fazê-lo. Para Miranda e Miranda (1993), a tarefa de orientar é descrita como o ato de avaliar com o cliente as alternativas de ações possíveis e assim facilitar a escolha de uma delas. Esse autor aponta que à medida que o terapeuta atende, responde e personaliza, o cliente começa a comportar-se de modo a promover sua própria mudança. Isso quer dizer que, explorada sua situação insatisfatória e compreendidas as várias peças dessa situação, o cliente muitas vezes elabora sozinho seu plano de ação (autoexploração), sem ajuda direta do terapeuta.

A orientação direta do terapeuta só é considerada necessária por terapeutas não comportamentais (Corey, 1983; Miranda \& Miranda, 1993) quando, por exemplo, o 
cliente não tem domínio do assunto abordado, quando se encontra claramente em perigo de prejudicar-se (como na ameaça de suicídio) ou prejudicar outros, ou quando se vê por certo tempo incapacitado para fazer opções. Ainda assim, eles consideram que a decisão final sempre é do cliente.

Quando terapeutas como Corey (1983) e Miranda e Miranda (1993) afirmam que o terapeuta se comporta de forma a fazer com que o cliente encontre novas formas de ação "sem ajuda direta", eles de acordo com a abordagem comportamental provavelmente estão realizando modelagem direta do comportamento verbal, incluindo a modelagem de autorregras. Tal procedimento estaria em acordo com a sugestão de Catania (1998/1999) de que a mudança do comportamento verbal do indivíduo pode facilitar a mudança do comportamento não-verbal correspondente. Nessa forma de intervenção, o terapeuta modelaria o comportamento verbal do cliente em vez de instruí-lo diretamente.

Quanto à análise de qual processo de mudança, regras ou modelagem pelas contingências, é responsável pelas mudanças clínicas, não se deve perder de vista que mesmo que o processo acima descrito seja o de modelagem de autorregras (modelagem dentro da sessão terapêutica), ainda assim a mudança produzida pela psicoterapia na vida diária do cliente seria obtida primordialmente pela introdução ou alteração de regras, quer formuladas pelo terapeuta, quer pelo cliente.

\subsection{Variáveis intervenientes}

O tópico anterior ressaltou a relação entre variáveis como abordagem teórica e a emissão de regras e autorregras (mais especificamente orientação e auto-orientação). No entanto, alguns pesquisadores como Margotto (1998), Novaki (2003) e Wielenska (2002) sugerem que algumas outras variáveis - do terapeuta, do cliente, da relação 
terapêutica - podem ser consideradas como variáveis terapêuticas importantes que interferem nas diferentes etapas do processo terapêutico, podendo facilitar ou dificultar a obtenção dos resultados almejados. Considerou-se necessário então abordar nesta pesquisa variáveis como: experiência dos terapeutas, idade, motivação e resistência do cliente, história de vida do cliente, tema (conteúdo/assunto) da sessão.

\subsubsection{Experiência do terapeuta}

Poucas são as pesquisas que relacionam experiência do terapeuta às emissões de regras. Algumas pesquisas relacionam experiência à formação de vínculo ou a comportamentos dos terapeutas em sessão, porém a maioria das pesquisas encontradas relaciona experiência a resultados em psicoterapia (Ex.: Propst, 1994; Blatt, 1996; Luborsky, 1997; Hupert, 2001).

Quanto à formação de vínculo, vários estudos demonstraram que não há diferenças significativas entre terapeutas experientes e pouco-experientes (Garfield, 1995; Dunkle \& Friedlander, 1996; Prado, 2002; Novaki, 2003; Hersoug, 2009). Mas a experiência pode ser determinante na forma como os terapeutas iniciantes se comportam ao longo das sessões. Hackney (1977) afirma que os terapeutas iniciantes apresentam excesso de movimentação corporal, abundância de gestos, desassossego, grande animação, expressão demasiada, chegando muitas vezes a ponto de dispersar-se. O discurso é caracterizado por emissão de palavras, frequentemente fluxo verbal compulsivo, além de carregado de pormenores e repetições. As repostas costumam ser mais longas do que as respostas imediatamente anteriores do cliente. A velocidade do discurso é geralmente alta, há poucas pausas entre as sentenças e o tom de voz usualmente é alto e agudo. O terapeuta principiante apoia-se firmemente em afirmações de orientação e de confrontação, pulando em seguida para conclusões. 
Pesquisas que correlacionavam experiência do terapeuta e resultados de psicoterapia foram conduzidas por alguns autores como Propst et al. (1994); Blatt et al. (1996); Luborsky (1997), Hupert, Bufka et al. (2001). Nessas pesquisas avaliações das terapias eram conduzidas após o término do tratamento. Em todas as pesquisas foram encontradas correlações positivas entre a maior experiência do terapeuta e os melhores resultados obtidos.

Outros estudos (também baseados em avaliações após o termino do tratamento) apontam que a forma como os clientes veem seus terapeutas parece ser mais relevante do que a experiência em si. Segundo LaCrosse (1980) as habilidades dos terapeutas (medidas em termos de domínio de técnicas) em conduzir as sessões são indicadores de consentimento do cliente a procedimentos mais diretivos. Tais dados são corroborados por Heppner e Heeseckar (1982/1983). Estes autores encontraram em sua pesquisa que as avaliações dos clientes sobre habilidades dos terapeutas não foram afetadas pelo nível real de experiência destes; ou seja, clientes que avaliavam que seus terapeutas dominavam técnicas e sabiam o que faziam em sessão, foram considerados pelos clientes como mais experientes do que de fato eram. Dados semelhantes foram encontrados nas pesquisas de Ryan e Gizynski (1971); Schindler et al., (1983) e Bennun et al., (1986). Tais estudos investigaram a avaliação de clientes após o término do tratamento psicoterápico cognitivo-comportamental. Na pesquisa de Ryan e Gizynski (1971), os clientes que mais melhoraram foram os que consideraram seus terapeutas como confiantes e persuasivos (diretivos). Na pesquisa de Schindler (1983) os clientes que mais melhoram foram os que consideraram seus terapeutas mais diretivos e ativos; já na pesquisa de Bennun et al. (1986) as melhoras relatadas foram associadas aos clientes que consideram seus terapeutas mais competentes e experientes. 
Vários estudos que avaliaram a atividade, habilidade, autoconfiança e diretividade dos terapeutas em fases precoces do tratamento também relataram associações significativas com os resultados (Bennun \& Schindler, 1988; Elliot, Barker, Caskey, \& Pistrang, 1982; Williams \& Chambless, 1990). Porém resultados na direção oposta também foram encontrados. Alexander et al. (1976) relataram associações não significativas entre habilidades, autoconfiança e diretividade dos terapeutas em fases precoces do tratamento e os resultados. Keijsers et al. (1995) realizaram um estudo com um grupo de 30 clientes com transtorno de pânico. Nesse estudo foi verificado se a frequência de afirmações diretivas e explicações durante as primeiras e as terceiras sessões de tratamentos poderia ser associada com os resultados do tratamento. $\mathrm{O}$ procedimento utilizado pelos autores consistia em gravações das sessões dos diferentes terapeutas (com diferentes experiências) e avaliações dos clientes sobre as sessões após o término de cada sessão. Correlações entre afirmações diretivas e explicativas e a avaliação dos clientes foram estabelecidas. Os resultados encontrados indicaram associações negativas entre afirmações diretivas e explicações nas primeiras sessões de tratamento, mas não nas terceiras sessões, independente da experiência dos terapeutas. A inconsistência dos resultados encontrados é atribuída a problemas de regulação e não vinculados à experiência dos terapeutas. Keijsers et al. (1995) discutem que a questão não deveria ser se afirmações diretivas dos terapeutas, explicações e conselhos aumentam a probabilidade de mudanças comportamentais por parte do cliente, mas especialmente em que hora ou sob que circunstâncias elas são aceitas e obedecidas pelos clientes.

Alguns pesquisadores como Gold e Dole (1989); Bergin (1997); Beutler (1997); Lambert e Okiishi (1997); Luborsky et al. (1997); Strupp e Anderson (1997), e Hersoug et al. (2009) apontam que idade é muitas vezes confundida com nível de 
experiência e nível de treinamento em que o terapeuta está. No entanto, a variável idade do terapeuta tem um valor limitado na predição dos resultados, e nem mesmo a similaridade de idade de clientes e terapeutas contribui de forma significativa para os resultados do tratamento.

De maneira geral, a literatura em psicologia não traz resultados consistentes sobre a importância de experiência do terapeuta e a utilização de determinadas estratégias (como a emissão de regras) em intervenções clínicas. Mas analisando especificamente o caso da orientação, uma série de estudos foi realizada levando-se em consideração a experiência do terapeuta. No primeiro estudo realizado por Meyer e Donadone (2002) foram analisadas emissões de orientações em sessões de terapeutas experientes. Os resultados encontrados indicaram uma baixa frequência de orientação nas sessões destes terapeutas. Tais resultados foram substancialmente diferentes do encontrado no treino de categorização realizado por esses autores. Nesse treino de categorização foram utilizadas sessões de terapeutas iniciantes e uma maior frequência de orientação nas sessões dos terapeutas principiantes foi encontrada. A partir dessa comparação não planejada, Donadone (2004) conduziu uma pesquisa na qual parte do procedimento do estudo anterior foi replicado, mas que contou também com a análise de auto-orientações. Esse estudo comparou o emprego de orientações tanto por terapeutas comportamentais experientes quanto por terapeutas com pouca experiência, assim como a emissão de auto-orientação pelos clientes dos diferentes terapeutas. Os resultados encontrados sugeriram que a maior experiência do terapeuta estava correlacionada à maior emissão de orientação por parte dos terapeutas, mas não à maior emissão de autoorientação pelos clientes. Dando continuidade aos dois estudos acima (Meyer e Donadone, 2002; Donadone, 2004), 45 terapias via internet conduzidas para o mestrado de Prado (2002) foram categorizadas com as mesmas categorias de Donadone (2004). A 
junção dos dados destas três pesquisas indicou que a experiência não foi estatisticamente diferente no uso de orientação, contrariamente à análise estatística encontrada na pesquisa de Donadone (2004). Por fim, Meyer (2009) criou um banco de dados reunindo e sistematizando os resultados de análises de 626 sessões de psicoterapia apresentados em 19 pesquisas brasileiras ${ }^{4}$ (Azevedo, 2001; Barbosa, 2006; Brandão, 2003; Colombini, 2007; Del Prette, 2006; Donadone, 2005; Maciel, 2004; Martins, 1999; Medeiros, 2001; Meyer \& Donadone, 2002; Oliveira, 2002; Rocha, 2008; Tourinho et al., 2007; Ulian, 2007; Wielenska, 2002; Yano, 2003; Yano, Almeida \& Meyer, 2008; Zamignani, 2001; Zamignani,2007) e os resultados encontrados indicaram que os terapeutas experientes orientam sistematicamente mais que os terapeutas com pouca experiência ou em formação.

Em suma, experiência parece ser uma variável bem estudada em relação aos resultados da psicoterapia, mas quando se analisam a experiência e níveis de emissão de regras, mais pesquisas devem ser realizadas para que se possam obter dados mais generalizáveis. Pesquisas que correlacionem emissão de regras e resultados de psicoterapia também devem ser conduzidas com o intuito de identificar se a emissão de regras pode ser correlacionada com os resultados de psicoterapia e se via regras podemse obter mudanças psicoterápicas desejáveis.

\subsubsection{Características dos clientes}

Falar sobre as variáveis dos clientes é extremamente complexo, uma vez que se sabe que nenhum cliente começa psicoterapia na mesma condição que outro. Cada cliente é único quanto a habilidades interpessoais, queixas, história de vida e predisposição para mudança. O número de variáveis do cliente com potencial de influenciar o processo e os resultados da psicoterapia é virtualmente ilimitado. Segundo

\footnotetext{
${ }^{4}$ Na pesquisa de Meyer (2009), as pesquisas de Donadone \& Meyer (2002) e Donadone (2004) foram incluídas.
} 
Clarkin e Levy (2004) “... tudo, do genoma à química cerebral, das variáveis demográficas e condições ambientais aos padrões de comportamento, da queixa até o problema diagnosticado, é relacionado à psicoterapia e a seus ingredientes”. Algumas variáveis podem ser externas ao indivíduo (exemplo: apoio social), invariantes (ex: gênero, grupo étnico), relativamente estáveis (ex: padrões de comportamento), ou muito variáveis (ex: motivação para mudança). As variáveis do cliente podem ser psicológicas em natureza (tais como padrões de comportamento) ou podem ser parte do sistema biológico do indivíduo (estágios característicos do sono REM) (Keijsers, Schaap, Hoogduin, Hoogsteyns, \& de Kemp, 1999; Rosembaum \& Horowitz, 1983). Os comportamentos dos clientes podem ainda ser influenciados por características e comportamentos do terapeuta.

Frente a essa dificuldade, pesquisadores se esforçam no intuito de encontrar possíveis regularidades nas variáveis dos clientes. Tal esforço baseia-se em alguns resultados de pesquisa como as conduzidas por Lambert (1992), Ablon e Jones (1999), Blatt, Quinlan, Pilkonis e Shea (1995) e Zuroff, et al. (2000) que apontam que as características dos clientes são melhores preditores de resultados do que tipos particulares de intervenções. Assim, para estes pesquisadores, uma ampla proporção da variação dos resultados em psicoterapia é devida a características pessoais e qualidades do cliente. Por exemplo, Lambert (1992) considera que até $40 \%$ da melhora do cliente em psicoterapia pode ser atribuída às variáveis do cliente e influências extraterapêuticas.

Um primeiro aspecto considerado pelos pesquisadores (Lambert, 1992; Ablon \& Jones, 1999; Blatt, Quinlan, Pilkonis, \& Shea, 1995; Zuroff et al., 2000) acerca das variáveis dos clientes seria que os dados obtidos sobre os clientes são advindos de uma pequena porcentagem da população que procura psicoterapia e permanece nela. $\mathrm{Na}$ população geral, aqueles que relatam sofrimento emocional (Veroff, Kulka, \& Douvan, 
1981; Ware, Manning, Duan, Wells, \& Newhouse, 1984), exibem sintomas psicológicos (Boyd, 1986; Yokopenic, Clark \& Aneshensel, 1983), e consideram sua saúde mental pobre (Leaf et al., 1985) são mais inclinados a procurar ajuda de profissionais da saúde mental. É mais provável mulheres procurarem apoio informal e ajuda profissional do que homens (Butler, Giordano, \& Neren, 1985; Horwitz, 1977; Kessler, Brown, \& Broman, 1981, Hersoug, 2009).

É muito comum haver comorbidades ${ }^{5}$ quando as pessoas procuram tratamento, e clientes com comorbidade têm piores resultados que clientes sem comorbidades (Orlinsky, Grawe, \& Parks, 1994). A duração das dificuldades (isto é, a cronicidade, frequência, e extensão da recaída) também deve ser considerada e está relacionada aos piores resultados obtidos em tratamento psicoterápico. Revisões prévias dos resultados de pesquisa geral concluíram que a severidade dos sintomas é relacionada à pouca resposta ao tratamento (Beckham, 1989; Beutler \& Hamblim, 1986; Garfield, 1994; Hoberman, Lewinsohn, \& Tilson, 1988; Lambert \& Anderson, 1996; Luborsky, CritsChristoph, Mintz, \& Auerbach, 1988). Os dados de pesquisa sugerem que clientes que apresentam como comorbidade transtornos de personalidade têm piores resultados de tratamento que os que não apresentam comorbidades (Orlinsky, Grawe, \& Parks, 1994).

Há evidências de que as expectativas e dificuldades dos clientes estão relacionadas ao comportamento do terapeuta. Clientes considerados por seus terapeutas como difíceis foram os que receberam tratamentos mais pobres ${ }^{6}$ em relação aos clientes que foram considerados participativos (Beckham, 1989; Beutler \& Hamblim, 1986;

\footnotetext{
5 Para Orlinsky, Grawe, e Parks (1994) comorbidade é definida como sintomas diagnosticáveis coexistindo. Por exemplo, desordens do eixo I do DSM-IVR coexistindo com desordens do eixo II do DSM-IVR.

${ }^{6}$ Tratamentos foram considerados pobres quando terapeutas avaliavam seu desempenho insatisfatório em sessões de psicoterapia. Essa avaliação de desempenho insatisfatória foi mais comum quando os terapeutas consideraram seus clientes como difíceis. (Beckham, 1989; Beutler \& Hamblim, 1986; Garfield, 1994; Hoberman, Lewinsohn, \& Tilson, 1988; Lambert \& Anderson, 1996; Luborsky, CritsChristoph, Mintz, \& Auerbach, 1988).
} 
Garfield, 1994; Hoberman, Lewinsohn, \& Tilson, 1988; Lambert \& Anderson, 1996; Luborsky, Crits-Christoph, Mintz, \& Auerbach, 1988). Expectativas negativas dos clientes sobre o tratamento foram associadas com suas próprias dificuldades, enquanto o nível de sintomas não. Já clientes que vêm procurar terapia conscientes de que alguns de seus comportamentos, atitudes e emoções serão mudados apresentaram melhores resultados do que os que não vêm com esta preparação (Beckham, 1989; Beutler \& Hamblin, 1986; Garfield,1994; Hoberman, Lewinsohn, \& Tilson, 1988; Lambert \& Anderson, 1996; Luborsky, Crits-Christoph, Mintz, \& Auerbach,1988).

Idade é também relacionada ao comportamento de procurar ajuda. Os indivíduos mais velhos são mais relutantes que os mais novos em procurar ajuda de profissionais de saúde mental. Fiorot, Boswell, e Murray (1990), Tompson, Gallagher, e Czirr (1988) relataram que tratamentos com clientes mais velhos, usando terapia comportamental, dinâmica, ou eclética, tiveram resultados pobres para clientes com comorbidade com transtorno de personalidade. Quanto ao preconceito etário, sabe-se que aparentemente terapeutas guardam uma visão negativa e estereotipada de clientes mais velhos (Danzinger \& Welfel, 2000; Yvey, Wieling, \& Harris, 2000).

Há ainda algumas variáveis que não produziram resultados satisfatórios e conclusivos. Entre elas estão sexo, opção sexual, raça ou etnia, valores, atitudes e crenças, religião do terapeuta (Orlinsky, Grawe, \& Parks, 1994).

Quanto ao sexo do terapeuta, pouca relação foi encontrada entre essa variável e os resultados do tratamento (Hersoug et al., 2009), e praticamente não há estudos que correlacionam a opção sexual dos clientes com os resultados dos tratamentos, mas podese inferir que terapeutas preconceituosos terão mais taxa de abandono de clientes homossexuais. Entre os terapeutas heterossexuais, Liddle (1995) concluiu que mulheres foram avaliadas como mais efetivas que homens. A transparência de falta de 
entendimento para questões homossexuais de alguns terapeutas (independente do sexo) foram correlacionadas negativamente ao grau de comprometimento e permanência dos clientes em terapia.

Poucas pesquisas que comparam os resultados de psicoterapia como um efeito direto da raça ou etnia do terapeuta, independente da do cliente, são encontradas na literatura. Porém das poucas pesquisas encontradas, a maioria delas aponta que quando clientes e terapeutas dividem certas experiências étnicas, os resultados podem ser melhorados. Tais resultados, no entanto devem ser olhados com cautela, pois até esse momento ainda há falta de pesquisas empíricas para suportar esses dados (Beutler et al., 1990).

Também há poucas pesquisas sobre a influência de valores, atitudes e crenças sobre os resultados da psicoterapia. Uma justificativa para um número reduzido de pesquisas sobre tais variáveis deve-se à dificuldade em se definir o que é valor, crença etc. Assim não há nada que comprove que valores do terapeuta podem ser usados para aumentar a eficácia das predições de resultados (Beutler, 1981; Kelly, 1990; Richards \& Bergin, 2000; Shafranske, 1996).

Por fim, religião também não parece afetar o trabalho dos terapeutas (Propst, Ostrom, Watkins, Deant, \& Mashburn, 1992; Worthington et al., 1996). Aqui também se deve ter cautela, pois até então pesquisas nesta área são escassas e conclusões seriam precipitadas.

\subsubsection{Motivação e resistência do cliente}

Uma das variáveis do cliente que deve ser considerada ao se observar tratamentos psicológicos é a motivação ou resistência do cliente em sessões psicoterápicas.

A literatura apresenta uma grande quantidade de pesquisas que leva em consideração a motivação ou a resistência dos clientes em tratamento. No entanto, 
motivação e resistência podem ser entendidas de forma diferente em diferentes abordagens e delimitar tais conceitos torna-se uma tarefa árdua. Por exemplo: alguns autores entendem motivação como introspecção, outros como disponibilidade para mudança, outros como comprometimento para mudança e outros ainda entendem motivação como aceitação de procedimentos (como realização de tarefas de casa) e tratamentos psicológicos (Keijsers, Schaap, Hoogduin, Hoogsteyns, \& de Kemp, 1999; Rosembaum \& Horowitz, 1983). Situação similar ocorre no caso da resistência. Vários modelos teóricos têm sido propostos para explicar tal fenômeno e vários sinônimos são usados para exprimir resistência como: reativo, não cumpridor (recusa), reacionário, intratável, não motivado e opositor.

Além da dificuldade em operacionalizar o que se entende por motivação ou resistência, há poucos estudos comportamentais que abordam especificamente tais questões.

Apesar dos obstáculos apontados acima e dificuldades de delimitação e operacionalização do que seria motivação e resistência, considerou-se útil buscar na literatura estudos empíricos que abordassem tais temas. O objetivo maior desta secção seria encontrar estudos que ao menos sugerissem se diferentes perfis de clientes (motivados ou resistentes) poderiam ser variáveis que influenciassem a emissão de regras por parte dos terapeutas.

Quanto à motivação, nesta pesquisa foram analisados estudos que a entendiam como disponibilidade para mudança, participação, colaboração e aceitação de procedimentos diretivos (como por exemplo, realização de tarefas de casa).

Motivação, avaliada como disponibilidade e entusiasmo para mudança foi abordada no estudo conduzido por Miler e Rollnick (1993). Estes autores apontaram que clientes que apresentaram uma maior disponibilidade para mudança foram os que 
obtiveram os melhores resultados em psicoterapia. Resultados similares foram encontrados por Kanfer e Grimm (1980). Segundo Kanfer et al. (1980) a disponibilidade do cliente era pré-requisito para a introdução de técnicas cognitivocomportamentais.

Outros pesquisadores têm tentando definir a motivação baseados em critérios de participação, cooperação e complacência durante o curso do tratamento. Na revisão realizada por Orlinsky e Howard (1986), dezoito estudos foram analisados e foi investigado se a motivação (entendida como engajamento ativo, participação, cooperação e complacência dos clientes) se correlacionava significativamente aos resultados. Desses dezoito estudos empíricos, treze apresentaram correlações significativas positivas com os resultados dos tratamentos e apenas cinco não apresentaram correlações significativas.

Schefft e Kanfer (1987), ao analisarem a questão da motivação em terapia cognitivo-comportamental, observaram que adicionar condições promotoras de mudanças (tais como negociação sobre os objetivos do tratamento, estruturação dos papéis de terapeuta e cliente, e aumento de comprometimento para a mudança por parte do cliente) produziu melhores resultados de tratamento em treinos de assertividade quando comparados à terapia cognitivo-comportamental ou terapia orientada para relacionamento sem a adição das condições promotoras. Interessantemente, ganhos superiores em um número de variáveis de processo, possivelmente mediadas por mudanças reais, tais como crença na mudança e aumento da percepção de controle, foram identificados depois das primeiras três sessões de tratamento.

Fatores de motivação dos clientes parecem afetar significativamente os resultados em tratamentos de desordens de ansiedade (Bennum \& Schindler, 1988; de Haan et al., 1997; Hoogduin \& Duivenvoorden, 1988; Kampman \& Keijsers, Hoogduin 
et al., 1991; Keijsers et al., 1994a, 1994b, Nelson \& Borkovec, 1989). Vários estudos indicaram uma relação significativa entre baixos graus de motivação e abandono do tratamento (de Haan et al., 1997; Keijsers et al., 1999; Simpson \& Joe, 1993). Alguns desses estudos usaram como instrumento de avaliação da motivação, a lista de motivação Niejmegen (NML). O NML foi desenvolvido para avaliar a própria avaliação do cliente de sua motivação para o tratamento; e os dados encontrados nas pesquisas que usaram este instrumento indicaram que a avaliação de pouca motivação pelo próprio cliente foi correlacionada a resultados inexpressivos em terapia ou abandono de terapia (Blaauw \& Emmelkamp, 1991; de Beurs, 1993, Mathews, Johnston, Shave \& Gelder, 1974; Mathew et al., 1976; Mawson, Marks, \& Ramm, 1982). Em outros estudos, onde a avaliação da motivação era feita pelos terapeutas ou por avaliadores independentes, resultados similares foram encontrados (Bennum \& Schindler, 1988; de Haan et al., 1997; Hoogduin \& Duivenvoorden, 1988; Hoogduin et al., 1991).

Além da participação do cliente em sessão é comum que se avalie motivação em pesquisas de terapia cognitivo-comportamental pelo nível de realização de tarefa de casa. O fazer tarefas de casa, apesar de medido de forma inconsistente em diferentes estudos, foi significativamente relacionado aos resultados de tratamento em três estudos (Burns \& Nolen-Hoeksema, 1991/1992; Neimeyer \& Feixas, 1990 [apesar de não seguimento]; Persons, Burns, \& Perloff, 1988).

Sete outros estudos falharam em demonstrar uma relação significativa entre cumprimento de tarefa e resultados de tratamento (Barlow, O'Brien, \& Last, 1984; Edelman \& Chambless, 1993; Fals-Stewart \& Lucente, 1993; Kornblith, Rehm, O’Hara \& Lamparski, 1983, Lax, Basoglu, \& Marks, 1992; Nelson \& Borkovec, 1989, Startup \& Edmons, 1994). No estudo de Barlow et al. (1984), mesmo os clientes que não realizaram tarefas de casa, mas foram expostos de forma gradual a situações temidas, 
obtiveram resultados similares aos dos clientes que realizavam todas as tarefas terapêuticas solicitadas. No estudo de Edelman (1993) resultados semelhantes foram encontrados. A realização das tarefas não influenciou nos resultados, assim como não houve diferenças entre os clientes que realizaram tarefas e aqueles que se negaram a fazê-las. Fals-Stewart et al. (1993) analisaram a correlação entre a realização de tarefas de casa e os resultados da terapia cognitivo-comportamental em clientes com transtorno obsessivo compulsivo. Não foi encontrada correlação positiva entre resultados de psicoterapia e clientes cumpridores de tarefas de casa. A tarefa de casa neste estudo não parecia ser um indicativo de maior motivação ou engajamento dos clientes em terapia. Dados semelhantes foram encontrados por Lax et al. (1992). Estes autores também trabalharam com clientes com transtorno obsessivo compulsivo e como resultados encontraram que tarefas de casa não são bons preditores de resultados. Kornblith, Rehm, O’Hara e Lamparski, (1983) realizaram um estudo em que clientes deprimidos eram treinados a avaliarem seus comportamentos. Estratégias de autocontrole e autorreforçamento também eram treinadas. Um grupo de clientes além de relatar seus comportamentos em sessão deveria realizar como tarefa de casa anotações sobre as situações vivenciadas. A comparação do grupo que realizou a tarefa com o grupo que não realizou a tarefa indicou que a realização das tarefas não foi relacionada significativamente aos resultados da terapia e nem à motivação. Nelson et al. (1989) realizaram um estudo onde a participação do cliente em terapia foi analisada. Estes autores não encontraram relação significativa entre realização de tarefa de casa e participação ativa nos tratamentos, ou seja, em algumas situações clientes podiam realizar a tarefa de casa, mas não estar de fato engajado no processo psicoterápico. Por fim Startup et al. (1994) avaliaram a realização de tarefas de casa em clientes deprimidos submetidos a terapia cognitivo-comportamental. Nesta pesquisa a 
realização de tarefas de casa não foi um preditor de resultados satisfatórios em psicoterapia.

Todas estas pesquisas em que não foram encontradas correlações entre a tarefa de casa e os resultados da terapia sugerem que a quantidade ou qualidade da tarefa de casa não têm um impacto consistente sobre os resultados. Além disso, o cumprimento da tarefa de casa na maioria das pesquisas é correlacionado moderadamente à motivação, sendo importante destacar que outros fatores de motivação como expectativa e disposição para mudança são melhores preditores de motivação do que a tarefa de casa em si (Burns \& Nolen-Hoeksema, 1991; Lax et al., 1992; Nelson \& Borkovec, 1989; Startup \& Edmons, 1994). Ou seja, tais autores apontam que não há correlação direta entre a quantidade ou mesmo a realização de tarefas de casa e alto nível de motivação. Esses dados vão contra a concepção popular em terapia cognitivo-comportamental de que clientes altamente motivados beneficiam-se mais com o tratamento porque tendem a cumprir necessariamente a tarefa de casa, enquanto que clientes não motivados não o fazem.

Além da motivação do cliente, outra variável importante refere-se à resistência em psicoterapia.

Alguns estudos relacionam a resistência do cliente à diretividade do terapeuta (incluindo a emissão de regras). Beutler, Moleiro e Talebi (2002) realizaram uma revisão de vinte estudos que verificaram os efeitos diferenciais da diretividade do terapeuta, tendo em vista a resistência dos clientes. Foi constatado que $80 \%$ desses estudos demonstraram que intervenções diretivas funcionaram melhor entre clientes com baixo nível de resistência, enquanto intervenções não-diretivas funcionaram melhor entre clientes com graus mais altos de resistência, sugerindo que os efeitos da 
resistência podem ser driblados pelo uso de intervenções não-diretivas e autodirecionadas.

Chamberlain, Patterson, Reid, Kavanagh, e Forgath (1984) desenvolveram um sistema de observação para avaliar o comportamento resistente do cliente durante o treino de pais. Eles encontraram que famílias com altos níveis de resistências abandonaram significativamente mais o tratamento que famílias com baixos níveis de resistência ou motivadas. Entretanto, é difícil interpretar a relação causal entre comportamento resistente durante o curso do tratamento e resultados do tratamento (avaliados pelos terapeutas).

As pesquisas realizadas indicando uma forte correlação entre a resistência do cliente e um resultado negativo da terapia e/ou abandono dela, e entre a resistência do cliente e comportamentos diretivos do terapeuta (Ablon \& Jones, 2002; Beutler, Moleiro, \& Talebi, 2002; Bischoff \& Tracey, 1995) sugerem que o uso de estratégias diretivas, tal como a orientação, não deveria estar vinculado apenas à linha teórica e à preferência do terapeuta. A história do cliente de seguimento de regras e instruções deve ser levada em consideração. Por exemplo, para clientes com uma história de dificuldades de seguimento de regras não seria recomendado o uso de procedimentos muito estruturados.

Há alguns casos na literatura onde a resistência a intervenções clínicas foi relacionada a outros fatores e não só à diretividade do terapeuta. A pesquisa realizada por Nardi (2004) é um exemplo ilustrativo. Este autor analisou o comportamento de clientes com dores crônicas em sessões de psicoterapia. Ele observou que clientes com dores crônicas tendem a ser mais hostis (Murta, 1999; Thornton \& Silvermann, 1998, Loduca, 1999) e belicosos (Teixeira, 1994). Ainda, raiva e irritabilidade estão descritas entre as reações normais à dor crônica (James, 1992; Kanner, 1998). Segundo Kanner 
(1998), a hostilidade na prática clínica pode ser entendida como um comportamento resistente. Em sua pesquisa, Nardi (2004) observou que como clientes com dores crônicas tendem a ser mais resistentes, é necessário que o terapeuta consiga discriminar quais são os temas que produzem respostas de resistência, visto que a maioria dos temas abordados em terapia que não sejam a dor crônica em específico podem gerar resistência e hostilidade. Scarpelli (2007) aponta que o terapeuta também pode encontrar outros problemas para atingir seus objetivos, pois o incentivo à retomada das atividades diárias pode ser entendido pelo cliente como erro de diagnóstico ou menosprezo por suas queixas. Esta situação expõe o terapeuta a um conflito: incentivar o cliente a retomar atividades e propor tratamentos que aparentemente pouco têm a ver com o seu problema ou queixa. Por outro lado, abordar em terapia exaustivamente o tema dor, pode não ser adequado à medida que o terapeuta pode fortalecer as respostas de dor que se deseja extinguir. Assim o trabalho precisa ser feito sob uma ação mais discreta, menos diretiva, pois a percepção por parte do cliente de que seu problema está sendo menosprezado poderia gerar hostilidade e baixa adesão (Nardi, 2004). Cabe ao terapeuta manejar essas dificuldades e conseguir realizar a intervenção adequada para ter os resultados desejados na psicoterapia com estes clientes, e uma das possibilidades seria uma menor emissão de regras a eles.

Outras considerações sobre a resistência do cliente a mudanças foram feitas por Guilhardi (2002) e sobre o manejo da resistência sob o enfoque analíticocomportamental por Cautilli e Connor (2000). Para esses autores, a resistência pode ser entendida e, portanto, trabalhada por meio de análise funcional. Os problemas que produzem resistência podem ser cinco: (a) falta de motivação, ou seja, reforçamento insuficiente para executar a tarefa ou punição por executá-la, ou existência de demasiados obstáculos; (b) tempo insuficiente para praticar a habilidade antes de usá-la; 
(c) necessidade de mais ajuda para implementar a habilidade nas condições existentes;

(d) a habilidade é uma exigência inédita, que a pessoa não precisou fazer antes; (e) a habilidade é complexa demais (Cautilli \& Connor, 2000).

A não-adesão ou não-aderência ao tratamento também pode ser entendida como uma forma de resistência. Problemas de adesão ou de aderência têm sido preocupação de profissionais da saúde e de relevantes pesquisas. Malerbi (2000), ao analisar a questão da adesão aos tratamentos médicos, afirmou que o nível de adesão não aumentou muito no período de mais de 20 anos de estudos sobre o problema. A pesquisadora verificou, em levantamento bibliográfico, que o fator mais importante que afeta a adesão é a complexidade do tratamento, ou seja, quanto mais complexo o tratamento, menor a adesão.

Conclui-se que os dados empíricos que relacionam motivação, participação, e resistência são pouco generalizáveis. Os únicos dados consistentes vêm de estudos que usam o NML (lista de motivação Niejmegen) para avaliar motivação. Este é um dado surpreendente porque as propriedades psicrométricas do NML são especialmente pobres (Keijsers, Hoogduin, et al., 1991). É, entretanto, o único instrumento que tem sido repetidamente usado em estudos de predição de resultados em terapia. É também um dos poucos instrumentos que avalia a avaliação do próprio cliente sobre sua motivação para o tratamento. Isto pode ser de interesse porque as avaliações do cliente parecem um preditor mais consistente dos resultados que as avaliações do terapeuta ou avaliações por avaliadores independentes em vários outros comportamentos interpessoais de clientes e terapeutas. Além disso, há divergências sobre os impactos da motivação sobre os resultados de tratamento, seja a motivação analisada considerando a pré-disposição para a mudança, seja a analisada considerando a realização de tarefas de casa. 
Assim, dos estudos analisados nesta secção, a maioria (apesar de apresentar diferentes significados ao que se entende por motivação) apresenta dados que sugerem que clientes considerados motivados são mais participativos, engajados e mais complacentes com as técnicas utilizadas por seus terapeutas. A única exceção refere-se aos estudos que avaliam motivação via realização de tarefa de casa. Correlações negativas foram encontradas nos estudos que avaliavam a resistência do cliente e os resultados do tratamento psicológico. Tais análises nos permitem inferir que a introdução de diferentes intervenções, incluindo emissão de regras, parece ser mais aceita e produzir resultados quando clientes se mostram motivados e pouco resistentes. Além disso, as pesquisas sugerem que terapeutas levam em consideração a motivação do cliente quando propõem intervenções mais diretivas como, por exemplo, orientações para tarefas de casa.

\subsubsection{História de vida do cliente}

A história de vida do cliente é outra variável relevante quando se analisam regras. Hayes, Kohlenberg e Melancon (1989) ao analisarem desordens clínicas sugeriram que clientes podem apresentar problemas: (a) na formulação de autorregras, (b) nas regras aprendidas, (c) no não-seguimento de regras e (d) no seguimento excessivo de regras.

No entanto, para o entendimento dos problemas no seguimento de regras é necessário analisar os controles envolvidos no aquiescer e no rastrear.

Zettle e Hayes (1982) apontam que ao menos cinco variáveis ou circunstâncias modulam o comportamento controlado por regras do tipo aquiescer. São elas: (a) a habilidade ou capacidade do agente social de monitorar o comportamento de seguir a regra; (b) a habilidade ou capacidade do agente social de realmente poder cumprir com as consequências previstas; (c) a importância das consequências previstas, ou a 
magnitude do reforço; (d) a história de confiabilidade do agente social; e (e) a importância das consequências previstas para outros comportamentos que não o de seguir a regra.

Já no caso do comportamento de rastrear, Matos (2001) aponta ao menos três variáveis que influenciam tal comportamento. São elas: (a) a concordância da regra aos eventos (por exemplo, sua clareza, sua precisão, o fato de a regra ser completa ou incompleta), (b) por variáveis que afetam a importância dessa concordância, das consequências existentes para outros comportamentos que não o instruído, e (c) a importância ou magnitude da consequência prevista na regra. Ao contrário do aquiescer, o rastrear praticamente dispensa a figura do agente social (Matos, 2001).

\subsubsection{Problemas na formulação de autorregras}

É desejável que clientes formulem autorregras, sendo este um repertório importante, especialmente nos casos em que o comportamento gerador de problemas está sob um maior controle das contingências diretas e imediatas, como ocorre na impulsividade. Segundo Hayes \& Ju (1998), quando o repertório de seguimento de regras de uma pessoa não está bem desenvolvido, ela pode ser rotulada tanto como impulsiva quanto como preguiçosa, antissocial ou imoral. De acordo com esses autores, autorregras introduzem novas formas de regulação social propiciando maior resistência à extinção ou a consequências imediatas, e estas são características similares às do seguimento de regras enunciadas por outros.

No entanto, desordens na formulação de autorregras ocorrem quando regras não são formuladas em situações em que seria vantajoso formulá-las ou quando as regras formuladas são feitas de maneira imprecisa e não realista. De acordo com Hayes e Ju (1998) a estratégia terapêutica nesses casos pode ser a de ensinar formulação apropriada 
de regras, ou seja, ensinar o cliente a colocar seu comportamento verbal sob controle direto dos eventos vivenciados e de suas consequências naturais.

\subsubsection{Problemas nas regras formuladas pelo grupo}

Algumas regras formuladas pela comunidade verbal em geral podem ser inadequadas ou mesmo imprecisas. Por exemplo, uma subcultura religiosa pode desenvolver regras sobre cura pela fé que proíbam seus adeptos de procurar ajuda médica para doenças que ameacem a vida. Similarmente, uma cultura pode deixar de dar qualquer orientação verbal sobre tópicos importantes de saúde (Hayes et al., 1989). Nessas situações, o terapeuta pode tanto procurar na cultura em questão uma melhor formulação de regras como colocar o comportamento do cliente em contato direto com as contingências naturais.

\subsubsection{Falha em seguir regras}

Além de formular regras vantajosas, é desejável que as pessoas sejam capazes e compreendê-las e segui-las. Quando não há um repertório de ambos os aspectos do seguimento de regras, padrões desordenados de comportamento são prováveis.

Em algumas circunstâncias é desejável que regras possam competir efetivamente com os efeitos destrutivos de algumas formas de controle imediato por contingências. Por exemplo, a regra "Não às drogas!" tem a intenção de estabelecer insensibilidade comportamental a determinadas contingências diretas. Entretanto, mesmo que um adolescente saiba que fazer uso de drogas que viciam pode levá-lo a problemas extremamente indesejáveis, as contingências sociais imediatas (e.g., aceitação do grupo de amigos) e os efeitos imediatos da própria droga podem conduzi-lo a um padrão de vício. Sem um padrão suficientemente forte de seguimento de regras, é mais provável que a pessoa tenha seu comportamento controlado pelas contingências imediatas, mesmo sendo o resultado destrutivo (Hayes et al., 1989). 
Um maior grau de seguimento de regras pode ser conseguido com algumas técnicas usadas com pessoas com transtorno de caráter ou impulsivas. Exemplos dessas técnicas são os programas de tratamento em grupo para drogados, em que basicamente toda a estrutura do programa é organizada em torno de regras de conduta claramente especificadas. A obediência às regras é promovida através de encontros em grupo, que enfocam o sucesso e as infrações dos membros do grupo. Esse controle social intenso pode ser entendido como uma tentativa de estabelecer aquiescência às regras do programa. Segundo Hayes et al., (1989) contingências sociais fortes e consistentes são dadas para o seguimento de ordens, possivelmente com a esperança de que surja um maior grau de insensibilidade a consequências indesejáveis e imediatas. Procedimentos similares são empregados em programas como o dos vigilantes do peso e nos grupos anônimos e estes frequentemente alcançam adesão às regras.

\subsubsection{Seguimento excessivo de regras}

Quando a formulação e/ou seguimento de regras é muito forte, o comportamento pode ser descrito como obsessivo, ansioso, dependente, insensível ou rígido. Nestes casos o ensino de formulação de regras ou o aumento da insensibilidade às contingências diretas podem piorar o problema. Hayes e Ju (1998) sugerem que a estratégia recomendada nestes casos seria diminuir ou evitar o controle por regras. A diminuição do controle exercido pelas regras, ou seja, do controle exercido pela aprovação social é uma das importantes funções da terapia, sendo desejável o aumento do controle das contingências naturais e "genuínas". A literatura aponta que comportamentos governados por regras nunca apreendem de forma completa as sutilezas do comportamento controlado diretamente pela experiência. Dirigir um carro após ler um livro a esse respeito não equivale a dirigir após haver dirigido por muitos meses. Interagir com membros do sexo oposto após receber algumas dicas de amigos 
não é o mesmo que a interação de um indivíduo socialmente experiente (apud Meyer 2009).

Algumas regras podem ser apoiadas de maneira generalizada pela comunidade verbal de tal forma que a experiência direta pode não sobrepujar os efeitos da regra. A pesquisa básica indica que há casos em que o uso anterior de regras pode interferir com o controle de experiências diretas de tal forma que os benefícios da experiência direta subsequente são atenuados. Nestes casos, pode ser importante considerar o alerta dado por Matos (2001): se um comportamento foi instalado e está sendo mantido por consequências sociais, mesmo existindo consequências naturais colaterais, não será suficiente, para o terapeuta, trabalhar com consequências naturais ao tentar eliminar um comportamento controlado por regras. Se for desejável modificar ou afetar um comportamento controlado por regras, pode ser preciso mudar a regra.

Dois cursos terapêuticos parecem disponíveis quando o controle por regras é indesejável. São eles: (1) evitar controle verbal ou (2) alterá-lo de forma a diminuir os efeitos de produção de insensibilidade. Segundo Meyer (2009), a terapia de aceitação e compromisso (ACT), proposta por Hayes, Strosahl, e Wilson (1999), e a psicoterapia analítica funcional (PAF), proposta por Kohlenberg e Tsai (1991/2001), exemplificam essas estratégias terapêuticas. De acordo com as bases teóricas da ACT (Hayes et al.,1999), quando determinadas regras tornam o comportamento do indivíduo insensível às contingências naturais, elas podem adquirir uma autonomia funcional e podem se tornar a causa presumida do comportamento problemático, de forma que a tentativa de eliminar esta causa por meio de outras regras pode piorar o problema. A ACT, então, atuaria para alterar o contexto em que as regras são formuladas, e não as regras em si (Hayes \& Ju, 1998). Já na PAF, o terapeuta prioriza a modelagem direta dos comportamentos clinicamente relevantes que ocorrem na sessão. As reações genuínas 
do terapeuta ao comportamento do cliente reforçam, provavelmente, de maneira natural, melhoras à medida que elas ocorrem na sessão terapêutica. Por exemplo, ao invés de instruir o cliente que procurou ajuda por problemas de intimidade em relacionamentos a realizar exercícios de comunicação com seu companheiro, o terapeuta pode reforçar melhoras nas respostas de retraimento que ocorrem na própria relação com o terapeuta (Kohlenberg \& Tsai, 1991/2001). Para Hayes et al. (1989), o único tipo de regra que é formalmente estimulado é o rastreamento, de modo que tanto o cliente quanto o terapeuta são encorajados a descrever verbalmente as contingências envolvidas em experiências vividas.

\subsubsection{Temas}

Um dos objetivos desta pesquisa foi verificar se tema é uma variável que está correlacionada com a emissão de regras/autorregras e também levantar se há regularidade entre os temas discutidos em diferentes sessões de psicoterapia.

A revisão da literatura indica que temas/conteúdos ou assuntos são abordados em pesquisas sobre interação terapêutica (por exemplo, Baptistussi, 2001; Barbosa, 2006; Eells, Kendjelic, \& Lucas, 1998; Garcia, 2001; Goldberg, Hobson, Maguire, Margison, Osborn \& Moss, 1984; Yano, 2003 e Zamignani \& Andery, 2005).

Apesar de diferentes objetivos, através da análise de categorias temáticas, pesquisadores conduziram estudos em que foi possível caracterizar o processo terapêutico, avaliar resultados do processo terapêutico assim como avaliar a atuação do terapeuta. Em todos os estudos, no entanto, as categorias temáticas eram criadas a partir da análise de interação específica, possibilitando pouca generalização de quais categorias temáticas poderiam ocorrer em interações terapêuticas em geral. Os estudos 
apontados a seguir são exemplos de como análises baseadas em categorias temáticas foram realizadas.

Baptistussi (2001) e Garcia (2001) conduziram estudos sobre a audiência não punitiva e bloqueio de esquiva, e seus possíveis efeitos sobre o responder do cliente. A condução desses estudos exigiu a classificação da interação em torno de assuntos ou temas. Assim, estes pesquisadores utilizaram o aumento ou diminuição na variedade de temas trazidos pelo cliente para a conversação como indicador de respostas de adesão ou esquiva. Tanto Baptistussi (2001) como Garcia (2001) utilizaram categorias por meio das quais se identificava qual dos membros da díade introduzia assuntos novos e em que momento isso ocorria ou, ainda, se o terapeuta ou o cliente mudavam de assunto ou derivavam a partir do assunto corrente. Esse tipo de categorização foi importante para verificar quanto o tipo de intervenção utilizada pelo terapeuta criava condições para que o cliente introduzisse assuntos que, supostamente, teriam sido punidos em sua história de vida. Zamignani (2007) aponta que além da utilidade desse tipo de categorização, como a demonstrada no estudo de Garcia (2001) e Baptistussi (2001), a identificação da condução da sessão pode ser importante para estudos que investigam o domínio da sessão por parte de um ou outro membro da díade, tal como conduzidos por Lichtenberg e Heider-Barke (1981) e Tracey (1985).

O estudo realizado por Wielenska (1989) tinha como principal objetivo identificar alguns dos controles cooperantes na relação entre um terapeuta comportamental e seus clientes. A análise dos dados permitiu identificar que o comportamento da terapeuta nas sessões de atendimento esteve sob o controle dos comportamentos dos clientes e de outras variáveis geradas em outros contextos. Um dos resultados encontrados refere-se aos temas discutidos em sessões. Observou-se um padrão de respostas da terapeuta às queixas nas unidades de análise (baseada em temas 
distintos). Quando os temas discutidos em sessão relacionavam-se a queixas, o padrão de interação do terapeuta era invariável, mas quando os temas discutidos em sessão relacionavam-se a outros temas (que não a queixa) o padrão de comportamento do terapeuta era mais variável.

Estudos que caracterizavam o processo terapêutico analítico-comportamental através da classificação em torno de temas também foram conduzidos. Destaca-se entre estes estudos o trabalho de Zamignani e Andery (2005) com clientes diagnosticados com Transtorno Obsessivo-Compulsivo. Neste estudo, a subdivisão das categorias interpessoais do terapeuta e do cliente, quanto a seu tema ser ou não relacionado à queixa do cliente permitiu a identificação de processo tais como o reforçamento diferencial de verbalizações e a intervenção por meio de análise de contingências e aconselhamento.

Em contexto muito diferente, pois trabalhou com clientes em situação pósoperatória, Starling (1999) enfatizou o conteúdo (assunto ou tema). Episódios verbais foram separados por seus subtemas ou conteúdos e esses conteúdos organizados em categorias e subcategorias. Essas categorias e subcategorias foram obtidas através de sucessivos exames do material registrado. Neste estudo, os conteúdos verbais foram considerados como subcategorias e as unidades temáticas que agregavam essas subcategorias foram denominadas categorias. Assim, clientes pós-cirúrgicos foram observados considerando os temas ou "conteúdos" das verbalizações, os quais foram classificados em categorias (episódio pós-cirúrgico, relações sociais, vida cotidiana, mais a categoria residual "outras") e subcategorias (exemplo de subcategorias da categoria "episódios clínico do pós-cirúrgico", alta hospitalar, estado físico, estado psicológico, medicação, dor, relações com médico). Os resultados indicaram que 59\% dos 763 conteúdos se referiam à categoria episódio clínico pós-cirúrgico, 33,7\% 
referiam-se a relações sociais; $4,5 \%$ à vida cotidiana e $2,9 \%$ à categoria residual. $O$ autor considera, no entanto, que frequência de temas sobre o episódio pós-cirúrgico pode ter funcionado como uma operação estabelecedora. Tais dados são apoiados pelos resultados que mostraram que a fala sobre episódio pós-cirúrgico foi maior antes e imediatamente após a cirurgia. Já falas sobre, por exemplo, vida cotidiana foram aumentando gradativamente após a intervenção cirúrgica. O autor aponta que mais pesquisas são necessárias, uma vez que, sabendo-se quais temas são mais comuns em relatos de clientes cirúrgicos e como esses temas oscilam ao longo da internação, podese planejar uma atuação psicológica que seja adequada à situação em si.

Avaliações de resultados também foram conduzidas baseadas em temas. Um exemplo disto é o estudo de Yano (2003), no qual a categorização em torno de eventos (alguns destes eventos referentes a temas) considerados relevantes pelo terapeutapesquisador permitiu a avaliação de resultados do processo terapêutico por parte da pesquisadora.

Característica comum a todos os trabalhos até então relatados é a formação de categorias referentes aos temas definidos a posteriori a partir dos dados previamente observados. Segundo Zamignani (2007), esta escolha provavelmente advém da grande variedade dos temas possíveis que podem ser abordados em uma intervenção terapêutica. Para este autor, embora seja passível uma categorização a priori dos temas da sessão, ela precisaria contemplar uma ampla gama de possibilidades de interação do cliente com critérios de inclusão e exclusão bastante específicos a fim de evitar sobreposições, o que dificultaria bastante sua execução. Além disso, o autor aponta que é possível que, para um determinado cliente, um único tema possa ser explorado com profundidade e relacionado a outros assuntos e aspectos de sua vida, o que exigiria do pesquisador, provavelmente, uma subdivisão em aspectos relacionados a esse tema. 
Zamignani (2007) desenvolveu um sistema de categorização do comportamento verbal e não-verbal na interação terapêutica. Tal sistema é composto por três eixos (o eixo I refere-se às categorias do comportamento verbal vocal e não-vocal do terapeuta e do cliente; o eixo II refere-se ao tema da sessão e o eixo III refere-se à categoria de registro de respostas motoras do terapeuta e do cliente). Especificamente quanto aos temas da sessão (eixo II) o autor aponta que cuidados devem ser tomados, como: realizar a categorização independente do falante e realizar adaptações de modo a responder às especificidades do caso clínico estudado. Assim, quando há algum tema central tratado pelo cliente da sessão, que não consta entre as possibilidades de categorias, o tema deverá ser apresentado ao rol e considerado na análise. Levando em consideração esses cuidados, as seguintes categorias foram formadas no estudo de Zamignani (2007): (1) Relação terapêutica; (2) Relação com cônjuge/parceiro, (3) Relações com filhos ou enteados; (4) Relações com pais ou madrasta/padrasto; (5) Relações com outros familiares; (6) Trabalho, estudo e/ou carreira; (7) Religião; (8) Relações interpessoais; (9) Sentimentos em geral, julgamentos ou tendências à ação; (10) Questões existenciais; (11) Eventos traumáticos; (12) Atividade de fantasia ou jogo; (13) Desenvolvimento de técnicas/procedimentos ou entrevistas padronizadas; (14) Queixas psiquiátricas e sintomas médicos; (15) Silêncio; (16) Outros temas. O autor aponta que além de se considerar as categorias temáticas, qualificadores destas também devem ser considerados. São eles: tempo no qual o assunto é tratado (aqui agora na sessão, tempo atual fora da sessão, tempo passado, tempo futuro, outros); condução do tema na sessão (com o objetivo de identificar qual dos membros da díade introduz temas novos e em que momento isso ocorre, ou ainda se terapeuta ou cliente mudam ou derivam a partir do assunto corrente). 
Apesar de o autor não ter desenvolvido pesquisa referente à validação deste eixo, aparentemente este é o trabalho mais completo sobre categorias temáticas. Zamignani (2007) aponta que a identificação do tema na interação favorece a delimitação de episódios nas quais ocorrem fenômenos relevantes, bem como a busca por episódios significativos quanto à queixa do cliente. Os temas incluídos no eixo II foram selecionados considerando eventos típicos da interação do indivíduo em seu cotidiano, assim como aspectos relevantes da própria interação terapeuta-cliente.

Botomé e Souza (1982) salientam que focalizar o conteúdo é uma alternativa que pode ser e que vem sendo cada vez mais utilizada por pesquisadores que estudam diferentes aspectos relacionados ao comportamento verbal. Recorrer aos temas como uma forma de se estudar o comportamento verbal parece ser uma estratégia interessante. Sabe-se, no entanto, que o predomínio de um tema ou outro depende de uma série de variáveis, tais como: a necessidade de discutir certo conteúdo apresentado pelo cliente em função de um evento externo; a análise de contingências que o terapeuta desenvolve e dos procedimentos terapêuticos derivados desta análise; a modelagem do repertório verbal do cliente - que relatos e que conteúdos o terapeuta reforça, pune, coloca em extinção; e a modelagem do repertório verbal do terapeuta - que relatos se mantêm ou se extinguem a partir da interação com o cliente, da evolução do processo terapêutico que problemática são resolvidas, quais são as que começam a surgir (Baptistussi, 2001). Levando-se em consideração todas essas variáveis, questiona-se se há regularidades ao se trabalhar com determinados temas, e se a busca de regularidades entre temas pode ser útil na verificação de quais temas são mais evocadores de regras e autorregras.

\subsection{Perguntas e autoconhecimento}

Realizar perguntas ao longo das intervenções clínicas é uma estratégia comumente utilizada (Skinner, 1953/1967; Stiles \& Sultan, 1979; Fontaine \& Ylieff, 
1981; Elliot et al., 1982; Hill et al.,1983; Skinner, 1984; Stiles et al., 1988; Hill et al., 1988; Wielenska, 1989; Schindler, Hohenberger-Sieber, \& Hahlweg, 1989; Verhulst \& van de Vijver, 1990; Skinner, 1989/1991; Kaimer et al. 1991; Skinner, 1974/1993; Keijsers,1994; Keijsers et al. 1995; Zamignani, 1996b; de Rose, 1997; de Rose 1999; Banaco, Zamignani \& Kovac 1999; Zamignani 2000; Silveira \& Kerbauy, 2000; Guilhardi \& Queiroz, 2001; Kohlenberg \& Tsai 2001; Delitti, 2001;Vanderberge, 2002; Guilhardi, 2004; Meyer, 2009).

A realização das perguntas pode servir a diferentes funções, como: coleta de dados; promoção da auto-observação; promoção de uma boa relação terapêutica ao demonstrar interesse através de perguntas; bloqueio de esquiva, promoção de autoconhecimento; identificação de variáveis estabelecedoras, mantenedoras do comportamento; explicitação das consequências do comportamento; e realização de análise funcional. Terapeutas, quando formulam perguntas e conduzem observações sobre as ocasiões em que a resposta ocorre, sobre a própria resposta e sobre as consequências mantenedoras, identificam se as relações são de dependência entre eventos, produzindo assim análises comportamentais hipotéticas. Vanderberge (2002) afirma ainda que o motivo para fazer e tentar responder a estas perguntas se encontra na busca de variáveis que controlam o comportamento segundo o raciocínio do paradigma operante.

$\mathrm{Na}$ revisão realizada na presente pesquisa, as perguntas apontadas pelos pesquisadores como sendo as mais comumente realizadas referiam-se aos antecedentes do comportamento, maciçamente ao comportamento em si e em poucas ocasiões às consequências da emissão do comportamento. Tais perguntas buscaram tanto a descrição de comportamentos públicos (ex: o que você falou?) quanto de comportamentos encobertos (ex: o que você pensou?). 
Quando o cliente é capaz de relatar e descrever seus comportamentos e sentimentos, diz-se que esse cliente se autoconhece, é consciente de seus comportamentos. Saber descrever as variáveis que mantêm o comportamento é uma etapa importante para obtenção de mudanças comportamentais.

O próprio Skinner (1989/1991, pp. 46-47), quando fala sobre autoconhecimento, aponta que "a psicoterapia é, freqüentemente, um esforço para melhorar a autoobservação, para 'trazer à consciência' uma parcela maior daquilo que é feito e das razões pelas quais as coisas são feitas". A comunidade verbal (no caso da psicoterapia o psicoterapeuta) pode estabelecer contingências que levam ao autoconhecimento. Segundo o autor "as pessoas são solicitadas a falar sobre o que estão fazendo ou por que estão fazendo e, ao responderem, podem tanto falar a si próprias como a outrem" (Skinner, 1989/1991, p.146). E continua: "Nós estamos conscientes do que estamos fazendo quando descrevemos a topografia do nosso comportamento. Estamos conscientes de por que o fazemos quando descrevemos variáveis relevantes, tais como aspectos relevantes da situação ou o reforço. A comunidade verbal (ou no caso o psicoterapeuta) gera o comportamento autodescritivo, perguntando 'O que você está fazendo?' ou 'Por que você faz isso? ' e reforçando nossas respostas apropriadamente" (Skinner, 1984, p. 356) e complementa que há vantagens em se tornar 'consciente' já “que 'uma pessoa que se tornou consciente de si mesma' por meio de perguntas que lhe foram feitas, está em melhor posição de prever e controlar seu próprio comportamento" (Skinner, 1974/1993, p.31). Por fim afirma que "somente quando somos indagados sobre o que fizemos, ou estamos fazendo, ou estamos prestes a fazer, ou por quê, é que temos motivo para observar ou recordar nosso comportamento ou suas variáveis controladoras" (Skinner, 1989/1991, p.88). 
Para de Rose (1997), muitas vezes o terapeuta pode não saber o que controla o comportamento do cliente, sendo então necessário que se realize perguntas ao cliente na tentativa de deixá-lo 'consciente'. O terapeuta deve entender que: a) o cliente pode não saber que fez alguma coisa. Isto pode ocorrer, pois o cliente talvez não tenha um repertório de auto-observação instalado. Outra possibilidade é que o cliente até tenha o repertório de auto-observação, mas o controle de estímulos pode ter agido de forma imprecisa sobre o comportamento descritivo; b) o cliente pode não saber que está fazendo alguma coisa. Quando o repertório de auto-observação não está instalado, o comportamento pode ocorrer de forma totalmente 'inconsciente'; c) o cliente pode não saber que tende a, ou vai fazer algo. Este repertório descritivo depende de que o cliente tenha observado, ao longo do tempo, sob que variáveis determinadas respostas teriam maior ou menor probabilidade de serem emitidas. Se o cliente não tinha um repertório de auto-observação no passado, é compreensível que não saiba dizer se fará algo ou não; e por fim, d) o cliente pode não conhecer as variáveis que controlam seu comportamento. Assim, da mesma forma que a auto-observação pode ser deficiente, as variáveis ambientais responsáveis pela emissão de determinadas respostas podem ter exercido um controle discriminativo fraco sobre o comportamento descritivo.

Este mesmo autor (de Rose, 1999) apresentou uma sistematização sobre quais informações podem ser adquiridas através de relatos verbais ao se conduzir uma pesquisa. Apesar de sua proposta ser genérica, como ela engloba comportamentos públicos e encobertos, pode ser adaptada para a pesquisa clínica. De Rose (1999) aponta que independente de orientação teórica, pesquisadores precisam recorrer a relatos verbais se quiserem ter acesso a algumas informações. Muitas vezes, a forma de se acessar informações como as apontadas a seguir é são os questionamentos. Para o autor, em muitas ocasiões é somente por meio de relatos verbais que é possível obter 
informações sobre: 1. Comportamentos manifestos, como: (a) comportamentos ocorridos no passado; (b) comportamentos pouco acessíveis a observação, como por exemplo: comportamento sexual; uso de drogas; (c) comportamentos cuja probabilidade é afetada pela presença de observador; (d) comportamentos cuja observação envolve alto custo material ou humano; 2. Outros eventos públicos, como: (a) situações ou condições de estímulo nas quais um comportamento foi emitido ou é tipicamente emitido; (b) consequências de um comportamento; 3. Eventos privados, como: (a) comportamentos encobertos, por exemplo: pensamentos ou verbalizações encobertos na solução de problemas; ou imagens; (b) comportamentos incipientes: tendências ou inclinações para agir; (c) sensações, sentimentos, estados emocionais; (d) atribuições de causas a comportamentos, estados emocionais etc.

Nesse mesmo ano, Kerbauy (1999) afirmou que através da interação terapêutica, o terapeuta dá condições (e uma das formas de dar condições é realizando perguntas aos clientes) para que o cliente verifique o que faz, quando faz e as consequências de seu comportamento, tanto em um passado distante como no momento atual, e a relação entre esses comportamentos, quando existe. Nesse sentido, o cliente vai discriminando as contingências existentes em sua vida e levantando hipóteses que, posteriormente, poderá ou não testar fora do consultório. Guilhardi (2004) apontou que não importa se o antecedente do comportamento se encontra em um passado distante. O terapeuta deve investigá-lo da mesma maneira. Assim, perguntas relativas ao passado devem ser realizadas, pois, segundo o autor, a função dos eventos é adquirida na história de contingências a que a pessoa foi exposta, e tais funções permanecem enquanto não forem mudadas diante de novas contingências. O passado tem relevância no presente, enquanto as funções dos eventos, adquiridas no passado, se mantiverem as mesmas no presente. Em outras palavras, o passado é simplesmente o momento em que as funções 
dos eventos comportamentais se instalaram. Só existe função atual dos estímulos, no presente. Assim, os comportamentos atuais não são determinados pelo passado, mas sim pelas funções presentes dos estímulos adquiridas no passado, mas - o que é relevante mantidas, até o presente momento, pelas contingências de reforçamento que estão atuando agora.

Para Guilhardi e Queiroz (2001) o ponto da partida para a atuação do terapeuta é a queixa inicial. Quando o cliente chega à clínica, questionamentos sobre o que o levou a procurar ajuda psicoterápica, e pedidos de esclarecimento sobre a queixa são realizados. Esses autores apontam que, em geral, a queixa descreve ações do próprio cliente ou de pessoas importantes no seu contexto de vida e pode até mesmo sugerir algumas relações entre o cliente e seu ambiente, como se fossem descrições das contingências em operação. Esses autores destacam, no entanto, que a queixa do cliente não define completamente sua real problemática. Raramente as descrições apresentadas pelos clientes sobre suas queixas de fato apresentam descrições das contingências em operação. Talvez a descrição das contingências em operação não seja feita, pois como destaca Zamignani (2000), em geral, a queixa apresentada pelo cliente na terapia é resultado de controle aversivo. Skinner, em Ciência e Comportamento Humano (1953/1967), enumera uma série de subprodutos de controle aversivo exercido pelo grupo social ou por agências religiosas, governamentais, familiares etc. Entre estes subprodutos do controle estariam respostas abertas de fuga, revolta, resistência, assim como efeitos emocionais, tais como, medo, ansiedade, ira, raiva, depressão e outros padrões emocionais que constituem parte do campo de trabalho do terapeuta (Skinner, 1953/1967).

Assim, para o terapeuta a queixa é um dado, dentre muitos outros que ele observará, e que no seu conjunto lhe permitirão formular hipóteses sobre quais 
contingências estão possivelmente atuando. A partir daí cabe a ele levar o cliente a discriminá-las e testar seu funcionamento. Uma das formas que pode levar o cliente à discriminação de quais contingências seu comportamento é função seria a realização de perguntas pertinentes por parte do terapeuta. Dessa forma, o conhecimento do terapeuta deve habilitá-lo a fazer previsão e controle do comportamento. Ao sugerir que tais contingências estão operando, é possível prever alguns comportamentos do cliente e do meio social que o cerca. Porém, só a previsão não basta. Há necessidade de manejar as contingências a fim de demonstrar que são elas que estão controlando o comportamento em estudo.

Ao formular hipóteses sobre as contingências em operação, o terapeuta está de fato sistematizando dados: ações do cliente, eventos ambientais e suas possíveis interrelações. Esta sistematização é um ponto de partida - uma hipótese de trabalho - que servirá como controle de estímulos para orientar seu comportamento e o do cliente; levá-los a, sistematicamente, observar as interrelações e a testá-las. Depois disso podese dizer, então, que o terapeuta e o cliente estão conscientes do comportamento e dos seus controles (conhecem as contingências que estão atuando). É o primeiro passo, essencial, para alterá-los.

A psicoterapia pode ser entendida então, ao menos em parte, como uma metodologia para refinar o autoconhecimento, especialmente no que diz respeito ao controle discriminativo exercido pelo mundo privado do indivíduo. Um dos requisitos para isto provavelmente é que o terapeuta desenvolva uma sensibilidade para as correlações entre eventos privados e comportamentos manifestos. Isto permite ao terapeuta inferir aspectos do mundo privado do cliente a partir de manifestações sutis; com base nestas inferências, ele pode auxiliar o cliente no treino das discriminações que ajudam a desenvolver o autoconhecimento (isto é, evidentemente, complementado 
por métodos padronizados de avaliação e diagnóstico, que o terapeuta também aprende a usar e interpretar).

Em geral, um dos fatores pelos quais os operantes verbais são emitidos de modo privado é porque eles evitam punição (Skinner, 1953/1967). Além de evitar punição, podem também funcionar como ocasião para novos comportamentos (Anderson et al., 1997; Anderson et al., 2000)

Banaco, Zamignani e Kovac (1999) indicam que terapeutas comportamentais têm utilizado o questionamento a seus clientes também para ter acesso a esses possíveis eventos encobertos, utilizando-se de perguntas básicas como: "o que você sente quando...?” ou “o que você pensa quando...?”. Tal procedimento é eficaz na publicitação de eventos que permaneciam encobertos, no caso, o relato do participante é sobre um evento passado, seja ele mais ou menos remoto. No entanto, segundo Banaco (1999), as respostas têm sido equivocadamente utilizadas mais como um fim do que como um meio para a obtenção de informações sobre as contingências em ação.

Segundo Delitti (2001) ao questionar sobre um evento encoberto, por exemplo: “o que você está sentindo agora?” o terapeuta está tentando analisar as contingências do momento da sessão.

Parte do trabalho realizado pelo terapeuta analista do comportamento é baseada em relatos trazidos pelo cliente sobre as relações por ele vividas. O terapeuta procura analisar os eventos relatados e, em alguns casos, sugerir formas de alterar as relações estabelecidas. Outra parte importante deste trabalho é desenvolvida a partir da própria relação terapêutica. O terapeuta, como parte do ambiente do cliente, tem condições de observar o seu comportamento e contingenciá-lo de forma a desenvolver um repertório que proporcione ao cliente desenvolver em seu dia-a-dia interações menos aversivas que aquelas preexistentes. 
Silveira e Kerbauy (2000) apresentaram uma tentativa de sistematização do padrão de interação verbal de terapeutas e clientes. Estas autoras relataram que é comum em sessões de psicoterapia que o terapeuta faça perguntas sobre o problema do qual o cliente se queixa, e o cliente a responde descrevendo detalhes da queixa. Após a descrição da queixa, o terapeuta provê atenção seletiva, direcionando suas perguntas a aspectos incompatíveis com o problema. O cliente então normalmente pode seguir dois caminhos. Ou ele reapresenta a queixa, ou apresenta a queixa com outro tema. O terapeuta comumente faz perguntas e/ou provocações, sugerindo condições sobre as quais o cliente não tem controle direto e o cliente responde a estes questionamentos descrevendo história de vida e história de aprendizagem do comportamento-problema, apresentando assim verbalizações que não pertencem à "queixa inicial”.

É evidente que terapeutas questionam seus clientes visando a acessar, via descrição, comportamentos que podem estar 'inconscientes', e que via descrição podem auxiliar terapeutas e clientes a modificar padrões de interação e ao mesmo tempo contingências mantenedoras. No entanto, a presença de perguntas deve ser utilizada com cautela. Autores como Hill et al., (1983); Keijsers et al., (1995); Schindler, Hohenberger-Sieber, e Hahlweg, (1989); Stiles et al., (1988); Stiles \& Sultan, (1979) apontaram que clientes podem apresentar respostas curtas para as perguntas dos terapeutas, mostrando claramente que muitas perguntas podem se tornar aversivas a determinados clientes. Em uma pesquisa realizada por Kaimer et al. (1991) os comportamentos de terapeutas e clientes em casos de sucesso e insucesso na terapia cognitivo-comportamental foram comparados. Tais pesquisadores encontraram que clientes que usavam significativamente mais descrição dos problemas e significativamente poucas respostas curtas durante as sessões apresentaram melhoras significativas quando comparados a clientes que descreviam pouco as situações e 
apresentavam alta incidência de respostas curtas. Tais dados foram corroborados por Keijsers et al. (1995). Este pesquisador verificou que a alta ocorrência de respostas curtas tais como "sim", "não" ou "faz 10 anos agora" foi repetidamente associada com resultados de tratamento menos favoráveis. Além disto, a ocorrência de descrição de problemas do cliente e observação de autoexposição, dividida pela ocorrência de respostas curtas, mostrou-se um forte preditor de resultados em todas as formas de comportamento interpessoal (Keijsers, 1994).

Dados semelhantes foram encontrados por Verhulst e van de Vijver (1990). Os autores demonstraram que o estilo dos terapeutas (comportamentos de procurar informações tais como questionar o cliente sobre a natureza e origem de seus problemas) era mais provavelmente eliciador da resistência dos clientes em terapia comportamental e terapia psicodinâmica. Intuitivamente, faz sentido que clientes que não se sentem bem em falar muito sobre seus problemas limitem-se a respostas curtas, ou, alternativamente, que terapeutas tendam a usar questões fechadas com os clientes que hesitam mais em abrir-se. Elliot et al. (1982) e Hill et al. (1988) observaram que questões fechadas foram avaliadas como sendo menos úteis entre todos os comportamentos verbais dos terapeutas. Parece que a prontidão dos clientes em discutir seus problemas durante o tratamento tem uma influência sobre os resultados terapêuticos. Concluindo, apesar de falar sobre seus sentimentos e problemas ser considerado importante por muitos clientes que recebem tratamento psicoterápico, o terapeuta deve atentar para a reação do cliente (aberto ou fechado a questionamentos) frente a perguntas feitas por ele.

A realização de perguntas por parte dos terapeutas pode ser uma estratégia necessária para que possa ser realizada a análise funcional. É através dela que se 
procura entender as interações entre os comportamentos estudados e as variáveis que os determinam (Fontaine \& Ylieff, 1981).

Terapeutas fazem perguntas como estratégias de intervenção. Eles também parecem concordar que essa é uma estratégia de intervenção importante, pois é por meio dela que o terapeuta pode identificar as variáveis estabelecedoras e mantenedoras do comportamento, além de promover o autoconhecimento e realizar análise funcional. Comportamentos públicos e encobertos podem ser descritos e auxiliar na análise de contingências. Tentativas de sistematizar quais perguntas devem ser realizadas em sessões de psicoterapia foram feitas por pesquisadores (de Rose, 1997/1999; Silveira e Kerbauy, 2000), porém ainda não foram encontradas pesquisas que mostram quais as perguntas comumente feitas em sessões de psicoterapia (enfocando os três elos: antecedente-comportamento-consequente) e nem sobre a regularidade destas perguntas.

O tópico a seguir apresentará os alcances e limites de análises baseadas no governo por regras.

\subsection{Alcances e limites de análises baseadas no governo por regras}

Como exposto em tópicos anteriores, há vantagens no controle por regras. Homens podem, utilizando descrições verbais, induzir uns aos outros - ou a si mesmos - a se comportarem de modo efetivo sem que haja necessidade de exposição, geralmente longas, às consequências descritas (Skinner, 1974/1982). Esta característica do comportamento governado por regras parece especialmente necessária quando as consequências produzidas pelo comportamento são muito atrasadas ou escassas, tornando-se, portanto, ineficazes na modificação de comportamentos, ou ainda quando os comportamentos que seriam modelados pelas contingências em vigor são indesejáveis. Por outro lado, há desvantagens em seguir regras, especialmente quando as contingências mudam e as regras não. Pode ocorrer a insensibilidade às contingências, 
ou seja, a não alteração do desempenho e a continuidade de emissão da resposta anteriormente necessária à sua produção.

Meyer (2009) aponta que a terapia comportamental tem tido amplo reconhecimento e aceitação, especialmente em casos difíceis de transtornos psiquiátricos. Uma das vantagens apontadas é a rapidez com que os resultados são obtidos. E a rapidez da aprendizagem é uma das vantagens dos comportamentos governados por regras. Segundo a autora, é possível inferir que o sucesso dos procedimentos usados nestes casos se deva, em parte, a esta vantagem do controle por regras.

Terapeutas podem também trabalhar de forma a favorecer o autoconhecimento de seus clientes, ou seja, promover a identificação e a descrição das prováveis contingências que controlam os comportamentos atuais e as que foram responsáveis por sua instalação no passado. Meyer (2009) aponta que, conforme visto, descrições de contingências são regras se elas controlarem o comportamento subsequente. Assim, um comportamento modelado por contingências pode passar a ser em parte controlado pela sua descrição, uma vez que a regra produzida pode facilitar o desempenho (Skinner, 1974/1982). Deve-se, no entanto, atentar para o fato de que descrever contingências não significa necessariamente que as regras passaram a participar do controle do comportamento descrito. Comportamentos não precisam de descrição para mudar. Segundo Simonassi (1999), é possível, por exemplo, solucionar problemas sem prévia descrição das contingências em vigor.

A questão da influência do comportamento verbal sobre o não-verbal foi analisada por Kohlenberg e Tsai (1991/2001), ao falarem dos papéis que os pensamentos podem ter. Para estes autores esta influência deve ser considerada levando em conta a relação entre respostas e não uma relação de causalidade, uma vez que na 
abordagem analítico-comportamental a explicação do comportamento é encontrada no ambiente. Após esta explicação, tais autores definem pensamento como tato (descrições) e mando (solicitações) a si mesmo. Kohlenberg e Tsai (1991/2001) indicam que os pensamentos podem assumir três papéis: (a) o pensamento influencia comportamentos subsequentes; (b) o pensamento não influencia comportamentos subsequentes; (c) o pensamento contribui para aumentar a força de um comportamento subsequente modelado por contingências. $\mathrm{O}$ grau de controle exercido pelo pensamento sobre problemas clínicos estaria num continuum. Abreu-Rodrigues e Sanabio (2001) também descreveram sete possíveis relações entre eventos privados e públicos, algumas delas descritas na discussão sobre correspondência entre autorrelato e desempenho nãoverbal, no tópico "Contribuições da pesquisa básica".

Diferentes tipos de controle implicam diferentes análises e tratamentos. Segundo Kohlenberg e Tsai (1991/2001), quando o pensamento ou evento privado tem influência no problema do cliente, o procedimento indicado pode ser o de mudança dos pensamentos, ou seja, o procedimento é aplicado a um elo da cadeia comportamental e mudanças são observadas no nível do problema comportamental apresentado. O terapeuta pode apresentar argumentos lógicos, questionamento das evidências e apresentação de instruções para mudança de crenças. No caso de o pensamento ou evento privado não influenciar comportamento subsequente, o tratamento deve ser direcionado para mudar diretamente as ações do indivíduo que estão lhe causando problemas. Nesta situação, o terapeuta cria condições de expor o comportamento do cliente a reforçamento positivo na sessão de terapia e no ambiente natural, que poderia modelar e manter novos comportamentos.

O conceito de governo por regras dever ser usado com cautela ao explicar fenômenos que ocorrem na clínica. Segundo Costa (2002) não se deve confundir 
crenças, conceito usado pelos terapeutas comportamentais cognitivos, com regras, apesar de existirem algumas semelhanças. Afirmar que um cliente possui uma crença, muitas vezes irracional, e que ela é responsável por comportamentos que causam problemas, é usualmente uma afirmação sobre a probabilidade de comportamento (e não sobre o controle do comportamento por um estímulo discriminativo verbal que descreve uma contingência) e está baseada na observação de instâncias ou relatos passados do comportamento.

Segundo Baum (1994/1999), muitos analistas clínicos do comportamento utilizam o termo "regra" de forma inadequada, indicando probabilidade de comportamento. Este erro advém do fato de que alguns terapeutas declaram que uma pessoa está seguindo uma regra ao perceber algum tipo de regularidade no comportamento. Por exemplo, um terapeuta pode ter identificado que seu cliente apresenta um comportamento inadequado na aproximação de mulheres, tendo também identificado uma história de punição para essa classe de ações. Não seria correto concluir que esta história o levou ao desenvolvimento da regra "se eu for falar com alguma moça, vai dar tudo errado", que teria, então, passado a controlar seu comportamento de esquiva social. Segundo Meyer (2009) não há necessidade de supor que uma regra esteja controlando o comportamento: identificar contingências que atuaram na história de vida provavelmente é suficiente para entender a função deste comportamento.

Está implícito nas considerações anteriores o cuidado que se deve ter ao afirmar que um comportamento é insensível a contingências. A insensibilidade pode ocorrer com relação a algumas consequências diretas da ação instruída, mas não se pode dizer que o comportamento de seguir regras não é mantido por contingências (sociais). 
A introdução do presente trabalho apresentou, até aqui, a contextualização desta pesquisa. Para tanto, foi citada a definição de Skinner (1974/1982) sobre orientação, assim como a revisão da literatura sobre regras, contribuições da pesquisa básica, regras e psicoterapia, e uso de orientação, influência de variáveis intervenientes e alcances e limites de análises baseadas no governo por regras. No entanto, pouco foi mencionado sobre como a análise de dados será realizada nesta pesquisa. As seções seguintes esboçam como a literatura será utilizada no auxílio das análises realizadas nesta tese.

\subsection{Análise de verbalizações e análise de episódios}

Segundo Zamignani (2007), grande parte dos estudos clínicos até então desenvolvidos sobre a interação terapêutica tem caracterizado o comportamento verbal vocal dos participantes a partir da análise de textos das transcrições de sessões gravadas em áudio ou vídeo. Ações apontadas pela literatura clínica como típicas de uma interação verbal terapêutica (chamadas, em alguns estudos, de variáveis interpessoais), são consideradas e formam categorias de análise (ex. Almásy, 2004; Barbosa, 2001; Chamberlain et al., 1984; Donadone, 2004; Garcia, 2001; Hill, 1978; Hill et al. 1992; Kovac, 2001; Maciel, 2004; Margotto, 1998; Martins, 1999; Meyer \& Donadone, 2002; Moreira, 2001; Oliveira, 2002; Silva, 2001; Vermes, 2000; Yano, 2003; Zamignani \& Andery, 2005).

No estudo de Donadone (2004), análises de verbalizações de terapeutas e clientes foram realizadas pela categorização do comportamento de orientar do terapeuta e de auto-orientar do cliente. As categorias de orientação e auto-orientação foram desenvolvidas com base no conceito de orientação de B. F. Skinner (1974/1982) e na revisão da literatura sobre regras. A análise de dados baseou-se então em identificar, nas transcrições de sessões dos terapeutas experientes e pouco experientes, a emissão de 
orientação e auto-orientação. No entanto, esta categoria descritiva mostrou-se pouco produtiva, uma vez que ofereceu pouca informação sobre o que determinava a ocorrência da resposta.

Hill (2001), Russel e Trull (1986) e Stiles (1999) apontaram que a medida apropriada para o estudo de processo deveria não só registrar a ocorrência da resposta, mas informações das microssituações nas quais ocorrem processos interpessoais relevantes. A simples medida de frequência de uma determinada habilidade do terapeuta não permite avaliar a sua qualidade ou efetividade, bem como o momento ou o contexto no qual ela seria mais apropriada (Hill, 2001; Stiles, 1999). Algumas pesquisas realizadas na área de categorização do conteúdo do processo terapêutico sugerem que a compreensão do contexto - ou seja, informações sobre o caso ao qual correspondem às sessões a serem categorizadas - parece ser uma das variáveis de controle importantes para o sucesso de tais estudos (Batista, 2006; Canaan, 2002; Chequer, 2002; OliveiraSilva \& Tourinho, 2006). Concluiu-se então que para entender os determinantes da interação terapeuta-cliente essa deveria ser analisada a cada momento da ocorrência de um evento sob análise (no caso orientações do terapeuta e auto-orientações do cliente), por meio da análise das contingências envolvidas em cada unidade de interação.

Diante desta constatação, nesta pesquisa, além das categorias de orientação e auto-orientação utilizadas no estudo de Donadone (2004), considerou-se necessária a inclusão do contexto em que a emissão de regras e autorregras ocorria. Brandão (2003) analisou episódios emocionais em sessões de psicoterapia. Esta autora considerava que um episódio emocional era delimitado pela soma de alguns fatores como a ocorrência de expressão emocional e o contexto em que a expressão emocional ocorria. Assim um episódio emocional se iniciava quando terapeuta ou cliente introduziam um 
determinado assunto e expressões emocionais ocorriam e tal episódio emocional era finalizado quando um novo tema ou assunto era introduzido.

Transpondo para a presente pesquisa as informações apresentadas acima, considerou-se como episódio de orientação um trecho da sessão em que o cliente ou terapeuta começam a abordar um tema até a última fala do cliente ou do terapeuta sobre tal tema e a ocorrência de no mínimo uma orientação ou auto-orientação. Assim, uma sessão poderia conter nenhum ou vários episódios de orientação ou auto-orientação.

\subsection{Análise funcional da orientação e auto-orientação}

A análise descritiva do comportamento de orientar e auto-orientar baseada em critérios morfológicos foi realizada no estudo de Donadone (2004). Foi contado o número de palavras em falas com orientação e auto-orientação nas sessões dos terapeutas experientes e pouco experientes. Segundo Skinner (1957) "a contagem de palavras é, muitas vezes, uma tentativa de desenvolver uma análise puramente formal da variável dependente isolada". Apesar de ser útil saber que uma resposta de certa forma é frequententemente emitida, "é também importante saber as condições predominantes" (Skinner, 1957).

Para Skinner (1974/1982) as variáveis externas das quais os comportamentos são função, dão origem ao que pode ser chamado de análise funcional.

“Tentamos prever e controlar o comportamento de um organismo individual. Esta é nossa 'variável dependente' - o efeito para o qual procuramos a causa. Nossas 'variáveis independentes' - as causas do comportamento - são as condições externas das quais o comportamento é função. Relações entre as duas - as relações de 
'causas e efeito' no comportamento - são as leis de uma ciência”.

(Skinner, 1974/1982, p. 38)

Como na presente pesquisa a ênfase dada será na identificação das contingências e não na manipulação e experimentação das variáveis, o termo utilizado na presente análise será análise de contingências ao invés de análise funcional. Esta diferenciação (entre análise funcional e análise de contingências) foi proposta inicialmente por Bori (1974) e difundida por Matos (1997). Para Matos (1997) “o behaviorismo radical não trabalha propriamente com o comportamento, ele estuda e trabalha com contingências comportamentais, isto é, com o comportar-se dentro de contextos" (p. 46). Seria desta afirmação de Matos (1997) que teria surgido a proposição de que o analista do comportamento faria uma "análise das contingências" ou uma "análise de contingências" e não uma "análise do comportamento" ou uma "análise experimental ou funcional do comportamento".

Levando em consideração as afirmações de Skinner (1957), no presente estudo, além da resposta de orientação e auto-orientação, o contexto de emissão das respostas passou a ser considerado. A inclusão do contexto possibilita que se observe a ocasião em que a resposta ocorre (antecedente), a própria resposta (orientação) e o consequente. Tal inclusão do contexto na análise baseia-se nas afirmações de Skinner de que comportamentos não acontecem no vácuo e que seu entendimento se dá pela identificação dos antecedentes e consequentes das respostas sob análise.

Algumas considerações sobre antecedentes, comportamento, consequentes e subsequentes mostram-se necessárias. Como dito anteriormente, entende-se antecedente como tudo aquilo que é anterior ao comportamento (inclusive temporalmente) e que sinaliza uma oportunidade para a resposta ser emitida assumindo a função de estabelecer ocasião em que uma resposta se torna mais provável. Por exemplo: nesta 
pesquisa busca-se identificar o que antecede a emissão de orientação na interação terapêutica ou, dizendo de outra forma, busca-se identificar se há algum estímulo discriminativo ou operação estabelecedora que exerça algum efeito sobre o comportamento de orientar, aumentado a probabilidade de sua ocorrência. Um comportamento frequentemente é controlado por um estímulo e seguido por uma consequência que, dependendo da história de reforçamento de cada indivíduo, tende a fortalecer ou enfraquecer o comportamento. A análise funcional baseia-se no estudo da relação entre as variáveis dependentes e independentes e enfatiza a importância da relação de contingência que deve existir entre uma variável e outra, estabelecendo uma dependência entre eventos que antecedem o comportamento, o próprio comportamento e suas consequências (Skinner, 1974/1982). A probabilidade de o comportamento voltar a ocorrer ou não é dada pela consequência deste comportamento. Na presente pesquisa, os comportamentos subsequentes à orientação foram considerados, já que normalmente a consequência mantenedora do comportamento é o estímulo que vem logo após a resposta, porém no caso desta pesquisa não temos como verificar se realmente o estímulo subsequente é a conseqüência mantenedora da orientação e auto-orientação.

Através destes elos da cadeia comportamental, podemos proceder à análise de contingências de comportamento de orientar e auto-orientar.

O arcabouço teórico até então explicitado será considerado. Assim, a partir do entendimento de que orientação e auto-orientação são regras tanto em sua topografia quanto em sua função e de que, segundo a literatura básica, alguns aspectos devem ser considerados quanto à emissão de regras, como conteúdo, variabilidade comportamental, densidade de reforços, história de reforços e grau de discriminabilidade das contingências, pretende-se encontrar regularidades nos 
antecedentes para que ocorra a emissão da orientação, regularidades nas próprias orientações e auto-orientações, assim como regularidades no consequente da emissão de orientações e auto-orientações. Para isso as sessões utilizadas no estudo de Donadone (2004) serão lidas novamente, e os episódios de orientação e auto-orientação serão selecionados. A partir daí será verificado se terapeutas e clientes comportam-se de forma característica antes e após a emissão de regras. Variáveis intervenientes como motivação, resistência e idade serão consideradas.

\subsection{Objetivos}

\section{Objetivo Geral:}

Verificar variáveis que determinam o comportamento do terapeuta de orientar e do cliente de se auto-orientar.

\section{Objetivos Específicos:}

Responder às seguintes perguntas:

a) As variáveis responsáveis pela orientação e auto-orientação são diferentes quando se comparam terapeutas experientes e pouco experientes?

b) Existe relação entre a presença de orientação/auto-orientação e o tema da sessão?

c) Existe relação entre a sequência de perguntas feitas pelo terapeuta e respectivas respostas dos clientes com a subsequente orientação/autoorientação?

d) Quais são as classes de respostas da díade terapeuta-cliente que antecedem o comportamento de orientar e de se auto-orientar? 
e) Quais são as classes de respostas da díade terapeuta-cliente que sucedem o comportamento de orientar e de se auto-orientar?

f) Existe correlação entre a presença de orientação/auto-orientação e a avaliação feita pelo terapeuta quanto à motivação e cooperação?

g) Existe correlação entre a presença de orientação/auto-orientação e a escolaridade, idade e situação financeira dos clientes?

\section{Método}

Nesta pesquisa foram utilizados os dados coletados no estudo de Donadone (2004).

\subsection{Descrição dos participantes da pesquisa de Donadone (2004):}

\subsubsection{Terapeutas}

Participaram da pesquisa nove terapeutas, sendo seis pouco experientes (T.P.E.) e três experientes (T.E.).

A diferenciação feita entre terapeutas experientes e pouco experientes baseou-se nos anos de formados e não no número de casos atendidos ao longo da carreira. Terapeutas com menos de três anos de formados foram considerados nesta pesquisa como terapeutas pouco experientes. Já terapeutas com mais de dez anos de formados foram considerados terapeutas experientes.

Nesta amostra, os terapeutas pouco experientes tinham o mínimo de dois anos e nove meses de atuação clínica e o máximo de três anos de experiência em atendimento clínico e foram divididos em três blocos com base na faculdade de graduação e no supervisor em comum durante a graduação. Dois deles eram diplomados em uma universidade pública $(\mathrm{PR})$ e haviam sido supervisionados pelo mesmo supervisor clínico; outros dois em uma universidade particular (PR) também tendo tido um 
supervisor em comum, e os dois restantes formados em uma universidade pública (SP), tendo sido supervisionados pelo mesmo supervisor clínico. Quanto aos terapeutas experientes o mínimo de tempo de experiência foi de 15 anos e o máximo de experiência em atendimento clínico foi de 28 anos. Todos os terapeutas experientes realizaram sua graduação em instituições particulares.

Dois dos três terapeutas experientes concluíram o doutorado, realizando além do atendimento clínico atividades acadêmicas, e um terapeuta cursou especializações e manteve-se exclusivamente realizando atendimentos clínicos. Quanto aos terapeutas pouco experientes, três estavam, no momento da coleta dos dados da pesquisa, realizando mestrado, dois haviam feito especialização e um se dedicava a atendimentos clínicos.

Tabela 1 - Descrição dos terapeutas considerando-se as seguintes variáveis: anos de experiência, graduação, pós-graduação, $\mathrm{n}^{\circ}$ total de casos atendidos $\left(\mathrm{n}^{\circ}\right.$ de casos de crianças, adolescentes e adultos atendidos)

\begin{tabular}{|c|c|c|c|c|c|c|c|c|}
\hline & 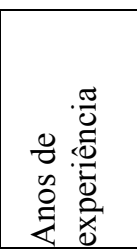 & 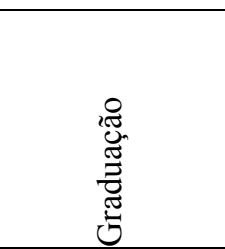 & 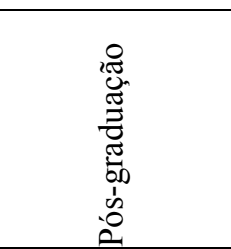 & 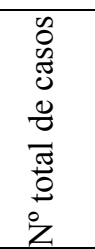 & 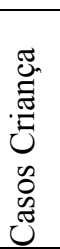 & 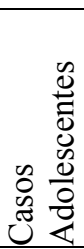 & 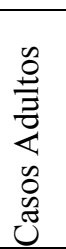 & \\
\hline T.P.E.1A & $\begin{array}{l}2 \text { anos e } \\
9 \text { meses }\end{array}$ & $\begin{array}{l}\text { Universidade } \\
\text { Pública - PR }\end{array}$ & $\begin{array}{l}\text { Mestrado } \\
\text { (em } \\
\text { andamento) }\end{array}$ & 18 & 2 & 6 & 10 & \multirow{2}{*}{$\begin{array}{l}\mathbb{w} \\
\grave{O} \\
0 \\
D\end{array}$} \\
\hline T.P.E.2A & $\begin{array}{l}2 \text { anos e } \\
9 \text { meses }\end{array}$ & $\begin{array}{l}\text { Universidade } \\
\text { Pública - PR }\end{array}$ & Especialização & 30 & 20 & 0 & 10 & \\
\hline T.P.E.1B & $\begin{array}{l}2 \text { anos e } \\
9 \text { meses }\end{array}$ & $\begin{array}{l}\text { Universidade } \\
\text { Particular - PR }\end{array}$ & $\begin{array}{l}\text { Mestrado } \\
\text { (em } \\
\text { andamento) }\end{array}$ & $\begin{array}{c}150 \\
(10)^{*}\end{array}$ & 1 & 1 & 8 & \multirow{2}{*}{$\begin{array}{l}\frac{\sigma}{0} \\
\stackrel{0}{\sigma} \\
\tilde{\sigma}\end{array}$} \\
\hline T.P.E.2B & $\begin{array}{l}2 \text { anos e } \\
9 \text { meses }\end{array}$ & $\begin{array}{l}\text { Universidade } \\
\text { Particular - PR }\end{array}$ & $\begin{array}{l}\text { Mestrado } \\
\text { (em } \\
\text { andamento) }\end{array}$ & 45 & 0 & 10 & 35 & \\
\hline T.P.E.1C & 3 anos & $\begin{array}{l}\text { Universidade } \\
\text { Pública - SP }\end{array}$ & $\begin{array}{l}\text { Várias } \\
\text { especializações }\end{array}$ & 100 & 20 & 30 & 50 & \multirow{2}{*}{$\begin{array}{l}\frac{w}{0} \\
0 \\
0\end{array}$} \\
\hline T.P.E.2C & 3 anos & $\begin{array}{l}\text { Universidade } \\
\text { Pública - SP }\end{array}$ & --- & 25 & 0 & 10 & 15 & \\
\hline T.E.D & 23 anos & $\begin{array}{l}\text { Universidade } \\
\text { Particular - SP }\end{array}$ & Doutorado & 100 & 26 & 9 & 39 & T.E.D. \\
\hline
\end{tabular}




\begin{tabular}{|l|c|l|l|c|c|c|c|c|}
\hline T.E.E & 15 anos & $\begin{array}{l}\text { Universidade } \\
\text { Particular - SP }\end{array}$ & $\begin{array}{l}\text { Várias } \\
\text { especializações }\end{array}$ & 350 & 100 & 60 & 190 & T.E.E. \\
\hline T.E.F & 28 anos & $\begin{array}{l}\text { Universidade } \\
\text { Particular - SP }\end{array}$ & Doutorado & $\begin{array}{c}1400 \\
(380)^{* *}\end{array}$ & 80 & 90 & 210 & T.E.F. \\
\hline
\end{tabular}

* 150 atendimentos, sendo 140 ambulatoriais e 10 de psicoterapia em moldes convencionais

**1.400 atendimentos, sendo a grande maioria em grupos de curta duração (em média 12 atendimentos) e 380 atendimentos de psicoterapia em moldes convencionais

O número de casos atendido pelos terapeutas experientes variou de 100 a 380, sendo que em todos os casos predominava o atendimento clínico a adultos. O terapeuta experiente $\mathrm{F}$ atendeu aproximadamente 1.400 casos, porém a grande maioria destes atendimentos ocorria em grupo em instituições psiquiátricas e no formato de terapia breve (média de 12 sessões). Já o número de casos atendidos por terapeutas pouco experientes variou de 18 a 100 sendo que o terapeuta pouco experiente $2 \mathrm{~B}$ atendeu aproximadamente 140 casos em atendimentos ambulatoriais (atendimentos sem continuidade, tipo de aconselhamento, ou seja, apenas algumas sessões enquanto as pessoas recebiam tratamento médico).

\subsubsection{Clientes}

Participaram da pesquisa 27 clientes, 22 do sexo feminino e cinco do sexo masculino. A idade dos clientes variou de 18 a 54 anos, e o estado civil predominante foi solteiro (19 clientes), seguido de casados (seis clientes) e divorciados (dois).

Quanto à escolaridade, um cliente tinha feito ensino fundamental, 11 ensino médio completo e quatro ensino médio incompleto. Cinco estavam cursando o ensino superior e seis haviam concluído o curso superior.

Quanto à ocupação, seis clientes estavam desempregados, nove empregados, sete estudavam, dois realizavam estágio, um deles remunerado, dois clientes exerciam atividades domésticas e um não possuía ocupação. A renda familiar de dois terços dos 
clientes estava acima de 1.000 reais por mês (18 clientes), nove clientes tinham uma renda familiar abaixo de 1.000 reais.

O tempo de terapia (na época da coleta de dados) variava de quatro a 48 meses (quatro anos), e diferentes queixas foram apresentadas (Tabela 2 a seguir).

Segundo a avaliação dos terapeutas, dos 27 clientes, nove foram considerados cooperativos, dois motivados, sete cooperativos e motivados, dois motivados e resistentes, dois desmotivados, quatro resistentes e um cliente foi considerado resistente e desmotivado. A avaliação dos terapeutas não era excludente, sendo assim alguns clientes foram considerados, por exemplo, motivados e resistentes.

Uma maior especificação a respeito de cada cliente é apresentada na tabela a seguir. 
Tabela 2 - Descrição dos clientes participantes dessa pesquisa. Cada bloco (A, B, C) era formado por dois terapeutas pouco experientes formados na mesma universidade. Cada terapeuta coletou dados de três clientes diferentes.

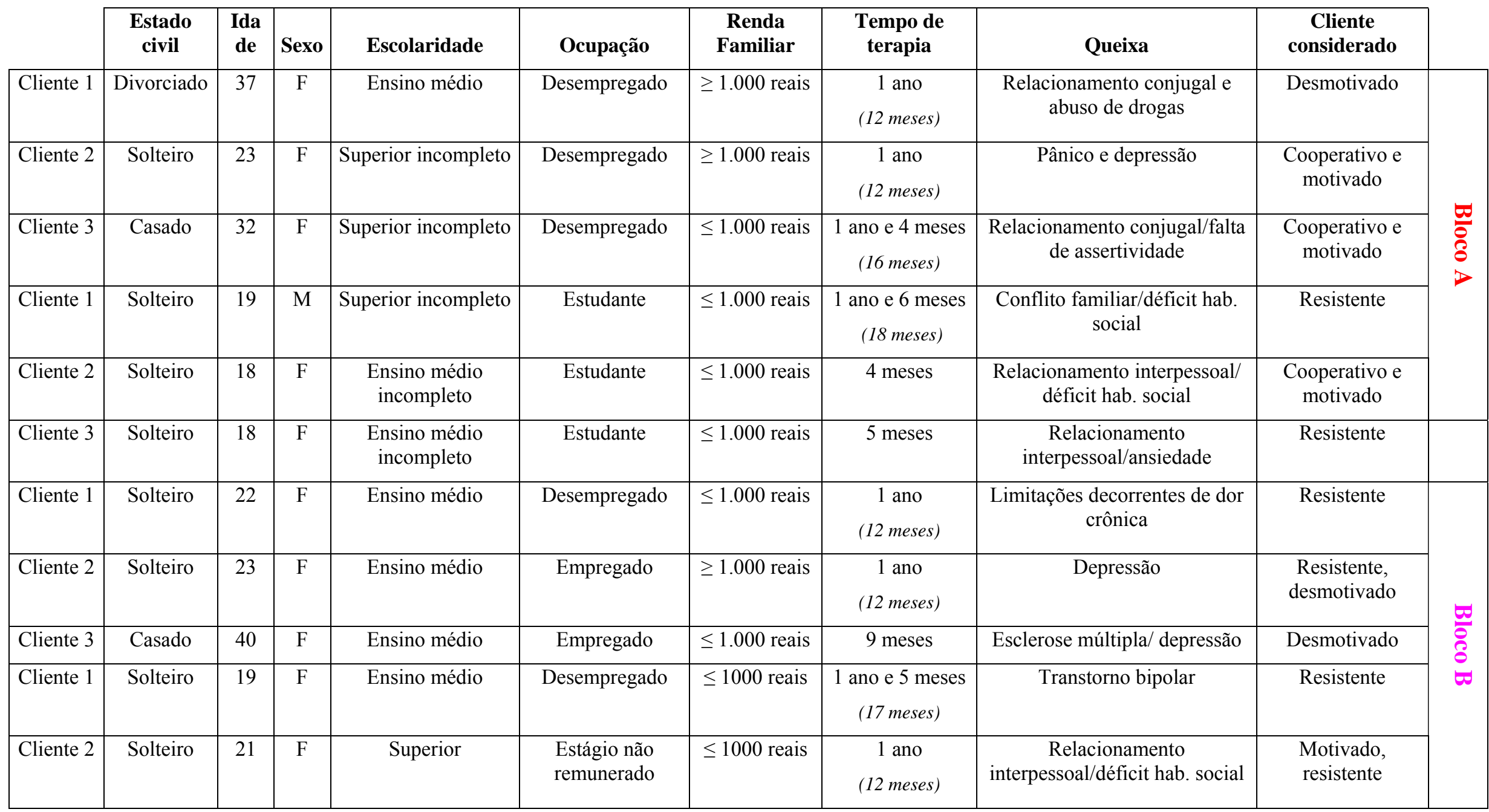




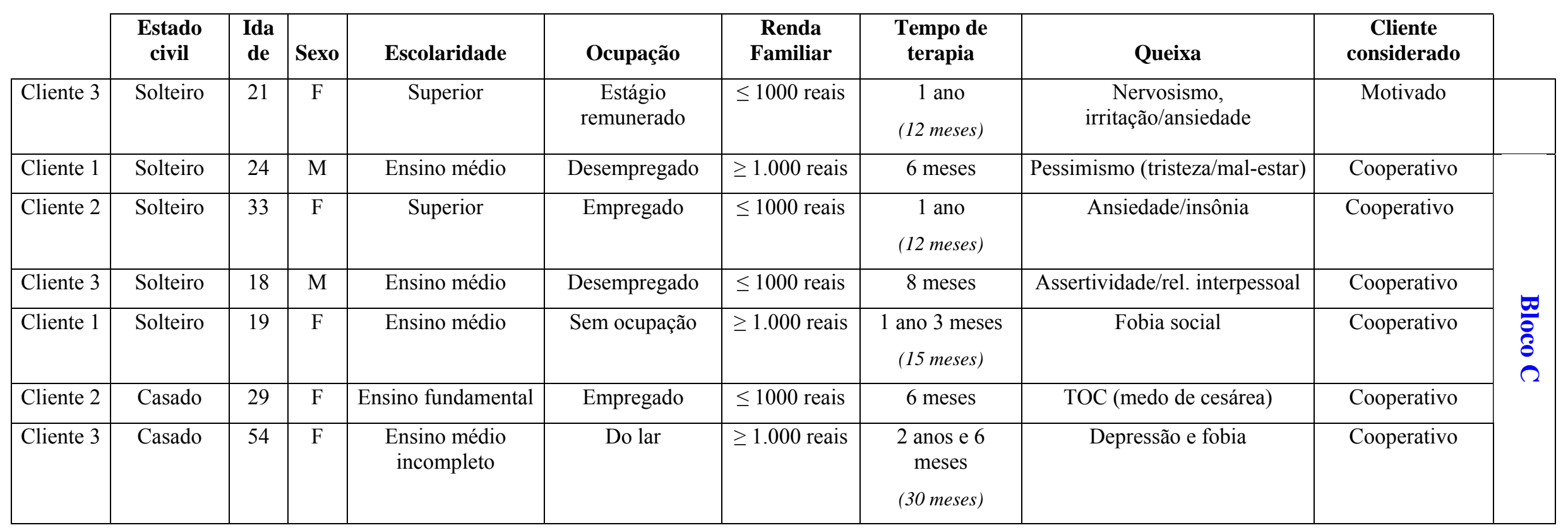




\begin{tabular}{|c|c|c|c|c|c|c|c|c|c|c|}
\hline & $\begin{array}{c}\text { Estado } \\
\text { civil }\end{array}$ & Idade & Sexo & Escolaridade & $\begin{array}{c}\text { Situação } \\
\text { atual }\end{array}$ & $\begin{array}{c}\text { Renda } \\
\text { Familiar }\end{array}$ & $\begin{array}{l}\text { Tempo de } \\
\text { terapia }\end{array}$ & Queixa & $\begin{array}{c}\text { Cliente } \\
\text { considerado }\end{array}$ & \\
\hline Cliente 1 & Solteiro & $\begin{array}{c}30 \\
\text { anos }\end{array}$ & $\mathrm{M}$ & Superior & Empregado & $\begin{array}{c}\leq 1.000 \\
\text { reais }\end{array}$ & 4 meses & Relacionamento interpessoal & $\begin{array}{c}\text { Cooperativo e } \\
\text { motivado }\end{array}$ & \multirow{3}{*}{$\underline{\underline{T}}$} \\
\hline Cliente 2 & Solteiro & $\begin{array}{c}34 \\
\text { anos }\end{array}$ & $\mathrm{F}$ & $\begin{array}{l}\text { Superior } \\
\text { incompleto }\end{array}$ & Empregado & $\begin{array}{c}\geq 1.000 \\
\text { reais }\end{array}$ & $\begin{array}{c}3 \text { anos } \\
\text { (36 meses) }\end{array}$ & $\begin{array}{l}\text { Relacionamento interpessoal, ansiedade, entre } \\
\text { outros }\end{array}$ & $\begin{array}{c}\text { Cooperativo e } \\
\text { motivado }\end{array}$ & \\
\hline Cliente 3 & $\begin{array}{l}\text { Divorciad } \\
\quad \text { o }\end{array}$ & $\begin{array}{c}29 \\
\text { anos }\end{array}$ & $\mathrm{F}$ & Superior & Empregado & $\begin{array}{c}\geq 1.000 \\
\text { reais }\end{array}$ & $\begin{array}{l}2 \text { anos e } 4 \\
\text { meses } \\
\text { (28 meses) }\end{array}$ & $\begin{array}{l}\text { Relacionamento interpessoal, dependência } \\
\text { financeira dos pais }\end{array}$ & $\begin{array}{l}\text { Cooperativo e } \\
\text { motivado }\end{array}$ & \\
\hline Cliente 1 & Solteiro & $\begin{array}{c}18 \\
\text { anos }\end{array}$ & $\mathrm{F}$ & Ensino médio & Estudante & $\begin{array}{l}\geq 1.000 \\
\quad \text { reais }\end{array}$ & $\begin{array}{c}4 \text { anos } \\
\text { (48 meses) }\end{array}$ & Pânico e agorafobia & Cooperativo & \multirow{3}{*}{ 畄 } \\
\hline Cliente 2 & Casado & $\begin{array}{c}43 \\
\text { anos }\end{array}$ & $\mathrm{F}$ & Ensino médio & Do lar & $\begin{array}{c}\leq 1000 \\
\text { reais }\end{array}$ & $\begin{array}{c}3 \text { anos } \\
\text { (36 meses) }\end{array}$ & Hipocondria e fobia & Cooperativo & \\
\hline Cliente 3 & Solteiro & $\begin{array}{c}25 \\
\text { anos }\end{array}$ & $\mathrm{F}$ & Superior & Empregado & $\begin{array}{l}\leq 1000 \\
\text { reais }\end{array}$ & $\begin{array}{l}1 \text { ano e } 6 \\
\text { meses } \\
\text { (18 meses) }\end{array}$ & Ansiedade & Cooperativo & \\
\hline Cliente 1 & Casado & $\begin{array}{c}35 \\
\text { anos }\end{array}$ & $\mathrm{F}$ & Ensino médio & Empregado & $\begin{array}{l}\leq 1000 \\
\text { reais }\end{array}$ & $\begin{array}{c}2 \text { anos } \\
\text { (24 meses) }\end{array}$ & Depressão moderada/problemas conjugais & Motivado & \multirow{3}{*}{$\stackrel{\theta}{H}$} \\
\hline Cliente 2 & Solteiro & $\begin{array}{c}18 \\
\text { anos }\end{array}$ & $\mathrm{F}$ & $\begin{array}{l}\text { Ensino médio } \\
\text { incompleto }\end{array}$ & Estudante & $\begin{array}{c}\leq 1000 \\
\text { reais }\end{array}$ & 6 meses & Ansiedade, obesidade, disfluência & $\begin{array}{l}\text { Motivado, } \\
\text { cooperativo }\end{array}$ & \\
\hline Cliente 3 & Solteiro & $\begin{array}{c}33 \\
\text { anos }\end{array}$ & $\mathrm{M}$ & $\begin{array}{c}\text { Superior } \\
\text { incompleto }\end{array}$ & Estudante & $\begin{array}{c}\leq 1000 \\
\text { reais }\end{array}$ & $\begin{array}{c}1 \text { ano e } 6 \\
\text { meses } \\
(18 \text { meses })\end{array}$ & $\begin{array}{c}\text { Relacionamento interpessoal, dificuldade na } \\
\text { fala e nos critérios de relacionamento homem- } \\
\text { mulher }\end{array}$ & $\begin{array}{l}\text { Motivado, } \\
\text { resistente }\end{array}$ & \\
\hline
\end{tabular}




\subsection{Coleta e tratamento dos dados:}

Foi solicitado aos terapeutas comportamentais experientes e pouco experientes gravações de três sessões com três diferentes clientes com qualquer tipo de queixa. O tempo de gravação de cada sessão deveria ser de uma hora e as sessões não deveriam ser as iniciais, pois haveria pequena probabilidade de ocorrer orientações nas primeiras sessões, já que no início a terapia é uma fase predominantemente de coleta de dados e de estabelecimento de vínculo.

Tanto os clientes como os terapeutas receberam um termo de consentimento (Anexos II e III) contendo todas as informações pertinentes sobre os objetivos da pesquisa antes da gravação das sessões. Esse documento também continha todos os esclarecimentos necessários quanto às pessoas autorizadas a manusearem o material produzido e quanto ao sigilo das informações e qualquer tipo de identificação do cliente, assegurando assim os aspectos éticos da pesquisa. Os clientes e terapeutas que concordaram em participar da pesquisa assinaram o termo de consentimento para que fosse possível gravar as sessões e realizar as categorizações e posterior análise dos resultados. Aos terapeutas foi solicitado, além do termo de consentimento, o preenchimento de um questionário solicitando informações gerais (Anexo IV).

As fitas gravadas foram transcritas, as falas numeradas e categorizadas. $\mathrm{O}$ número de palavras em falas com orientações e os subtipos de orientações (orientação para ação específica, orientação para ação genérica, orientação para tarefa, orientação para encobertos) foram contados, o mesmo ocorrendo para a auto-orientação (autoorientação para ação específica, auto-orientação para ação genérica, auto-orientação para tarefa e auto-orientação para encoberto). Para maior compreensão é importante ver as definições de orientação/auto-orientação na introdução deste trabalho (pp.6-8).

\subsection{Delineamento de pesquisa}


O delineamento da presente pesquisa seguiu o método proposto pela 'Grounded Theory' (traduzida para o português como Teoria Fundamentada nos Dados) de Glasser e Strauss (1967). Estes autores propõem uma forma de estudar fenômenos, desenvolvida conceitualmente através de um processo de coleta e de análise de dados sistematicamente conduzido. O objetivo deste método de análise é justamente gerar uma teoria que explique os dados coletados, ou seja, gerar uma teoria fundamentada nos dados.

Fernandes e Maia (2001) apontam que o método de comparação constante é o princípio central da 'Grounded Theory' e consiste num movimento contínuo entre a construção do investigador e o retorno aos dados, até este processo ficar saturado. É este método que permite que as elaborações do observador se mantenham próximas aos dados (grounded). Na medida em que a análise vai se desenvolvendo, outras questões vão sendo formuladas, exigindo um retorno aos dados. As questões evoluem de questões abertas para as mais focalizadas e orientadas. Elas orientam o investigador para os processos do fenômeno estudado. A "amostra teórica" vai sendo construída pela própria análise, e não selecionada na íntegra previamente. A amostra vai se diferenciando em função de questões surgidas durante, não se tratando de uma amostra representativa das características dos participantes, mas relevante para o fenômeno em estudo, e que pretende ser representativa das variações e tipicidades do fenômeno, e por isso é dirigida intencionalmente pelo processo de análise de dados.

O procedimento de análise de dados na presente pesquisa baseou-se em grande parte no que os teóricos do 'Grounded Theory' chamam de codificação aberta. Entendese por codificação aberta a decomposição, análise, comparação, conceituação e categorização dos dados. Nesta pesquisa, todas as análises realizadas se iniciavam a partir da leitura das sessões. O passo seguinte foi a decomposição das sessões em 
episódios de orientação e auto-orientação. Após a decomposição, iniciou-se a análise das variáveis encontradas nesses episódios de orientação/auto-orientação e, com base no arcabouço teórico, em alguns momentos categorias foram formadas e em outros momentos categorias de comportamento já existentes na literatura foram utilizadas (Ex.: Brandão, 2003; Zamignani \& Meyer, 2007).

Após a categorização dos dados analisados (seja nos episódios de orientação/ auto-orientação, seja na análise de contingências), buscaram-se regularidades entre alguns aspectos das variáveis responsáveis pelo comportamento de orientar ou autoorientar por meio do estabelecimento de relações e correlações. Para os autores do 'Grounded Theory' essa fase é chamada de codificação seletiva. É na codificação seletiva que há integração do material analisado com a teoria vigente.

A forma de condução desta investigação foi uma busca da compreensão do processo, partindo de procedimentos mais simples (leitura de sessões) para procedimentos mais complexos (Ex.: análise de contingências). O procedimento adotado permitiu comparação constante dos dados e das análises com construção e reconstrução das categorias.

Na presente pesquisa, a análise dos dados foi subdividida em cinco etapas.

1. Análise de temas abordados nas sessões;

2. Análise das perguntas realizadas durante os episódios de orientação/autoorientação;

3. Análise das respostas a cada pergunta realizada nos episódios de orientação/auto-orientação;

4. Análise de contingências das orientações e auto-orientações; 
5. Análise das correlações: escolaridade-orientação/auto-orientação; queixaorientação/orientação; perfil do cliente-orientação/auto-orientação; idade do clienteorientação/auto-orientação, tempo de terapia-orientação/auto-orientação e situação financeira-orientação/auto-orientação.

A seguir, será detalhado cada um dos itens trabalhados.

\subsection{Procedimento}

\subsubsection{Temas}

A análise dos resultados iniciou-se com a releitura das sessões de psicoterapia dos diferentes terapeutas sendo anotados os diferentes temas discutidos ao longo das sessões. Separaram-se os temas nos quais ocorriam emissão de orientação e os temas nos quais ocorriam emissão de auto-orientação. Após a identificação e separação dos temas, comparou-se o número de temas encontrados nas sessões dos diferentes terapeutas com o número de temas sobre os quais ocorriam orientação e auto-orientação nas sessões desses terapeutas. Para esta comparação utilizou-se o cálculo da frequência relativa ${ }^{7}$.

Para analisar os temas discutidos na sessão utilizou-se uma adaptação do modelo de grupos temáticos da tese de Zamignani (2007). Cinco grandes grupos temáticos foram utilizados: 1. Relacionamento interpessoal (subdividido em: 1.1 Relacionamentos com cônjuge/ parceiro; 1.2 Relacionamentos com filhos/enteados; 1.3 Relacionamentos com pais ou padrasto/madrasta; 1.4 Relacionamentos com outros familiares; 1.5 Outros relacionamentos; 1.6 Questões gerais sobre relacionamentos); 2. $\underline{\text { Trabalho/estudo e ou carreira; 3. Queixas psiquiátricas e psicológicas; 4. Problemas }}$

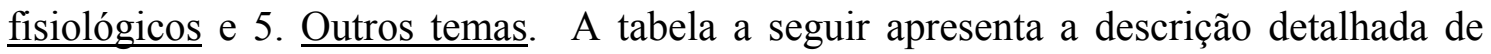
cada grupo temático.

\footnotetext{
${ }^{7}$ Frequência relativa (fr) é o quociente entre a frequência absoluta do valor da variável dividido pelo número total de observações. Geralmente é apresentada na forma de porcentagem.
} 
Tabela 3 - Grupos temáticos

\begin{tabular}{|c|c|}
\hline Grupos temáticos & Descrição das Categorias \\
\hline $\begin{array}{l}\text { 1.1 Relacionamentos } \\
\text { com cônjuge/ parceiro }\end{array}$ & $\begin{array}{l}\text { O assunto corrente diz respeito aos relacionamentos do cliente fora da sessão, } \\
\text { que se refiram a envolvimento afetivo amoroso com um parceiro/parceira, ou } \\
\text { a busca de um parceiro/parceira, independentemente de haver } \\
\text { correspondência por parte da outra pessoa. Podem envolver questões de } \\
\text { relacionamento tais como: dificuldades de convivência, queixas, reclamações } \\
\text { ou acusações, bem como qualquer tipo de interação - amigável ou não - com } \\
\text { pessoas com as quais haja interesse amoroso por parte do cliente, ou com o(a) } \\
\text { namorado(a), cônjuge ou companheiro(a). }\end{array}$ \\
\hline $\begin{array}{l}\text { 1.2 Relacionamentos } \\
\text { com filhos/ enteados }\end{array}$ & $\begin{array}{l}\text { O assunto corrente diz respeito aos relacionamentos do cliente fora da sessão } \\
\text { com um filho ou enteado. Podem envolver questões de relacionamento tais } \\
\text { como: dificuldades de convivência, queixas, reclamações ou acusações, } \\
\text { orientação de pais, bem como o relato de qualquer tipo de interação - } \\
\text { amigável ou não. }\end{array}$ \\
\hline $\begin{array}{l}\text { 1.3 Relacionamentos } \\
\text { com pais ou } \\
\text { padrasto/madrasta }\end{array}$ & $\begin{array}{l}\text { O assunto corrente diz respeito aos relacionamentos do cliente fora da sessão, } \\
\text { com pais ou padrastos. Podem envolver questões de relacionamento tais } \\
\text { como: dificuldades de convivência, queixas, reclamações ou acusações, bem } \\
\text { como qualquer tipo de interação - amigável ou não. }\end{array}$ \\
\hline $\begin{array}{l}\text { 1.4 Relacionamentos } \\
\text { com outros familiares }\end{array}$ & $\begin{array}{l}\text { O assunto corrente diz respeito aos relacionamentos do cliente com } \\
\text { familiares. Podem envolver dificuldades de convivência, queixas, } \\
\text { reclamações ou acusações, bem como qualquer tipo de interação - amigável } \\
\text { ou não - com familiares que não o cônjuge/companheiro. }\end{array}$ \\
\hline $\begin{array}{l}1.5 \text { Outros } \\
\text { relacionamentos }\end{array}$ & $\begin{array}{l}\text { O assunto corrente diz respeito aos relacionamentos com amigos, colegas, } \\
\text { vizinhos. Podem envolver dificuldades de convivência, queixas, reclamações } \\
\text { ou acusações, bem como qualquer tipo de interação - amigável ou não - com } \\
\text { pessoas que não sejam familiares ou cônjuge/companheiro. }\end{array}$ \\
\hline $\begin{array}{l}\text { 1.6 Questões gerais } \\
\text { sobre relacionamentos }\end{array}$ & $\begin{array}{l}\text { O assunto corrente diz respeito a comportamentos e sentimentos decorrentes } \\
\text { da interação interpessoal. }\end{array}$ \\
\hline $\begin{array}{l}\text { 2. Trabalho/estudo e ou } \\
\text { carreira }\end{array}$ & $\begin{array}{l}\text { O assunto corrente diz respeito a questões do cliente relacionadas a trabalho, } \\
\text { estudo ou carreira, tanto no que se referem a projetos, decisões, dúvidas, } \\
\text { planejamento, problemas de trabalho ou estudo, dificuldades de } \\
\text { relacionamento interpessoal que interferem no trabalho ou estudo ou } \\
\text { relacionamentos com colegas de trabalho que têm implicações diretas } \\
\text { (implicações sugeridas no relato presente do cliente) no trabalho ou estudo. }\end{array}$ \\
\hline $\begin{array}{l}\text { 3. Queixas } \\
\text { psiquiátricas e } \\
\text { psicológicas }\end{array}$ & $\begin{array}{l}\text { O assunto corrente diz respeito a sintomas relacionados a quadros } \\
\text { psiquiátricos, e seus tratamentos, médicos ou psicológicos, bem como } \\
\text { procedimentos tomados por clientes, familiares ou outros em situações de } \\
\text { crise. }\end{array}$ \\
\hline $\begin{array}{l}\text { 4. Problemas } \\
\text { fisiológicos }\end{array}$ & $\begin{array}{l}\text { O assunto corrente diz respeito a problemas fisiológicos como: desconforto } \\
\text { físico, descontentamento, desprazer, ou dor relacionada a problemas de saúde } \\
\text { - doenças ou sintomas físicos, incluindo a descrição de procedimentos } \\
\text { médicos relacionados. }\end{array}$ \\
\hline 5. Outros temas & $\begin{array}{l}\text { Essa categoria é utilizada quando não é possível identificar o tema principal } \\
\text { da conversação ou quando o tema em curso não se refere a nenhum dos } \\
\text { anteriormente previstos. }\end{array}$ \\
\hline
\end{tabular}


Para a realização da comparação entre as orientações e auto-orientações emitidas nas sessões dos terapeutas experientes e pouco experientes dentro de cada grupo temático, calculou-se a frequência média por terapeuta de emissão de orientação e autoorientação. A utilização da frequência média por terapeuta justificou-se pelo fato de que o número de terapeutas experientes assim como de seus clientes era inferior ao número de terapeutas pouco experientes. Assim, dividiu-se o número total de ocorrências de orientação e auto-orientação emitidas por terapeutas experientes por três (terapeutas), e no caso dos terapeutas pouco experientes dividiu-se por seis (terapeutas). A estratégia de se utilizar frequência média possibilitou a comparação entre as emissões de orientações e auto-orientações dos diferentes terapeutas dentro dos grupos temáticos.

\subsubsection{Análise das perguntas realizadas durante os episódios de O/AO}

Para alcançar o objetivo do estudo de identificar contingências de reforçamento das respostas de orientar de terapeutas e de se auto-orientar de clientes em sessões de terapia analítico-comportamental, fez-se necessário achar o contexto no qual ocorriam as orientações e auto-orientações. Este contexto foi denominado episódio de orientação/auto-orientação. Um Episódio de orientação/auto-orientação foi definido como um trecho da sessão em que o cliente ou terapeuta começam a abordar um tema até a última fala do cliente ou terapeuta sobre tal tema e a ocorrência de no mínimo uma orientação ou auto-orientação. Assim, uma sessão poderia conter nenhum ou vários episódios de orientação ou auto-orientação.

A partir da definição do que era um episódio de orientação/auto-orientação, foi realizada a releitura das sessões e delimitação dos episódios de orientação/autoorientação (Exemplo na página 97). A delimitação dos episódios de orientação/autoorientação foi necessária para encontrar as perguntas realizadas pelos terapeutas e as 
respostas dos clientes e para fazer as análises de contingências do comportamento de emitir orientação dos terapeutas e do comportamento de emitir auto-orientação dos clientes.

Verificaram-se quantas falas de terapeutas e clientes existiam dentro de um episódio de orientação e auto-orientação e qual a porcentagem dessas falas ${ }^{8}$ dentro das sessões dos diferentes terapeutas, de forma a caracterizar o quanto das sessões é despendido em episódios de orientação/auto-orientação.

Para facilitar a compreensão é apresentado um exemplo de um episódio de orientação. Neste exemplo a fala de número 32 da cliente (32C) foi o início do episódio de orientação e a fala de número 44 do terapeuta (44T) foi o fim do episódio de orientação. Como no episódio de orientação/auto-orientação é levada em conta a interação terapeuta-cliente, pode-se dizer que nesse episódio houve 12 sequências de falas de ambos interlocutores (12 falas do cliente e 12 falas do terapeuta). Se o exemplo tivesse sido retirado de uma sessão com 120 sequências de falas e dessas 120 sequências 12 fossem em um único episódio de orientação, a porcentagem de ocorrência de falas relacionadas à orientação nessa sessão seria de $10 \%$.

Realizou-se um levantamento geral das perguntas realizadas pelos terapeutas e respostas emitidas pelos clientes durante os episódios de orientação/auto-orientação. Através desse levantamento de perguntas realizadas pelos terapeutas e respondidas pelos clientes, formulou-se a hipótese (hipótese formulada a partir dos dados) de que em um episódio de orientação/auto-orientação os terapeutas realizavam as seguintes perguntas e estas ocorriam em sua maioria das vezes na seguinte sequência:

(a) Quando ocorreu a situação relatada?

(b) Por que ocorreu aquela situação (a que o cliente atribui a situação relatada)?

\footnotetext{
${ }^{8}$ No estudo de Donadone (2004) foi feita uma comparação do número de falas com orientação com o número de orientação, e não foram encontradas diferenças significativas.
} 
(c) Como o cliente lidou com a situação-problema?

(d) Qual é a avaliação do cliente sobre a forma como lidou com a situação?

(e) O que o cliente sentiu naquela situação?

(f) Passada a situação o cliente é capaz de verbalizar o que deveria fazer em situações similares ou de emitir a reação pretendida?

É importante mencionar que mais importante que a sequência das perguntas, era sua ocorrência. Sendo assim, caso não acontecesse nessa sequência, ela seria anotada da mesma forma.

Veja o exemplo na página a seguir. 
Exemplo de episódio de orientação:

32C: fora o calor, tá tudo certo, ando me sentindo mais ou menos bem, pois a enxaqueca diminuiu consideravelmente de frequência.... Ai ai... Ah (suspiro profundo)... Ahm... enrolei até agora, mas tenho que te contar uma coisa... Tô meio nervosa, mas vamos lá (risos)

32T: pode falar...

33C: fiz uma coisa que provavelmente você não irá gostar... ou não (risos). Preciso te dizer que anda acontecendo... Andei ligando pro W... (riso nervoso) 33T: É mesmo?(surpreso)... Quando você ligou pra ele?

34C:Ontem....(suspiro profundo). Então... Na quinta-feira vim aqui, conversamos $e$ fiquei mais consciente (risos). Mas com o passar do tempo parece que vou enfraquecendo... Nesta quarta-feira acordei com a ideia fixa de falar com meu ex. Aí fui trabalhar e tentar me distrair. Mas sabe aqueles dias onde o mundo resolve te estressar e te contrariar... Só sei que quando eu vi já tinha ligado pra ele... Aí pensei pra variar fiz o que não devia... Ligar pra quê?

34T: uhm... Sei! Mas o que foi que aconteceu?Ou melhor, porque você ligou pra ele? Porque você acha que isso aconteceu?

35C: Calma... Vou te explicar por partes... Sempre tem um porquê né... (risos)... Tudo começou com a minha chefe... Ela é fogo... Uma beleza (ironicamente)... Enfim, briguei com a minha chefe por conta de um memorando, e ela no meio da briga me chamou de mal amada! Mal amada eu! Quem é ela pra falar isso... Aí eu pensei a culpa é minha... Que eu fico falando pra todo mundo o que meu ex-marido me fez, que ele me trocou por uma ninfetinha mais magra... Até o porteiro do prédio que trabalho sabe disso... Ninguém manda ter boca grande... Mas as pessoas são ruins, na hora que briga, vira e usa o que você falou como arma contra você... Enfim, só sei que fiquei chateada, saí do trabalho com vontade de matar um... Quando tô indo pra casa, uma pessoa vomita no meu pé no metrô...

35T: Nossa!...

36C: Só sei que saí do metrô chorando, passei na padaria e não tinha a bomba de chocolate que eu queria... Cheguei em casa tomei banho e fui pra frente da TV, morta de fome e raiva... Nisso começo a ver a novela... E o mocinho todo romântico... Num impulso catei o telefone e liguei pro $W$.

36T: Ahm... E aí como foi?

37C: Vou te contar o que rolou... Bom, ele atendeu ao telefone e logo foi perguntando do filho. Eu respondi que tava tudo bem e que ele estava na avó. Aí então ele me responde: que bom, então diga, o que você quer? Eu fiquei meio gaga, e ele já se antecipou... Ah só bater papo e começou com aquelas perguntinhas que me irritam: Você está bem? E o trabalho? Tá se cuidando! Até aí eu fui respondendo, aí quando eu fiz as mesmas perguntas, ele disse que tava ótimo, que) tinha sido promovido e assim por diante... Eu comecei a ficar muito brava, mas isso 
é ilógico porque quem perguntou fui eu e ele só respondeu, não é? Enfim, acho que tudo isso aconteceu por uma soma de coisas. Acho que a minha chefe extrapolou, me levou ao limite e depois o que me aconteceu no metrô, foi pra acabar... Acho que essa série de porcarias me deixaram mais sensível e por isso eu liguei.

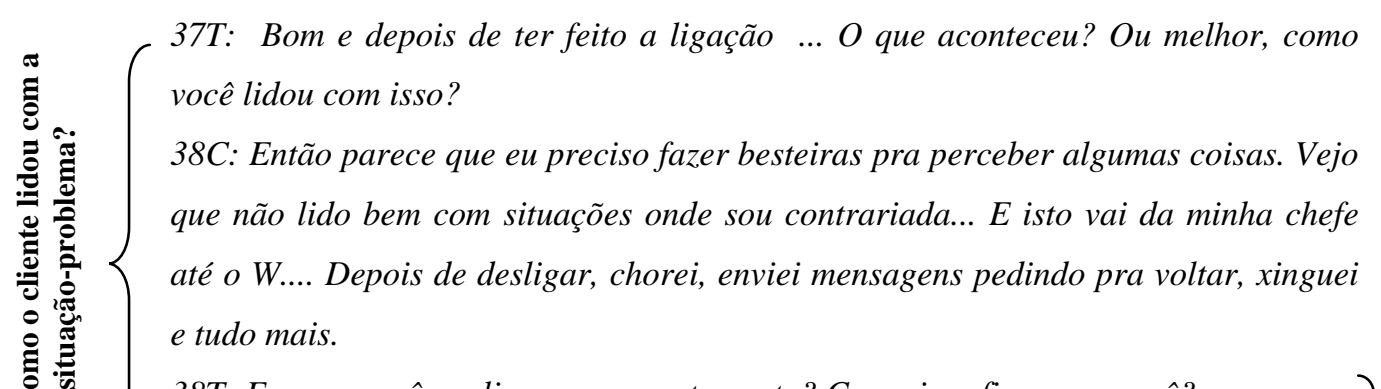

38T: E como você avalia seu comportamento? Como isso ficou pra você?

39C: Ahm...é como eu te disse acho que me comportei mal, que recaí, mas é tão difícil né... Eu ainda me descontrolo...

$39 T:$ É ainda difícil pra você falar com ele né... Mas me diga... Como você se sentiu
ao ligar? Valeu a pena falar com ele, apesar dos pesares?
40C: Ahm...Não gostei de falar com ele não... E ainda de quebra não me senti nada
bem... Na hora que desliguei o telefone, percebi que tinha 'recaído' e feito tudo
errado. Me senti muito mal, chorei... E ainda fiquei deprimida. Não é desta forma
que quero a atenção dele... Depois de um tempo, comecei a pensar, pensar e não me
senti mais mal, conclui que isso só aconteceu, pois minha chefe me levou à loucura
e meu dia foi uma lástima... 40T: Peraí... Devagar nessa hora... (risos). Você mesmo me disse que já vinha pensando em ligar pra ele naquele dia pela manhã. Concordo com você que seu dia não foi dos melhores... Agora dizer que um dia ruim te levou a ligar pra ele e falar o que você falou já não é verdade, não é... Você está passando por uma série de coisas, mas o principal é que não parece ter assimilado bem o rompimento do casamento; e principalmente está comparando sua vida com a dele... Colocando tudo no mesmo balaio e as coisas que te acontecem e não te agradam você considera responsabilidade dele. Não é isso?

41C: Não sei... (silencio longo). Mas o dia ruim deu uma ajudadinha (riso nervoso)... Ahm... (pausa longa)... Odeio quando você tem razão (risos) e você me fala as verdades de um jeito mansinho... (riso nervoso).

41T: Mas me diga, você provavelmente passará por outras situações semelhantes... o que quero dizer é que provavelmente ainda doerá o fim do casamento $e$ provavelmente terá dias estressantes no trabalho! O que queria dizer é: como você provavelmente pretende lidar com isso?

42C: Boa pergunta (risos).. (pausa longa). Olha... (suspiros). Vou te contar a minha vontade agora. Juntar o telefone e falar horrores pra ele, pra nova esposa dele. Quanto à minha chefe, quero que ela se exploda... Odeio cargos de confiança. Mas 
sei que essa não é a melhor forma de se resolver esta situação, mas é assim que acabo agindo.

42T: É, complicado mesmo, mas sabendo como fatores estressantes do dia-a-dia te abalam, "quero que você pense nesta semana em estratégias de como lidar com essa situação, ok. Pode ser?” (Orientação para Encoberto)

43C: (risos). Vou tentar... Não sei se vou conseguir pensar em nada... Falando em pensar, você viu que terá uma festa grande no clube $X$ neste sábado?

43T: (risos). É difícil pensar sobre algumas coisas, né... Mais tarde retornaremos a esta questão... (risos). Tá, mas o que você quer me dizer sobre a festa do clube $X$ ! 44 C: Fazer o quê? (risos)... Estamos aqui pra isso! (referindo-se a falar e pensar em seu comportamento com seu ex)... Então a festa vai estar ótima, não sei se vou...

44T: É... a festa é grande né...

Também foi verificado se os clientes respondiam às perguntas acima. Assim, quando em um episódio de orientação/auto-orientação era encontrado e as perguntas feitas pelo terapeuta seguidas pelas respostas dos clientes, anotava-se SIM para essa díade de pergunta e resposta e quando a díade (pergunta-resposta) não era encontrada anotava-se NÃO. Observe que SIM significava que havia sim ocorrido a pergunta seguida da resposta do cliente e NÃO significava que não havia ocorrido a pergunta seguida da resposta do cliente. Assim, num primeiro momento, o foco de análise era a ocorrência das perguntas-respostas e não era o conteúdo da resposta em si.

Posteriormente, a observação das sequências de perguntas que antecediam a emissão de orientação e auto-orientação permitiu que duas suposições fossem levantadas. A primeira referia-se à emissão de orientação. Levantou-se a hipótese de que a orientação teria maior probabilidade de ocorrer quando fossem realizadas as seguintes perguntas pelos terapeutas seguidas das respostas dos clientes: (a) Quando ocorreu a situação relatada? (b) Por que ocorreu aquela situação (a que o cliente atribuiu a situação relatada)? (c) Como o cliente lidou com a situação-problema? (e) O que o cliente sentiu naquela situação? E quando não fossem realizadas as seguintes perguntas 
pelos terapeutas ou quando não houvesse respostas dos clientes: (d) Qual é a avaliação do cliente sobre a forma como lidou com a situação? (f) Passada a situação o cliente é capaz de verbalizar o que deveria fazer em situações similares ou de emitir a reação pretendida? Assim, o terapeuta emitiria orientação quando o cliente, diante das perguntas (d) e (f), não conseguisse discriminar qual o comportamento que deveria ter, ou quando o cliente não conseguisse sequer dizer qual reação deveria ter ocorrido diante de determinada situação (ou seja, a orientação era emitida quando claramente o cliente não se encontrava em contato com as contingências). Seguindo a lógica da suposição levantada, a sequência de perguntas-respostas características nos episódios de orientação seria apresentada da seguinte maneira: SIM-SIM-SIM-NÃO-SIM-NÃO. [Quer dizer: SIM (ocorreu a pergunta (a) seguida da resposta) - SIM (ocorreu a pergunta (b) seguida da resposta) - SIM (ocorreu a pergunta (c) seguida da resposta) - NÃO (não ocorreu a pergunta (d) seguida da resposta) - SIM (ocorreu a pergunta (e) seguida da resposta) - NÃO (não ocorreu a pergunta (f) seguida da resposta)].

No caso da auto-orientação, supôs-se que a emissão desta ocorreria em maior proporção se fossem realizadas todas as perguntas listadas acima pelos terapeutas seguidas por respostas dos clientes a todas essas perguntas, ou seja, a auto-orientação ocorreria quando os clientes sabiam avaliar e prever respostas. Seguindo a lógica da hipótese levantada a sequência característica nos episódios de auto-orientação seria apresentada da seguinte maneira: SIM-SIM-SIM-SIM-SIM-SIM. [Quer dizer: SIM (ocorreu a pergunta (a) seguida da resposta) - SIM (ocorreu a pergunta (b) seguida da resposta) - SIM (ocorreu a pergunta (c) seguida da resposta) - SIM (ocorreu a pergunta (d) seguida da resposta - SIM (ocorreu a pergunta (e) seguida da resposta) - SIM (ocorreu a pergunta (f) seguida da resposta)]. 
Para que ocorresse essa análise específica, primeiramente separaram-se os episódios de orientação dos episódios de auto-orientação. Após a separação foram relidos os episódios e anotadas quais as sequências de perguntas-respostas presentes. Anotou-se também qual a sequência de perguntas-respostas mais frequente. Verificouse então se a sequência mais frequente estava de acordo com as duas suposições sobre perguntas e repostas nos episódios de orientação/auto-orientação.

2.4.3. Análise das respostas a cada pergunta realizada nos episódios de orientação e auto-orientação

Para todas as perguntas encontradas nos episódios de orientação e autoorientação foi feito um levantamento das respostas emitidas pelos diferentes clientes e categorias de respostas foram formadas, ou foram usadas categorias de respostas encontradas na literatura. Calculou-se a frequência relativa percentil (apresentada em porcentagem) das diferentes categorias de respostas nos episódios de orientação e autoorientação dos diferentes terapeutas.

Quando a análise visava a comparar categorias de respostas emitidas nas sessões dos terapeutas experientes e pouco experientes, calculou-se o número médio de respostas. $\mathrm{O}$ cálculo do número médio de resposta justifica-se, pois a comparação era feita entre três terapeutas experientes e seis terapeutas pouco experientes. $\mathrm{O}$ número médio foi calculado dividindo-se as categorias de respostas encontradas nas sessões dos terapeutas experientes por três (três terapeutas experientes) e dos terapeutas pouco experientes por seis (seis terapeutas pouco experientes).

Para (a) “Quando ocorreu a situação relatada pelo cliente?” foram formadas duas categorias de respostas. Os clientes podiam relatar uma situação ocorrida em tempo presente ou em tempo passado. Situações ocorridas no presente incluíam relatos 
de eventos ocorridos na semana do cliente, ou eventos recentes tratados pelo cliente ou outras pessoas no tempo presente fora da sessão. Situações relatadas como referidas à 'semana passada' ou 'esses dias' eram consideradas como presente. Situações ocorridas no passado incluíam relatos de eventos ocorridos no passado distante do cliente ou de pessoas ligadas ao cliente. Exemplos de situações ocorridas no passado incluíam descrição de eventos que vinham ocorrendo há mais tempo, por exemplo, infância, adolescência, acontecimentos de meses, anos ou décadas atrás.

Para (b) “Por que ocorreu aquela situação?” (a que o cliente atribuiu a situação relatada), os fatores que os clientes atribuíram à situação relatada estão apresentados na Tabela 4:

Tabela 4 - Categorias de respostas emitidas pelos clientes à pergunta: "Por que ocorreu a situação?"

\section{Categorias de respostas a pergunta: "Por que ocorreu a situação?"}

1. Sabe dizer o porquê de a situação ter ocorrido (descreve contingências).

2. Não sabe dizer o porquê de a situação ter ocorrido, mas avalia seu comportamento como 'inadequado'.
Exemplos

Ex1: "É muito fácil te responder por que tudo isso que estou te contando aconteceu... Na tentativa de compensar meu sofrimento com a separação, gastei desenfreadamente... Comprava tudo o que via e queria... Meu lado menina mimada aflorou, gastei e gasto ainda hoje o que tenho e o que não tenho... Assumo o que faço e não vou por a culpa no W..."

Ex1: "Só sei que quando eu vi já tinha transado com uma garota de programa sem camisinha, mesmo sabendo que isso é errado", Ex2: "Em um segundo tava tudo bem, no segundo seguinte tinha pegado minha mãe pelo colarinho... Quase bati na minha própria mãe, que horror... mãe é sagrado... não se bate, né?"
3. A orientação ou a análise do terapeuta foi seguida ou deixou de ser seguida.

Ex1: "Se a situação está mais estável hoje é porque consegui falar. Só estou conseguindo me expressar graças às suas dicas. Se hoje sou elogiada no trabalho é porque você me aconselhou a falar o que pensava." Ex2: "Porque estamos nessa situação... porque como já analisamos aqui não há diálogo... como sair dessa crise se marido e mulher não se conversam...” Ex3: “ Hoje vejo que se tivesse colocado em prática o que discutimos aqui, não estaria me sentido um lixo. Porque eu deixei a encrenca crescer... a situação não chegou a esse pé do nada, né."

4. Responsabiliza a situação ao comportamento de outra pessoa.
Ex1: "Essa ansiedade toda é culpa do meu namorado. Ele tinha que me falar que odeia minha companheira de república... Agora quando ele fala 


\begin{tabular}{|l|l|}
\hline & $\begin{array}{l}\text { que vem me visitar fico ansiosa uma semana } \\
\text { antes... Se ele não tivesse falado nada estaria } \\
\text { bem..." Ex2: "Fui chamada até a escola do meu } \\
\text { filho, pois ele está sendo agressivo com seus } \\
\text { coleguinhas, e pior que falar com meu marido não } \\
\text { adianta... Essa agressividade do meu filho é culpa } \\
\text { do meu marido que é sempre ausente... o menino } \\
\text { precisa chamar a atenção... e eu que sou } \\
\text { repreendida na escola... justo eu que não fiz anda } \\
\text { de errado." Ex3: "Quando eu vi, eles estavam } \\
\text { discutindo e eu estava bem no meio da briga... } \\
\text { Também toda vez que eles bebem, discutem... Eu } \\
\text { entrei nessa de gaiato... a polícia tinha que } \\
\text { entender isso... não fiz nada e agora tô sendo } \\
\text { acusada." }\end{array}$ \\
\hline $\begin{array}{l}\text { 5. Não sabe discriminar o porquê de a situação } \\
\text { ter ocorrido. }\end{array}$ & $\begin{array}{l}\text { Ex1: "Não tenho a menor ideia do que aconteceu } \\
\text { para que as coisas tomassem este rumo.". }\end{array}$ \\
\hline
\end{tabular}

Para (c) “Como o cliente lidou com a situação-problema?”, as possibilidades de resposta são:

Tabela 5 - Categorias de respostas emitidas pelos clientes à pergunta: "Como o cliente lidou com a situação-problema?"

\begin{tabular}{|c|c|}
\hline $\begin{array}{c}\text { Categorias de resposta à pergunta: } \\
\text { “Como o cliente lidou com a situação- } \\
\text { problema?". }\end{array}$ & Exemplos \\
\hline $\begin{array}{l}\text { 1. Comportou-se de forma que considerou } \\
\text { 'apropriada', apesar de as consequências nem } \\
\text { sempre serem as esperadas. }\end{array}$ & $\begin{array}{l}\text { Ex1: "Diante da ausência de recursos, fiz o melhor } \\
\text { que um médico pode fazer... E, aliás, acho que fiz } \\
\text { muito bem feito... Falei pra A ou nos adequamos } \\
\text { ou paramos de atender em serviços públicos... É } \\
\text { assim que agi e pretendo continuar agindo... Sem } \\
\text { briga, sem estresse, fiz o que a situação exigia que } \\
\text { eu fizesse..." Ex2: Quando ele veio me falar sobre } \\
\text { sua ex-namorada, respondi: não falo sobre sua ex e } \\
\text { ponto." Ex3: "Eu sei que fiz a melhor coisa, mas } \\
\text { falar a verdade a meu chefe só serviu para que eu } \\
\text { tivesse fama de fofoqueira no setor." }\end{array}$ \\
\hline 2. Seguiu a orientação do terapeuta. & $\begin{array}{l}\text { Ex1: "Tô feliz essa semana, na hora que meu } \\
\text { namorado começou a falar besteira, lembrei da } \\
\text { terapia, respirei fundo e disse: F, isso eu não } \\
\text { discuto e saí..." }\end{array}$ \\
\hline $\begin{array}{l}\text { 3. Analisou a situação, ou seja, cliente levantou } \\
\text { as principais variáveis que mantêm } \\
\text { determinada situação. }\end{array}$ & $\begin{array}{l}\text { Ex1: "Fiquei pensando por que não consigo me } \\
\text { livrar desta tristeza, e percebi que várias coisas } \\
\text { ajudam para que eu não consiga me livrar, por } \\
\text { exemplo, minha situação financeira, não saber } \\
\text { fazer diferente e (risos) a vantagem que tenho em } \\
\text { ser deprimida..." }\end{array}$ \\
\hline $\begin{array}{l}\text { 4. Cliente não lidou/enfrentou a situação, ou } \\
\text { seja, diante de uma situação, cliente esquiva-se. }\end{array}$ & $\begin{array}{l}\text { Ex1: "Não adianta dialogar com meu marido, não } \\
\text { acho que isso vai me levar a algum lugar..." Ex2: } \\
\text { "Não sei lidar com essa doença (referindo-se a }\end{array}$ \\
\hline
\end{tabular}




\begin{tabular}{|l|l|}
\hline & $\begin{array}{l}\text { câncer da esposa), na hora que as crises dela } \\
\text { começam, saio pra caminhar e só volto a noite... É } \\
\text { o meu jeito e também acho que não ajudaria em } \\
\text { nada..." }\end{array}$ \\
\hline $\begin{array}{l}\text { 5. Não sabe dizer, ou seja, cliente não sabe dizer } \\
\text { como lidou (se comportou) em determinada } \\
\text { situação. }\end{array}$ & $\begin{array}{l}\text { Ex1: "Não tenho a menor idéia do que fiz para } \\
\text { isso ter acontecido". Ex2: "Sabe quando você não } \\
\text { tem a menor idéia de por que os outros te tratam } \\
\text { mal... Essa sou eu! Se fiz alguma coisa, juro que } \\
\text { não sei o que fiz... na verdade não sei por que tudo } \\
\text { isso tá rolando." }\end{array}$ \\
\hline
\end{tabular}

Para (d) “Qual é a avaliação do cliente sobre a forma como lidou com a situação?” as respostas foram:

Tabela 6 - Categorias de respostas emitidas pelos clientes à pergunta: "Qual é a avaliação do cliente sobre a forma como lidou com a situação"

\begin{tabular}{|l|l|}
\hline $\begin{array}{l}\text { Possíveis respostas à pergunta: "Qual é } \\
\text { a avaliação do cliente sobre a forma } \\
\text { como lidou com a situação?” }\end{array}$ & \multicolumn{1}{|c|}{ Exemplos } \\
\hline $\begin{array}{l}\text { 1) Considera seu comportamento adequado à } \\
\text { situação. }\end{array}$ & $\begin{array}{l}\text { Ex1: "Tô bem satisfeita comigo mesma, fiz o que } \\
\text { deveria ser feito... Não dá pra eu ficar esperando a } \\
\text { vida inteira pra saber se ele vai deixar a mulher ou } \\
\text { não... agora quem não quer mais sou eu... E a vida } \\
\text { continua..." }\end{array}$ \\
\hline $\begin{array}{l}\text { 2) Considera seu comportamento inadequado, } \\
\text { mas sabe descrever qual deveria ser a reação } \\
\text { adequada à situação. }\end{array}$ & $\begin{array}{l}\text { Ex1: "Nunca deveria ter reagido à provocação } \\
\text { dele... Agora ele passou por bonzinho e eu por } \\
\text { descontrolada... Mas não vejo a hora de ter outra } \\
\text { oportunidade... Quando ele começar a me xingar } \\
\text { baixinho, vou virar e dizer na lata... Não adianta } \\
\text { que não vai conseguir me desestabilizar..." }\end{array}$ \\
\hline $\begin{array}{l}\text { 3) Não saber dizer se o comportamento emitido } \\
\text { é considerado desejável ou não. }\end{array}$ & $\begin{array}{l}\text { Ex1: "Tô te contando tudo isso, mas não tenho a } \\
\text { menor idéia se fiz a melhor coisa ou não... Só sei } \\
\text { que fiz (risos)..." }\end{array}$ \\
\hline
\end{tabular}

Para (e): “O que o cliente sentiu diante daquela situação?” utilizou-se uma

readaptação do esquema básico de palavras emocionais (adaptado por Brandão, 2003, de Korman \& Greenberg, 1998). Algumas expressões emocionais foram incorporadas (Ex.: a subcategoria aflição na categoria medo); a categoria sem classificação foi substituída por não sabia dizer o que sentiu na situação que estava sendo analisada e a categoria 'misto' (quando o cliente relatava mais de uma emoção, por exemplo: raiva e 
medo) foi removida. Na tabela a seguir está a nova divisão das palavras emocionais após a readaptação. 
Tabela 7 - Esquema básico de palavras emocionais (adaptado de Shaver et al. 1987 - readaptado por Donadone \& Meyer, 2009)

\begin{tabular}{|c|c|c|}
\hline Amor & Raiva & Alegria \\
\hline $\begin{array}{l}\text { 1. Adoração } \\
\text { 2. Afeição } \\
\text { 3. Amar } \\
\text { 4. Apreciação } \\
\text { 5. Atração (atraído) } \\
\text { 6. Carinho } \\
\text { 7. Compaixão } \\
\text { 8. Desejo } \\
\text { 9. Empolgada (quanto ao } \\
\text { outro) } \\
\text { 10. Estimular } \\
\text { 11. Gamado, louco de paixão } \\
\text { 12. Gostar } \\
\text { 13. Luxúria ou desejo ardente } \\
\text { 14. Paixão } \\
\text { 15. Prazeroso } \\
\text { 16. Proteção } \\
\text { 17. Segura (na relação/ quanto } \\
\text { ao relacionamento) } \\
\text { 18. Sentimentalidade } \\
\text { 19. Ser cuidado por } \\
\text { 20. Ternura } \\
\text { 21. Vontade }\end{array}$ & $\begin{array}{l}\text { 1. Abominação } \\
\text { 2. Agitação } \\
\text { 3. Amargura } \\
\text { 4. Aversão } \\
\text { 5. Bravo } \\
\text { 6. Ciúmes } \\
\text { 7. Contrariado } \\
\text { 8. Desdenho } \\
\text { 9. Desgostar (não } \\
\text { gostar) } \\
\text { 10. Desprezo } \\
\text { 11. Enganado } \\
\text { 12. Estressado (irritado) } \\
\text { 13. Exaltação } \\
\text { 14. Exasperação } \\
\text { 15. Feroz } \\
\text { 16. Frustração } \\
\text { 17. Fúria } \\
\text { 18. Hostilidade } \\
\text { 19. Incomodado } \\
\text { 20. Incompreensão } \\
\text { 21. Indignação } \\
\text { 22. Inveja } \\
\text { 23. Ira } \\
\text { 24. Irritação } \\
\text { 25. Mágoa } \\
\text { (ressentimento) } \\
\text { 26. Nojo } \\
\text { 27. Odio } \\
\text { 28. Raiva } \\
\text { 29. Rancor } \\
\text { 30. Repugnância } \\
\text { 31. Resmungar } \\
\text { 32. Ressentimento } \\
\text { 33. Ser rabugento } \\
\text { 34. Ser zangado } \\
\text { 35. Tormento } \\
\text { 36. Ultrajar } \\
\text { 37. Vingança } \\
\text { 38. Vigiado (controlado, } \\
\text { sufocado) }\end{array}$ & $\begin{array}{l}\text { 1. Alegria } \\
\text { 2. Alívio } \\
\text { 3. Animado } \\
\text { 4. Ânsia } \\
\text { 5. Bem (estar bem) } \\
\text { 6. Confiante } \\
\text { 7. Contentamento } \\
\text { 8. Coragem } \\
\text { 9. Deleite } \\
\text { 10. Distração (prazer) } \\
\text { 11. Ditoso } \\
\text { 12. Diversão } \\
\text { 13. Elação } \\
\text { 14. Emoção } \\
\text { 15. Empolgado (entusiasmado) } \\
\text { 16. Encanto } \\
\text { 17. Enfeitiçada } \\
\text { 18. Enlevo } \\
\text { 19. Entusiasmo } \\
\text { 20. Esperança } \\
\text { 21. Euforia } \\
\text { 22. Excitação } \\
\text { 23. Exxito } \\
\text { 24. Exxtase } \\
\text { 25. Exultar } \\
\text { 26. Felicidade } \\
\text { 27. Gozo } \\
\text { 28. Jovialidade } \\
\text { 29. Júbilo } \\
\text { 30. Livre } \\
\text { 31. Orgulho } \\
\text { 32. Otimismo } \\
\text { 33. Prazer } \\
\text { 34. Relaxado } \\
\text { 35. Satisfação } \\
\text { 36. Seguro (quanto à vida) } \\
\text { 37. Sentir-se melhor } \\
\text { 38. Sortudo (feliz) } \\
\text { 39. Tranquilo } \\
\text { 40. Ventura } \\
\text { 41. Vitorioso } \\
\text { 42. Zelo } \\
\text { (2) }\end{array}$ \\
\hline
\end{tabular}




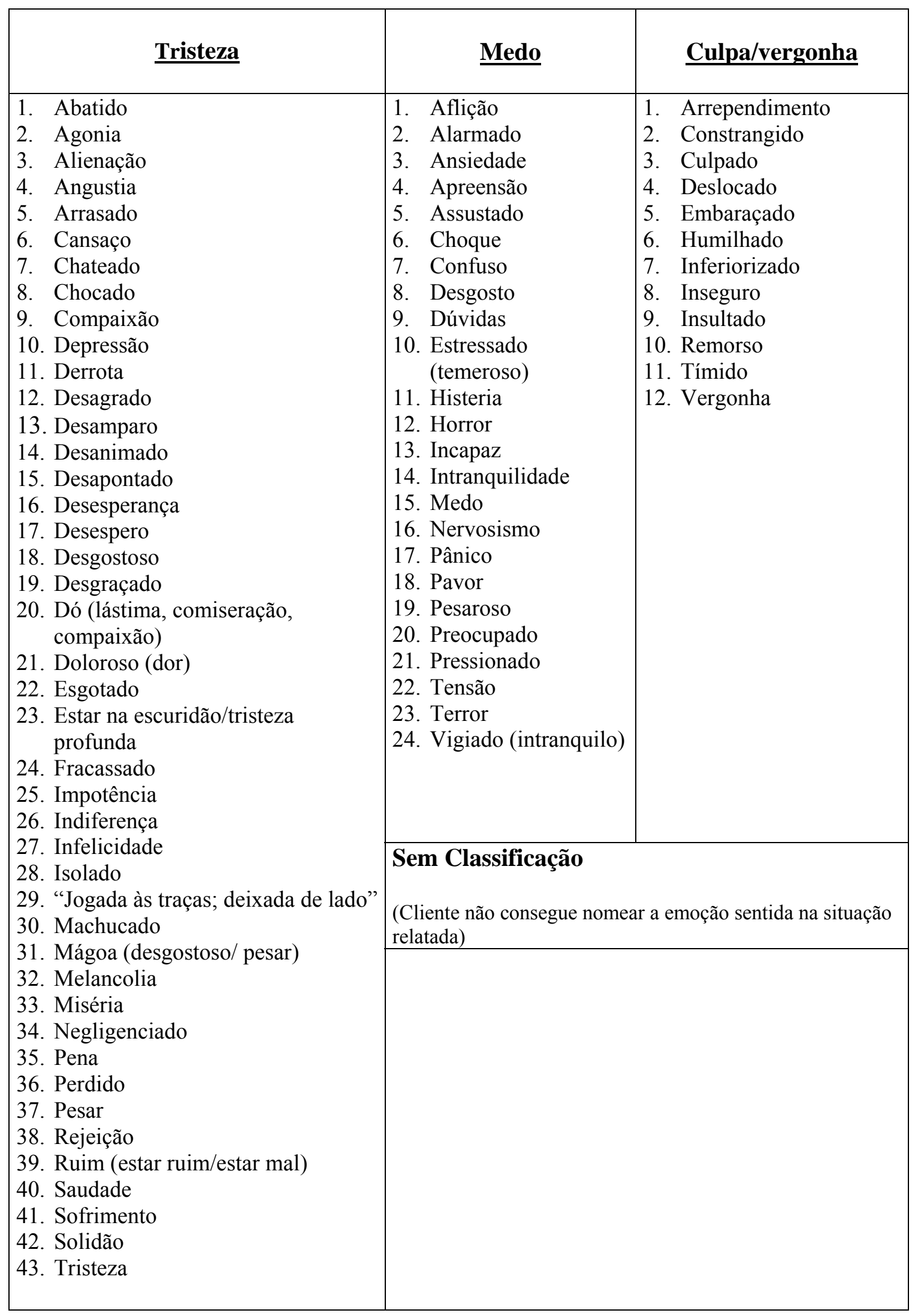


Após a readaptação dos esquemas de palavras emocionais, expressões emocionais encontradas nos episódios de orientação/auto-orientação foram agrupadas em categorias e subcategorias.

Para (f) "Passada a situação o cliente é capaz de verbalizar o que deveria fazer em situações similares ou emitiu a reação pretendida?” as respostas estão na tabela a seguir.

Tabela 8 - Categorias de respostas emitidas pelos clientes à pergunta: "Passada a situação o cliente é capaz de verbalizar o que deveria fazer em situações similares ou emitiu a reação pretendida?"

\begin{tabular}{|c|c|}
\hline $\begin{array}{c}\text { Categorias de respostas à pergunta: } \\
\text { “Passada a situação o cliente é capaz de } \\
\text { verbalizar o que deveria fazer em } \\
\text { situações similares ou emitiu a reação } \\
\text { pretendida?” }\end{array}$ & Exemplos \\
\hline $\begin{array}{l}\text { 1) Sim, é capaz de verbalizar o que deveria } \\
\text { fazer em situações similares ou emitir a reação } \\
\text { pretendida. }\end{array}$ & $\begin{array}{l}\text { Ex1: "Agora eu aprendi... Ficar no pé de homem } \\
\text { não garante fidelidade, pelo contrário (risos)... Por } \\
\text { isso que não vejo a hora de arrumar um novo } \\
\text { namorado e colocar em prática tudo que aprendi } \\
\text { aqui... Nada de ligações altas horas, nem verificar } \\
\text { celular... Aprendi... E de agora em diante o que } \\
\text { tiver que ser será!" Ex2: "Agora que vou ter } \\
\text { dinheiro de novo, sei que dinheiro não aceita } \\
\text { desaforo, vou economizar e fazer um fundo de } \\
\text { reserva para momentos difíceis. To feliz que a vida } \\
\text { tá me dando a chance de mostrar que sou capaz. } \\
\text { Agora é só ficar esperto." }\end{array}$ \\
\hline $\begin{array}{l}\text { 2) Não sabe dizer se emitiu o comportamento } \\
\text { adequado à situação ou não sabe avaliar se em } \\
\text { situações similares reagiria de outra forma. }\end{array}$ & $\begin{array}{l}\text { Ex1: "Acho que se passasse por essa situação de } \\
\text { novo, não saberia o que fazer de novo (risos)... É } \\
\text { muito difícil agir diferente, afinal sou eu...” Ex2: } \\
\text { Eu nunca sei o que fazer quando alguém me } \\
\text { ofende... Nunca tenho reação e acho que não } \\
\text { saberia o que fazer se passasse por uma ofensa de } \\
\text { novo..." }\end{array}$ \\
\hline
\end{tabular}

\subsubsection{Análise de contingências das orientações e auto-orientações}

Levando-se em consideração a revisão da literatura sobre a análise de contingências e a leitura dos episódios de orientação e auto-orientação, ampliou-se o modelo de análise de contingências de três termos, antecedente-comportamentoconsequente. Foram adicionados mais elos ao antecedente. Elementos como a narrativa 
do cliente e as intervenções realizadas pelos terapeutas antes da emissão da orientação ou auto-orientação foram considerados como antecedentes adicionais. Assim, a análise de contingências teve cinco elementos: 1. Narrativa do cliente; 2. Intervenções do terapeuta que antecedem a emissão de orientação/auto-orientação; 3. Antecedente; 4.

\section{Comportamento; 5. Consequente.}

Para melhor compreensão de como foi realizada esta análise de contingências, apresenta-se brevemente o que se entende nesta pesquisa por:

(1) Narrativa do Cliente: narração do cliente em sessão sobre o que ocorreu com ele fora da sessão, incluindo possíveis explicações para que se comportasse ou se sentisse de determinada maneira. A narrativa do cliente poderia ser entremeada de intervenções do terapeuta como, por exemplo, verbalizações mínimas, solicitação de informações (investiga), facilitação, exceto a emissão de orientação.

(2) Intervenções do terapeuta que antecedem a emissão de orientação/auto-orientação: os comportamentos dos terapeutas durante as narrativas dos clientes que assumem $a$ função de intervenção (exemplo: empatia, confrontação) antes da emissão de regras (orientações por parte do terapeuta).

(3) Antecedente: o último comportamento do cliente ou terapeuta imediatamente anterior à emissão de orientação e auto-orientação.

(4) Comportamento: Nesta pesquisa analisou-se o comportamento de terapeutas de emitirem orientação e o comportamento de clientes de emitirem auto-orientação.

(5) Consequente: comportamento do cliente ou terapeuta imediatamente após a emissão de orientação/auto-orientação.

O exemplo apresentado a seguir ilustra um episódio de orientação em que foram identificados os cinco elementos apresentados acima como componentes da análise de contingências. 
Exemplo de episódio de orientação:

32C: fora o calor, tá tudo certo, ando me sentindo mais ou menos bem, pois a enxaqueca diminuiu consideravelmente de frequência.... Ai... ai... Ah!... (suspiro profundo) Ahm... Enrolei até agora, mas tenho que te contar uma coisa... Tô meio nervosa, mas vamos lá (risos)

32T: Pode falar...

33C: Fiz uma coisa que provavelmente você não irá gostar... ou não (risos). Preciso te dizer que anda acontecendo... Andei ligando pro W... (riso nervoso)

33T: É mesmo?(surpreso)... Quando você ligou pra ele?

34C: Ontem....(suspiro profundo). Então... Na quinta-feira vim aqui, conversamos $e$ fiquei mais consciente (risos). Mas com o passar do tempo parece que vou enfraquecendo... Nesta quarta-feira acordei com a ideia fixa de falar com meu ex. Aí fui trabalhar e tentar me distrair. Mas sabe aqueles dias onde o mundo resolve te estressar e te contrariar... Só sei que quando eu vi já tinha ligado pra ele... Aí pensei pra variar fiz o que não devia... Ligar pra quê?

34T: Uhm... uhm... Sei! Mas o que foi que aconteceu?Ou melhor, por que você ligou pra ele? Por que você acha que isso aconteceu?

35C: Calma... Vou te explicar por partes... Sempre tem um porque né... (risos)... Tudo começou com a minha chefe... Ela é fogo... Uma beleza (ironicamente)... Enfim, briguei com a minha chefe por conta de um memorando, e ela no meio da briga me chamou de mal amada! Mal amada eu!Quem é ela pra falar isso... Aí eu pensei a culpa é minha... Que eu fico falando pra todo mundo o que meu ex-marido me fez, que ele me trocou por uma ninfetinha mais magra... Até o porteiro do prédio que trabalho sabe disso... Ninguém manda ter boca grande... Mas as pessoas são ruins, na hora que briga, vira e usa o que você falou como arma contra você... Enfim, só sei que fiquei chateada, saí do trabalho com vontade de matar um... Quando tô indo pra casa, uma pessoa vomita no meu pé no metrô...

35T: Nossa!

36C: só sei que saí do metrô chorando, passei na padaria e não tinha a bomba de chocolate que eu queria... Cheguei em casa tomei banho e fui pra frente da TV, morta de fome e raiva... Nisso começo a ver a novela... E o mocinho todo romântico... Num impulso catei o telefone e liguei pro $W$.

36T: Ahm... E aí como foi?

37C: Vou te contar o que rolou... Bom, ele atendeu ao telefone e logo foi perguntando do filho. Eu respondi que tava tudo bem e que ele estava na avó. Aí então ele me responde: que bom, então diga, o que você quer? Eu fiquei meio gaga, e ele já se antecipou... Ah só bater papo e começou com aquelas perguntinhas que me irritam: Você está bem? E o trabalho? Tá se cuidando! Até aí eu fui respondendo, Vai quando eu fiz as mesmas perguntas, ele disse que tava ótimo, que tinha sido promovido e assim por diante... Eu comecei a ficar muito brava, mas isso 
é ilógico porque quem perguntou fui eu e ele só respondeu, não é? Enfim, acho que tudo isso aconteceu por uma soma de coisas. Acho que a minha chefe extrapolou, me levou ao limite e depois o que me aconteceu no metrô, foi pra acabar... Acho que essa série de porcarias me deixaram mais sensível e por isso eu liguei.

37T: Bom e depois de ter feito a ligação... O que aconteceu? Ou melhor, como você lidou com isso?

38C: Então parece que eu preciso fazer besteiras pra perceber algumas coisas. Vejo que não lido bem com situações onde sou contrariada... E isto vai da minha chefe até o W.... Depois de desligar, chorei, enviei mensagens pedindo pra voltar, xinguei e tudo mais.

38T: E como você avalia seu comportamento? Como isso ficou pra você?

39C: Ahm...é como eu te disse acho que me comportei mal, que recaí, mas é tão difícil né... Eu ainda me descontrolo...

39T: É ainda difícil pra você falar com ele né... Mas me diga... Como você se sentiu ao ligar? Valeu a pena falar com ele, apesar dos pesares?

40C: Ahm...Não gostei de falar com ele não... E ainda de quebra não me senti nada bem... Na hora que desliguei o telefone, percebi que tinha 'recaído' e feito tudo errado. Me senti muito mal, chorei... E ainda fiquei deprimida. Não é desta forma que quero a atenção dele... Depois de um tempo, comecei a pensar, pensar e não me senti mais mal, conclui que isso só aconteceu, pois minha chefe me levou à loucura e meu dia foi uma lástima...

40T: Peraí... Devagar nessa hora... (risos). Você mesmo me disse que já vinha pensando em ligar pra ele naquele dia pela manhã. Concordo com você que seu dia não foi dos melhores... Agora dizer que um dia ruim te levou a ligar pra ele e falar o que você falou já não é verdade, não é... Você está passando por uma série de coisas, mas o principal é que não parece ter assimilado bem o rompimento do casamento; e principalmente está comparando sua vida com a dele... Colocando tudo no mesmo balaio e as coisas que te acontecem e não te agradam você considera responsabilidade dele. Não é isso?

41C: Não sei... (silencio longo). Mas o dia ruim deu uma ajudadinha (riso nervoso) Ahm... (pausa longa)... Odeio quando você tem razão (risos) e você me fala as verdades de um jeito mansinho... (riso nervoso).

41T: Mas me diga, você provavelmente passará por outras situações semelhantes... o que quero dizer é que, provavelmente, ainda doerá o fim do casamento e provavelmente terá dias estressantes no trabalho! O que queria dizer é: como você provavelmente pretende lidar com isso?

42C: Boa pergunta (risos).. (pausa longa). Olha... (suspiros). Vou te contar a minha vontade agora. Juntar o telefone e falar horrores pra ele pra nova esposa dele. Quanto à minha chefe, quero que ela se exploda... Odeio cargos de confiança. Mas 
sei que essa não é a melhor forma de se resolver esta situação, mas é assim que acabo agindo.

(20T: É complicado mesmo, mas sabendo como fatores estressantes do dia-a-dia te abalam, “quero que você pense nesta semana em estratégias de como lidar com essa situação, ok. Pode ser?” (Orientação para Encoberto) em seu comportamento com seu ex) Então a festa vai estar ótima, não sei se vou... 44T: É... a festa é grande né... 
Todos os elementos que compunham a análise de contingências foram analisados.

O primeiro passo realizado quanto à (1) Narrativa do cliente anterior à intervenção do terapeuta foi a verificação da ocorrência/não ocorrência das narrativas nos episódios de orientação e auto-orientação. Os episódios de $\mathrm{O} / \mathrm{AO}$ dos terapeutas experientes e pouco experientes foram separados e comparou-se a ocorrência/não ocorrência de narrativa dos clientes nos episódios de orientação e auto-orientação.

Durante as narrativas dos clientes, terapeutas aparentemente fazem algumas intervenções. Para verificar se realmente havia (2) Intervenções que antecediam a emissão de orientação/auto-orientação, todo o episódio foi relido. Anotou-se a ocorrência/não ocorrência dessas intervenções.

Após a verificação da presença das intervenções que antecediam a emissão de orientação/auto-orientação, analisou-se quais as intervenções eram mais frequentes. Para isso, utilizou-se uma adaptação das 'categorias de comportamento verbal vocal do terapeuta' de Zamignani e Meyer (2007) e calculou-se o número médio ${ }^{9}$ e a frequência relativa percentil de cada categoria. Análises estatísticas foram realizadas posteriormente (teste de igualdade de duas proporções). Nesta adaptação apenas a categoria recomendação (ou orientação) foi removida uma vez que o enfoque nesta análise era o comportamento do terapeuta após a narrativa do cliente e anterior à orientação ou auto-orientação (para melhor compreensão das categorias sugere-se consultar Sistema multidimensional de categorização de comportamentos da interação terapêutica de Zamignani e Meyer, 2007). A tabela a seguir apresenta de forma

\footnotetext{
${ }^{9}$ O número médio da cada categoria de intervenção dos diferentes terapeutas foi calculado dividindo-se a ocorrência total de cada categoria de intervenção por nove (terapeutas). Para que fosse possível a comparação entre os terapeutas experientes e pouco experientes, calculou-se o número médio de ocorrências de cada categoria de intervenção dos terapeutas experientes e pouco experientes. No caso dos terapeutas pouco experientes cada ocorrência total de categoria de intervenção foi dividida por seis (terapeutas) e no caso dos terapeutas experientes foi dividida por três (terapeutas).
} 
resumida e adaptada, as categorias de comportamento verbal vocal do terapeuta elaboradas por Zamignani e Meyer (2007) com exemplos retirados da presente pesquisa.

Tabela 9 - Adaptação das categorias de comportamento verbal vocal do terapeuta de Zamignani e Meyer (2007) e exemplos

\section{Definição da categoria verbal vocal do terapeuta $\quad$ Exemplos}

1. Solicitação de relato: Contempla verbalizações do Ex1: "O que gostaria que você descrevesse terapeuta nas quais ele solicita ao cliente descrições a melhor é o porquê não falou nada, não reagiu à respeito de ações, eventos, sentimentos ou provocação do seu chefe..."

pensamentos.

2. Facilitação: É caracterizada por verbalizações Ex1: "Hum... hum... Sei."

curtas ou expressões paralinguísticas que ocorrem durante a fala do cliente. Tipicamente, estas verbalizações indicam atenção ao relato do cliente e sugerem sua continuidade.

3. Empatia: Contempla ações ou verbalizações do Ex1: “... Realmente você tem razão... Seu terapeuta que sugerem acolhimento, aceitação, chefe está passando dos limites...”

cuidado, entendimento, validação da experiência ou sentimento do cliente.

4. Informação: Contempla verbalizações nas quais o terapeuta relata eventos ou informa o cliente sobre eventos (que não o comportamento do cliente ou de terceiros), estabelecendo ou não relações causais ou explicativas entre eles.

5. Solicitação de reflexão: Contempla verbalizações nas quais o terapeuta solicita ao cliente qualificações, explicações, interpretações, análises ou previsões a respeito de qualquer tipo de evento. $\mathrm{O}$ terapeuta solicita que o cliente analise ou estabeleça relações entre os eventos em discussão.

6. Interpretação: Contempla verbalizações nas quais o terapeuta descreve, supõe ou infere relações causais e/ou explicativas (funcionais, correlacionais, ou de contiguidade) a respeito do comportamento do cliente ou de terceiros, ou identifica padrões de interação do cliente e/ou de terceiros.

7. Aprovação: Contempla verbalizações do terapeuta Ex1: "Muito bem, A. Acho que você que sugerem avaliação ou julgamentos favoráveis a conseguiu de forma sucinta mostrar seu ponto respeito de ações, pensamentos, características ou de vista para seu marido..."

avaliações do cliente. Verbalizações de aprovação dirigem-se a ações ou características específicas do cliente e pressupõem o terapeuta como alguém que pode selecionar e fortalecer aspectos de seu comportamento que seriam mais ou menos apropriados.

8. Reprovação: Contempla verbalizações do terapeuta Ex1: "A vida é feita de escolhas... Você pode que sugerem avaliação ou julgamento desfavorável a continuar casada e infeliz... Há muitas pessoas respeito de ações, pensamentos, características que preferem ter o status do casamento a específicas do cliente e pressupõem o terapeuta como enfrentar a vida e tentar ser feliz... São alguém que pode selecionar e fortalecer aspectos de escolhas."

seu comportamento que seriam mais ou menos apropriados. de um antidepressivo não é imediata... O organismo precisa de no mínimo 15 dias..."

Ex1: "Você está me dizendo que algumas coisas te irritam em seu chefe, você já observou quais aspectos em si fazem com que ele aja de uma forma ou outra e qual sua participação nisso... Sei lá..."

Ex1: "Toda vez que você força um encontro com seu ex, sai deste encontro mais machucada do que antes, não é?" 


\begin{tabular}{|l|l|}
\hline $\begin{array}{l}\text { 9. Outras verbalizações do terapeuta: Esta categoria } \\
\text { inclui verbalizações do terapeuta não classificáveis } \\
\text { nas categorias anteriores. }\end{array}$ & $\begin{array}{l}\text { Ex1: "O problema de atender aqui a noite é o } \\
\text { barulho de escola de samba, avião... Tem que } \\
\text { rir pra não chorar." }\end{array}$ \\
\hline $\begin{array}{l}\text { 10. Terapeuta permanece em silêncio: Esta } \\
\text { categoria deve ser selecionada quando uma resposta } \\
\begin{array}{l}\text { verbal do terapeuta é encerrada sem que uma nova } \\
\text { resposta verbal do mesmo falante seja iniciada. }\end{array}\end{array}$ & $\begin{array}{l}\text { Essa categoria relaciona-se à ausência de } \\
\text { intervenções do terapeuta antes do episódio de } \\
\text { orientação. }\end{array}$ \\
\hline
\end{tabular}

Para a análise dos (c) antecedentes, contou-se o número de ocorrências/não ocorrências dos antecedentes nos episódios de orientação/auto-orientação. Em seguida, utilizou-se uma adaptação das 'categorias de comportamento verbal vocal dos clientes' de Zamignani e Meyer (2007). Nesta adaptação, a única alteração foi na categoria metas, na qual foi incluída a auto-orientação (para melhor compreensão das categorias sugere-se consultar Sistema multidimensional de categorização de comportamento da interação terapêutica de Zamignani e Meyer, 2007). Calculou-se o número médio e a frequência relativa percentil de cada categoria. Análises estatísticas foram realizadas posteriormente (teste de igualdade de duas proporções). A tabela a seguir apresenta, de forma resumida e adaptada, as categorias de comportamento verbal vocal do cliente elaborada por Zamignani e Meyer (2007) com exemplos retirados da presente pesquisa.

Tabela 10 - Adaptação das categorias de comportamento verbal vocal do cliente de Zamignani e Meyer (2007) e exemplos

\begin{tabular}{|c|c|}
\hline Definição da categoria verbal vocal do cliente & Exemplos \\
\hline $\begin{array}{l}\text { 1. Solicitação: É caracterizada por verbalizações nas } \\
\text { quais o cliente apresenta pedidos ou questões ao } \\
\text { terapeuta. }\end{array}$ & $\begin{array}{l}\text { Ex1: "O que você quer dizer com isso... Acho } \\
\text { que não entendi a diferença entre salário } \\
\text { líquido e bruto e a relação com meu salário..." }\end{array}$ \\
\hline $\begin{array}{l}\text { 2. Relato: Contempla verbalizações nas quais o } \\
\text { cliente descreve ou informa ao terapeuta a ocorrência } \\
\text { de eventos, ou aspectos relativos a eventos, respostas } \\
\text { emocionais suas ou de terceiros, seus estados } \\
\text { motivacionais e/ou tendências a ações, sem } \\
\text { estabelecer relações causais ou funcionais entre eles. }\end{array}$ & $\begin{array}{l}\text { Ex1: "Ah tá... Vou explicar, desculpe tem } \\
\text { horas que me esqueço de dizer os detalhes... } \\
\text { Voltando... Estava saindo de casa..." Ex2: } \\
\text { "Acho que não tinha nada que falar pra ele no } \\
\text { primeiro encontro sobre minhas dificuldades } \\
\text { financeiras... Depois fiquei pensando que o } \\
\text { cara vai achar que sou endividada." }\end{array}$ \\
\hline $\begin{array}{l}\text { 3. Melhora: É caracterizada por verbalizações nas } \\
\text { quais o cliente relata mudanças satisfatórias quanto à } \\
\text { sua queixa clínica, problemas médicos, } \\
\text { comportamentos relacionados à sua queixa, ou } \\
\text { comportamentos considerados pelo cliente ou pelo } \\
\text { terapeuta como indesejáveis ou inadequados } \\
\text { (independentemente da concordância de ambos }\end{array}$ & $\begin{array}{l}\text { Ex1: "To bem feliz com nossa terapia. Hoje já } \\
\text { consigo sair de casa sem ajuda de ninguém... } \\
\text { Isso significa bastante para mim..." }\end{array}$ \\
\hline
\end{tabular}




\begin{tabular}{|c|c|}
\hline quanto à melhora). & \\
\hline $\begin{array}{l}\text { 4. Metas: Contempla verbalizações dos clientes nas } \\
\text { quais ele descreve seus projetos, planos ou estratégias } \\
\text { para a solução de problemas trazidos como queixas } \\
\text { para a terapia. Incluem-se aqui as auto-orientações. }\end{array}$ & $\begin{array}{l}\text { Ex1: "Na próxima vez que minha mãe falar } \\
\text { isso... vou apontar pra ela os pontos positivos } \\
\text { do meu trabalho (AOAE)." Ex2: "Vou } \\
\text { conseguir arrumar um trabalho, aguarde e } \\
\text { confira." }\end{array}$ \\
\hline $\begin{array}{l}\text { 5. Relações: É caracterizada por verbalizações, nas } \\
\text { quais o cliente estabelece relações causais e /ou } \\
\text { explicativas (funcionais, correlacionais ou de } \\
\text { contiguidade) entre eventos, descrevendo-as de forma } \\
\text { explícita ou sugerindo por meio de metáforas ou } \\
\text { analogias. }\end{array}$ & $\begin{array}{l}\text { Ex1: "Talvez esse namoro não seja tão ruim } \\
\text { assim... Afinal, faz anos que ele me garante } \\
\text { financeiramente, também não custa eu engolir } \\
\text { alguns sapinhos... risos." Ex2: "Acho que agi } \\
\text { adequadamente quando expliquei pra ele o que } \\
\text { penso sobre cuidados excessivos com animais, } \\
\text { por outro lado não há lógica alguma em me } \\
\text { submeter a isso..." Ex3: "Engolir tudo como } \\
\text { fiz, só me trouxe problemas, estresse e nenhum } \\
\text { benefício. Nada anda bem, só enfrento } \\
\text { problemas... Coisas boas, jamais..." }\end{array}$ \\
\hline $\begin{array}{l}\text { 6. Concordância: É caracterizada por verbalizações } \\
\text { nas quais o cliente expressa julgamento ou avaliação } \\
\text { favoráveis a respeito de afirmações, sugestões, } \\
\text { análises ou outros comportamentos emitidos pelo } \\
\text { terapeuta ou relata satisfação, esperança ou confiança } \\
\text { no terapeuta e/ou no processo terapêutico. Inclui } \\
\text { também verbalizações nas quais o cliente } \\
\text { complementa ou resume a fala do terapeuta, ou } \\
\text { episódios nos quais o cliente sorri em concordância } \\
\text { com o terapeuta. }\end{array}$ & $\begin{array}{l}\text { Ex1: "Concordo com o que você acabou de } \\
\text { dizer. Você conseguiu me entender } \\
\text { perfeitamente!" }\end{array}$ \\
\hline $\begin{array}{l}\text { 7. Oposição: É caracterizada por verbalizações nas } \\
\text { quais o cliente expressa discordância, julgamento ou } \\
\text { avaliação desfavoráveis a respeito de afirmações, } \\
\text { sugestões, análise ou outros comportamentos emitidos } \\
\text { pelo terapeuta. }\end{array}$ & $\begin{array}{l}\text { Ex1: "Não, não, não... Não é nada disso. Acho } \\
\text { que você não tá querendo entender minhas } \\
\text { limitações." Ex2: "Mas eu faço isso que você } \\
\text { falou, só que não acho que tem o resultado } \\
\text { esperado." Ex3: "Acho que não rola eu falar o } \\
\text { que penso pro meu chefe, até porque se não } \\
\text { falo também não preciso me preocupar com } \\
\text { possíveis mudanças e arcar com as } \\
\text { consequências boas e ruins... Ele é genioso... } \\
\text { Eu também não sou santa..." Ex.: "É difícil } \\
\text { mesmo (se referindo ao estabelecimento de } \\
\text { relações feito pelo terapeuta)... Deixa eu te } \\
\text { contar da minha vizinha louca" (mudança de } \\
\text { assunto). }\end{array}$ \\
\hline $\begin{array}{l}\text { 8. Outras verbalizações do cliente: } \\
\text { verbalizações não classificáveis nas catempla } \\
\text { anteriores. Inclui também verbalizações do cliente ao } \\
\text { cumprimentar o terapeuta em sua chegada ou partida, } \\
\text { anúncios de interrupções ou comentários alheios ao } \\
\text { tema em discussão. }\end{array}$ & $\begin{array}{l}\text { Ex1: (barulho estridente)... Nossa que susto... } \\
\text { Acho que caiu um lenço (risos). Ex.: "Aí ele } \\
\text { chegou... Meu deus, estão matando a criança na } \\
\text { sala ao lado (risos), desculpe... Eu tava dizendo } \\
\text { que.. Risos... Como crianças choram, não?" }\end{array}$ \\
\hline $\begin{array}{l}\text { 9. Cliente permanece em silêncio: Esta categoria } \\
\text { deve ser selecionada quando uma resposta verbal do } \\
\text { cliente é encerrada sem que uma nova resposta verbal } \\
\text { do mesmo falante seja iniciada. }\end{array}$ & $\begin{array}{l}\text { Após a intervenção do terapeuta, cliente não } \\
\text { emite nenhuma resposta antes da orientação do } \\
\text { terapeuta. }\end{array}$ \\
\hline
\end{tabular}


Para a análise do comportamento de orientação e auto-orientação as sessões foram recategorizadas, e comparadas à categorização realizada no estudo de Donadone (2004). O teste estatístico de igualdade de duas proporções foi realizado possibilitando a verificação de perda entre as categorias nos diferentes momentos (pesquisa de mestrado e de doutorado), ou seja, verificou-se a porcentagem de categorias que não foram possíveis de serem identificadas (ou encontradas) na atual pesquisa.

Calculou-se também o índice de concordância de Kappa para medir o grau de concordância das categorizações realizadas no estudo de 2004 e no presente estudo. Para complementar a análise de concordância via índice Kappa, utilizou-se a técnica de Intervalo de confiança. Tal técnica é extremamente útil, pois permite observar quando a média pode variar numa determinada probabilidade de confiança.

Para a pesquisa de mestrado foram criados quatro subtipos de orientações, pois estudos experimentais indicam que diferentes características de orientações podem produzir diferentes resultados (Donadone, 2004). Estes foram: orientações ou autoorientações para ação específica (OAE e AOAE), ação genérica (OAG e AOAG), tarefa (OT e AOT) e encobertos (OE e AOE). Na categorização feita para o mestrado não foi encontrado nenhum caso de auto-orientação para tarefa (AOT) e este dado foi confirmado na categorização realizada no doutorado. A Tabela 11 apresenta a definição de cada subtipo de orientação e auto-orientação e seus respectivos exemplos.

Tabela 11 - Definição de orientação e auto-orientação e seus respectivos exemplos

\begin{tabular}{|l|l|}
\hline \multicolumn{1}{|c|}{ Definição } & \multicolumn{1}{|c|}{ Exemplo } \\
\hline $\begin{array}{l}\text { Por orientação para ação específica (OAE) } \\
\text { entendeu-se a orientação para que o cliente se } \\
\text { comportasse da forma indicada em seu cotidiano com } \\
\text { especificação da topografia do comportamento a ser } \\
\text { desenvolvido. }\end{array}$ & $\begin{array}{l}\text { quer ir à festa do banco...” o seu marido que não } \\
\end{array}$ \\
\hline
\end{tabular}


Por orientação para ação genérica (OAG)|Ex1: “... Mas enfim, faça coisas que você entendeu-se a orientação para que o cliente se goste, tente estar sempre, cada vez mais comportasse da forma indicada em seu cotidiano, recheando a tua vida de coisas legais." (OAG) porém não indicando a ação que deveria ser executada, e sim qual o resultado a ser atingido com qualquer topografia de comportamento.

Por orientação para encobertos (OE) entendeu-se como uma recomendação para que o cliente refletisse sobre um tema proposto ou observasse suas ações e pensamentos.

Por orientação para tarefa (OT), entendeu-se a orientação para que o cliente executasse uma tarefa terapêutica.

Ex1: "Não seria interessante você pensar nas implicações que teria ao contar ou não contar o que aconteceu para o seu noivo?” (OE)

Ex1: "Vamos tentar descobrir o que pode estar provocando as suas dores de cabeça. Para isso, anote durante a semana as coisas que aconteceram nos dias em que você sentir essas dores." (OT)

Por auto-orientação para ação específica (AOAE) entendeu-se a auto-orientação feita pelo próprio cliente para que se comportasse da forma indicada em seu cotidiano com especificação da topografia do comportamento a ser desenvolvido.

Por auto-orientação para ação genérica (AOAG) entendeu-se a auto-orientação feita pelo próprio cliente para que se comportasse da forma indicada em seu cotidiano, porém não indicando a ação que deveria ser executada, e sim qual o resultado a ser atingido com qualquer topografia de comportamento.

Ex1: "Vou fazer assim... Não vou responder a emails, nem a mensagens dele esta semana, $e$ pior que eu sei que vai ser difícil, mas preciso me posicionar." (AOAE)

Ex1: "Eu ainda não sei como exatamente vou fazer, só sei que a partir de hoje vou assumir as rédeas de minha vida, e começar a me impor." (AOAG)

Por auto-orientação para encobertos (AOE) entendeu-se como uma recomendação feita pelo próprio cliente para que refletisse sobre um tema proposto ou observasse suas ações e pensamentos.

Ex1: "Acho que vou pensar esta semana seriamente sobre que rumo quero tomar em minha vida, pois preciso definir algumas coisas... (risos), depois te conto..." (AOE)

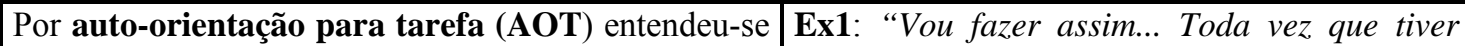
a auto-orientação emitida pelo próprio cliente para que executasse uma tarefa terapêutica.

pesadelos, vou anotar... Não só o pesadelo, mas o que eu fiz antes de dormir e o que aconteceu depois. Vai ficar mais fácil pra mim na hora que for te contar, tá bom?" (AOT)

Com base na definição dos diferentes subtipos de orientação e auto-orientação e após confirmação das ocorrências dos diferentes subtipos de orientação e autoorientação, comparou-se dentro do total de orientações e auto-orientações dos terapeutas experientes e pouco experientes, qual seria a distribuição de frequência relativa percentil por terapeuta.

Esta comparação foi realizada em um primeiro momento entre terapeutas experientes versus terapeutas pouco experientes e em um segundo momento a 
comparação da emissão dos diferentes subtipos de orientação/auto-orientação foi feita entre terapeutas, independente de experiência.

Através da leitura de todas as orientações e auto-orientações emitidas pelos diferentes terapeutas, regularidades gerais e específicas para cada subtipo de orientação e auto-orientação foram procuradas e, caso encontradas, foram anotadas.

A leitura do conteúdo das orientações e auto-orientações indicou que estas podiam ou não ser semelhantes em seu conteúdo explícito e em sua função ${ }^{10}$.

Duas situações foram encontradas: 1) as orientações emitidas pelos terapeutas (ou auto-orientações emitidas pelos clientes) eram diferentes tanto em seu conteúdo explicito como em sua função; e 2) as orientações/auto-orientações emitidas eram diferentes em seu conteúdo explícito, porém similares em sua função conforme a Tabela 12.

Tabela 12 - Exemplos de orientações e auto-orientações, enfatizando conteúdo explícito e função

\begin{tabular}{|c|c|}
\hline $\begin{array}{l}\text { Conteúdo e função das orientações e auto- } \\
\text { orientações }\end{array}$ & Exemplos \\
\hline $\begin{array}{l}\text { (1) As orientações emitidas pelos terapeutas são } \\
\text { diferentes tanto em seu conteúdo explícito como } \\
\text { em sua função. }\end{array}$ & $\begin{array}{l}\text { Em uma sessão o terapeuta pode emitir as } \\
\text { seguintes orientações para seu cliente em } \\
\text { momentos diferentes: } \\
\text { Ex1: "Tente falar para o seu marido que não quer } \\
\text { ir à casa da tia dele..." (OAE); Ex2: "Vamos } \\
\text { tentar descobrir o que pode estar provocando as } \\
\text { suas dores de cabeça. Para isso, anote durante a } \\
\text { semana as coisas que aconteceram nos dias em } \\
\text { que você sentir essas dores." (OT) }\end{array}$ \\
\hline $\begin{array}{l}\text { (2) As orientações emitidas são diferentes em seu } \\
\text { conteúdo explícito, porém similares em sua } \\
\text { função. }\end{array}$ & $\begin{array}{l}\text { Em uma sessão o terapeuta pode emitir as } \\
\text { seguintes orientações para seu cliente em } \\
\text { momentos diferentes: } \\
\text { Ex1: "Converse com sua mãe sobre o que vocêe } \\
\text { acha da postura dela, tente dizer a ela de forma } \\
\text { clara o que a incomoda... Ela só saberá o que a } \\
\text { incomoda se você se impor, falar... Pense } \\
\text { nisso!"(OE) Ex2: "Sua tarefa essa semana é falar } \\
\text { ao seu chefe todas as coisas que você fez neste } \\
\text { último projeto, ok?" (OT) }\end{array}$ \\
\hline $\begin{array}{l}\text { (3) As auto-orientações emitidas pelos clientes são } \\
\text { diferentes tanto em seu conteúdo explícito como } \\
\text { em sua função. }\end{array}$ & $\begin{array}{ll}\text { Em uma sessão o cliente } & \text { pode emitir as } \\
\text { seguintes } & \begin{array}{l}\text { auto-orientações } \\
\text { em momentos } \\
\text { diferentes: }\end{array}\end{array}$ \\
\hline
\end{tabular}

\footnotetext{
${ }^{10}$ Função: efeito de uma contingência.
} 


\begin{tabular}{|l|l|}
\hline & $\begin{array}{l}\text { Ex1: “A partir de hoje não vou mais beber... Isso } \\
\text { tá me trazendo muitos problemas e não tem razão } \\
\text { pra eu ficar bebendo." (AOAE) Ex2:" Tenho que } \\
\text { expor minha opinião quando o assunto for filhos." } \\
\text { (AOAG) }\end{array}$ \\
\hline $\begin{array}{l}\text { (4) As auto-orientações emitidas são diferentes em } \\
\text { seu conteúdo explícito, porém similares em sua } \\
\text { função. }\end{array}$ & $\begin{array}{l}\text { Em uma sessão o cliente pode emitir as } \\
\text { seguintes auto-orientações em momentos } \\
\text { diferentes: } \\
\text { Ex1: “Acho que já posso sair de casa sem minha } \\
\text { mãe... Vou tentar fazer isso esta semana.” } \\
\text { (AOAE) Ex2: "Vou pensar esta semana em como } \\
\text { parar de fugir dos meus medos e me expor." } \\
\text { (AOE) }\end{array}$ \\
\hline
\end{tabular}

Na Tabela 12 no Ex1 de (1) 'orientações diferentes em seu conteúdo explícito e função’ o terapeuta está trabalhando funcionalmente com a assertividade do cliente e no Ex2, o terapeuta está trabalhando com questões fisiológicas. Tanto no Ex1 como no Ex2 o conteúdo da resposta é diferente. Para (2) 'orientações diferentes em seu conteúdo explícito, mas similares em função', observa-se que tanto o Ex1 como o Ex2 são diferentes no conteúdo, mas similares na função. Funcionalmente nos dois exemplos o terapeuta está trabalhando com assertividade.

O mesmo foi observado no caso da auto-orientação. Assim para (3) 'autoorientações diferentes em seu conteúdo explícito e função’ no Ex1 o cliente está funcionalmente se auto-orientando quanto a seus vícios e no Ex2 o cliente está funcionalmente se auto-orientando quanto à sua assertividade. Tanto no Ex1 como no Ex2 o conteúdo da resposta é diferente. Para (4) 'auto-orientações diferentes em seu conteúdo explícito, mas similares em função' funcionalmente nos dois exemplos o cliente está emitindo autorregras com a mesma função, o enfrentamento de seus medos.

Após a diferenciação entre conteúdo explícito e função a ser definida, todas as orientações e auto-orientações emitidas (Ex.: todas as orientações emitidas pelo TED para o C1TED e todas as auto-orientações emitidas por este cliente) foram lidas e foi verificado se havia diferenças no conteúdo explícito e na função das orientações e auto- 
orientações. Compararam-se posteriormente a ocorrência de orientações com diferentes conteudos e funções dos terapeutas experientes e dos terapeutas pouco experientes. Realizou-se também a comparação da ocorrência (quanto ao conteúdo explícito e função) entre as auto-orientações emitidas pelos clientes dos terapeutas experientes e pelos clientes dos terapeutas pouco experientes.

$\mathrm{Na}$ análise do (e) consequente, os episódios de orientação/auto-orientação foram relidos e foi anotada a ocorrência/não ocorrência de consequentes após a emissão de orientação/auto-orientação. Após a verificação geral da existência do consequente após a emissão de orientação/auto-orientação, separaram-se os episódios de orientação/autoorientação dos terapeutas experientes e pouco experientes e realizou-se a comparação entre eles.

Em seguida, desenvolveram-se categorias de consequentes, compostas da adaptação de algumas 'categorias do comportamento verbal vocal do terapeuta e do cliente' de Zamignani e Meyer (2007). Para melhor compreensão das categorias, sugere-se consultar Sistema multidimensional de categorização de comportamentos da interação terapêutica dos autores citados acima. Calculou-se o número médio e a frequência relativa percentil de cada categoria de consequente nos episódios de orientação. Análises estatísticas foram realizadas posteriormente (teste de igualdade de duas proporções).

A tabela a seguir apresenta as definições dos consequentes ao comportamento de orientar encontrados, assim como exemplos retirados da presente pesquisa.

Tabela 13 - Categorias de consequentes ao comportamento de orientar, adaptadas das categorias de comportamento verbal vocal do terapeuta e do cliente (Zamignani e Meyer, 2007) e exemplos

\begin{tabular}{|c|c|c|}
\hline & Consequentes encontrados & Exemplos \\
\hline & $\begin{array}{l}\text { 1. Solicitação: É caracterizada por verbalizações nas } \\
\text { quais o cliente apresenta pedidos ou questões ao } \\
\text { terapeuta. }\end{array}$ & $\begin{array}{l}\text { Ex1: "O que seria um acompanhante } \\
\text { terapêutico. Preciso entender melhor } \\
\text { isso." }\end{array}$ \\
\hline
\end{tabular}




\begin{tabular}{|c|c|c|}
\hline & $\begin{array}{l}\text { 2. Relato: Contempla verbalizações nas quais o cliente } \\
\text { descreve ou informa ao terapeuta a ocorrência de } \\
\text { eventos, ou aspectos relativos a eventos, respostas } \\
\text { emocionais suas ou de terceiros, seus estados } \\
\text { motivacionais e/ou tendências a ações, sem estabelecer } \\
\text { relações causais ou funcionais entre eles. }\end{array}$ & $\begin{array}{l}\text { Ex1: "Só pra você entender melhor... } \\
\text { Tomo esse medicamento há dois anos... E } \\
\text { antes tomava homeopatia." }\end{array}$ \\
\hline & $\begin{array}{l}\text { 3. Concordância: É caracterizada por verbalizações } \\
\text { nas quais o cliente expressa julgamento ou avaliação } \\
\text { favoráveis a respeito de afirmações, sugestões, análises } \\
\text { ou outros comportamentos emitidos pelo terapeuta ou } \\
\text { relata satisfação, esperança ou confiança no terapeuta } \\
\text { e/ou no processo terapêutico. Inclui também } \\
\text { verbalizações nas quais o cliente complementa ou } \\
\text { resume a fala do terapeuta ou episódios nos quais o } \\
\text { cliente sorri em concordância com o terapeuta. }\end{array}$ & $\begin{array}{l}\text { Ex1: "Exatamente... Concordo que não } \\
\text { dá pra ficar com as migalhas." }\end{array}$ \\
\hline & $\begin{array}{l}\text { 4. Oposição: É caracterizada por verbalizações nas } \\
\text { quais o cliente expressa discordância, julgamento ou } \\
\text { avaliação desfavoráveis a respeito de afirmações, } \\
\text { sugestões, análise ou outros comportamentos emitidos } \\
\text { pelo terapeuta. }\end{array}$ & $\begin{array}{l}\text { Ex.: "Você não tá me entendendo. Não } \\
\text { foi isso não." Ex2: "Acho que não } \\
\text { concordo com tudo o que disse, é fácil } \\
\text { você me dizer pra fazer assim ou assado, } \\
\text { mas você não tem noção o que é o meu } \\
\text { chefe... E eu tenho dificuldades de me } \\
\text { expor, sendo assim fico nessa..." Ex3: "... } \\
\text { não sei não, acho que já faço isso. Vivo } \\
\text { falando pra ele o que quero." }\end{array}$ \\
\hline & $\begin{array}{l}\text { 5. Cliente permanece em silêncio: Esta categoria } \\
\text { deve ser selecionada quando uma resposta verbal do } \\
\text { cliente é encerrada sem que uma nova resposta verbal } \\
\text { do mesmo falante seja iniciada. }\end{array}$ & $\begin{array}{l}\text { Cliente não responde nada após a } \\
\text { emissão de orientação. }\end{array}$ \\
\hline & $\begin{array}{l}\text { 6. Auto-orientaçoes: Contempla verbalizações dos } \\
\text { clientes nas quais ele descreve seus projetos, planos ou } \\
\text { estratégias para a solução de problemas trazidos como } \\
\text { queixas para a terapia. Zamignani (2007) nomeou essa } \\
\text { categoria como Meta. }\end{array}$ & $\begin{array}{l}\text { Ex1: "Você tem razão. Hoje vou chegar } \\
\text { em casa e colocar meu plano em } \\
\text { prática... De hoje não passa." }\end{array}$ \\
\hline 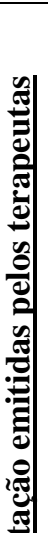 & $\begin{array}{l}\text { 7. Reprovação: Contempla verbalizações do terapeuta } \\
\text { que sugerem avaliação ou julgamento desfavorável a } \\
\text { respeito de ações, pensamentos, características } \\
\text { específicas do cliente e pressupõe o terapeuta como } \\
\text { alguém que pode selecionar e fortalecer aspectos de } \\
\text { seu comportamento que seriam mais ou menos } \\
\text { apropriados. }\end{array}$ & $\begin{array}{l}\text { Ex1: terapeuta emite uma orientação } \\
\text { ("Talvez se você falasse a verdade a ele } \\
\text { teria uma dupla vantagem: ser mais } \\
\text { confiável e não se sentir ansiosa por } \\
\text { mentir... Pense nisso, ok?") e logo em } \\
\text { seguida, como consequente a } \\
\text { orientação emitida, reprova o } \\
\text { comportamento do cliente que } \\
\text { provavelmente o levou a emitir a } \\
\text { orientação ("Agora, voltando ao que eu } \\
\text { tava te falando... Não posso concordar } \\
\text { com essa sua idéia de fingir uma } \\
\text { doença...") }\end{array}$ \\
\hline 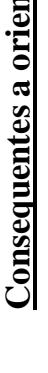 & $\begin{array}{l}\text { 8. Orientação: Contempla verbalizações nas quais o } \\
\text { terapeuta sugere alternativas de ação do cliente ou } \\
\text { solicita o seu engajamento em ações ou tarefas. Deve } \\
\text { ser utilizada quando o terapeuta especifica a resposta a } \\
\text { ser (ou não) emitida pelo cliente. A literatura refere-se } \\
\text { a essa categoria como aconselhamento, recomendação, } \\
\text { comando, ordem. }\end{array}$ & $\begin{array}{l}\text { Ex1: Após a emissão de uma } \\
\text { orientação, ("Além de impor limites ao } \\
\text { seu namorado; você deve essa semana } \\
\text { procurar um novo emprego, ok?"), } \\
\text { terapeuta consequencia esta orientação } \\
\text { com uma nova orientação ("Fora isso, } \\
\text { mudando de foco... essa semana você } \\
\text { deve ir ao ginecologista, não dá mais pra } \\
\text { adiar... vamos dona A... coragem...). }\end{array}$ \\
\hline
\end{tabular}


Análise similar foi feita com os consequentes da auto-orientação. Assim, a análise dos consequentes da auto-orientação foi feita a partir do desenvolvimento de categorias de consequentes compostas da adaptação de algumas 'categorias do comportamento verbal vocal do terapeuta e do cliente' de Zamignani e Meyer (2007). Calculou-se o número médio e a frequência relativa percentil por categoria de consequente nos episódios de auto-orientação. Análises estatísticas foram realizadas posteriormente (teste de igualdade de duas proporções).

Tabela 14 - Categorias de consequentes ao comportamento de auto-orientar, adaptadas das categorias de comportamento verbal vocal do terapeuta e do cliente (Zamignani e Meyer, 2007) e exemplos

\begin{tabular}{|c|c|c|}
\hline & Consequentes encontrados & Exemplos \\
\hline \multirow{4}{*}{ 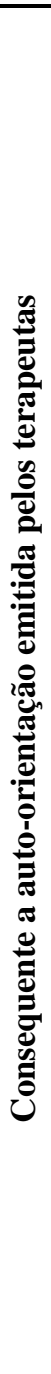 } & $\begin{array}{l}\text { 1. Facilitação: } \text { É caracterizada por } \\
\text { verbalizações curtas ou expressões } \\
\text { paralinguísticas do terapeuta que ocorrem } \\
\text { durante a fala do cliente. Tipicamente, estas } \\
\text { verbalizações indicam atenção ao relato do } \\
\text { cliente e sugerem sua continuidade. }\end{array}$ & Ex1: "Hu hu...sei, sei." \\
\hline & $\begin{array}{l}\text { 2. Solicitação de reflexão: Contempla } \\
\text { verbalizações nas quais o terapeuta solicita } \\
\text { ao cliente qualificações, explicações, } \\
\text { interpretações, análises ou previsões a } \\
\text { respeito de qualquer tipo de evento. O } \\
\text { terapeuta solicita que o cliente analise ou } \\
\text { estabeleça relações entre os eventos em } \\
\text { discussão. }\end{array}$ & $\begin{array}{l}\text { Ex1: "Você acaba de me dizer que vai lutar por } \\
\text { seus ideais, como por exemplo, mudar de emprego. } \\
\text { Quero saber como você pensa em fazer isso e quais } \\
\text { são seus novos ideais." }\end{array}$ \\
\hline & $\begin{array}{l}\text { 3. Interpretação: Contempla verbalizações } \\
\text { nas quais o terapeuta descreve, supõe ou } \\
\text { infere relações causais e/ou explicativas } \\
\text { (funcionais, correlacionais, ou de } \\
\text { contiguidade) a respeito do comportamento } \\
\text { do cliente ou de terceiros, ou identifica } \\
\text { padrões de interação do cliente e/ou de } \\
\text { terceiros. }\end{array}$ & $\begin{array}{l}\text { Ex1: “L. estávamos falando de seu trabalho e você } \\
\text { mudou de assunto e começou a falar do clube. É } \\
\text { difícil falar sobre o trabalho, né?" }\end{array}$ \\
\hline & $\begin{array}{l}\text { 4. Aprovação: Contempla verbalizações do } \\
\text { terapeuta que sugerem avaliação ou } \\
\text { julgamentos favoráveis a respeito de ações, } \\
\text { pensamentos, características ou avaliações } \\
\text { do cliente. Verbalizações de aprovação } \\
\text { dirigem-se a ações ou características } \\
\text { específicas do cliente e pressupõe o terapeuta } \\
\text { como alguém que pode selecionar e } \\
\text { fortalecer aspectos de seu comportamento } \\
\text { que seriam mais ou menos apropriados. }\end{array}$ & $\begin{array}{l}\text { Ex1: "Também acho que é o melhor a fazer. Diga o } \\
\text { que sente, pô!" Ex2: "Que legal te ver falando } \\
\text { assim M. Faça isso e coloque seus planos em ação. } \\
\text { Parabéns. Tô gostando de ver hein... (risos)". }\end{array}$ \\
\hline
\end{tabular}




\begin{tabular}{|c|c|c|}
\hline & $\begin{array}{l}\text { 5. Reprovação: Contempla verbalizações do } \\
\text { terapeuta que sugerem avaliação ou } \\
\text { julgamento desfavorável a respeito de ações, } \\
\text { pensamentos, características específicas do } \\
\text { cliente e pressupõe o terapeuta como alguém } \\
\text { que pode selecionar e fortalecer aspectos de } \\
\text { seu comportamento que seriam mais ou } \\
\text { menos apropriados. }\end{array}$ & $\begin{array}{l}\text { Ex1: "Não, não, não. Você está se contradizendo. } \\
\text { Não é isso que você quer fazer. Toda vez que você } \\
\text { faz barraco com ele na hora de pegar o filho, } \\
\text { depois você fica mal..." }\end{array}$ \\
\hline & $\begin{array}{l}\text { 6. Orientação: Contempla verbalizações nas } \\
\text { quais o terapeuta sugere alternativas de ação } \\
\text { do cliente ou solicita o seu engajamento em } \\
\text { ações ou tarefas. Deve ser utilizada quando o } \\
\text { terapeuta especifica a resposta a ser (ou não) } \\
\text { emitida pelo cliente. A literatura refere-se a } \\
\text { essa categoria como aconselhamento, } \\
\text { recomendação, comando, ordem. }\end{array}$ & $\begin{array}{l}\text { Ex1: "É isso aí. Vamos fazer o seguinte: anote em } \\
\text { um caderno toda vez que tiver essas dores de } \\
\text { cabeça." }\end{array}$ \\
\hline & $\begin{array}{l}\text { 7. Outras verbalizações do terapeuta: Esta } \\
\text { categoria inclui verbalizações do terapeuta } \\
\text { não classificáveis nas categorias anteriores. }\end{array}$ & $\begin{array}{l}\text { Ex1: "Legal. Mas vamos voltar à construção da } \\
\text { hierarquia de medos, senão não terminamos isso } \\
\text { hoje." }\end{array}$ \\
\hline & $\begin{array}{l}\text { 8. Terapeuta permanece em silêncio: Esta } \\
\text { categoria deve ser selecionada quando uma } \\
\text { resposta verbal do terapeuta é encerrada sem } \\
\text { que uma nova resposta verbal do mesmo } \\
\text { falante seja iniciada. }\end{array}$ & $\begin{array}{l}\text { Após a emissão de auto-orientação do cliente, } \\
\text { terapeuta não consequencia este comportamento } \\
\text { com nenhuma resposta. }\end{array}$ \\
\hline 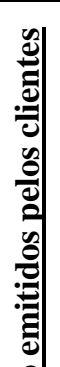 & $\begin{array}{l}\text { 9. Relato: Contempla verbalizações nas } \\
\text { quais o cliente descreve ou informa ao } \\
\text { terapeuta a ocorrência de eventos, ou } \\
\text { aspectos relativos a eventos, respostas } \\
\text { emocionais suas ou de terceiros, seus estados } \\
\text { motivacionais e/ou tendências a ações, sem } \\
\text { estabelecer relações causais ou funcionais } \\
\text { entre eles. }\end{array}$ & $\begin{array}{l}\text { Ex1: Após a emissão de auto-orientação ("Eu } \\
\text { não vou ficar sozinha... vou arrumar um parceiro... } \\
\text { esse é meu objetivo"), cliente consequencia a sua } \\
\text { própria auto-orientação descrevendo ou } \\
\text { informando sobre eventos ("Porque vou falar o } \\
\text { que sinto... Não sei se te contei, mas quando minha } \\
\text { mãe era viva, sempre dizia o que sentia e foi a } \\
\text { época mais feliz da minha vida... Naquela época foi } \\
\text { quando conheci o J."). }\end{array}$ \\
\hline 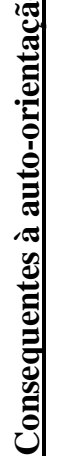 & $\begin{array}{l}\text { 10. Auto-orientação: } \\
\text { verbalizações do cliente nas quais ele } \\
\text { descreve seus projetos, planos ou estratégias } \\
\text { para a solução de problemas trazidos como } \\
\text { queixas para a terapia. Zamignani (2007) } \\
\text { nomeou essa categoria como Meta. }\end{array}$ & $\begin{array}{l}\text { Ex1: Após a emissão de uma auto-orientação } \\
\text { (“De hoje não passa, falarei o que penso sobre } \\
\text { comprar um carro novo ao meu marido"), cliente a } \\
\text { consequencia com a emissão de nova auto- } \\
\text { orientação ("Além de falar o que penso, essa } \\
\text { semana quero mudar meus filhos de escola e } \\
\text { procurar o advogado."). }\end{array}$ \\
\hline
\end{tabular}


2.4.5. Correlação entre escolaridade-orientação/auto-orientação; queixa-orientação/auto-orientação; perfil do cliente-orientação/auto-orientação; idade do cliente-orientação/auto-orientação; tempo de terapia-orientação/autoorientação e situação financeira-orientação/auto-orientação.

Para a realização das correlações entre escolaridade e orientação/autoorientação, organizou-se o grau de escolaridade dos clientes desta amostra em ordem crescente (da menor escolaridade para a maior). Em seguida, separou-se o número de orientações e auto-orientações recebidas e emitidas por cada cliente. O teste de correlação de Pearson foi utilizado então para medir o grau de relação entre a escolaridade do cliente e o número de orientações recebidas, assim como o número de auto-orientações emitidas.

Para a realização das correlações entre queixa e orientação/auto-orientação, organizaram-se as queixas em ordem crescente (da mais branda à mais severa). A construção hierárquica baseada na severidade dos casos foi feita a partir das respostas dos terapeutas ao questionário enviado a eles na pesquisas de mestrado, e a confirmação por meio de entrevistas presenciais com os terapeutas participantes assim como por meio da leitura das sessões. Em seguida, separou-se o número de orientações e autoorientações recebidas e emitidas por cada cliente. O teste de correlação de Pearson foi utilizado para medir o grau de relação entre a queixa do cliente e o número de orientações recebidas, assim como o número de auto-orientações emitidas.

Quanto às possíveis correlações entre o perfil ${ }^{11}$ dos clientes (Tabela 2 no método) e a emissão de orientação e auto-orientação, foram listados em ordem decrescente os clientes que mais receberam orientação e auto-orientação.

\footnotetext{
${ }^{11}$ No estudo de Donadone (2004), os terapeutas disponibilizaram algumas informações sobre os clientes participantes da pesquisa. Uma dessas informações referia-se ao perfil do cliente. Os clientes participantes apresentaram as seguintes possibilidades de perfis: motivado; cooperativo; cooperativo e motivado; motivado e resistente; desmotivado, resistente, desmotivado e resistente.
} 
Simultaneamente os perfis dos clientes foram agrupados em três grandes grupos: (1) clientes considerados cooperativos; motivados; cooperativos e motivados; (2) clientes considerados motivados e resistentes; e (3) clientes considerados resistentes; desmotivados; resistentes e desmotivados. Calculou-se a porcentagem de clientes considerados cooperativos/motivados; motivados e resistentes; e resistentes e desmotivados.

Em seguida realizou-se a análise estatística através do teste ANOVA. Por meio deste teste buscou-se observar se perfis de clientes estavam relacionados à maior emissão de orientação/auto-orientação e também se havia um subtipo de orientação/ auto-orientação mais característico dos diferentes perfis dos clientes.

Para a realização das correlações entre idade do cliente e orientação/autoorientação, identificaram-se as diferentes idades dos clientes. Em seguida, separou-se o número de orientações e auto-orientações recebidas e emitidas por cada cliente. O teste de correlação de Pearson foi utilizado para medir o grau de relação entre a idade do cliente e o número de orientações recebidas, assim como o número de auto-orientações emitidas.

Já para a correlação entre o tempo de terapia e orientação/auto-orientação, foi identificado o tempo em que cada cliente estava em terapia (meses). Em seguida separou-se o número de orientações e auto-orientações recebidas e emitidas por cada cliente. O teste de correlação de Pearson foi utilizado então para medir o grau de relação entre o tempo de terapia e o número de orientações recebidas, assim como o número de auto-orientações emitidas.

Por fim, para a correlação entre situação financeira e orientação/auto-orientação, foram identificados os clientes que possuíam uma renda familiar acima de 1000 reais ou abaixo de 1000 reais. Em seguida separou-se o número de orientações e auto- 
orientações recebidas e emitidas por cada cliente. O teste de correlação de Pearson foi utilizado para medir o grau de relação entre a situação financeira e o número de orientações recebidas, assim como o número de auto-orientações emitidas.

\subsubsection{Criação de banco de dados IACON (instrumento de análise de} contingências)

Para que fosse possível a análise dos cinco passos citados acima, foi criado um banco de dados com o auxílio de um técnico de informática. Este técnico desenvolveu um sistema computacional baseado no sistema Delphi capaz de recuperar e cruzar as informações coletadas $^{12}$. O nome dado a este banco de dados foi IACON (Instrumento de Análise de Contingências). Veja a figura a seguir:

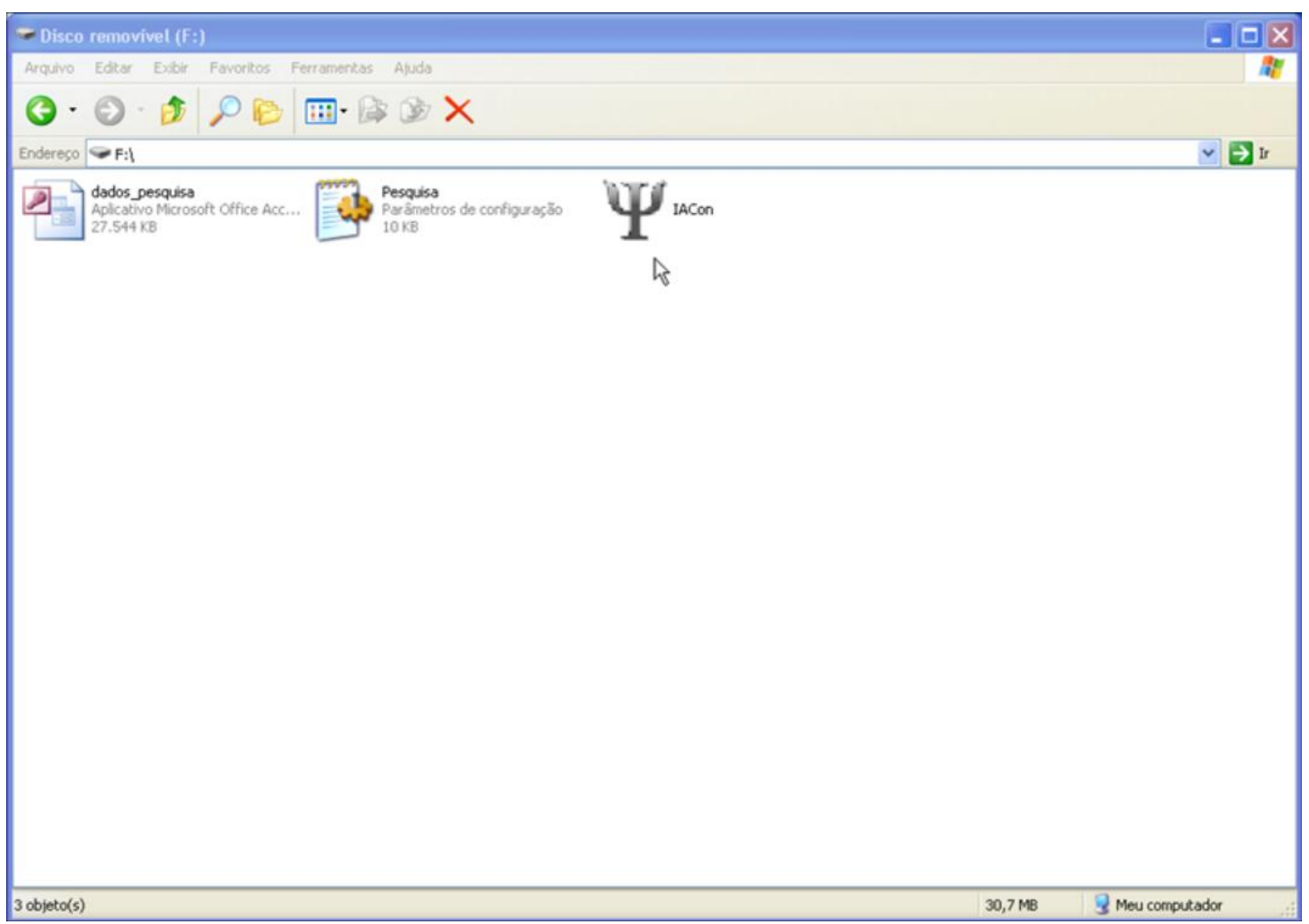

Figura 1: Banco de dados IACON (instrumento de análise de contingências)

\footnotetext{
${ }^{12}$ Antes da utilização do Delphi estava sendo usado o banco de dados Access e duas planilhas de Excel. Como havia uma grande quantidade de informações coletadas, tornou-se necessário o auxílio de um gerenciador de banco de dados capaz de cruzar todas as informações (no caso o Delphi).
} 
Com auxílio do IACON, diferentes informações foram armazenadas, e foi possível acessá-las quando necessário. O IACON permitiu uma organização dos dados das diferentes sessões com diferentes terapeutas e clientes. A leitura das sessões também produziu um grande volume de dados. Os dados que iam sendo coletados a partir das leituras das sessões e os dados coletados anteriormente (via questionário, por exemplo) foram incluídos no banco de dados através do preenchimento de diferentes campos. Cada campo correspondia a uma categoria de informação coletada.

No IACON (gerenciador de banco de dados) foram criados os seguintes campos: identificação do terapeuta; identificação do cliente; sessão $\left(1^{\mathrm{a}}, 2^{\mathrm{a}}\right.$ ou $\left.3^{\mathrm{a}}\right)$; temas da sessão; tipo de orientação; episódio de orientação (na qual a O/AO foi emitida); O (na íntegra); AO (na íntegra), categorização; tema da orientação; presença de perguntas durante os episódios de O/AO (Quando ocorreu? Por que ocorreu? Como o cliente lidou com a situação-problema? Qual é a avaliação do cliente sobre a forma como lidou com a situação? Qual sentimento na situação? Teve a reação pretendida?); respostas emitidas por clientes durante os episódios de $\mathrm{O} / \mathrm{AO}$; antecedente (qual o comportamento emitido pelo cliente antes da apresentação de $\mathrm{O} / \mathrm{AO}$ ); comportamento (no caso $\mathrm{O} / \mathrm{AO}$ ); consequente (qual o comportamento emitido pelo cliente ou terapeuta após a emissão de orientação); dados referentes ao terapeuta (experiência do terapeuta (terapeuta foi considerado experiente ou pouco experiente); experiência em anos do terapeuta (quantos anos o terapeuta tinha de formado no momento da coleta de dados); local de graduação do terapeuta (instituição em que o terapeuta era formado e se essa instituição era pública ou privada); modalidade de pós-graduação do terapeuta; número geral de casos atendidos; número de crianças atendidas; número de adolescentes atendidos e número de adultos atendidos); dados referentes ao cliente (idade, estado civil, sexo, escolaridade, ocupação, empregado/desempregado, renda familiar, motivo 
de procura por terapia conforme avaliação do terapeuta); tempo de terapia; diagnóstico conforme avaliação do terapeuta; perfil do cliente (cooperativo, motivado, resistente, desmotivado). Para melhor compreensão do banco de dados IACON, sugere-se a análise da figura a seguir.

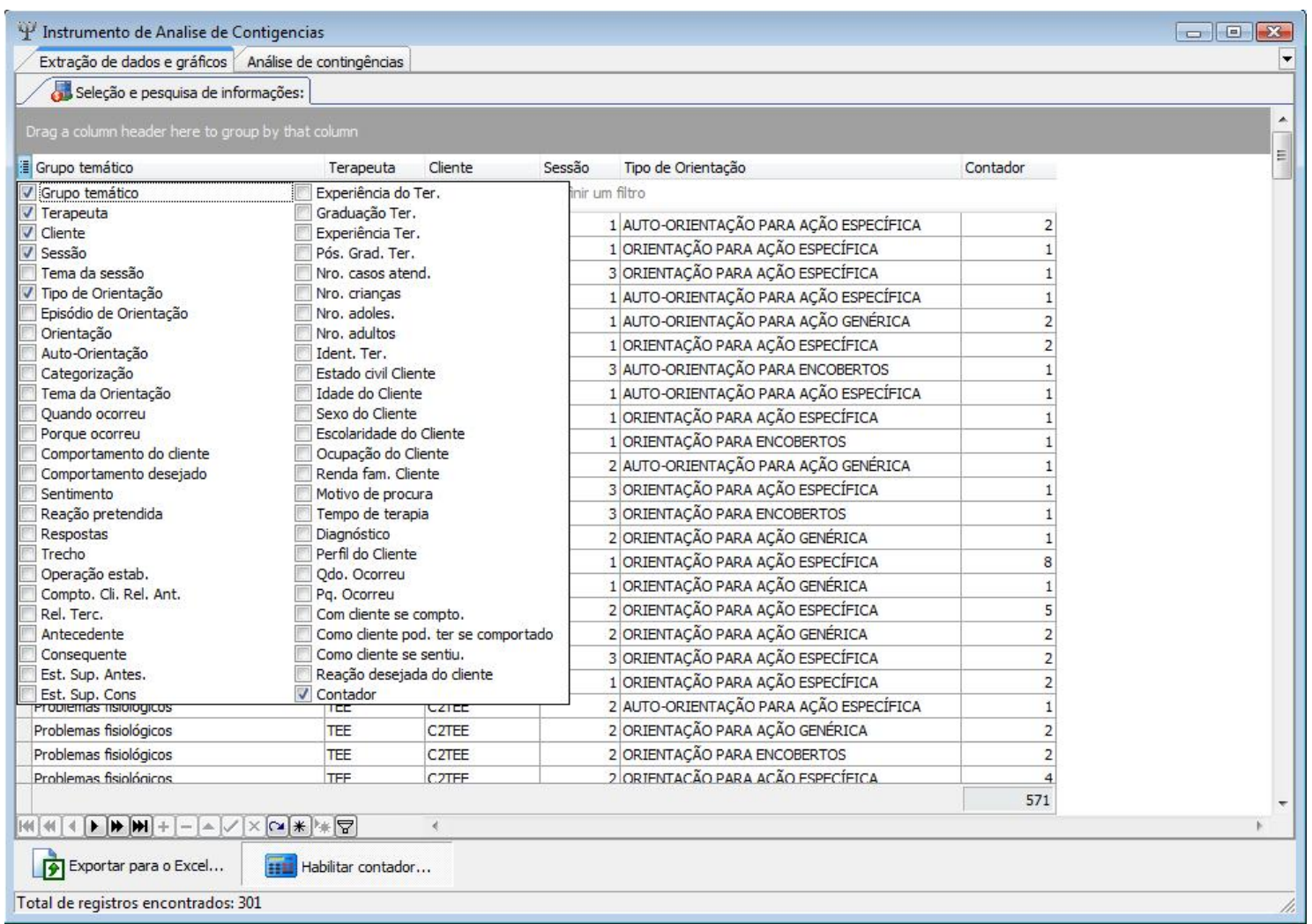

Figura 2: Diferentes campos criados no IACON

Através do recurso do banco de dados, uma grande quantidade de informações pôde ser manipulada possibilitando que a maioria das análises apontadas acima ocorresse.

Um CD auto-explicativo também foi desenvolvido com o intuito de ampliar o entendimento do IACON (ver Anexo I).

Além de ser possível realizar diferentes análises, o IACON também produz graficamente análises de contingências. Sugere-se a observação do diagrama a seguir baseado no exemplo apresentado na página 97. 


\subsection{Instrumentos}

Os instrumentos utilizados neste trabalho foram as transcrições das sessões, as definições de orientação e auto-orientação e seus subtipos, o programa computacional gerenciador de dados IACON que foi desenvolvido em Delphi (http://www.geocities.com/SiliconValley/Bay/1058/isdelphi.html) e os softwares (SPSS V16, Minitab 15 e Excel Office 2007).

\subsection{Teste de concordância}

Realizou-se o teste de concordância com $10 \%$ da amostra, ou seja, nove sessões (sendo uma de cada terapeuta participante). Para isso elaborou-se um manual de instrução para o juiz, assim como um modelo de folhas de respostas (Anexo V). O material foi entregue ao juiz, e uma sessão dentre as nove sessões utilizadas no teste de concordância foi escolhida aleatoriamente e utilizada para elucidação de dúvidas. As outras oito sessões foram categorizadas pelo juiz e posteriormente comparadas às categorizações realizadas pelo pesquisador.

Nessa análise dez pontos foram considerados para a análise de concordância: 1 . Identificação de temas discutidos na sessão; 2. Identificação de orientações; 3. Identificação de subtipos de orientações, 4. Identificação de auto-orientações; 5. Identificação de subtipos de auto-orientações; 6. Identificação de número de episódios de orientação/auto-orientação; 7. Identificação dos trechos dos episódios de orientação;

8. Média de concordância de perguntas e respostas encontradas nos episódios I; 9. Média de concordância de perguntas e respostas encontradas nos episódios II e 10. Média de concordância de perguntas e respostas encontradas nos episódios III.

Esta comparação foi feita via análise estatística. O teste utilizado nesta análise foi a ANOVA. 


\subsection{Análise estatística}

Após o tratamento dos dados coletados, realizou-se a análise estatística nos dados considerados mais relevantes.

O nível de significância definido para as análises estatísticas deste trabalho foi de $0,05(5 \%)$, ou seja, os resultados encontrados nessas análises foram construídos com 95\% de confiança estatística, admitindo-se erro estatístico de 5\%.

O nível de significância adotado é importante, pois o resultado de cada comparação estatística possui um p-valor. É a partir da comparação do nível de significância com o p-valor que se pode concluir a respeito dos diferentes testes estatísticos realizados. Quando o p-valor é maior que o nível de significância adotado (erro ou $\alpha$ ), concluiu-se que a $H_{0}$ (a hipótese nula) é a hipótese verdadeira, caso contrário ficamos com $H_{1}$, a hipótese alternativa.

O teste de igualdade de duas proporções foi utilizado para avaliar as intervenções que antecediam a emissão de orientação e auto-orientação; os antecedentes de orientação e auto-orientação; o índice de perda ${ }^{13}$ nas categorizações realizadas no estudo de Donadone (2004) e no atual estudo; e os consequentes de orientação e autoorientação. Este teste (igualdade de duas proporções) é um teste não paramétrico que compara se a proporção de respostas de duas variáveis e/ou seus níveis é estatisticamente significante.

Para o cálculo de concordância das categorias de comportamento de orientação e auto-orientação dois testes estatísticos foram realizados: o teste de igualdade de duas proporções e o índice de concordância Kappa. Por meio do teste de igualdade de duas proporções foi possível verificar o índice de perda nas categorizações realizadas no estudo de Donadone (2004) e no presente estudo, ou seja, verificou-se a porcentagem de

\footnotetext{
${ }^{13}$ Índice de perda é a expressão utilizada para designar o quanto categorias deixam de ser identificadas ou encontradas em dois momentos distintos de categorização.
} 
categorias que não foram possíveis de serem identificadas (ou encontradas) na atual pesquisa. O índice de concordância de Kappa é uma estatística utilizada para medir o grau de concordância entre duas variáveis e/ou resultados. Neste teste há uma divisão arbitrária para interpretação dos resultados. Assim, quando o índice Kappa for inferior a 20\% , considera-se o resultado desprezível. Quando o índice Kappa variar de 21 a 40\% considera-se o resultado mínimo. Quando o índice Kappa variar de 41 a 60\% considerase o resultado regular. Quando variar de 61 a $80 \%$ considera-se o resultado bom e por fim quando variar de 81 a 100\% considera-se o resultado ótimo (Consulte-se o anexo VI - metodologia estatística, para maior compreensão). Por meio do índice de concordância Kappa, mediu-se o grau de concordância entre as categorias de orientação e auto-orientação utilizadas no estudo de Donadone (2004) e no atual estudo. Esta análise foi feita tanto para o comportamento de orientar dos terapeutas quanto para os comportamentos de auto-orientar dos clientes. Para complementar a análise de concordância via índice Kappa, utilizou-se a técnica de Intervalo de confiança. Tal técnica é extremamente útil, pois permite observar quando a média pode variar numa determinada probabilidade de confiança.

O teste ANOVA (Analysis of Variance) foi utilizado para comparar os diferentes perfis de clientes e a emissão de orientação e auto-orientação, assim como para verificar se clientes de diferentes perfis recebiam mais de um subtipo de orientação ou emitiam mais um subtipo de auto-orientação. A ANOVA é um teste paramétrico bastante usual que compara médias utilizando variância.

Para a correlação entre escolaridade, queixa, idade do cliente, tempo de terapia e número de orientações recebidas e número de auto-orientações emitidas utilizou-se o teste de correlação de Pearson. Esta técnica serve para "medir" (mensurar) o quanto as variáveis estão interligadas, ou seja, o quanto uma variável está relacionada com a outra. 
Quando a correlação for positiva temos que à medida que uma variável aumenta seu valor, a outra correlacionada a esta também aumenta proporcionalmente. Já se a correlação for negativa, conclui-se que as variáveis são inversamente proporcionais, ou seja, à medida que uma variável aumenta seu valor, a outra variável diminui, e viceversa. A determinação de quão boa é uma correlação é feita através de uma divisão arbitrária para a interpretação dos resultados. Assim, quando o índice $P$ for inferior a $20 \%$, considera-se a correlação péssima. Quando o índice $P$ variar de 21 a $40 \%$ considera-se a correlação ruim. Quando o índice $P$ variar de 41 a $60 \%$ considera-se a correlação regular. Quando $P$ variar de 61 a $80 \%$ considera-se a correlação boa e por fim quando $P$ variar de 81 a 100\% considera-se a correlação ótima (Para melhor compreensão o Anexo VI - metodologia estatística pode ser consultado).

A última análise estatística realizada foi a análise de concordância entre pesquisador e juiz. Para tal análise utilizou-se a ANOVA (definição do teste e conceitos complementares estão explicados acima).

\section{Resultados e discussão}

\subsection{Temas}

A análise dos resultados iniciou-se com a identificação dos diferentes temas discutidos ao longo das sessões e separação dos temas sobre os quais ocorreu orientação e dos temas sobre os quais ocorreu auto-orientação. Tais procedimentos possibilitaram a comparação entre o número de temas encontrados nas sessões dos diferentes terapeutas com o número de temas sobre os quais ocorreu orientação e auto-orientação. A tabela a seguir mostra os resultados. 
Tabela 15. Temas da sessão, temas sobre os quais ocorreram orientações, temas sobre os quais ocorreram auto-orientações e frequência relativa percentil (apresentada em porcentagem)

\begin{tabular}{|c|c|c|c|c|c|c|}
\hline Terapeuta & Cliente & $\begin{array}{c}\mathbf{N}^{0} \text { de temas } \\
\text { nas três } \\
\text { sessões de } \\
\text { cada } \\
\text { terapeuta }\end{array}$ & $\begin{array}{l}\text { Temas sobre } \\
\text { os quais } \\
\text { ocorreram } \\
\text { orientações }\end{array}$ & \begin{tabular}{|c|} 
Temas sobre os \\
quais \\
ocorreram \\
auto- \\
orientações
\end{tabular} & $\begin{array}{c}\text { Frequência } \\
\text { relativa percentil } \\
\text { (\%) dos temas } \\
\text { sobre os quais } \\
\text { ocorreram } \\
\text { orientações }\end{array}$ & $\begin{array}{c}\text { Frequência relativa } \\
\text { percentil (\%) dos } \\
\text { temas sobre os } \\
\text { quais ocorreram } \\
\text { auto-orientações }\end{array}$ \\
\hline \multirow{3}{*}{$\begin{array}{c}\text { TED (72 } \\
\text { temas em } \\
\text { nove sessões) }\end{array}$} & C1TED & 8 & 7 & 5 & $88 \%$ & $63 \%$ \\
\hline & C2TED & 41 & 26 & 22 & $63 \%$ & $54 \%$ \\
\hline & C3TED & 23 & 20 & 16 & $87 \%$ & $70 \%$ \\
\hline \multirow{3}{*}{\begin{tabular}{|c|} 
TEE $(78$ \\
temas em \\
nove sessões)
\end{tabular}} & C1TEE & 29 & 22 & 1 & $76 \%$ & $3 \%$ \\
\hline & C2TEE & 34 & 25 & 13 & $74 \%$ & $38 \%$ \\
\hline & C3TEE & 15 & 9 & 5 & $60 \%$ & $33 \%$ \\
\hline \multirow{3}{*}{$\begin{array}{c}\text { TEF (55 } \\
\text { temas em } \\
\text { nove sessões) }\end{array}$} & C1TEF & 19 & 16 & 12 & $84 \%$ & $63 \%$ \\
\hline & C2TEF & 15 & 11 & 0 & $73 \%$ & $0 \%$ \\
\hline & C3TEF & 21 & 16 & 7 & $76 \%$ & $33 \%$ \\
\hline \multirow{3}{*}{\begin{tabular}{|c|} 
TPE1A (19 \\
temas em \\
nove sessões) \\
\end{tabular}} & C1TPE1A & 8 & 5 & 3 & $63 \%$ & $38 \%$ \\
\hline & C2TPE1A & 5 & 4 & 3 & $80 \%$ & $60 \%$ \\
\hline & C3TPE1A & 6 & 6 & 5 & $100 \%$ & $83 \%$ \\
\hline \multirow{3}{*}{\begin{tabular}{|c|} 
TPE2A (19 \\
temas em \\
nove sessões) \\
\end{tabular}} & C1TPE2A & 6 & 4 & 1 & $67 \%$ & $17 \%$ \\
\hline & C2TPE2A & 8 & 8 & 3 & $100 \%$ & $38 \%$ \\
\hline & C3TPE2A & 5 & 5 & 0 & $100 \%$ & $0 \%$ \\
\hline \multirow{3}{*}{\begin{tabular}{|c|} 
TPE1B (24 \\
temas em \\
nove sessões)
\end{tabular}} & C1TPE1B & 6 & 5 & 1 & $83 \%$ & $17 \%$ \\
\hline & C2TPE1B & 7 & 4 & 0 & $57 \%$ & $0 \%$ \\
\hline & C3TPE1B & 11 & 9 & 0 & $82 \%$ & $0 \%$ \\
\hline \multirow{3}{*}{\begin{tabular}{|c|} 
TPE2B (26 \\
temas em \\
nove sessões)
\end{tabular}} & C1TPE2B & 8 & 7 & 3 & $88 \%$ & $38 \%$ \\
\hline & C2TPE2B & 8 & 7 & 1 & $88 \%$ & $13 \%$ \\
\hline & C3TPE2B & 10 & 9 & 3 & $90 \%$ & $33 \%$ \\
\hline \multirow{3}{*}{$\begin{array}{c}\text { TPE1C (17 } \\
\text { temas em } \\
\text { nove sessões) }\end{array}$} & C1TPE1C & 4 & 4 & 1 & $100 \%$ & $25 \%$ \\
\hline & C2TPE1C & 4 & 3 & 3 & $75 \%$ & $75 \%$ \\
\hline & C3TPE1C & 9 & 5 & 0 & $56 \%$ & $0 \%$ \\
\hline \multirow{3}{*}{$\begin{array}{c}\text { TPE2C (28 } \\
\text { temas em } \\
\text { nove sessões) }\end{array}$} & C1TPE2C & 7 & 7 & 3 & $100 \%$ & $43 \%$ \\
\hline & C2TPE2C & 14 & 11 & 5 & $79 \%$ & $36 \%$ \\
\hline & C3TPE2C & 7 & 7 & 1 & $100 \%$ & $14 \%$ \\
\hline Média & & 13 & 10 & 4 & $81 \%$ & $33 \%$ \\
\hline
\end{tabular}

A análise dos temas indicou que nesta amostra mais temas foram abordados nas sessões conduzidas pelos terapeutas experientes (variação de oito a 41 temas) do que nas sessões conduzidas pelos terapeutas pouco experientes (variação de quatro a quatorze temas).

Em média $76 \%$ (variação de 60 a $87 \%$ ) dos temas discutidos nas sessões dos terapeutas experientes também eram temas de orientações. No caso dos terapeutas pouco experientes $84 \%$ (variação de $56 \%$ a $100 \%$ ) dos temas discutidos nas sessões também eram temas de orientação. Portanto, a maior parte dos temas abordados em sessão podia conter orientações. 
Quanto às auto-orientações emitidas pelos clientes dos terapeutas experientes a porcentagem dos temas de auto-orientação em relação aos temas discutidos nas sessões foi $40 \%$ em média (variação de $0 \%$ a $70 \%$ ). Para os clientes dos terapeutas pouco experientes, $29 \%$ em média (variação de $0 \%$ a $83 \%$ ) dos temas discutidos em sessão foram temas de auto-orientações.

Os dados sobre o número de temas são reapresentados na figura a seguir.

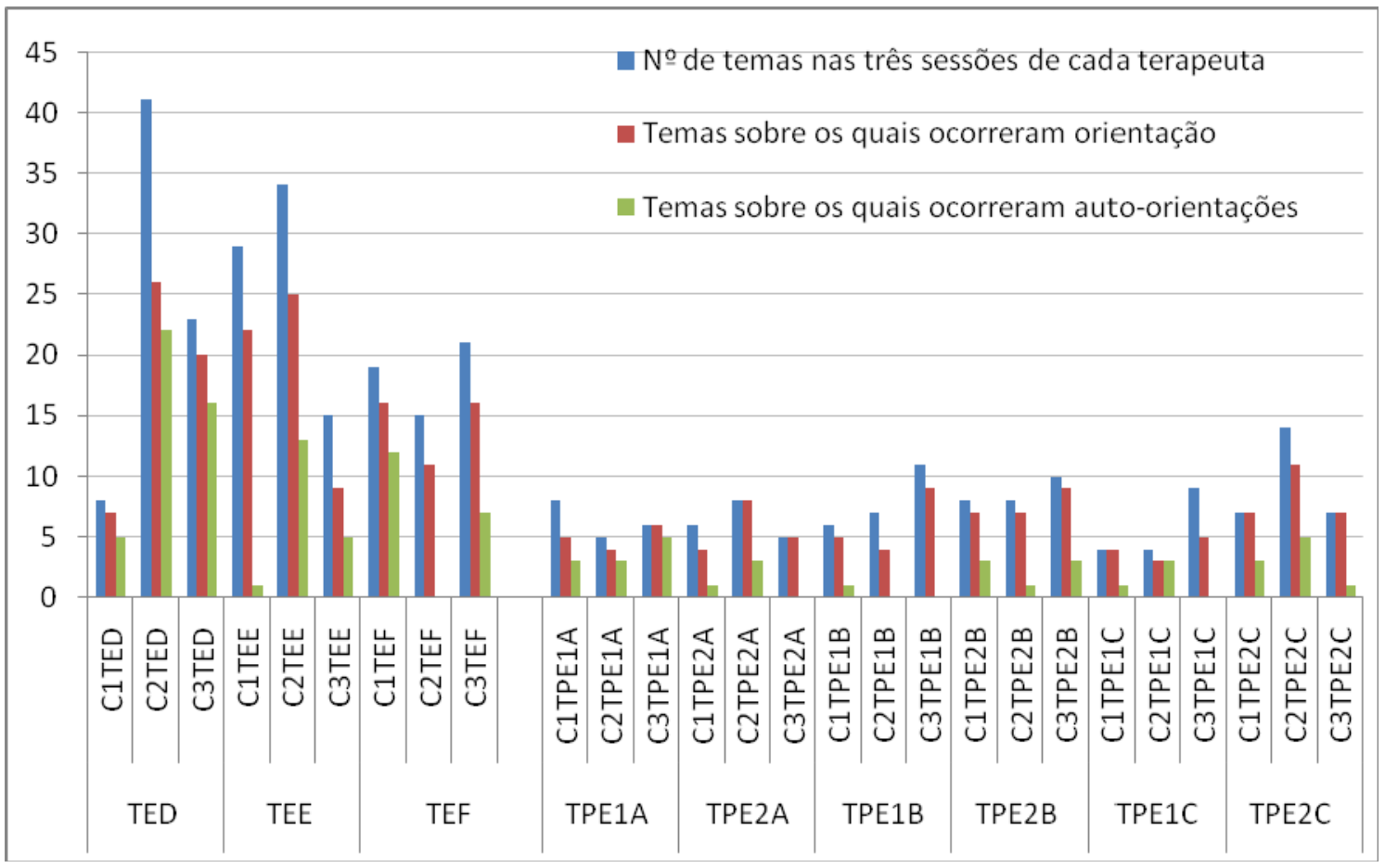

Figura 3. Número de temas na sessão, número de temas sobre os quais ocorreram orientações, número de temas sobre os quais ocorreram auto-orientações nas sessões dos diferentes terapeutas. $\mathrm{O}$ eixo $\mathrm{X}$ apresenta os diferentes terapeutas e o eixo Y apresenta o número de ocorrências.

Na maioria das sessões analisadas, o número de temas presentes nas sessões era superior ao número de temas para os quais o terapeuta emitia orientações e maior ainda do que o número de temas de auto-orientação. Nesta figura aparece com nitidez que são abordados mais temas pelos terapeutas experientes que pelos terapeutas pouco experientes. No entanto, o número de temas da sessão em que ocorria emissão de orientação é mais expressivo nas sessões dos terapeutas pouco experientes. O número de temas sobre os quais ocorriam auto-orientações mostra-se superior no caso dos 
clientes dos terapeutas experientes quando comparados aos clientes dos terapeutas pouco experientes.

\subsubsection{Grupos temáticos}

Através da utilização das categorias temáticas de Zamignani (2007) constatou-se que, nesta pesquisa, a maioria dos temas abordados nas sessões analisadas pertencia ao grupo temático relacionamento interpessoal (55\%), seguido pelo grupo temático queixas psiquiátricas e psicológicas (22\%), trabalho/estudo e ou carreira (13\%), problemas fisiológicos (7\%) e outros temas (3\%).

O passo seguinte foi verificar se havia grupos temáticos nos quais era mais comum a emissão de orientação por parte dos terapeutas e auto-orientação por parte dos clientes. A figura a seguir ilustra isso.

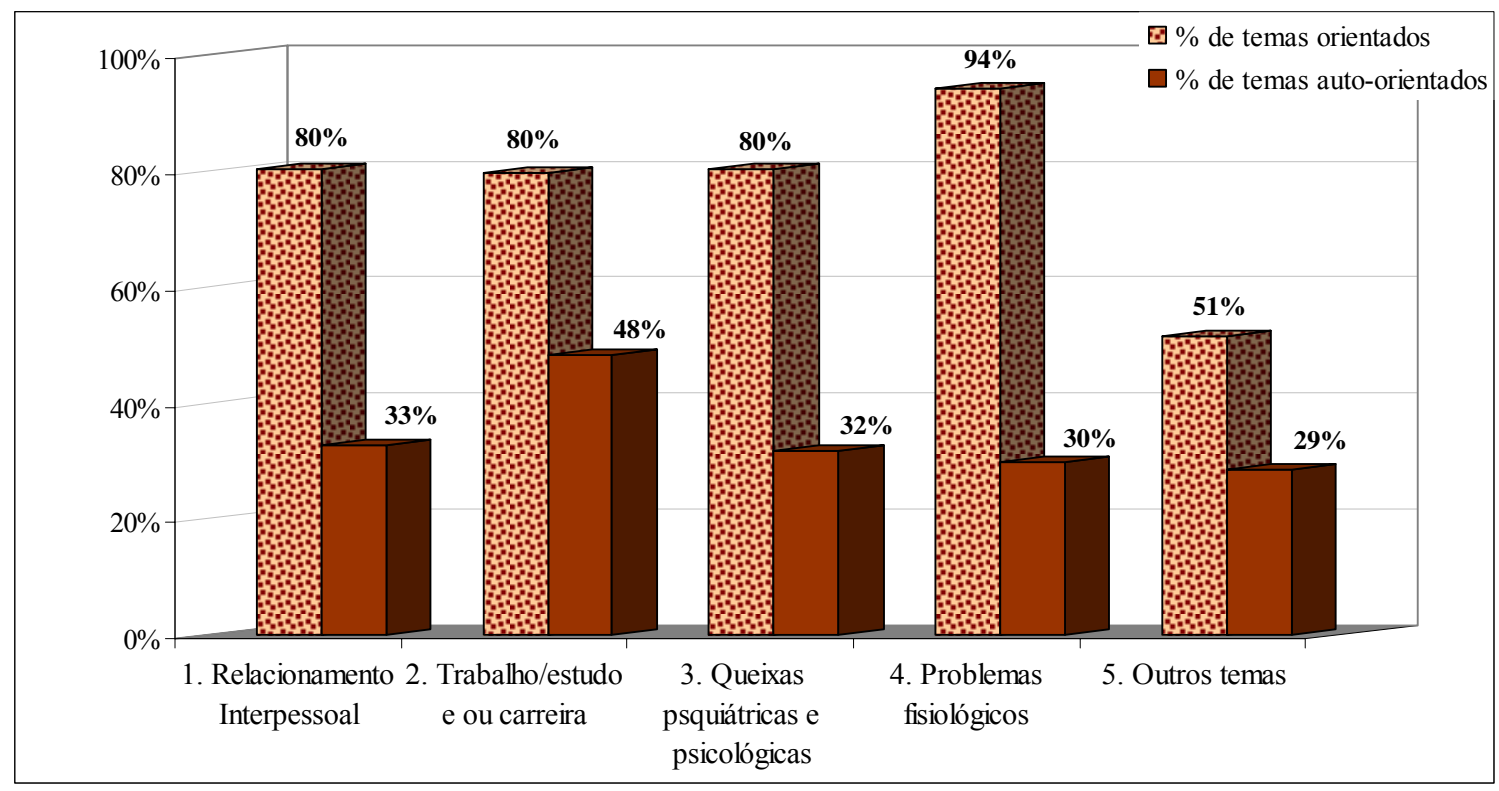

Figura 4. Porcentagem de temas nos quais ocorreram orientação e auto-orientação dentro de cada grupo temático. O Eixo $\mathrm{X}$ apresenta os diferentes grupos temáticos e o eixo Y a porcentagem de ocorrências.

Orientações foram fornecidas em $80 \%$ das vezes em que se conversou sobre relacionamento interpessoal, trabalho/estudo e ou carreira e queixas psiquiátricas e psicológicas. Se o tema da interação eram problemas fisiológicos a ocorrência de orientação era quase certa: 94\%. 
Auto-orientações ocorriam em aproximadamente 30\% das vezes em que se conversou sobre relacionamento interpessoal, queixas psiquiátricas e psicológicas, problemas fisiológicos e outros temas. Quando o tema era trabalho/estudo/carreira a ocorrência de auto-orientação era maior: 48\%.

\subsubsection{Grupos temáticos e subtipos de orientação/auto-orientação}

Das 465 orientações emitidas nas 81 sessões analisadas, 281(60\%) orientações ocorreram quando o assunto tratado em sessão se referia a relacionamento interpessoal; $70(15 \%)$ orientações ocorreram quando se discutia sobre queixas psiquiátricas $e$ psicológicas; 65 (14\%) orientações ocorreram quando se discutia sobre trabalho/estudo e ou carreira; 41 (9\%) orientações foram emitidas quando o conteúdo da discussão eram problemas fisiológicos e $8(2 \%)$ orientações ocorreram quando outros temas estavam sendo discutidos nas sessões analisadas.

O grupo temático que mais obteve ocorrências foi o grupo relacionamento interpessoal. Ao se conversar sobre relacionamento interpessoal, 45\% das orientações emitidas eram para ação específica, 27\% para ação genérica ou para encobertos e somente $0,35 \%$ eram orientações para tarefa. Apesar da alta incidência de orientações específicas, falar sobre relacionamento interpessoal suscita regras amplas, genéricas, conforme indicado pela soma da incidência de orientações genéricas (27\%) e orientações para encobertos $(27 \%)$. 
Tabela 16. Ocorrências e frequência relativa percentil (apresentada em porcentagem) de subtipos de orientações nos diferentes grupos temáticos.

\begin{tabular}{|c|c|c|c|c|c|}
\hline $\begin{array}{c}\text { 1. Relacionamento } \\
\text { Interpessoal }\end{array}$ & $127(45 \%)$ & $76(27 \%)$ & $77(27,4 \%)$ & $1(0,35 \%)$ & $\mathbf{2 8 1}(100 \%)$ \\
\hline $\begin{array}{c}\text { 2. Trabalho/estudo } \boldsymbol{O} \\
\text { ou carreira }\end{array}$ & $32(49 \%)$ & $11(17 \%)$ & $21(32 \%)$ & $1(1,53 \%)$ & $\mathbf{6 5}(100 \%)$ \\
\hline $\begin{array}{c}\text { 3. Queixas } \\
\text { psiquiátricas ou } \\
\text { psicológicas }\end{array}$ & $27(38,6 \%)$ & $13(18,6 \%)$ & $13(18,6 \%)$ & $17(24,3 \%)$ & $\mathbf{7 0}(100 \%)$ \\
\hline $\begin{array}{c}\text { 4. Problemas } \\
\text { fisiológicos }\end{array}$ & $31(75,6 \%)$ & $6(14,6 \%)$ & $2(4,8 \%)$ & $2(4,8 \%)$ & $\mathbf{4 1}(100 \%)$ \\
\hline 5. Outros temas & $4(50 \%)$ & $1(12,5 \%)$ & $3(37,5 \%)$ & $0(0 \%)$ & $\mathbf{8}(100 \%)$ \\
\hline
\end{tabular}

O segundo grupo temático que obteve mais ocorrências de orientação foi o de queixas psiquiátricas e psicológicas. De maneira muito diferente do que com os outros temas, este produziu maior frequência relativa percentil de orientação para ação específica $(38,6 \%)$ e orientação para tarefa $(24,3 \%)$. Orientações para ação genérica e para encobertos tiveram frequência relativa percentil similar de ocorrências $(18,6 \%)$. Possivelmente o uso de regras mais precisas (OAE + OT) ocorre para esse tema, pois o terapeuta apresenta um maior domínio de procedimentos e técnicas reconhecidas.

Quanto ao grupo temático trabalho/estudo e ou carreira, a maior incidência é do subtipo de orientação para ação específica (OAE - 49\%), seguido por orientação para encobertos (OE - 32\%), orientação para ação genérica (OAG - 17\%) e orientação para tarefas $(\mathrm{OT}-1,53 \%)$. A soma das regras mais específicas (OAE+ OT) comparada à soma das regras mais genéricas $(\mathrm{OE}+\mathrm{OAG})$ indica que quando conversam sobre trabalho/estudo e ou carreira, terapeutas empregam tanto regras mais genéricas (nas quais pedem aos clientes que avaliem ou pensem sobre seu futuro profissional), quanto regras mais específicas (que apontam ações bem específicas, como por exemplo: “... 
compre o caderno de empregos e selecione os anúncios que te interessa. Semana que vem quero ver este caderno todo riscado. Traga aqui pra eu ver.”).

Para o grupo temático problemas fisiológicos em que há uma incidência de ocorrências inferior aos demais grupos temáticos há maior emissão de regras específicas $(\mathrm{OAE}=75,6 \%$ e $\mathrm{OT}=4,8 \%$, por exemplo: “... vá ao médico a hora que sair daqui”.) do que regras genéricas $(\mathrm{OAG}=14,6 \%$ e $\mathrm{OE}=4,8 \%$, por exemplo: “... pense o que te causou essa dor de estômago.").

'Outros temas', por ser uma categoria residual, teve baixa ocorrência de orientações. Nessa amostra a distribuição de orientações mais específicas e genéricas ocorreu praticamente ao acaso, ou seja, quando se falou nas sessões sobre outros temas, $50 \%$ das orientações emitidas foram para regras específicas (OAE-50\%) e 50\% para regras mais genéricas (OE-37,5\% e OAG-12,5\%).

Análise semelhante foi realizada para as auto-orientações. Das 105 autoorientações emitidas nas 81 sessões analisadas, 56 (53\%) auto-orientações ocorreram quando o assunto tratado em sessão se referia a relacionamento interpessoal; 24 (23\%) das auto-orientações ocorreram quando o assunto tratado se referia a trabalho/estudo e ou carreira; $16(15 \%)$ auto-orientações ocorreram quando se discutia sobre queixas psiquiátricas e psicológicas; 2 (2\%) auto-orientações foram emitidas quando o conteúdo da discussão eram problemas fisiológicos e 7 (7\%) auto-orientações ocorreram quando outros temas estavam sendo discutidos nas sessões analisadas.

A Tabela 17 apresenta a distribuição das ocorrências e a frequência relativa percentil de subtipos de auto-orientações nos diferentes grupos temáticos.

Tabela 17. Ocorrências e frequência relativa percentil (apresentada em porcentagem) de subtipos de autoorientações nos diferentes grupos temáticos 


\begin{tabular}{|c|c|c|c|c|}
\hline & AOAE & AOAG & AOE & Total \\
\hline $\begin{array}{l}\text { 1. Relacionamento } \\
\text { Interpessoal }\end{array}$ & $29(51,8 \%)$ & $19(33,9 \%)$ & $8(14,3 \%)$ & $56(100 \%)$ \\
\hline $\begin{array}{l}\text { 2. Trabalho/estudo e } \\
\text { ou carreira }\end{array}$ & $15(62,5 \%)$ & $9(37,5 \%)$ & $0(0 \%)$ & $24(100 \%)$ \\
\hline $\begin{array}{c}\text { 3. Queixas } \\
\text { psiquiátricas ou } \\
\text { psicológicas }\end{array}$ & $8(50 \%)$ & $6(37,5 \%)$ & $2(12,5 \%)$ & $16(\mathbf{1 0 0 \% )}$ \\
\hline $\begin{array}{l}\text { 4. Problemas } \\
\text { fisiológicos }\end{array}$ & $1(50 \%)$ & $1(50 \%)$ & $0(0 \%)$ & $2(100 \%)$ \\
\hline 5. Outros temas & $3(42,8 \%)$ & $3(42,8 \%)$ & $1(14,3 \%)$ & $7(100 \%)$ \\
\hline
\end{tabular}

O grupo temático que mais obteve ocorrências foi o grupo relacionamento interpessoal. Ao se conversar sobre relacionamento interpessoal, 51,8\% das autoorientações emitidas pelos clientes eram para ação específica, 33,9\% eram para ação genérica e 14,9\% eram auto-orientações para encobertos.

No grupo temático trabalho/estudo e ou carreira houve emissão de autorregras apenas para ação sendo 62,5\% para ação específica e 37,5\% para ação genérica. Falar sobre trabalho/estudo ou carreira não fez com que os clientes emitissem autorregras para encobertos.

Quanto ao grupo temático queixas psiquiátricas e psicológicas houve prevalência de ocorrências dos subtipos de auto-orientação para ação específica (AOAE $=50 \%)$ seguido por auto-orientação para ação genérica $(\mathrm{AOAG}=37,5 \%)$ e autoorientação para encobertos $(\mathrm{AOE}=12,5 \%)$.

No grupo temático problemas fisiológicos houve apenas auto-orientações para ação, sendo que 50\% delas eram para ação específica (AOAE) e 50\% para ação genérica (AOAG). Tais resultados devem ser olhados com cautela, uma vez que a frequência absoluta de auto-orientações quando problemas fisiológicos estavam sendo discutidos foi bem discreta. Uma possível justificativa para a baixa ocorrência de auto- 
orientações neste grupo temático se deva ao fato de que, provavelmente, é mais difícil se auto-orientar quanto a problemas fisiológicos, sendo necessária a intervenção de um profissional especializado, mas caso isso ocorra a autorregra emitida será voltada para a ação.

Quando outros temas estavam sendo discutidos em sessão, as autorregras emitidas em sua maioria foram para ação (42,8\% de AOAE e 42,8\% de AOAG). Apenas 14,3\% das autorregras emitidas eram voltadas para a reflexão (AOE -14,3\%).

Após a análise de quais subtipos de orientações e auto-orientações ocorriam nos diferentes grupos temáticos, observou-se se havia diferenças quando as orientações e auto-orientações eram emitidas nas sessões com terapeutas experientes ou com terapeutas pouco experientes dentro desses grupos temáticos. Como o número de terapeutas experientes era inferior ao número de terapeutas pouco experientes, e consequentemente o número de clientes também, os dados apresentados deverão ser lidos como frequência média por terapeuta. Calculou-se a frequência média dos terapeutas, dividindo o número de orientações e auto-orientações dos terapeutas experientes por três (terapeutas) e o dos terapeutas pouco experientes por seis (terapeutas), conforme ilustra a tabela a seguir. 
Tabela 18 - Frequência média de orientação e auto-orientação dos diferentes terapeutas nos grupos temáticos

\begin{tabular}{|c|c|c|c|c|c|c|c|c|c|c|}
\hline & \multicolumn{2}{|c|}{$\begin{array}{l}\text { 1. Relacionamento } \\
\text { interpessoal }\end{array}$} & \multicolumn{2}{|c|}{$\begin{array}{l}\text { 2. Trabalho/estudo e ou } \\
\text { carreira: }\end{array}$} & \multicolumn{2}{|c|}{$\begin{array}{c}\text { 3. Queixas } \\
\text { psiquiátricas e } \\
\text { psicológicas }\end{array}$} & \multicolumn{2}{|c|}{$\begin{array}{l}\text { 4. Problemas } \\
\text { fisiológicos }\end{array}$} & \multicolumn{2}{|c|}{ 5. Outros temas } \\
\hline & TE & TPE & TE & TPE & TE & TPE & TE & TPE & TE & TPE \\
\hline 虽 & 23 & 9,7 & 3 & 3,8 & 7,7 & 1 & 8 & 1,2 & 0,3 & 0,5 \\
\hline מ & 9,3 & 8 & 0,3 & 1,7 & 0,7 & 1,8 & 1,3 & 0,3 & 0 & 0,2 \\
\hline 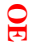 & 10 & 7,8 & 2 & 2,5 & 0,3 & 2 & 0,7 & 0 & 0,3 & 0,3 \\
\hline 号 & 0 & 0,2 & 0 & 0,2 & 0 & 2,8 & 0 & 0,3 & 0 & 0 \\
\hline 疍 & 5,3 & 2,2 & 3,3 & 0,8 & 1,7 & 0,5 & 0,3 & 0 & 0,3 & 0,3 \\
\hline مُ & 3,3 & 1,5 & 1,7 & 0,7 & 1,3 & 0,3 & 0 & 0,2 & 0 & 0,5 \\
\hline 焉 & 1,7 & 0,5 & 0 & 0 & 0,7 & 0 & 0 & 0 & 0 & 0,2 \\
\hline
\end{tabular}

A Tabela 18 mostra que diferenças foram encontradas ao se comparar a frequência média de orientação por terapeuta nos diferentes grupos temáticos.

Os terapeutas experientes apresentaram uma frequência média superior em todos os subtipos de orientação quando comparados aos terapeutas pouco experientes nos grupos temáticos relacionamento interpessoal e problemas fisiológicos.

Quando o assunto tratado se referia a trabalho/estudo e ou carreira, os terapeutas pouco experientes apresentaram uma frequência média superior aos terapeutas experientes em todos os subtipos de orientação.

Se o tema tratado na sessão se referia a problemas psiquiátricos e psicológicos, os terapeutas experientes emitiram uma frequência média de orientação para ação específica superior à dos terapeutas pouco experientes. Já os terapeutas pouco experientes ao tratarem sobre este assunto emitiram uma frequência média de orientação para ação genérica e para encobertos superior à dos terapeutas pouco experientes.

Quando outros temas eram tratados em sessão, terapeutas pouco experientes emitiram uma frequência média de orientação para ação específica superior às emitidas 
pelos terapeutas experientes. Somente os terapeutas pouco experientes emitiram orientação para ação genérica neste grupo temático, e terapeutas experientes e pouco experientes emitiram uma frequência média de orientação para encobertos similar.

Somente os terapeutas pouco experientes emitiram orientações para tarefa. Dessa forma não foi realizada a comparação de frequência média por orientação para tarefa nos diferentes grupos temáticos.

Os clientes dos terapeutas experientes tiveram uma frequência média de autoorientação superior em todos os grupos temáticos. Duas exceções ocorreram: 1. No grupo temático problemas fisiológicos apenas os clientes dos terapeutas pouco experientes se auto-orientaram para ação genérica e 2. No grupo temático outros temas apenas os clientes dos terapeutas pouco experientes se auto-orientaram para ação genérica e auto-orientação para encobertos.

\subsubsection{Conclusão geral a respeito dos temas}

Nas sessões psicoterápicas analisadas nesta pesquisa, vários temas foram abordados ao longo das sessões. 55\% dos temas discutidos em sessão foram relacionados ao grupo temático relacionamento interpessoal; $22 \%$ foram relacionados ao grupo temático queixas psiquiátricas e psicológicas; $13 \%$ ao grupo temático trabalho/estudo e ou carreira e 7\% ao grupo temático problemas fisiológicos. Como a maioria dos temas conversados na sessão são temas em que ocorre emissão de orientação (e eventualmente auto-orientação), pode-se concluir que a emissão de orientação ou auto-orientação pode acontecer ao se conversar sobre qualquer um desses temas. Houve aproximadamente $80 \%$ de ocorrências de orientação quando os temas abordados foram relacionamento interpessoal, trabalho/estudo e ou carreira e queixas psiquiátricas. Essa porcentagem foi ainda maior (94\%) quando o tema era relativo a 
problemas fisiológicos. Houve menor ocorrência de auto-orientação (48\%) quando o tema discutido era trabalho/estudo e ou carreira e ocorrência ainda menor (30\%) quando os temas discutidos na sessão pertenciam aos demais grupos temáticos.

De forma geral, falar sobre relacionamento interpessoal em sessões de psicoterapia produz a emissão de maior número de regras. Falar sobre relacionamento interpessoal no geral suscita regras amplas, entretanto diferenças foram encontradas quando se comparou a frequência média de orientação de terapeutas experientes e pouco experiente para este grupo temático. A análise da frequência média de orientação por terapeuta sugere que terapeutas experientes emitem mais regras específicas do que genéricas ao falar sobre relacionamento interpessoal. Já terapeutas pouco experientes emitem mais regras genéricas quando o assunto abordado é relacionamento interpessoal. Clientes emitem mais autorregras quando o assunto abordado se refere a relacionamento interpessoal. Da mesma forma que o caso da orientação neste grupo temático, as autorregras são mais específicas do que genéricas.

Quando o assunto tratado em sessões de psicoterapia se relacionava a queixas psiquiátricas e psicológicas, houve uma diferença entre o comportamento de terapeutas e clientes. No geral, terapeutas emitiram mais regras específicas. Mas a comparação entre a frequência média de orientação dos terapeutas indicou que terapeutas experientes emitiram mais regras específicas e os pouco experientes emitiram tanto regras específicas como genéricas. Os clientes dos diferentes terapeutas emitiram tanto autorregras genéricas como específicas.

Terapeutas e clientes comportaram-se de forma diferente quando a questão levantada em sessão se relacionava a trabalho/estudo e ou carreira. Enquanto os terapeutas oscilavam entre a emissão de orientações genéricas e orientações específicas, os clientes emitiram maciçamente autorregras para ação específica. 
Tanto os terapeutas como os clientes desta amostra ao falarem sobre problemas fisiológicos emitiram mais regras para ação do que para reflexão.

\subsection{Episódios de orientação/auto-orientação}

Episódios de orientação/auto-orientação foram identificados nas 81 sessões. Foram contadas quantas falas de terapeutas e clientes existiam dentro de um episódio de orientação e auto-orientação e calculou-se a porcentagem (\%) dessas falas dentro das sessões dos diferentes terapeutas.

Os episódios de orientação ocuparam apenas uma parcela da sessão: nas sessões dos terapeutas experientes, em média $36 \%$ das falas pertenciam a episódios de orientação. No caso das sessões dos terapeutas pouco experientes, em média $26 \%$ das falas da sessão pertenciam a episódios de orientação.

A média de falas da sessão em que ocorriam episódios de auto-orientação é ainda menor. Em média, em $12 \%$ das falas das sessões dos terapeutas experientes e em 7\% das falas das sessões dos pouco experientes ocorreram episódios de auto-orientação.

Estes dados encontram-se na Tabela 19.

Tabela 19. Média e porcentagem do número de falas em episódios de orientação/auto-orientação nas sessões dos terapeutas experientes e pouco experientes

\begin{tabular}{l|l|l}
\hline & Episódios de Orientação & Episódios de Auto-orientação \\
\hline Terapeutas experientes & 65 falas em média (36\%) & 46 falas em média (12\%) \\
\hline $\begin{array}{l}\text { Terapeutas pouco } \\
\text { experientes }\end{array}$ & 59 falas em média (26\%) & 23 falas em média (7\%) \\
\hline
\end{tabular}

A Tabela 19 mostra que os episódios de orientação dos terapeutas experientes apresentaram em média mais falas do que nos episódios dos terapeutas pouco experientes. Tais resultados permitem inferir que a interação entre terapeutas experientes e seus clientes é mais complexa e que os terapeutas experientes utilizam-se 
de mais estratégias antes ou após emitir a orientação do que os terapeutas pouco experientes.

Nos episódios de auto-orientação em média os clientes dos terapeutas experientes dialogam mais com seus terapeutas antes de emitir auto-orientações do que os clientes dos terapeutas pouco experientes. Além disso, a maior porcentagem de episódios de auto-orientação nas sessões dos terapeutas experientes se deve ao fato de que os clientes dos terapeutas experientes emitiram mais auto-orientações que os clientes dos terapeutas pouco experientes.

\subsection{Análise das perguntas realizadas durante os episódios de O/AO}

Os dados apresentados na Tabela 20 apresentam a ocorrência das respostas dos clientes às perguntas dos terapeutas durante os episódios de orientação/auto-orientação. A tabela foi organizada de maneira que as sequências apresentadas partem de episódios nos quais $N A ̃ O$ foi encontrada nenhuma ocorrência das perguntas e respostas-hipóteses desta pesquisa durante os episódios de orientação/auto-orientação até episódios em que, SIM, foram encontradas ocorrências de todas as perguntas e respostas-hipóteses. Vale ressaltar que nesta análise a ocorrência de perguntas seguidas pela respostas é o foco de análise e não o conteúdo das perguntas ou respostas. 
Tabela 20. Ocorrências e frequência relativa percentil (apresentada em porcentagem) de perguntas realizadas pelos terapeutas e respostas dos clientes durante os episódios de orientação e auto-orientação

\begin{tabular}{|c|c|c|c|c|c|c|c|c|}
\hline 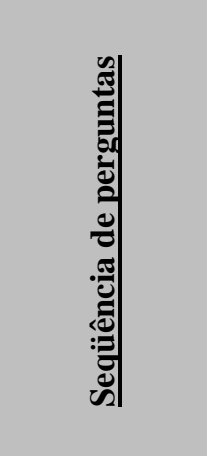 & 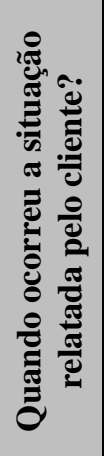 & 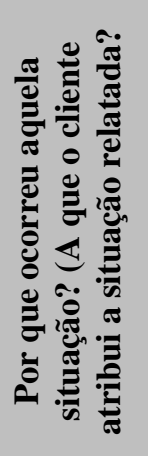 & 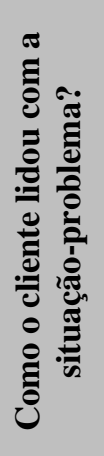 & 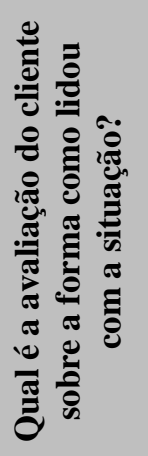 & 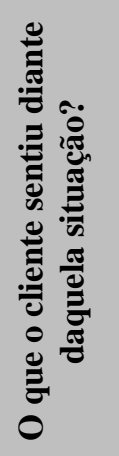 & 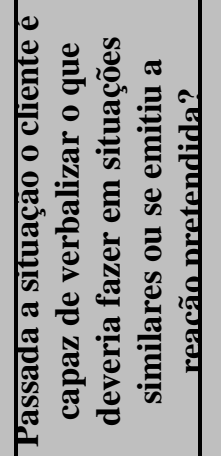 & 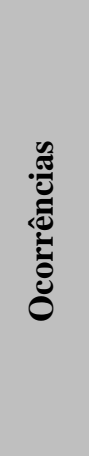 & 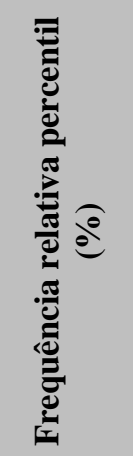 \\
\hline Seqüência 1 & $\mathrm{NA \tilde {O }}$ & NÃO & NÃO & $\overline{\mathrm{NÃO}}$ & NÃO & 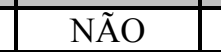 & 2 & $0,35 \%$ \\
\hline Seqüência 2 & NÃO & NÃO & NÃO & SIM & NÃO & SIM & 2 & $0,35 \%$ \\
\hline Seqüência 3 & $\mathrm{NÃO}$ & $\mathrm{NÃO}$ & SIM & NÃO & $\mathrm{NÃO}$ & $\mathrm{NÃO}$ & 2 & $0,35 \%$ \\
\hline Seqüência 4 & $\mathrm{NÃO}$ & $\mathrm{NÃO}$ & SIM & NÃO & SIM & $\mathrm{NÃO}$ & 1 & $0,17 \%$ \\
\hline Seqüência 5 & NÃO & SIM & SIM & SIM & $\mathrm{NÃO}$ & SIM & 1 & $0,17 \%$ \\
\hline Seqüência 6 & SIM & $\mathrm{NÃO}$ & SIM & NÃO & NÃO & NÃO & 2 & $0,35 \%$ \\
\hline Seqüência 7 & SIM & SIM & NÃO & NÃO & NÃO & NÃO & 1 & $0,17 \%$ \\
\hline Seqüência 8 & SIM & SIM & NÃO & NÃO & SIM & NÃO & 1 & $0,17 \%$ \\
\hline Seqüência 9 & SIM & SIM & $\mathrm{NÃO}$ & SIM & SIM & SIM & 1 & $0,17 \%$ \\
\hline Seqüência 10 & SIM & SIM & SIM & $\mathrm{NÃO}$ & $\mathrm{NÃO}$ & $\mathrm{NÃO}$ & 35 & $6,29 \%$ \\
\hline Seqüência 11 & SIM & SIM & SIM & $\mathrm{NÃO}$ & $\mathrm{NÃO}$ & SIM & 7 & $1,25 \%$ \\
\hline Seqüência 12 & SIM & SIM & SIM & NÃO & SIM & NÃO & 414 & $74,46 \%$ \\
\hline Seqüência 13 & SIM & SIM & SIM & $\overline{\mathrm{NÃO}}$ & SIM & SIM & 17 & $3,05 \%$ \\
\hline Seqüência 14 & SIM & SIM & SIM & SIM & NÃO & NÃO & 3 & $0,53 \%$ \\
\hline Seqüência 15 & SIM & SIM & SIM & SIM & $\mathrm{NÃO}$ & SIM & 13 & $2,33 \%$ \\
\hline Seqüência 16 & SIM & SIM & SIM & SIM & SIM & NÃO & 18 & $3,23 \%$ \\
\hline Seqüência 17 & SIM & SIM & SIM & SIM & SIM & SIM & 36 & $6,47 \%$ \\
\hline
\end{tabular}

Ao analisar conjuntamente os episódios de orientação e auto-orientação encontrou-se maciçamente a presença de perguntas realizadas pelo terapeuta seguidas por respostas. Houve somente duas ocorrências $(0,35 \%$ - Sequência 1$)$ de orientação em que o terapeuta não realizou nenhuma das perguntas apontadas acima e dessa forma não se analisou se o cliente respondeu ou não. As sequências onde predominantemente o terapeuta não realizou perguntas ou os clientes não responderam a perguntas mostraram-se pequenas (1,74 \% - somatória das Sequências 1, 2, 3, 4, 6 e 7). 
As Sequências 10,11,12, 13, 15, 16, 17 foram as que apresentaram ocorrências mais expressivas, sendo a sequência 12 a mais típica (SIM-SIM-SIM-NÃO-SIM-NÃO). Os terapeutas em $74 \%$ das vezes durante um episódio de orientação/auto-orientação realizaram as seguintes perguntas aos clientes e obtiveram respostas: (a) Quando ocorreu a situação relatada pelo cliente? (b) Por que ocorreu aquela situação (a que o cliente atribui a situação relatada)? (c) Como o cliente lidou com a situação-problema? (e) $\mathrm{O}$ que o cliente sentiu diante daquela situação? E não emitiram perguntas ou obtiveram respostas: (d) Qual é a avaliação do cliente sobre a forma como lidou com a situação? (f) Passada a situação o cliente é capaz de verbalizar o que deveria fazer em situações similares ou se emitiu a reação pretendida?

Outras sequências que se mostraram expressivas foram as Sequências 17 (SIMSIM-SIM-SIM-SIM) e 10 (SIM-SIM-SIM-NÃO-NÃO-NÃO). Na Sequência 17 observa-se que todas as perguntas foram realizadas pelos terapeutas e respondidas pelos clientes em 7\% das ocorrências (36 ocorrências). Já na Seqüência 10, os terapeutas em 6\% das ocorrências (35 ocorrências) realizaram as perguntas (a) Quando ocorreu a situação relatada pelo cliente? (b) Por que ocorreu aquela situação (a que o cliente atribui a situação relatada)? (c) Qual é a avaliação do cliente sobre a forma como lidou com a situação? e obtiveram respostas. As demais perguntas ou não foram realizadas pelos terapeutas ou o cliente não emitiu resposta para elas.

A alta ocorrência da sequência 12 está de acordo com a hipótese inicial levantada nesta pesquisa, a de que os terapeutas emitiriam orientações (regras) após verificarem que os clientes não discriminavam outras possibilidades de comportamento diante da situação relatada.

A Sequência 17 (SIM-SIM-SIM-SIM-SIM), em que o terapeuta realiza todas as perguntas e obtém todas as respostas do cliente esteve presente em apenas $22,68 \%$ dos 
episódios de auto-orientação. Este dado se opõe à hipótese inicial desta pesquisa, ou seja, a de que o cliente emitiria mais auto-orientações quando, ao ser questionado pelo terapeuta, fosse capaz de responder a todas as questões.

Verificou-se também se a auto-orientação estava de alguma forma vinculada à ocorrência das seguintes perguntas que poderiam proporcionar 'mais reflexões' seguidas por respostas dos clientes: (d) Qual é a avaliação do cliente sobre a forma como lidou com a situação? (e) O que o cliente sentiu diante daquela situação? (f) Passada a situação o cliente é capaz de verbalizar o que deveria fazer em situações similares ou emitiu a reação pretendida? Para isso somou-se a frequência relativa percentil de sequências em que ao menos duas das três perguntas apontadas acima estavam presentes. Os resultados dessa análise indicam que quando ocorreram duas perguntas que poderiam proporcionar 'mais reflexão', houve uma maior frequência relativa percentil de auto-orientação (33\% das vezes em que ocorreram duas perguntas que poderiam proporcionar 'mais reflexão', encontrou-se maior possibilidade de ocorrer auto-orientação). Essas perguntas aparentemente podem levar a uma avaliação da situação, dos sentimentos e do que pode ser feito a partir daí. Pode-se concluir então que quando se solicita mais reflexão, aumenta-se a chance de que ocorra auto-orientação.

\subsection{Análise de cada pergunta realizada durante os episódios de O/AO}

A primeira análise realizada foi relacionada à pergunta (a) “Quando ocorreu a

\section{situação relatada pelo cliente?”}

A Tabela 21 apresenta o número médio de respostas emitidas pelos diferentes clientes e a frequência relativa percentil destas ocorrências de respostas para os terapeutas. Nesta tabela também há a especificação de respostas nos episódios de orientação/auto-orientação dos terapeutas experientes e terapeutas pouco experientes. 
Tabela 21. Número médio de respostas emitidas pelos diferentes clientes aos terapeutas e frequência relativa percentil; respostas emitidas pelos clientes dos terapeutas experientes e pouco experientes tanto na orientação quanto na auto-orientação para a pergunta: "Quando ocorreu a situação relatada pelo cliente?"

\begin{tabular}{c|c|c|c|c|}
\hline \multirow{2}{*}{ Terapeuta Experiente } & \multicolumn{2}{|c|}{ Orientação } & \multicolumn{2}{c}{ Auto-orientação } \\
\cline { 2 - 5 } & Presente & Passado & Presente & Passado \\
\cline { 2 - 5 } $\begin{array}{c}\text { Terapeuta Pouco } \\
\text { Experiente }\end{array}$ & $54(\mathbf{8 9} \%)$ & $7(\mathbf{1 1 \%})$ & $16(\mathbf{8 4 \%})$ & $3(\mathbf{1 6 \%})$ \\
\hline
\end{tabular}

Os resultados mostram que a maioria das orientações e das auto-orientações era dada para problemas do cotidiano e não para problemas que vinham ocorrendo há mais tempo.

Nos episódios de orientação dos terapeutas experientes, $89 \%$ das respostas foram relacionadas a eventos presentes no cotidiano e $11 \%$ a eventos que vinham ocorrendo há mais tempo. Nos episódios de orientação dos terapeutas pouco experientes, $77 \%$ das respostas foram relacionadas a eventos presentes e $23 \%$ a eventos que vinham ocorrendo há mais tempo. Tendo sido observada uma diferença percentual superior a $10 \%$ é possível supor que a experiência clínica ensine a terapeutas a evitar procedimentos baseados em orientação quando o problema sob análise é antigo. Nessas situações mais crônicas é provável que familiares e amigos já tenham dado conselhos e sugestões, e que estes não tenham sido suficientes para promover as mudanças desejadas.

Nos episódios de auto-orientação dos clientes dos terapeutas experientes, 84\% das respostas à pergunta "Quando ocorreu a situação relatada pelo cliente?" foram relacionados a eventos presentes e 16\% a eventos que vinham ocorrendo há mais tempo. Nos episódios de auto-orientação dos terapeutas pouco experientes $88 \%$ das respostas 
foram relacionados a eventos cotidianos e $12 \%$ a eventos que vinham ocorrendo há mais tempo. Parece não haver diferenças significativas nas respostas apresentadas pelos clientes dos terapeutas experientes e pouco experientes.

Na Tabela 22 são analisadas as respostas à pergunta: (b) "Por que ocorreu aquela situação?” (a que o cliente atribui a situação relatada).

Tabela 22. Ocorrências e frequência relativa percentil de resposta à pergunta: "Por que ocorreu aquela situação?" dos diferentes clientes nos episódios de orientação e auto-orientação

\begin{tabular}{|c|c|c|c|c|c|}
\hline \multicolumn{7}{|c|}{ Por que ocorreu aquela situação? } \\
\hline$\underline{\text { Respostas }}$ & $\begin{array}{c}\text { 1. Sabe dizer o } \\
\text { porquê de a } \\
\text { situação ter } \\
\text { ocorrido } \\
\text { (descreve } \\
\text { contingências) }\end{array}$ & $\begin{array}{c}\text { 2. Não sabe dizer } \\
\text { o porquê de a } \\
\text { situação ter } \\
\text { ocorrido, mas } \\
\text { avalia seu } \\
\text { comportamento } \\
\text { como } \\
\text { inadequado' }\end{array}$ & $\begin{array}{c}\text { 3. A } \\
\text { orientação ou } \\
\text { a análise do } \\
\text { terapeuta foi } \\
\text { seguida ou } \\
\text { deixou de ser } \\
\text { seguida }\end{array}$ & $\begin{array}{c}\text { 4. } \\
\text { Responsabiliza } \\
\text { a situação ao } \\
\text { comportamento } \\
\text { de outra pessoa }\end{array}$ & $\begin{array}{c}\text { 5. Não sabe } \\
\text { discriminar } \\
\text { o porquê de } \\
\text { a situação } \\
\text { ter ocorrido }\end{array}$ \\
\hline Orientação & 73 (11\%) & $\begin{array}{c}154 \text { (24\%) } \\
72(11 \%)\end{array}$ & 332 (51\%) & 18 (3\%) \\
\hline $\begin{array}{c}\text { Auto- } \\
\text { orientação }\end{array}$ & 16 (11\%) & 21 (14\%) & 18 (12\%) & 96 (64\%) & 0 (0\%) \\
\hline
\end{tabular}

Os clientes participantes desta pesquisa em $11 \%$ das vezes sabiam dizer (descreviam contingências) por que a situação havia ocorrido. Em 24\% dos episódios os clientes não sabiam dizer por que a situação havia ocorrido, mas avaliavam seu comportamento como 'inadequado'. Em $11 \%$ das vezes, os clientes afirmavam que a situação havia ocorrido, pois os mesmos se comportaram de forma a confirmar/esquivar-se da orientação recebida por seus terapeutas. Em 51\% dos episódios de orientação, os clientes participantes desta pesquisa atribuíam o fato de a situação ter ocorrido ao comportamento de outras pessoas e por fim em apenas $3 \%$ dos episódios os clientes não sabiam discriminar o porquê de a situação ter ocorrido.

Chama a atenção que, em suas explicações, apenas em uma pequena parcela das vezes, os clientes sabem dizer o porquê de a situação ter ocorrido e assumem o comportamento que emitiram na situação relatada. Na maioria das vezes os clientes não 
se consideram iniciadores ou responsáveis pelas situações problemáticas descritas e que culminam em orientação e mesmo em auto-orientação. Os clientes ou atribuíam a situação ao comportamento de outras pessoas ou não discriminavam o porquê de a situação ter ocorrido, mas avaliavam seu comportamento como inadequado, ou indicavam que se comportaram de acordo/em contraposição às regras do terapeuta ou análise do terapeuta, ou seja, a responsabilidade era do terapeuta. A orientação parece, então, ter a função de indicar que a pessoa podia ter participação na ocorrência do evento.

Na Tabela 23 são analisadas as respostas à pergunta (c): “Como o cliente lidou

\section{com a situação problema?"}

Tabela 23. Ocorrências e frequência relativa percentil de respostas à pergunta: "Como o cliente lidou com a situação problema?" dos clientes dos terapeutas experientes (TE) e pouco experientes (TPE) nos episódios de orientação e auto-orientação

\begin{tabular}{|c|c|c|c|c|c|}
\hline \multicolumn{6}{|c|}{ Como o cliente lidou com a situação problema? } \\
\hline$\underline{\text { Respostas }}$ & $\begin{array}{l}\text { 1. Comportou- } \\
\text { se de forma } \\
\text { 'adequada', } \\
\text { apesar das } \\
\text { conseqüências } \\
\text { nem sempre } \\
\text { serem as } \\
\text { esperadas }\end{array}$ & $\begin{array}{c}\text { 2. Seguiu a } \\
\text { orientação } \\
\text { do } \\
\text { terapeuta }\end{array}$ & $\begin{array}{c}3 . \\
\text { Analisou } \\
\text { a } \\
\text { situação }\end{array}$ & $\begin{array}{l}\text { 4. Cliente não } \\
\text { lidou/enfrentou } \\
\text { a situação } \\
\text { (possível } \\
\text { esquiva) }\end{array}$ & $\begin{array}{c}\text { 5. Não sabe } \\
\text { dizer como } \\
\text { se lidou (se } \\
\text { comportou) } \\
\text { naquela } \\
\text { situação }\end{array}$ \\
\hline Orientação & $\begin{array}{c}97 \\
\mathbf{( 1 6 \% )} \\
\end{array}$ & $\begin{array}{c}19 \\
(3 \%)\end{array}$ & $\begin{array}{c}118 \\
(\mathbf{1 9 \%})\end{array}$ & $\begin{array}{c}374 \\
(\mathbf{6 1 \% )} \\
\end{array}$ & $\begin{array}{c}4 \\
(\mathbf{1 \%}) \\
\end{array}$ \\
\hline Auto-orientação & $\begin{array}{c}31 \\
(21 \%)\end{array}$ & $\begin{array}{c}6 \\
(4 \%)\end{array}$ & $\begin{array}{c}45 \\
(30 \%)\end{array}$ & $\begin{array}{c}64 \\
(44 \%)\end{array}$ & $\begin{array}{c}0 \\
(0 \%)\end{array}$ \\
\hline
\end{tabular}

Nesta amostra, as maneiras mais frequentes de os clientes lidarem com as situações relatadas tanto nos episódios de orientação como nos episódios de orientação foram: $1^{\circ}$ ) não enfrentamento da situação (possível esquiva); $2^{\circ}$ ) análise da situação; $3^{\circ}$ ) comportar-se de forma adequada à situação, apesar de nem sempre as consequências serem as esperadas e $4^{\circ}$ ) seguir a orientação do terapeuta. Apenas nos episódios de orientação, houve alguns relatos de clientes que não sabiam dizer (como lidaram) qual havia sido seu comportamento na situação relatada. Mas como esta resposta ocorreu em 
uma frequência pouco expressiva, esta não será analisada. Os resultados sugerem que a orientação e auto-orientação são mais prováveis quando há indicação da ocorrência de esquiva do tipo não enfrentamento, o que parece compatível com a análise anterior em que o cliente não assume a responsabilidade da ocorrência da situação problemática.

Na Tabela 24 são analisadas as respostas à pergunta (d): “Qual é a avaliação do

\section{cliente sobre a forma como lidou com a situação?”}

Tabela 24. Ocorrências e frequência relativa percentil de resposta à pergunta: "Qual é a avaliação do cliente sobre a forma como lidou com a situação?” dos clientes dos diferentes terapeutas nos episódios de orientação e auto-orientação

\begin{tabular}{|l|c|c|c|c|c|c|}
\hline \multicolumn{2}{|c|}{ 'Qual é a avaliação do cliente sobre a forma como lidou com a situação'? } \\
\hline & \multicolumn{3}{|c|}{ Orientaça } & \multicolumn{3}{|c|}{ Auto-orientação } \\
\hline Respostas & $\begin{array}{l}\text { Não sabe } \\
\text { dizer }\end{array}$ & 'Adequado' & $\begin{array}{l}\text { 'Inadequado', } \\
\text { mas sabe } \\
\text { descrever como } \\
\text { deveria agir }\end{array}$ & $\begin{array}{l}\text { Não sabe } \\
\text { dizer }\end{array}$ & 'Adequado' & $\begin{array}{l}\text { 'Inadequado' } \\
\text {,mas sabe } \\
\text { descrever } \\
\text { como deveria } \\
\text { agir }\end{array}$ \\
\hline Terapeutas & $\begin{array}{c}434 \\
(93 \%)\end{array}$ & $\begin{array}{c}14 \\
(3 \%)\end{array}$ & $\begin{array}{c}17 \\
(4 \%)\end{array}$ & $\begin{array}{c}65 \\
(64 \%)\end{array}$ & $\begin{array}{c}26 \\
(26 \%)\end{array}$ & $\begin{array}{c}10 \\
(10 \%)\end{array}$ \\
\hline
\end{tabular}

Na quase totalidade dos episódios de orientação (93\%) os clientes não sabiam dizer se a forma como lidaram com a situação era adequada ou não. Nos episódios de auto-orientação a frequência relativa percentil de ocorrências da resposta 'não sei dizer' também foi alta (64\%). Continuando a análise anterior, os clientes não se responsabilizam pela situação geradora do problema, não a enfrentam e dizem que não sabem avaliar se consideram sua resposta frente a essa situação adequada.

$\mathrm{Na}$ Tabela 25 são analisadas as respostas à pergunta (e): “O que o cliente sentiu diante daquela situação?”

Tabela 25. Número de ocorrência e frequência relativa percentil (apresentada em porcentagem) das emoções nos episódios de orientação e auto-orientação.

\begin{tabular}{l|c|c|c|c}
\hline \multirow{2}{*}{} & \multicolumn{2}{|c|}{ Episódios de Orientação } & \multicolumn{2}{c}{ Episódios de Auto-orientação } \\
\cline { 2 - 5 } & Ocorrências & $\begin{array}{c}\text { Frequência } \\
\text { relativa } \\
\text { percentil (\%) }\end{array}$ & Ocorrências & $\begin{array}{c}\text { Frequência relativa } \\
\text { percentil (\%) }\end{array}$ \\
\hline Amor & 7 & $1 \%$ & 0 & $0 \%$ \\
\hline Alegria & 20 & $3 \%$ & 10 & $8 \%$ \\
\hline Medo & 312 & $44 \%$ & 13 & $10 \%$ \\
\hline Tristeza & 167 & $23 \%$ & 35 & $27 \%$ \\
\hline
\end{tabular}




\begin{tabular}{l|c|c|c|c} 
Raiva & 111 & $16 \%$ & 37 & $28 \%$ \\
\hline Culpa/ vergonha & 54 & $8 \%$ & 11 & $8 \%$ \\
\hline Não sabe dizer & 44 & $6 \%$ & 25 & $19 \%$ \\
\hline
\end{tabular}

Tanto nos episódios de orientação como os episódios de auto-orientação, emoções 'positivas' foram encontradas de forma discreta. Em concordância com a resposta de não enfrentamento, medo foi o sentimento mais frequente nos episódios de orientação (44\%), seguido do sentimento de tristeza (23\%). Culpa e vergonha, sentimentos indicativos de que a pessoa se sente responsável pela situação, ocorreram em apenas 8\% dos episódios.

Nos episódios de auto-orientação os sentimentos mais frequentemente relatados foram os de raiva $(28 \%)$ e os de tristeza $(27 \%)$. Não houve a mesma prevalência do medo que nos episódios de orientação (10\%). Apesar de os sentimentos relatados terem sido 'negativos' tanto nas orientações quanto nas auto-orientações a diferença de prevalência dos sentimentos indica que possivelmente existem variáveis controladoras diferentes para as respostas que geram orientação e auto-orientação.

Na Tabela 26 são analisadas as respostas à pergunta (f): “Passada a situação o cliente é capaz de verbalizar o que deveria fazer em situações similares ou não emitiu a reação pretendida?” 
Tabela 26. Número médio de respostas emitidas pelos diferentes clientes aos terapeutas e frequência relativa percentil (apresentada em porcentagem); respostas emitidas pelos clientes dos terapeutas experientes e pouco experientes tanto na orientação quanto na auto-orientação para a pergunta: "Passada a situação o cliente é capaz de verbalizar o que deveria fazer em situações similares ou não emitiu a reação pretendida?"

\begin{tabular}{|c|c|c|c|c|}
\hline \multicolumn{5}{|c|}{$\begin{array}{c}\text { “Passada a situação o cliente é capaz de verbalizar o que deveria fazer em } \\
\text { situações similares ou não emitiu a reação pretendida?" }\end{array}$} \\
\hline & \multicolumn{2}{|c|}{ Orientação } & \multicolumn{2}{|c|}{ Auto-orientação } \\
\hline & $\begin{array}{l}\text { Não sabe } \\
\text { dizer }\end{array}$ & $\begin{array}{l}\text { Sim, é capaz de } \\
\text { verbalizar o que } \\
\text { deveria fazer em } \\
\text { situações similares ou } \\
\text { emitir a reação } \\
\text { pretendida. }\end{array}$ & $\begin{array}{l}\text { Não } \\
\text { sabe } \\
\text { dizer }\end{array}$ & $\begin{array}{l}\text { Sim, é capaz de } \\
\text { verbalizar o que } \\
\text { deveria fazer em } \\
\text { situações similares ou } \\
\text { emitir a reação } \\
\text { pretendida. }\end{array}$ \\
\hline Terapeutas & $49(\mathbf{9 4 \%})$ & $3(6 \%)$ & $5(42 \%)$ & $7(58 \%)$ \\
\hline $\begin{array}{l}\text { Terapeutas } \\
\text { Experientes }\end{array}$ & $58(95 \%)$ & $3(5 \%)$ & $5(26 \%)$ & $14(74 \%)$ \\
\hline $\begin{array}{l}\text { Terapeutas } \\
\text { Pouco } \\
\text { experientes }\end{array}$ & 44 (94\%) & $3(6 \%)$ & $4(57 \%)$ & $3(43 \%)$ \\
\hline
\end{tabular}

Ao se analisar os episódios de orientação encontrou-se que em média os clientes dos diferentes terapeutas em $94 \%$ das vezes respondiam que não sabiam dizer o que deveriam fazer em situações similares ou não emitiram a reação pretendida, de certa forma justificando-se, então, o uso da orientação. Somente em $6 \%$ das vezes, em média, esses clientes sabiam dizer qual a reação que deveriam ter tido em situações similares ou que emitiram a reação pretendida. Já nos episódios de auto-orientação, os clientes dos diferentes terapeutas não sabiam dizer o que deveriam fazer em situações similares ou não emitiram a reação pretendia em $42 \%$ das vezes, em média, e sabiam verbalizar qual o comportamento que deveriam ter em situações similares ou emitiram a reação pretendia em $58 \%$ dos episódios em média. Saber o que deveriam fazer faz parte da própria definição de auto-orientação. 
Houve diferenças nas respostas encontradas para esta pergunta ao se analisar os episódios de auto-orientação dos terapeutas experientes e dos terapeutas pouco experientes. Os clientes dos terapeutas experientes durante os episódios de autoorientação sabiam dizer após a situação ter ocorrido qual deveria ser seu comportamento ou emitiram a reação pretendida por eles em $74 \%$ das ocorrências. Somente em $26 \%$ das ocorrências os clientes afirmaram não saber como reagir em situações futuras. Já os clientes dos terapeutas pouco experientes souberam dizer qual deveria ser seu comportamento ou emitiram a reação pretendida em $43 \%$ dos episódios de autoorientação, não sabendo a resposta em $57 \%$ dos episódios, quase o dobro do percentual dos clientes dos terapeutas experientes. Os clientes dos terapeutas experientes emitem maior número de auto-orientações e conseguem em mais ocasiões dizer o que deveriam fazer em situações similares ou já se comportam da forma pretendida por eles. Estes dois eventos parecem estar relacionados, indicando que se os clientes conseguem descrever qual a reação pretendida, conseguem também se auto-orientar em mais ocasiões.

\subsection{Análise de contingências das orientações e auto-orientações}

\subsubsection{Narrativa do cliente}

O exemplo a seguir ilustra uma narrativa:

33C: Fiz uma coisa que provavelmente você não irá gostar... ou não (risos). Preciso te dizer que anda acontecendo... Andei ligando pro W... (riso nervoso)

33T: É mesmo?(surpreso)... Quando você ligou pra ele?

34C: Ontem....(suspiro profundo). Então... Na quinta-feira vim aqui, conversamos e fiquei mais consciente (risos). Mas com o passar do tempo parece que vou enfraquecendo... Nesta quarta-feira acordei com a ideia fixa de falar com meu ex. Aí fui trabalhar e tentar me distrair. Mas sabe aqueles dias onde o mundo resolve te estressar e te contrariar... Só sei que quando eu vi já tinha ligado pra ele... Aí pensei pra variar fiz o que não devia... Ligar pra quê?

34T: Uhm... uhm... Sei! Mas o que foi que aconteceu?Ou melhor, por que você ligou pra ele? Por que você acha que isso aconteceu?

35C: Calma... Vou te explicar por partes... Sempre tem um porquê né... (risos)... Tudo começou com a minha chefe... Ela é fogo... Uma beleza (ironicamente)... Enfim, briguei com a minha chefe por conta de 
um memorando, e ela no meio da briga me chamou de mal amada! Mal amada eu!Quem é ela pra falar isso... Aí eu pensei a culpa é minha... Que eu fico falando pra todo mundo o que meu ex-marido me fez, que ele me trocou por uma ninfetinha mais magra... Até o porteiro do prédio que trabalho sabe disso... Ninguém manda ter boca grande... Mas as pessoas são ruins, na hora que briga, vira e usa o que você falou como arma contra você... Enfim, só sei que fiquei chateada, saí do trabalho com vontade de matar um... Quando tô indo pra casa, uma pessoa vomita no meu pé no metrô...

35T: Nossa!

36C: Só sei que saí do metrô chorando, passei na padaria e não tinha a bomba de chocolate que eu queria... Cheguei em casa tomei banho e fui pra frente da TV, morta de fome e raiva... Nisso começo a ver a novela... E o mocinho todo romântico... Num impulso catei o telefone e liguei pro W.

36T: Ahm... E aí como foi?

37C: Vou te contar o que rolou... Bom, ele atendeu ao telefone e logo foi perguntando do filho. Eu respondi que tava tudo bem e que ele estava na avó. Aí então ele me responde: que bom, então diga, o que você quer? Eu fiquei meio gaga, e ele já se antecipou... Ah só bater papo e começou com aquelas perguntinhas que me irritam: você está bem? E o trabalho? Tá se cuidando! Até aí eu fui respondendo, aí quando eu fiz as mesmas perguntas, ele disse que tava ótimo, que tinha sido promovido e assim por diante... Eu comecei a ficar muito brava, mas isso é ilógico porque quem perguntou fui eu e ele só respondeu, não é? Enfim, acho que tudo isso aconteceu por uma soma de coisas. Acho que a minha chefe extrapolou, me levou ao limite e depois o que me aconteceu no metrô, foi pra acabar... Acho que essa série de porcarias me deixaram mais sensível e por isso eu liguei.

37T: Bom e depois de ter feito a ligação ... O que aconteceu? Ou melhor, como você lidou com isso?

38C: Então parece que eu preciso fazer besteiras pra perceber algumas coisas. Vejo que não lido bem com situações onde sou contrariada... E isto vai da minha chefe até o W.... Depois de desligar, chorei, enviei mensagens pedindo pra voltar, xinguei e tudo mais.

38T: E como você avalia seu comportamento? Como isso ficou pra você?

39C: Ahm... é como eu te disse acho que me comportei mal, que recaí, mas é tão difícil né... Eu ainda me descontrolo...

39T: É ainda difícil pra você falar com ele né... Mas me diga... Como você se sentiu ao ligar? Valeu a pena falar com ele, apesar dos pesares?

40C: Ahm...Não gostei de falar com ele não... E ainda de quebra não me senti nada bem... Na hora que desliguei o telefone, percebi que tinha 'recaído' e feito tudo errado. Me senti muito mal, chorei... E ainda fiquei deprimida. Não é desta forma que quero a atenção dele... Depois de um tempo, comecei a pensar, pensar e não me senti mais mal, conclui que isso só aconteceu, pois minha chefe me levou à loucura e meu dia foi uma lástima...

Neste exemplo o cliente narrou ao terapeuta a que ele atribuiu seu comportamento de ligar para o ex-marido. Durante a narrativa, o terapeuta realizou 
algumas intervenções (como solicitação de informação, facilitação), porém nenhuma dessas intervenções era emissão de regras (no caso, orientação).

A Tabela 27 ilustra a ocorrência ou não ocorrência de narrativa dos clientes nos episódios de orientação/auto-orientação.

Tabela 27. Ocorrência/não ocorrência de narrativa do cliente nos episódios de orientação/auto-orientação.

\begin{tabular}{|c|c|c|c|}
\hline & Terapeuta & Não ocorrência & Ocorrência \\
\hline \multirow{4}{*}{ Terapeutas Experientes } & TED & 2 & 85 \\
\cline { 2 - 4 } & TEE & 0 & 103 \\
\cline { 2 - 4 } & TEF & 0 & 51 \\
\hline \multirow{4}{*}{$\begin{array}{c}\text { Terapeutas Pouco } \\
\text { Experientes }\end{array}$} & TPE1A & 4 & 57 \\
\cline { 2 - 4 } & TPE2A & 12 & 48 \\
\cline { 2 - 4 } & TPE1B & 1 & 24 \\
\cline { 2 - 4 } & TPE2B & 1 & 59 \\
\cline { 2 - 4 } & TPE1C & 0 & 49 \\
\cline { 2 - 4 } & TPE2C & 2 & 65 \\
\hline
\end{tabular}

Os dados analisados indicaram que a maioria dos clientes narrava as situações vivenciadas nos episódios de orientação/auto-orientação. No caso dos clientes dos terapeutas experientes houve apenas duas ocorrências de ausência de relato de comportamento antes de o terapeuta iniciar a intervenção. Ex1: “...mudando de assunto, quero que você anote toda vez que se perder em suas fantasias, o que acontece antes $e$ depois... Estou falando isso agora, pois senão me esqueço e ficamos perdidas... (risos)”. Já no caso dos terapeutas pouco experientes, há um maior número de ausência de relatos de comportamentos antes das intervenções dos terapeutas. Destacam-se aqui os clientes do TPE2A (12 ocorrências de ausência de relato de comportamento) Ex: “... Fala com seu namorado sobre seus horários... (terapeuta muda de assunto repentinamente e diz: “... agora que sua mãe voltou, tente apoiá-la e passar mais tempo com ela...”) e os clientes do TPE1A (quatro ocorrências) Ex: ...terapeuta começa a sessão dizendo: “... você tem que caminhar, tirar uma hora por dia pra caminhar...”. 
Neste último exemplo provavelmente houve uma conversa no corredor, ou o terapeuta estava se referindo a algo que antecedeu a sessão.

Conclui-se então que na amostra analisada nesta pesquisa, os episódios de orientação/auto-orientação iniciavam-se quase sempre com o relato de uma situação vivenciada ao terapeuta. Em pouquíssimas situações isso não ocorreu, e em tais casos o episódio foi iniciado com uma intervenção do terapeuta.

\subsubsection{Intervenções do terapeuta que antecedem a emissão de orientação}

\section{ou auto-orientação}

A maioria dos terapeutas realizou outras intervenções antes de orientarem, ou antes de o cliente se auto-orientar dentro dos episódios de orientação/auto-orientação.

A Tabela 28 indica a ocorrência ou não ocorrência destas intervenções por parte dos diferentes terapeutas.

Tabela 28. Ocorrência/não ocorrência de intervenções do terapeuta que antecedem a emissão de orientação/auto-orientação

\begin{tabular}{|l|l|c|c|}
\hline & Terapeutas & Ocorrência & Não ocorrência \\
\hline \multirow{5}{*}{ Terapeutas Experientes } & TED & 86 & 1 \\
\cline { 2 - 4 } & TEE & 103 & 0 \\
\cline { 2 - 4 } & TEF & 51 & 0 \\
\hline \multirow{5}{*}{$\begin{array}{l}\text { Terapeutas Pouco } \\
\text { Experientes }\end{array}$} & TPE1A & 51 & 10 \\
\cline { 2 - 4 } & TPE2A & 47 & 13 \\
\cline { 2 - 4 } & TPE1B & 23 & 2 \\
\cline { 2 - 4 } & TPE2B & 59 & 1 \\
\hline & TPE1C & 49 & 0 \\
\hline & TPE2C & 67 & 0 \\
\hline
\end{tabular}

A maioria dos terapeutas apresentava outra intervenção terapêutica antes de orientar, após a narrativa do cliente. Os terapeutas pouco experientes TPE1A e TPE2A não fizeram qualquer tipo de intervenção antes da emissão da orientação ou autoorientação em parte dos episódios de orientação/auto-orientação. Estes são os mesmos terapeutas do Bloco A que orientaram na ausência de uma narrativa do cliente, ou seja, 
o episódio de orientação/auto-orientação podia se iniciar diretamente com a orientação ou com uma narrativa do cliente seguida de silêncio do terapeuta e em seguida uma orientação. Ou ainda, o cliente emitia uma auto-orientação após a narrativa sem haver intervenção do terapeuta.

As intervenções dos terapeutas foram categorizadas, sendo que podiam pertencer a mais de uma das categorias de comportamento verbal vocal do terapeuta de Zamignani e Meyer (2007). Ex: “... você tem que me falar mais sobre essa síndrome... Ela é hereditária!?”(solicitação de informação). “Agora... talvez o nenê que você perdeu anteriormente por outros motivos pode estar te levando a este comportamento obsessivo de descobrir todas as possíveis doenças que alguém de sua família ou da família de seu marido mencionou ter...” (interpretação).

Após a categorização das intervenções, episódios de orientação e autoorientação foram separados. Nos dois casos primeiramente buscou-se encontrar se havia diferenças estatísticas entre as intervenções utilizadas pelos terapeutas nos episódios de orientação e auto-orientação. Num segundo momento buscou-se verificar se as intervenções utilizadas pelos terapeutas experientes e pouco experientes nos episódios de orientação e auto-orientação eram significativamente diferentes.

Assim, iniciou-se a análise com as intervenções que antecediam a emissão de orientação.

Tabela 29. Número médio $(\mathrm{N})$ de ocorrências de categorias de intervenções dos diferentes terapeutas (nove terapeutas) nos episódios de orientação, frequência relativa percentil (apresentada em porcentagem) e p-valor

\begin{tabular}{cccc}
\hline Intervenções dos terapeutas nos & \multicolumn{2}{c}{ 9 Terapeutas } & p-valor \\
\cline { 2 - 4 } episódios de orientação & $\mathrm{N}$ & $\%$ & \\
\hline Solicitação de reflexão & 17,0 & $30,0 \%$ & \\
\hline Interpretação & 13,6 & $24,0 \%$ & 0,472 \\
\hline Solicitação de relato & 10,3 & $18,3 \%$ & 0,143 \\
\hline Informação & 5,3 & $9,4 \%$ & $0,006^{*}$ \\
\hline Aprovação & 3,3 & $5,9 \%$ & $<0,001^{*}$ \\
\hline Reprovação & 2,3 & $4,1 \%$ & $<0,001^{*}$ \\
\hline Outras verbalizações do terapeuta & 1,7 & $2,9 \%$ & $<0,001^{*}$ \\
\hline
\end{tabular}




\begin{tabular}{cccc}
\hline Terapeuta permanece em silêncio & 1,3 & $2,3 \%$ & $<0,001^{*}$ \\
\hline Facilitação & 1,0 & $1,8 \%$ & $<0,001^{*}$ \\
\hline Empatia & 0,7 & $1,2 \%$ & $<0,001^{*}$
\end{tabular}

Legenda:

* p-valores considerados estatisticamente significativos perante o nível de significância adotado.

Esta tabela foi organizada em ordem decrescente dos resultados mais prevalecentes para os menos prevalecentes. A coluna p-valor mostra a comparação de cada nível de categoria sempre em relação aos mais prevalecentes.

As intervenções dos terapeutas que antecediam a emissão da orientação eram predominantemente solicitação de reflexão e interpretação. Apesar de solicitação de reflexão ser a resposta mais prevalente, a análise estatística realizada não indicou diferenças significativas entre esta intervenção (solicitação de reflexão - 30\%), e as intervenções: interpretação (24\%) e solicitação de relato (18,3\%). As demais intervenções são significativamente diferentes quando comparadas à solicitação de reflexão, mas é importante mencionar que estas apresentam um número médio de ocorrências inferior às demais categorias.

As intervenções emitidas pelos terapeutas experientes e pouco experientes que antecediam a emissão de orientação foram comparadas, conforme demonstra a tabela a seguir.

Tabela 30. Número médio $(\mathrm{N})$ de ocorrências de categorias de intervenções, frequência relativa percentil e p-valor de categorias de intervenções emitidas pelos terapeutas experientes e pouco experientes nos episódios de orientação.

\begin{tabular}{|c|c|c|c|c|c|}
\hline \multirow{2}{*}{ 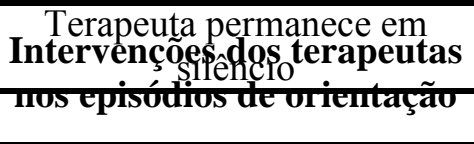 } & \multicolumn{2}{|c|}{ Derap0,Exp. } & \multicolumn{2}{|c|}{$\begin{array}{c}\text { Terap. Pouco } \\
\text { Exp. }\end{array}$} & \multirow[t]{2}{*}{ Pr,0GBot } \\
\hline & $\mathrm{N}$ & $\%$ & $\mathrm{~N}$ & $\%$ & \\
\hline Solicitação de relato & 7 & $9,0 \%$ & 12 & $26,1 \%$ & $0,011 *$ \\
\hline Facilitação & 1 & $1,3 \%$ & 1 & $2,2 \%$ & 0,703 \\
\hline Empatia & 2 & $2,6 \%$ & 0 & $0,0 \%$ & 0,274 \\
\hline Informação & 8 & $10,3 \%$ & 4 & $8,7 \%$ & 0,776 \\
\hline Solicitação de reflexão & 27 & $34,6 \%$ & 12 & $26,1 \%$ & 0,323 \\
\hline Interpretação & 23 & $29,5 \%$ & 9 & $19,6 \%$ & 0,223 \\
\hline Aprovação & 6 & $7,7 \%$ & 2 & $4,3 \%$ & 0,464 \\
\hline Reprovação & 3 & $3,8 \%$ & 2 & $4,3 \%$ & 0,891 \\
\hline $\begin{array}{c}\text { Outras verbalizações do } \\
\text { terapeuta }\end{array}$ & 1 & $1,3 \%$ & 2 & $4,3 \%$ & 0,283 \\
\hline
\end{tabular}


* p-valores considerados estatisticamente significativos perante o nível de significância adotado.

\# p-valores que por estarem próximos do limite de aceitação, tendem a ser significativos.

- x -, não é possível utilizar a estatística.

Não houve diferenças estatisticamente significativas entre as categorias de intervenções utilizadas pelos terapeutas experientes e pouco experientes nos episódios de orientação. A única exceção foi a categoria solicitação de relato. Os terapeutas pouco experientes apresentaram uma frequência relativa percentil (apresentada em porcentagem) maior de solicitação de relato do que os terapeutas experientes $(26,1 \%$ TPE e 9,0\% - TE), sendo esta diferença estatisticamente significativa.

Análise similar foi realizada para a auto-orientação. Assim, num primeiro momento buscou-se encontrar quais as intervenções que antecediam a emissão de autoorientação É o que mostra a Tabela 31 .

Tabela 31. Número médio $(\mathrm{N})$ de ocorrências de categorias de intervenções dos diferentes terapeutas (nove terapeutas) nos episódios de auto-orientação, frequência relativa percentil (apresentada em porcentagem) e p-valor.

\begin{tabular}{|c|c|c|c|}
\hline \multirow{2}{*}{$\begin{array}{l}\text { Intervenções dos terapeutas } \\
\text { nos episódios de auto- } \\
\text { orientação }\end{array}$} & \multicolumn{2}{|c|}{9 Terapeutas } & \multirow[t]{2}{*}{ p-valor } \\
\hline & $\mathrm{N}$ & $\%$ & \\
\hline Solicitação de reflexão & 8 & $32,0 \%$ & \\
\hline Interpretação & 8 & $32,0 \%$ & 1,000 \\
\hline Solicitação de relato & 3 & $12,0 \%$ & $0,088 \#$ \\
\hline Informação & 2 & $8,0 \%$ & $0,034 *$ \\
\hline Aprovação & 1 & $4,0 \%$ & $0,010^{*}$ \\
\hline Reprovação & 1 & $4,0 \%$ & $0,010^{*}$ \\
\hline $\begin{array}{c}\text { Outras verbalizações do } \\
\text { terapeuta }\end{array}$ & 1 & $4,0 \%$ & $0,010^{*}$ \\
\hline $\begin{array}{c}\text { Terapeuta permanece em } \\
\text { silêncio }\end{array}$ & 1 & $4,0 \%$ & $0,010 *$ \\
\hline Facilitação & 0 & $0,0 \%$ & $0,002 *$ \\
\hline Empatia & 0 & $0,0 \%$ & $0,002 *$ \\
\hline
\end{tabular}

Esta tabela foi organizada em ordem decrescente dos resultados mais prevalecentes para os menos prevalecentes. A coluna p-valor mostra a comparação de cada nível de categoria sempre em relação aos mais prevalecentes. 
As intervenções dos terapeutas que antecediam a emissão de auto-orientação também foram predominantemente solicitação de reflexão $(32 \%)$ e interpretação (32\%). Porém, apesar de estas duas intervenções serem mais prevalentes, elas não indicam diferenças estatisticamente significativas quando comparadas com solicitação de relatos (12\%). As demais categorias de intervenção que antecedem a emissão de auto-orientação apresentaram diferenças significativas, porém deve-se notar que a ocorrência média destas categorias é inexpressiva.

As intervenções emitidas pelos terapeutas experientes e pouco experientes que antecediam a emissão de auto-orientação foram comparadas.

Tabela 32. Número médio $(\mathrm{N})$ de ocorrências de categorias de intervenções, frequência relativa percentil e p-valor de intervenções emitidas pelos terapeutas experientes e pouco experientes nos episódios de auto-orientação

\begin{tabular}{|c|c|c|c|c|c|}
\hline \multirow{2}{*}{$\begin{array}{l}\text { Intervenções dos terapeutas nos } \\
\text { episódios de auto-orientação }\end{array}$} & \multicolumn{2}{|c|}{ Terap. Exp. } & \multicolumn{2}{|c|}{$\begin{array}{l}\text { Terap. Pouco } \\
\text { Experientes }\end{array}$} & \multirow[t]{2}{*}{ p-valor } \\
\hline & $\mathrm{N}$ & $\%$ & $\mathrm{~N}$ & $\%$ & \\
\hline 1. Solicitação de relato & 4 & $9,1 \%$ & 2 & $12,5 \%$ & 0,697 \\
\hline 2. Facilitação & 1 & $2,3 \%$ & 0 & $0,0 \%$ & 0,543 \\
\hline 3. Empatia & 0 & $0,0 \%$ & 0 & $0,0 \%$ & $-\mathrm{x}-$ \\
\hline 4. Informação & 3 & $6,8 \%$ & 1 & $6,3 \%$ & 0,938 \\
\hline 5. Solicitação de reflexão & 16 & $36,4 \%$ & 4 & $25,0 \%$ & 0,409 \\
\hline 6. Interpretação & 15 & $34,1 \%$ & 4 & $25,0 \%$ & 0,503 \\
\hline 7. Aprovação & 2 & $4,5 \%$ & 1 & $6,3 \%$ & 0,789 \\
\hline 8. Reprovação & 1 & $2,3 \%$ & 1 & $6,3 \%$ & 0,448 \\
\hline $\begin{array}{c}\text { 9. Outras verbalizações do } \\
\text { terapeuta }\end{array}$ & 1 & $2,3 \%$ & 1 & $6,3 \%$ & 0,448 \\
\hline $\begin{array}{l}\text { 10. Terapeuta permanece em } \\
\text { silêncio }\end{array}$ & 1 & $2,3 \%$ & 2 & $12,5 \%$ & 0,108 \\
\hline
\end{tabular}

Não houve diferenças estatisticamente significativas entre as categorias de intervenções utilizadas pelos terapeutas experientes e pouco experientes nos episódios de auto-orientação. Para ambos os terapeutas, as categorias de intervenções mais 
frequentes foram solicitação de reflexão (36,4\% - TE e 25\% TPE) e interpretação $(34,1 \%$ - TE e $25 \%$ TPE).

Tais resultados sugerem que terapeutas antes de orientar, tentam fazer com que os clientes se auto-orientem, pois solicitam reflexão e proporcionalmente fazem interpretações mais do que utilizam outras intervenções. Essa forma de agir nesta amostra parece ser independente da experiência do terapeuta.

\subsubsection{Antecedente (Comportamentos do cliente anteriores à} apresentação de orientação ou auto-orientação)

Tanto nos episódios de orientação/auto-orientação dos terapeutas experientes como nos episódios de orientação/auto-orientação dos terapeutas pouco experientes observou-se em 97\% dos casos antecedentes do comportamento de orientar ou autoorientar. Os 3\% dos casos sem antecedentes ou eram compostos de intervenções do terapeuta que assumiam a função do antecedente ao comportamento de orientar/autoorientar (seis ocorrências) ou a narrativa do cliente assumia a função de antecedente do comportamento de orientar/auto-orientar (uma ocorrência).

Já no caso dos terapeutas pouco experientes, em 87\% dos episódios de orientação/auto-orientação foram encontrados os antecedentes do comportamento de orientar ou auto-orientar e em 13\% não foram encontrados tais antecedentes. Nesses casos verificaram-se as seguintes possibilidades: as intervenções feitas pelos terapeutas funcionaram como antecedente do comportamento de orientar/auto-orientar (19 ocorrências); a narrativa do cliente funcionou como antecedente do comportamento de orientar/auto-orientar (19 ocorrências); e não houve ligação clara entre a emissão de orientação/auto-orientação e qualquer outro comportamento do cliente ou terapeuta no episódio de orientação/auto-orientação (duas ocorrências). Um exemplo dessa última 
situação foi: terapeuta inicia a sessão dizendo: “... quero que você vá caminhar todos os dias, isso te fará bem”. Provavelmente houve um conversa antes de o cliente entrar na sala para que então o terapeuta orientasse, ou o terapeuta estava se referindo a algo discutido em outra ocasião. De qualquer forma neste último caso não há como precisar o antecedente da emissão dessa orientação.

Para analisar quais os possíveis antecedentes do comportamento de orientar/auto-orientar, utilizou-se uma adaptação das 'categorias de comportamento verbal vocal dos clientes' de Zamignani e Meyer (2007). As falas do cliente que antecederam a orientação/auto-orientação podiam pertencer a mais de uma categoria. Ex.: “... não, não... você tá se confundindo... (oposição) o que to tentando dizer é que eu só bati no M., pois ele me levou à loucura... Qualquer pessoa no meu lugar teria feito o mesmo... não considero que fiz algo errado, fiz aquilo por razões óbvias... estava cansada, em TPM, com muito trabalho, ele já vinha me incomodando faz tempo, as coisas foram se acumulando, eu fui me enchendo... e ele parece não querer entender... (relações)"

Após a categorização dos antecedentes, episódios de orientação e autoorientação foram separados. Nos dois casos primeiramente buscou-se encontrar se havia diferenças estatísticas entre os antecedentes e emissão de orientação/autoorientação. Num segundo momento buscou-se verificar se os antecedentes e emissão de orientação/auto-orientação encontrados nas sessões de terapeutas experientes e pouco experientes eram significativamente diferentes.

Assim, iniciou-se a análise com os antecedentes à emissão de orientação, conforme nos mostra a tabela a seguir. 
Tabela 33. Número médio $(\mathrm{N})$ de ocorrências de categorias de antecedentes dos diferentes terapeutas (nove terapeutas) nos episódios de orientação, frequência relativa percentil (apresentada em porcentagem) e p-valor

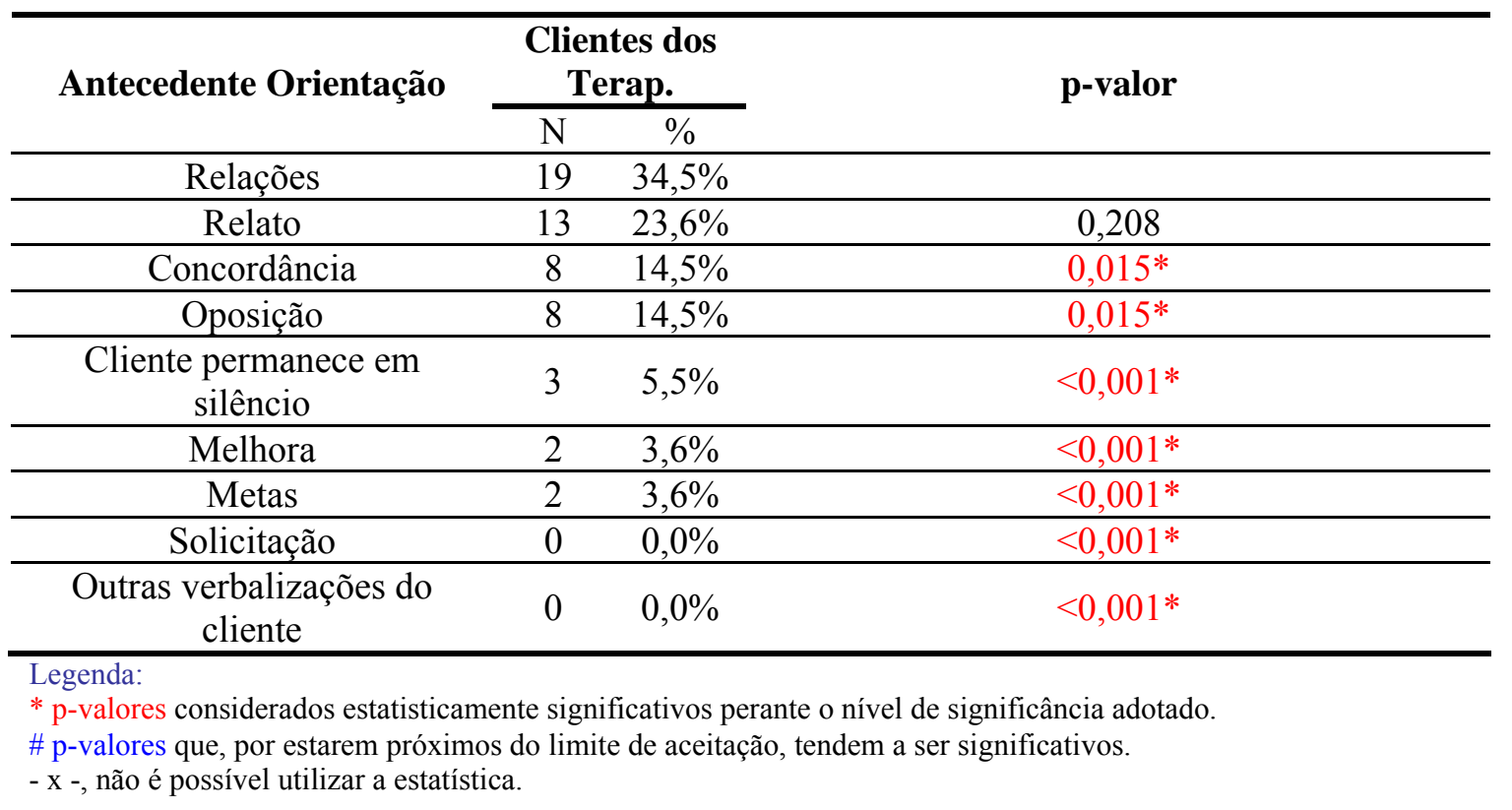

Esta tabela foi organizada em ordem decrescente, dos resultados mais prevalecentes para os menos prevalecentes. A coluna p-valor mostra a comparação de cada nível de categoria sempre em relação aos mais prevalecentes.

Funcionaram como antecedentes à emissão de orientação: 1. O comportamento dos clientes de estabelecer relações entre os eventos ocorridos; 2. Relatar o que ocorreu, descrevendo e informando ao terapeuta sobre os eventos; 3. Opor-se às verbalizações do terapeuta; 4. Concordar com o estabelecimento de relações feito pelos terapeutas. Análises estatísticas indicam que apesar de a categoria relações ser o antecedente mais prevalente, não houve diferenças significativas desta categoria de antecedente quando comparada com a categoria de antecedente relato. As demais categorias de antecedente apresentaram diferenças significativas quanto comparadas à categoria de antecedente relações, porém mais uma vez esta diferença deve ser olhada com cautela, pois a 
ocorrência média das categorias que mostram diferenças significativas são inexpressivas.

As categorias de antecedentes a emissão de orientações encontradas nas sessões dos terapeutas experientes e pouco experientes foram comparadas. A tabela a seguir mostra esta comparação.

Tabela 34. Número médio $(\mathrm{N})$ de ocorrências de categorias de antecedentes à emissão de orientação, frequência relativa percentil e p-valor de categorias de antecedentes emitidas nas sessões dos terapeutas experientes e pouco experientes.

\begin{tabular}{cccccc}
\hline \multirow{2}{*}{ Antecedente Orientação } & \multicolumn{2}{c}{$\begin{array}{c}\text { Terap. } \\
\text { Experientes }\end{array}$} & \multicolumn{2}{c}{$\begin{array}{c}\text { Terap. } \\
\text { Pouco Exp. }\end{array}$} & p-valor \\
\cline { 2 - 6 } & $\mathrm{N}$ & $\%$ & $\mathrm{~N}$ & $\%$ & \\
\hline Solicitação & 0 & $0,0 \%$ & 0 & $0,0 \%$ & $-\mathrm{x}-$ \\
\hline Relato & 18 & $25,4 \%$ & 11 & $26,2 \%$ & 0,921 \\
\hline Melhora & 3 & $4,2 \%$ & 2 & $4,8 \%$ & 0,893 \\
\hline Metas & 3 & $4,2 \%$ & 1 & $2,4 \%$ & 0,608 \\
\hline Relações & 26 & $36,6 \%$ & 10 & $23,8 \%$ & 0,158 \\
\hline Concordância & 9 & $12,7 \%$ & 7 & $16,7 \%$ & 0,557 \\
\hline Oposição & 9 & $12,7 \%$ & 8 & $19,0 \%$ & 0,360 \\
\hline $\begin{array}{c}\text { Outras verbalizações do } \\
\text { cliente }\end{array}$ & 0 & $0,0 \%$ & 0 & $0,0 \%$ & $-\mathrm{x}-$ \\
\hline $\begin{array}{c}\text { Cliente permanece em } \\
\text { silêncio }\end{array}$ & 3 & $4,2 \%$ & 3 & $7,1 \%$ & 0,504 \\
\hline
\end{tabular}

Legenda:

* p-valores considerados estatisticamente significativos perante o nível de significância adotado.

\# p-valores que, por estarem próximos do limite de aceitação, tendem a ser significativos.

- x -, não é possível utilizar a estatística.

Não houve diferenças estatísticas ao se comparar os antecedentes à emissão de orientação nas sessões dos terapeutas experientes e pouco experientes.

Os antecedentes à emissão de auto-orientação também foram analisados. A Tabela 35 apresenta esses dados. 
Tabela 35. Número médio $(\mathrm{N})$ de ocorrências de categorias de antecedentes dos diferentes terapeutas (nove terapeutas) nos episódios de auto-orientação, frequência relativa percentil (apresentada em porcentagem) e p-valor

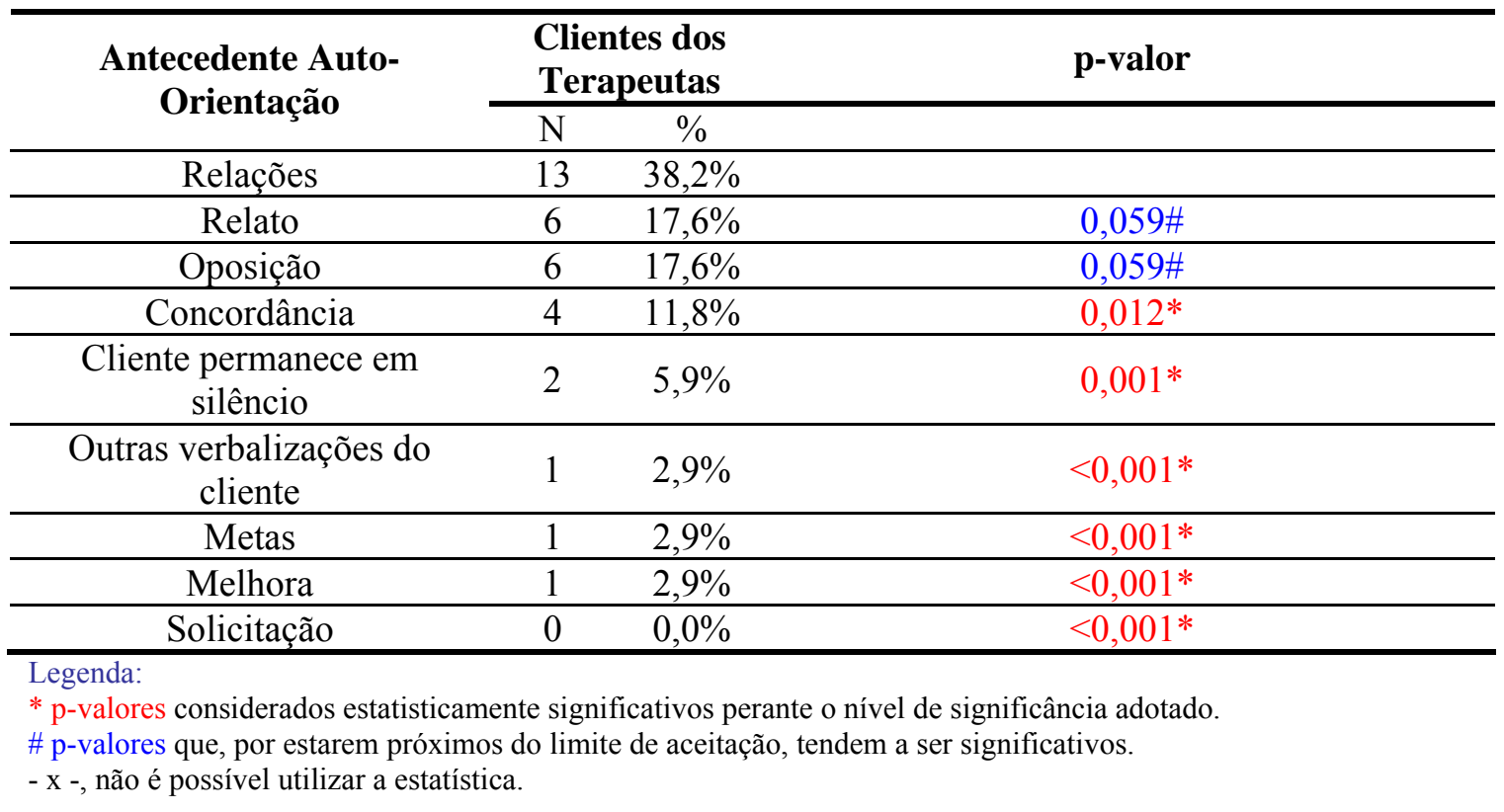

Esta tabela foi organizada em ordem decrescente, dos resultados mais prevalecentes para os menos prevalecentes. A coluna p-valor mostra a comparação de cada nível de categoria sempre em relação aos mais prevalecentes.

Os antecedentes à emissão de auto-orientação foram: 1. Estabelecimento de relações entre os eventos ocorridos; 2. Relato de situações vivenciadas; 3. Oposição às intervenções do terapeuta e 4. Concordância com as análises ou intervenções do terapeuta.

Análises estatísticas indicam que apesar de a categoria relações ser 0 antecedente mais prevalente, não houve diferenças significativas desta categoria de antecedente quando comparada com a categoria de antecedente relato. As demais categorias de antecedente apresentaram diferenças significativas quanto comparadas à categoria de antecedente relações, porém esta diferença deve ser olhada com cautela, 
pois a ocorrência média das categorias que mostram diferenças significativas são inexpressivas.

Tabela 36. Número médio $(\mathrm{N})$ de ocorrências de categorias de antecedentes à emissão de autoorientação, frequência relativa percentil e p-valor de categorias de antecedentes emitidas nas sessões dos terapeutas experientes e pouco experientes

\begin{tabular}{|c|c|c|c|c|c|}
\hline \multirow{2}{*}{$\begin{array}{l}\text { Antecedente Auto- } \\
\text { Orientação }\end{array}$} & \multicolumn{2}{|c|}{$\begin{array}{c}\text { Terap. } \\
\text { Experientes }\end{array}$} & \multicolumn{2}{|c|}{$\begin{array}{c}\text { Terap. } \\
\text { Pouco Exp. }\end{array}$} & \multirow[t]{2}{*}{ p-valor } \\
\hline & $\mathrm{N}$ & $\%$ & $\mathrm{~N}$ & $\%$ & \\
\hline Solicitação & 0 & $0,0 \%$ & 0 & $0,0 \%$ & $-x-$ \\
\hline Relato & 10 & $17,5 \%$ & 4 & $19,0 \%$ & 0,878 \\
\hline Melhora & 1 & $1,8 \%$ & 1 & $4,8 \%$ & 0,456 \\
\hline Metas & 2 & $3,5 \%$ & 1 & $4,8 \%$ & 0,799 \\
\hline Relações & 30 & $52,6 \%$ & 5 & $23,8 \%$ & $0,023 *$ \\
\hline Concordância & 3 & $5,3 \%$ & 2 & $9,5 \%$ & 0,496 \\
\hline Oposição & 7 & $12,3 \%$ & 5 & $23,8 \%$ & 0,211 \\
\hline $\begin{array}{c}\text { Outras verbalizações do } \\
\text { cliente }\end{array}$ & 1 & $1,8 \%$ & 1 & $4,8 \%$ & 0,456 \\
\hline $\begin{array}{l}\text { Cliente permanece em } \\
\text { silêncio }\end{array}$ & 3 & $5,3 \%$ & 2 & $9,5 \%$ & 0,496 \\
\hline
\end{tabular}

Tanto os clientes dos terapeutas experientes como os clientes dos terapeutas pouco experientes se auto-orientam em maiores proporções após eles mesmos: 1. estabelecerem relações entre eventos; 2. relatarem situações; 3. se oporem às intervenções dos terapeutas ou 4. concordarem com as análises e intervenções dos terapeutas. A análise estatística realizada indicou haver diferenças nos antecedentes dos terapeutas experientes e pouco experientes somente para a categoria de antecedente relações. Tais dados sugerem que aparentemente os terapeutas experientes esperam que clientes estabeleçam relações e emitam auto-orientação em mais ocasiões, modelando assim a resposta de emissão de autorregras. Já os clientes dos terapeutas experientes, apesar de apresentarem também mais auto-orientações após estabelecerem relações, apresentaram uma distribuição de categorias de antecedente mais dispersa. 


\subsubsection{Orientação/ auto-orientação}

Uma nova categorização das orientações e auto-orientações foi realizada na presente pesquisa. Após esta categorização, compararam-se os dados obtidos com a categorização realizada no estudo de Donadone (2004).

Dois testes estatísticos foram utilizados para a análise de concordância das categorias de comportamentos de orientação e auto-orientação.

Para verificar quantas categorias de orientação e auto-orientação deixaram de ser identificadas (perda) na presente pesquisa em comparação com a categorização realizada no estudo de Donadone (2004), utilizou-se o teste de igualdade de proporções, conforme mostra a tabela a seguir.

Tabela 37: Distribuição de perda ( $\mathrm{N}$ e \%) entre as categorizações do estudo de Donadone (2004) e a atual pesquisa

\begin{tabular}{cccc}
\hline Perda & $\mathbf{N}$ & $\mathbf{\%}$ & p-valor \\
\hline Terapeuta & 10 & $2,15 \%$ & $<0,001 *$ \\
\hline Cliente & 1 & $0,94 \%$ & $<$ \\
\hline $\begin{array}{l}\text { Legenda: } \\
* \text { p-valores considerados estatisticamente significativos perante o nível de significância adotado. }\end{array}$
\end{tabular}

A Tabela 37 indica que no caso da orientação, apenas dez categorizações $(2,15 \%)$ que foram feitas na pesquisa de mestrado não foram encontradas na atual pesquisa. No caso da auto-orientação, apenas uma categorização $(0,94 \%)$ que foi feita no mestrado não foi identificada na pesquisa atual. Conclui-se então que houve maior perda entre as categorizações de orientações dos terapeutas $(2,15 \%)$ do que das categorias de auto-orientações dos clientes. Ou seja, observa-se que, na categorização realizada na atual pesquisa, diminuiu mais o número de orientações do que de autoorientações. Porém nos dois casos os índices são extremamente baixos, o que indica que em apenas poucos casos as categorias de orientação e auto-orientação não foram encontradas ou identificadas na nova categorização realizada na presente pesquisa. 
Analisou-se também o índice de concordância de Kappa para medir o grau de concordância das categorizações de 2004 e da atual pesquisa. Esta análise foi feita para terapeutas e clientes, e foi medida tanto para cada subtipo de categoria quanto para as categorias no geral. Para complementar a análise de concordância via índice Kappa, utilizou-se a técnica de Intervalo de confiança. As tabelas a seguir mostram isso.

Tabela 38: Concordância entre as categorizações de orientação (emitidas pelos terapeutas) no estudo de Donadone (2004) e na atual pesquisa. Nesta tabela encontram-se: na primeira coluna os diferentes subtipos de orientação emitidos pelos terapeutas, na segunda coluna o índice de concordância Kappa, na terceira coluna o intervalo de confiança (IC) e na quarta o p-valor.

\begin{tabular}{cccc}
\hline Subtipos de O & Kappa & IC & p-valor \\
\hline OAE & $89,9 \%$ & $9,2 \%$ & $<0,001^{*}$ \\
\hline OAG & $79,0 \%$ & $9,2 \%$ & $<0,001^{*}$ \\
\hline OE & $89,7 \%$ & $9,2 \%$ & $<0,001^{*}$ \\
\hline OT & $85,9 \%$ & $9,2 \%$ & $<0,001^{*}$ \\
\hline Geral & $86,5 \%$ & $6,1 \%$ & $<0,001^{*}$ \\
\hline Legenda: &
\end{tabular}

A Tabela 38 indica que, de modo geral, houve um índice de concordância Kappa de $86,5 \%$ (intervalo de confiança - IC $=6,1 \%$ ) entre as categorias de orientação encontradas no estudo de Donadone (2004) e no atual estudo. Quando a análise recai para os diferentes subtipos de orientação, observou-se que os índices de concordância Kappa em sua maioria foram considerados ótimos (conforme análise estatística no método), com exceção da categoria OAG. Nesta categoria, a concordância entre o estudo de Donadone (2004) e o atual estudo foi de 79\% (intervalo de confiança - IC = 9,2\%), o que indica que a concordância é quase ótima.

Tabela 39: Concordância entre as categorizações de auto-orientação (emitidas pelos clientes) do estudo de Donadone (2004) e da atual pesquisa. Nesta tabela encontram-se: na primeira coluna os diferentes subtipos de auto-orientação emitidos pelos clientes, na segunda coluna o índice de concordância Kappa, na terceira coluna o intervalo de confiança (IC) e na quarta o p-valor.

\begin{tabular}{cccc}
\hline Subtipos de AO & Kappa & IC & p-valor \\
\hline AOAE & $96,2 \%$ & $19,3 \%$ & $<0,001^{*}$ \\
\hline AOAG & $89,8 \%$ & $19,2 \%$ & $<0,001^{*}$ \\
\hline AOE & $86,4 \%$ & $19,2 \%$ & $<0,001^{*}$ \\
\hline Geral & $91,9 \%$ & $15,0 \%$ & $<0,001^{*}$ \\
\hline $\begin{array}{l}\text { Legenda: } \\
\text { * p-valores considerados estatisticamente significativos perante o nível de significância adotado. }\end{array}$
\end{tabular}


A Tabela 39 indica que, de modo geral, houve concordância do índice Kappa de 91,9\% (intervalo de confiança - IC $=15 \%$ ) entre as categorias de auto-orientação encontradas no estudo de Donadone (2004) e no atual estudo. Quando a análise recai para os diferentes subtipos de auto-orientação, observou-se que os índices de concordância Kappa foram considerados ótimos, ou seja, para todos os subtipos de auto-orientação o índice de concordância encontra-se acima de 80\%.

Nas 81 sessões analisadas foram encontradas 465 orientações e 105 autoorientações. A Tabela 40 apresenta a quantidade de orientações e auto-orientações (dados brutos) por terapeuta.

Tabela 40. Distribuição de orientação e auto-orientação entre os diferentes terapeutas

\begin{tabular}{|c|c|c|c|}
\hline & Terapeutas & Orientação & Auto-orientação \\
\hline \multirow{3}{*}{ 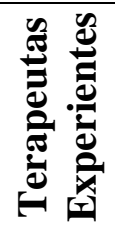 } & TED & 46 & 43 \\
\hline & TEE & 99 & 5 \\
\hline & TEF & 39 & 11 \\
\hline \multirow{7}{*}{ 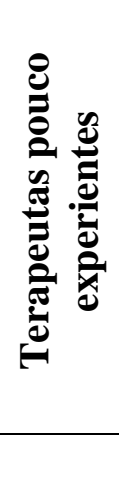 } & TPE1A & 55 & 11 \\
\hline & TPE2A & 56 & 3 \\
\hline & TPE1B & 25 & 1 \\
\hline & TPE2B & 48 & 13 \\
\hline & TPE1C & 36 & 11 \\
\hline & TPE2C & 61 & 7 \\
\hline & Total & 465 & 105 \\
\hline
\end{tabular}

Observa-se na Tabela 40 que o terapeuta experiente que emitiu o maior número de orientações foi o TEE (99), e o terapeuta pouco experiente que emitiu o menor número de orientação foi o TPE1B (25). Retirando esses dois extremos, todos os terapeutas, quer fossem experientes quer pouco experientes, emitiram aproximadamente de 40 a 60 orientações nas nove sessões realizadas por cada um.

O alto número de orientações do TEE não é característico de experiência e sim de um estilo pessoal mais diretivo. Se fosse a experiência, o número mais alto de 
orientações apareceria nas terapias dos outros terapeutas experientes. Não houve, tampouco, nenhuma característica de seus clientes que pudesse ser responsável por essa frequência mais alta. Já o baixo número de orientações do TPE1B parece estar relacionado ao perfil dos clientes com quem esse terapeuta trabalhava (dor crônica). Clientes com dores crônicas parecem aceitar menos estratégias diretivas. Tal afirmação encontra respaldo na literatura. Autores como Murta (1999), Teixeira (1994) e Kanner (1998) apontam que clientes com dores crônicas são mais hostis, belicosos, raivosos e irritadiços. Nardi (2004) afirma ainda que clientes com dores crônicas tendem a ser mais resistentes. Nardi (2004) e Scarpelli (2007) sugerem que trabalhos com clientes com dores crônicas deveriam ter ação mais discreta e menos diretiva, o que requer do terapeuta muita habilidade.

Quanto à auto-orientação apenas os clientes do TED apresentaram um número mais elevado de emissões (43), o que parece estar relacionado a alguma característica do trabalho deste terapeuta. Os clientes de todos os outros terapeutas, independente de experiência, apresentaram poucas auto-orientações.

Os subtipos de orientação e auto-orientação se distribuíram da seguinte maneira:

Tabela 41. Ocorrências e frequência relativa percentil (apresentada em porcentagem) de subtipos de orientação/auto-orientação

\begin{tabular}{|c|c|c|c|c|c|c|c|c|c|c|c|c|c|c|c|c|c|c|c|}
\hline & \multirow{2}{*}{ Subtipos de O/AO } & \multicolumn{2}{|c|}{ TED } & \multicolumn{2}{|c|}{ TEE } & \multicolumn{2}{|c|}{ TEF } & \multicolumn{2}{|c|}{ TPE1A } & \multicolumn{2}{|c|}{ TPE2A } & \multicolumn{2}{|c|}{ TPE1B } & \multicolumn{2}{|c|}{ TPE2B } & \multicolumn{2}{|c|}{ TPE1C } & \multicolumn{2}{|c|}{ TPE2C } \\
\hline & & $\mathbf{n}$ & $\%$ & $\mathbf{N}$ & $\%$ & $\mathbf{n}$ & $\%$ & $\mathbf{n}$ & $\%$ & $\mathbf{N}$ & $\%$ & $\mathbf{N}$ & $\%$ & $\mathbf{n}$ & $\%$ & $\mathbf{n}$ & $\%$ & $\mathbf{n}$ & $\%$ \\
\hline \multirow{5}{*}{ 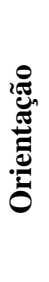 } & OAE & 15 & 33 & 72 & 73 & 22 & 56 & 17 & 31 & 16 & 29 & 10 & 40 & 25 & 52 & 11 & 31 & 33 & 54 \\
\hline & OAG & 13 & 28 & 17 & 17 & 5 & 13 & 21 & 38 & 19 & 34 & 9 & 36 & 11 & 23 & 5 & 14 & 7 & 12 \\
\hline & OE & 18 & 39 & 10 & 10 & 12 & 31 & 8 & 15 & 18 & 32 & 6 & 24 & 12 & 25 & 16 & 44 & 16 & 26 \\
\hline & OT & 0 & 0 & 0 & 0 & 0 & 0 & 9 & 16 & 3 & 5 & 0 & 0 & 0 & 0 & 4 & 11 & 5 & 8 \\
\hline & $\Sigma$ & 46 & 100 & 99 & 100 & 39 & 100 & 55 & 100 & 56 & 100 & 25 & 100 & 48 & 100 & 36 & 100 & 61 & 100 \\
\hline \multirow{5}{*}{ 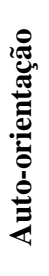 } & AOAE & 21 & 49 & 3 & 60 & 9 & 82 & 4 & 36 & 0 & 0 & 1 & 100 & 9 & 69 & 5 & 46 & 4 & 57 \\
\hline & AOAG & 15 & 35 & 2 & 40 & 2 & 18 & 7 & 64 & 3 & 100 & 0 & 0 & 3 & 23 & 3 & 27 & 3 & 43 \\
\hline & AOE & 7 & 16 & 0 & 0 & 0 & 0 & 0 & 0 & 0 & 0 & 0 & 0 & 1 & 8 & 3 & 27 & 0 & 0 \\
\hline & AOT & 0 & 0 & 0 & 0 & 0 & 0 & 0 & 0 & 0 & 0 & 0 & 0 & 0 & 0 & 0 & 0 & 0 & 0 \\
\hline & $\Sigma$ & 43 & 100 & 5 & 100 & 11 & 100 & 11 & 100 & 3 & 100 & 1 & 100 & 13 & 100 & 11 & 100 & 7 & 100 \\
\hline
\end{tabular}


Ao comparar a frequência relativa percentil (apresentada em porcentagem) de orientação para ação específica (OAE) emitida pelos diferentes terapeutas, foi possível observar que apenas quatro terapeutas (TED, TPE1A; TPE2A e TPE1C) apresentaram frequência relativa percentil em torno de $30 \%$ deste subtipo de orientação. Os demais terapeutas apresentaram frequência relativa percentil de orientação para ação específica (OAE) superiores a 40\%, destacando-se o TEE, que basicamente emitiu orientação para ação específica com frequência de $73 \%$.

Ao comparar a frequência relativa percentil de orientação para ação genérica (OAG) emitida pelos diferentes terapeutas foi possível observar que dos nove terapeutas participantes quatro (TEE, TEF, TPE1C e TPE2C) apresentaram frequência relativa percentil inferiores a $20 \%$ para este subtipo de orientação. Os demais terapeutas apresentaram frequência relativa percentil de orientação genérica superiores, destacando-se o TPE1A (38\%).

Ao comparar a frequência relativa percentil de orientação para encobertos (OE) emitida pelos diferentes terapeutas foi possível observar que dos nove terapeutas participantes quatro (TED, TEF, TPE2A e TPE1C) apresentaram frequência relativa percentil superior a $30 \%$.

Já ao comparar a frequência relativa percentil de orientações para tarefa (OT), verificou-se que apenas os terapeutas pouco experientes as emitiram.

Realizou-se também a comparação entre as auto-orientações emitidas pelos clientes dos diferentes terapeutas.

A auto-orientação para ação específica (AOAE) foi encontrada com alta frequência relativa percentil nas sessões de todos os terapeutas com exceção do TPE2A $(0 \%)$. 
Quanto à auto-orientação para ação genérica (AOAG) encontrou-se baixa frequência relativa percentil, apenas nas sessões do TEF e TPE1B.

Somente os clientes dos terapeutas TED, TPE2B e TPE1C emitiram autoorientação para encobertos.

Nenhum cliente emitiu auto-orientação para tarefa (AOT).

Grosso modo, pode-se concluir que os terapeutas participantes desta pesquisa quando emitiram orientações, utilizaram mais orientações para ação específica (OAE) e orientações para ação genérica (OAG). A emissão de orientações para encobertos (OE) foi encontrada de forma significativa nas sessões de quatro terapeutas. Os demais as emitiram de forma discreta. Já as orientações para tarefa (OT) só ocorreram nas sessões dos terapeutas pouco experientes. Os clientes dos diferentes terapeutas também utilizaram percentualmente mais auto-orientações para ação específica (AOAE) e autoorientações para ação genérica (AOAG) e houve baixa ocorrência de auto-orientações para encobertos (AOE). Nenhum cliente participante desta pesquisa emitiu autoorientação para tarefa (AOT).

Uma análise descritiva das orientações e auto-orientações mostrou que as orientações emitidas pelo terapeuta experiente D (TED), de forma geral, eram compostas de falas longas com bastante interpretação e informação (contextualização). O terapeuta parecia ter domínio do caso fazendo ligações entre comportamentos trazidos anteriormente (história de vida) e comportamentos trazidos na sessão.

Quanto ao terapeuta experiente E (TEE), observou-se que as orientações de forma geral eram compostas de falas longas com bastante interpretação e informação (contextualização), havia uso de metáforas em algumas emissões de orientação, porém a maioria das orientações emitidas por este terapeuta referia-se ao cotidiano e havia muita repetição de função e não de conteúdo explícito. 
Já quanto ao terapeuta experiente F (TEF), as orientações de forma geral eram compostas por falas longas, havia uso de metáfora em algumas emissões de orientação, porém não eram estabelecidas relações com a história de vida. A maioria das orientações era vinculada ao cotidiano. Muitas orientações eram encadeamentos para novas orientações e havia encadeamento de orientações emitidas pelo terapeuta e autoorientação emitida pelo cliente.

O terapeuta pouco experiente 1A (TPE1A) emitiu orientações de forma geral voltadas para o cotidiano. Essas orientações em sua maioria eram práticas, no intuito de resolver o que o cliente trazia de problema. Já o terapeuta pouco experiente $2 \mathrm{~A}$ (TPE2A) emitiu orientações que descreviam bastante o que o cliente deveria fazer, sendo que todas elas eram voltadas pra assuntos cotidianos e não havia ligações com história de vida anterior.

Quanto às orientações emitidas pelo terapeuta pouco experiente 1B $\left(\mathbf{T P E} \mathbf{B}^{14}\right)$, estas foram extremamente precisas, simples, curtas e voltadas para situações cotidianas. O terapeuta pouco experiente 2B (TPE2B) emitiu orientações objetivas e voltadas para questões atuais.

O terapeuta pouco experiente 1C (TPE1C) emitiu orientações voltadas basicamente para questões do cotidiano. Por fim, o terapeuta pouco experiente $2 \mathrm{C}$ (TPE2C) emitiu orientações bem descritivas e também voltadas para assuntos cotidianos.

Ao observar os diferentes subtipos de orientação emitidos pelos terapeutas experientes e pouco experientes, constatou-se que a emissão de Orientação para Ação Específica $(\underline{\mathbf{O A E}})$ era feita de modo geral por meio de:

\footnotetext{
${ }^{14}$ É importante ressaltar que a maioria dos clientes deste terapeuta relatava dores crônicas.
} 
(1) Modelos emitidos pelos terapeutas (o terapeuta dá o modelo exato de qual deveria ser a fala específica do cliente na situação) Ex1: "Numa situação como essa você deveria falar o seguinte: W. eu já te expliquei o que quero do seu trabalho, e já te expliquei que da próxima vez que você não fizer, será demitido... Não tenho mais nada que discutir com você... Entendeu? Você deve falar claramente isso a ele" Ex2: "Você deve falar o que te incomoda no teu marido, por exemplo: não gosto que você fique até tarde tomando chopinho com seus amigos, mas ao fazer isso você deve entender que seu comportamento terá uma consequência, como por exemplo, ele dizer que também não gosta que você fique horas na academia.”

(2) Especificação dos passos necessários para se atingir o objetivo desejado de acordo com a história do cliente. Ex1: "Baseado em tudo o que você vem me falando... Eu acho que você deveria fazer o seguinte... Primeiro tente falar com seu chefe sobre sua insatisfação com seu emprego, paralelamente mande currículos a outras empresas, faça cursos de aprimoramento na sua área, tenha claro o que você quer e quanto pretende investir... Esse é o caminho a ser percorrido para se chegar à satisfação profissional.”

(3) Indicação de comportamentos que eliminam situações aversivas. Ex1: "No estágio também, então, mas aí você leva alguma coisa para comer e come... Sabe, ou então pode até tomar um suco... Aí no final da tarde você janta direitinho, é para... É mudança de hábito mesmo M., infelizmente vocês adolescentes estão habituadas ao que vocês comem bem no café, mais ou menos no café da manhã... Ao se alimentar adequadamente você verá que metade dos seus problemas estomacais será reduzida.”

(4) Avaliação da situação em conjunto com o cliente e especificação de comportamentos a serem realizados. Ex1: "Mas você pode investir nela (carreira de músico), mas existe outro lado que você também quer desenvolver né... A escola que 
você está fazendo... Os planos que você tem... Então tomar uma decisão do que fazer agora, nesse momento é muito prematuro né... O legal é o quê? Conciliar as duas coisas que você está fazendo... Conciliar a escola... Os estudos e até porque um músico tem que ter cultura, saber outras línguas.”

A emissão de Orientação para Ação Genérica ( $\underline{\mathbf{O A G}})$ era feita de modo geral por meio de:

(1) Indicação de atuações genéricas que eliminam situações aversivas. Ex1: "Sumir por um tempo de tudo... Sem comunicação... Não há como ninguém te pedir mais nada... É difícil eu te dizer como fazer isso, mas você certamente se poupará de um alto nível de estresse."

(2) Avaliação da situação em conjunto com o cliente e indicação de atuações genéricas a serem realizadas. Ex1: "Vamos pensar o que você tem feito para chegar a essa felicidade que você tanto fala... Você já pensou sobre isso... Em termos de ação... Se você quer ser feliz, seja feliz... Mas até ser feliz requer um pouco de empenho... Para ser feliz, é necessário que façamos algumas coisinhas que nos proporcionem a felicidade. Então mãos a obra... Faça por onde..."

(3) Uso de Metáforas. Ex1: "Se Maomé não vai a montanha, a montanha vem até Maomé! Entende? Vá atrás de seus interesses.”

(4) Modelos emitidos pelos terapeutas. Ex1: "Se, por exemplo, você quer mais respeito de seu filho, faça com que ele te respeite... Se quer mais companheirismo crie situações pra obter isso... De acordo com o que você escolher para fazer saiba que seu grande objetivo é além da convivência, aumentar o diálogo.”

A emissão de Orientação para Encobertos $(\underline{\mathbf{O E}})$ era feita de modo geral por meio de:

(1) Estabelecimento de relação entre história de vida e situação atual. Ex1: "Quero que você pense nessa semana se o que você chama hoje de surto não tem relação direta 
com o que sua mãe dizia ser birra quando você era criança." Ex2: "Pense durante a semana se você se lembra que comportamentos você tinha quando era contrariada e se mudou alguma coisa nos dias de hoje no que se refere a ser contrariada. Você provavelmente verá que hoje você lida com as contrariedades de forma mais adequada e isto é muito bom... Você pode ir lembrando ao poucos, primeiro da sua infância, depois dos seus pais até chegar aos dias de hoje no que se refere ao seu relacionamento com seu marido, ok!” Ex3: "Preste atenção nessa semana o que mudou em você desde a separação! Tente listar coisas que mudaram para melhor, como por exemplo, voltar a dirigir, se cuidar mais...”

(2) Solicitação de avaliação da situação e levantamento de possibilidades de resolução. Ex1: "E o que você poderia fazer frente a tudo isso? Vamos pensar nisto esta semana?" Ex2: "Para pensar um pouquinho se não tem umas pessoas para te dar apoio, te dar uma força nessa hora. Ou pessoas que você possa passar horas agradáveis; sabe jantar com o teu tio que é uma pessoa agradável de conversar, e com o outro tio que você tem..." Ex3: "Você acha que falar que está grávida, resolveria mesmo seu problema? Como você levaria isso adiante! Isso não acabaria sendo pior para você mesma. Não seria no mínimo incoerente com sua idade. Tente pensar calmamente sobre isso estes dias antes de tomar atitudes, o?. Pense em outras possibilidades para que você se sinta protegida por ele.” Ex4: “Mas S., pensa bastante no que eu disse... Que você tem que fazer alguma coisa, nem que assim, mesmo que você não for aprender uma profissão, mesmo que você não for trabalhar, mas você tem que fazer alguma coisa para se realizar... Aprender fazer alguma coisa, aprender dançar, tocar é tão gostoso.” 
(3) Levantamento de objetivos de vida. Ex1: "Antes de você tomar qualquer atitude, você tem que ter claro o que quer na vida. Pense sobre isso!” Ex2: “Tente pensar num objetivo que você possa ter! O que você gostaria de fazer daqui pra frente?”

(4) Uso de Metáforas. Ex1: “Não sei, a gente tem que pensar sempre em melhoras pequenas, do que quê está fazendo efeito né... Às vezes também não é garantia total, a gente às vezes faz do jeito certinho a receita do bolo, mas aí tem alguma coisa que não dá certo, então a gente tem que avaliar o quê que não deu certo... né! Para não cair naquele tipo de pensamento: é que eu não tenho sorte, nada dá certo pra mim! Porque aí de novo vai entrar numa caverninha... né.”

(5) Solicitação de reflexão sobre outros assuntos que não a queixa do cliente. Ex1: "Vamos deixar um pouquinho de lado a compulsão... Tente pensar no que o rapaz que você conheceu te encanta! Você pensa e me conta a semana que vem, ok?”

(6) Modelos emitidos pelos terapeutas. Ex1: "Você vê como isso pode se generalizar para outras coisas. Eu posso explicar para os meus amigos lá da igreja, lá no futuro que você gosta de lá, você respeita o trabalho deles, que você não tem nada contra. Mas que nesse momento esse trabalho não cabe pra você. Você tem outros objetivos, você tem que estabelecer metas. Tem que estabelecer prioridades... olha eu só tenho um sábado, eu preciso dar esse sábado para uma coisa que é importante para mim. Então eu vou entrar na banda dos meninos, amigos e vou parar de vir aqui um pouco... viu como eu falei, pense sobre isso!”

(7) Solicitação de observação de padrões de comportamento dos clientes. Ex1: "Feito, $e$ observa essa coisa de aproximação das pessoas. E carinho... como é demonstrar!” Ex2: "Por via das dúvidas, é melhor se preparar, né. Bom então está bom, vai pensando nisso também, tá bom... é uma coisa importante, mas não é uma coisa... é hoje ou nunca, legal é pensar. E, mas o mais importante é isso, tem um feriado aí pra 
isso, treinar esses laços. Vamos ver se essas fibras entre você e sua mãe ficam mais consistentes.”

Apenas os terapeutas pouco experientes emitiram orientação para tarefa (OT). A emissão de Orientação para Tarefa $(\underline{\mathbf{O T}})$ era feita de modo geral por meio de:

(1) Modelos emitidos pelos terapeutas. Ex1: "Você viu como fizemos esta hierarquia dos medos? Quero que você anote essa semana da mesma forma que fizemos aqui variando de 0 a 10 o nível do seu medo pra realizar tarefas cotidianas.”

(2) Indicação de tarefas que eliminam situações aversivas. Ex1: "Quero que você estruture uma agenda pra você. Você estrutura uma agenda de estudo né, assinado por mim. Porque você não estabelece uma agenda com sua avó? Segunda eu estudo 1 hora e meia de tal hora a tal hora, terça, quarta, e quinta e sexta. Está vendo vovó eu vou estudar nesses horários nos outros dias eu vou descansar... fazendo assim sua avó não pegará no seu pé...”

(3) Solicitação de anotação de avaliação da situação vivenciada. Ex1: "Você vai pensar e escrever sobre isso... por que não consigo colocar em prática os incentivos? Pense, escreva e me traga pra semana que vem, ok?”

Verificou-se também se as orientações emitidas pelo terapeuta apresentavam diferenças em seu conteúdo explícito e em sua função. A Tabela 42 traz os resultados

Tabela 42. Conteúdo e função das orientações e auto-orientações para cada terapeuta

\begin{tabular}{c|c|c|c|c}
\hline & $\begin{array}{c}\text { Todas as } \\
\text { orientações }\end{array}$ & $\begin{array}{c}\text { Orientações com } \\
\text { diferentes } \\
\text { conteúdos e } \\
\text { diferentes } \\
\text { funções }\end{array}$ & $\begin{array}{c}\text { Orientações com conteúdo } \\
\text { diferente e função igual }\end{array}$ & $\begin{array}{c}\text { Total de } \\
\text { orientações } \\
\text { diferentes }\end{array}$ \\
\hline TED & 46 & 14 & $32(10$ orientações no total $)$ & 24 \\
\hline TEE & 99 & 27 & $72(19$ orientações no total $)$ & 46 \\
\hline TEF & 39 & 8 & $31(8$ orientações no total $)$ & 16 \\
\hline TPE1A & 55 & 9 & $46(9$ orientações no total $)$ & 18 \\
\hline TPE2A & 56 & 5 & $51(15$ orientações no total $)$ & 20 \\
\hline
\end{tabular}




\begin{tabular}{l|l|c|c|c}
\hline TPE1B & 25 & 10 & $15(6$ orientações no total $)$ & 16 \\
\hline TPE2B & 48 & 7 & $41(13$ orientações no total $)$ & 20 \\
\hline TPE1C & 36 & 9 & $27(8$ orientações no total $)$ & 17 \\
\hline TPE1C & 61 & 9 & $52(15$ orientações no total $)$ & 24 \\
\hline
\end{tabular}

$\mathrm{Na}$ Tabela 42 observam-se na primeira coluna os diferentes terapeutas, por exemplo, TED; na segunda coluna o número de orientações encontradas nas sessões dos diferentes terapeutas, por exemplo: 46 orientações do TED. Na terceira coluna encontrase o número de orientações que tinham conteúdos e funções diferentes, por exemplo: 14 orientações do TED. Na quarta coluna o número de orientações com conteúdo diferente e função igual, por exemplo: nas sessões do TED houve 32 orientações com conteúdo diferente e função igual. Quando foram isoladas apenas as orientações dentro dessas 32 orientações que apresentavam conteúdo diferente e função diferente, chegou-se ao número de 10 orientações. Na quinta coluna é apresentado o total de orientações com conteúdo e função diferente nas sessões dos terapeutas, por exemplo: no caso $14+10=$ 24 orientações com conteúdos e funções diferentes nas sessões do TED.

O número de orientações cai consideravelmente (aproximadamente $57 \%$ de diminuição) ao se analisar conteúdo e função. Duas considerações devem ser feitas aqui. A primeira delas refere-se ao fato de que aparentemente terapeutas tendem a 'repetir' funcionalmente a orientação. Talvez os terapeutas o façam no intuito de aumentar a probabilidade de ocorrências do comportamento do cliente, ou ainda com o intuito de garantir a manutenção de um novo comportamento instalado. A segunda consideração é que no estudo de Donadone (2004) onde somente o conteúdo da resposta foi considerado, a porcentagem de orientação era em média $13 \%$. Se fossem consideradas apenas as orientações com funções diferentes, em média apenas $8 \%$ das sessões seriam dedicadas à emissão de regras. Tal análise sugere que a emissão de regras parece não ser a estratégia preferida dos terapeutas participantes desta pesquisa e a emissão de 
orientação é apenas uma das muitas estratégias usadas por terapeutas analíticocomportamentais.

Análise similar foi feita para as auto-orientações emitidas pelos clientes dos terapeutas experientes e pouco experientes.

$\mathrm{Na}$ emissão de auto-orientação pelos clientes do TED, as auto-orientações muitas vezes pareciam apontar comportamentos que se realizados pelos clientes eliminavam aversivos. Foi interessante observar que esses clientes também foram os que mais conseguiram responder à pergunta (f): "Passada a situação o cliente é capaz de verbalizar qual o comportamento que deveria fazer em situações similares ou reagiu da forma pretendida?"'.

As auto-orientações emitidas pelos clientes do TEE eram todas voltadas para as ações que deveriam ser executadas no cotidiano.

As auto-orientações emitidas pelos clientes do TEF eram muitas vezes encadeadas a orientações anteriores e posteriores, e basicamente relacionadas a situações cotidianas.

As auto-orientações dos clientes do TPE1A, TPE2A, TPE1B, TPE2B e TPE1C eram simples e pareciam sempre voltadas para algo prático que o cliente deveria executar. As auto-orientações emitidas pelos clientes do TPE2C eram também simples e voltadas para o cotidiano, mas muitas auto-orientações eram fruto das discussões ocorridas nas sessões.

A observação dos diferentes subtipos de auto-orientação mostrou que a emissão de Auto-orientação para Ação Específica ( (1) Especificação dos passos necessários para se atingir o objetivo desejado. Ex1: "Primeiro vou quitar minhas dívidas, depois vou comprar o que preciso, só aí vou calcular se sobrou dinheiro e baseado nesse dinheiro vou planejar para onde irei 
viajar.” Ex2: “Tenho um plano. Vou me livrar gradativamente destes medicamentos. Primeiro vou intensificar minha vinda à terapia, segundo vou consultar meu médico, terceiro junto com ele defino gradativamente a retirada do medicamente e pronto... vou ser saudável, sem precisar me medicar.”

(2) Indicação de comportamentos que eliminam situações aversivas. Ex1: "É fácil. Eu não ligarei mais pra ele, e não passarei mais nervoso.” Ex2: “Eu tenho que parar com isso, talvez eu fique chateada, não é nem chateada, eu fico nervosa então eu já não quero, aí eu já não quero, é onde tem que falar pra resolver né. Vou fazer isso.”

(3) Levantamento de aspectos positivos de se comportarem de acordo com a auto-regra específica emitida. Ex1: “Me colocar na reunião me fez ver o quanto posso ser produtiva na empresa, vou continuar a me colocar e colher os benefícios.”

A emissão de Auto-orientação para Ação Genérica ( geral por meio de:

(1) Avaliação da situação e indicação de ações genéricas (pelo cliente). Ex1: "Diante dessa situação e avaliando tudo que já fiz, vou mudar... Não sei exatamente o que, mas alguma mudança será feita... Ficar parado não resolve minha situação... Agora é partir pra ação... Você vai ouvir eu te falar...” Ex2: “Eu não vou desistir, vou chegar lá... Vou decidir o que quero... (Risos)... Já avaliei tudo o que me aconteceu... Chega de passividade... E agora vou agir e conseguir!"”

A emissão de Auto-orientação para Encobertos ( $\underline{\text { AOE })}$ era feita de modo geral por meio de:

(1) Avaliação da situação (pelo cliente). Ex1: "Se eu não me acalmar, vou continuar fazendo besteira. Preciso pensar em uma forma de me acalmar." Ex2: "Será que a minha relação com o M. não é de terapeuta e doente? Porque ele é doente sim, mais do que uma relação de namorado e namorada? Vou pensar seriamente nisso.” Ex3: “Não 
ganho nada em ser brigão. Porque continuo assim? Vou pensar sobre isso! Deve ter uma razão.”

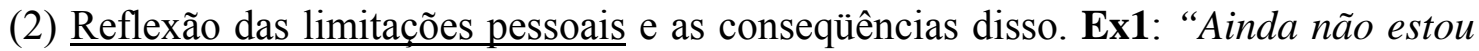
preparado para ir a bares, pois se me descontrolar, o que é provável nestes lugares, vou recair... Vou prestar atenção se quando vejo filmes em que pessoas bebem, me sinto diferente." Ex2: “ O fato de ser reumática não pode ser mais negado por mim... A vida é quase normal... mas veja bem quase não significa que posso fazer tudo que os outros fazem né. Tenho que sempre lembrar disso, pensar nisso!”

(3) Levantamento de objetivos de vida. Ex1: "Não posso continuar vivendo de dinheiro da mamãe. Preciso descobrir o que quero fazer, pra onde ir... Vou ser obrigado a pensar sobre isso." Ex1: "Preciso ter opinião, sair de cima do muro, pensar no que quero... Senão meu marido pensa por mim e eu acato sem saber se é isso que eu quero. Vou pensar nisso e sozinha... Prometo.”

A verificação de se todas as auto-orientações emitidas pelos clientes eram diferentes tanto em seu conteúdo explícito como em sua função produziu os seguintes resultados:

Tabela 43. Emissão de auto-orientação dos clientes terapeutas experientes e pouco experientes.

\begin{tabular}{|c|c|c|c|c}
\hline & $\begin{array}{c}\text { Todas } \\
\text { auto- } \\
\text { orientações }\end{array}$ & $\begin{array}{c}\text { Auto- } \\
\text { orientações com } \\
\text { diferentes } \\
\text { conteúdos e } \\
\text { diferentes } \\
\text { funções }\end{array}$ & $\begin{array}{c}\text { Auto-orientações com } \\
\text { conteúdo diferente e } \\
\text { função igual }\end{array}$ & $\begin{array}{c}\text { Total de auto- } \\
\text { orientações } \\
\text { diferentes }\end{array}$ \\
\hline Clientes do TED & 43 & 19 & $24(10$ auto- & 29 \\
\hline Clientes do TEE & 5 & 5 & 0 & 5 \\
\hline Clientes do TEF & 11 & 4 & $7(2$ auto-orientações $)$ & 6 \\
\hline Clientes do TPE1A & 11 & 9 & $1(2$ auto-orientações $)$ & 10 \\
\hline Clientes do TPE2A & 3 & 3 & 0 & 3 \\
\hline Clientes do TPE1B & 1 & 1 & 0 & 1 \\
\hline Clientes do TPE2B & 13 & 8 & $1(5$ auto-orientações $)$ & 9 \\
\hline Clientes do TPE1C & 11 & 6 & $2(5$ auto-orientações $)$ & 8 \\
\hline Clientes do TPE2C & 7 & 7 & 0 & 7 \\
\hline
\end{tabular}


$\mathrm{Na}$ Tabela 43 observam-se na primeira coluna os clientes dos diferentes terapeutas, por exemplo: clientes do TED; na segunda coluna o número de autoorientações encontradas nas sessões dos diferentes terapeutas experientes, por exemplo: 43 auto-orientações dos clientes do TED; na terceira encontra-se o número de autoorientações que tinham conteúdos e funções diferentes: 19 auto-orientações dos clientes do TED; na quarta coluna o número de auto-orientações com conteúdo diferente e função igual, por exemplo: nas sessões do TED houve 24 auto-orientações emitidas pelos clientes do TED com conteúdo diferente e função igual. Quando se isolou apenas as auto-orientações dentro dessas 24 auto-orientações que apresentavam conteúdo diferente e função diferente, chegou-se ao número de 10 auto-orientações. Na quinta coluna é apresentado o total de auto-orientações com conteúdo e função diferente nas sessões dos terapeutas, por exemplo: no caso $19+10=29$ auto-orientações com conteúdos e funções emitidos pelos clientes do TED.

O número de auto-orientações diminui aproximadamente $26 \%$ ao se analisar conteúdo e função das auto-orientações. Os clientes dos terapeutas experientes (com exceção dos clientes do TEF) em muitas ocasiões lançavam mão da estratégia de repetir funcionalmente a auto-orientação. O mesmo não aconteceu quando se analisou as autoorientações emitidas pelos clientes dos terapeutas pouco experientes. Os clientes dos terapeutas pouco experientes, TPE2A, TPE1B e TPE1C, emitiram somente autoorientações com diferentes conteúdos e diferentes funções. Os demais clientes dos terapeutas pouco experientes algumas vezes emitiram auto-orientações com conteúdos diferentes e funções iguais, porém em número reduzido. 


\subsubsection{Consequente}

Nas sessões analisadas, encontrou-se um consequente em $98 \%$ das vezes. Nas sessões dos terapeutas experientes, houve um consequente em $100 \%$ das vezes, ou seja, toda orientação emitida pelo terapeuta ou auto-orientação emitida por seus clientes era seguida ou de uma resposta do cliente ou de uma resposta do terapeuta. No caso dos terapeutas pouco experientes, houve um consequente em $95 \%$ das vezes. E em $5 \%$ das vezes ou o cliente não apresentava comportamentos que pudessem se classificados como consequentes após a emissão de orientação ou o terapeuta não consequenciava a auto-orientação emitida pelo cliente.

Os consequentes e a emissão de orientação/auto-orientação foram categorizados conforme adaptação de algumas 'categorias do comportamento verbal vocal do terapeuta e do cliente' de Zamignani e Meyer (2007)

Após a categorização dos consequentes, episódios de orientação e autoorientação foram separados. Nos dois casos primeiramente buscou-se encontrar se havia diferenças estatísticas entre os consequentes à emissão de orientação/autoorientação. Num segundo momento buscou-se verificar se os consequentes à emissão de orientação/auto-orientação encontrados nas sessões terapeutas experientes e pouco experientes eram significativamente diferentes.

Assim, iniciou-se a análise com os consequentes à emissão de orientação, como mostra a tabela a seguir.

Tabela 44. Número médio $(\mathrm{N})$ de ocorrências de categorias de consequentes dos diferentes terapeutas (nove terapeutas) nos episódios de orientação, frequência relativa percentil (apresentada em porcentagem) e p-valor

\begin{tabular}{cccc}
\hline \multirow{2}{*}{$\begin{array}{c}\text { Conseqüentes encontrados } \\
\text { nos episódios de orientação }\end{array}$} & \multicolumn{2}{c}{$\begin{array}{c}\text { Clientes dos } \\
\text { Terapeutas }\end{array}$} & p-valor \\
\cline { 2 - 4 } & $\mathrm{N}$ & $\%$ & \\
\hline Concordância & 24,0 & $46,2 \%$ & $0,042^{*}$ \\
\hline Oposição & 14,0 & $26,9 \%$ & $<0,001^{*}$ \\
\hline Orientação & 6,0 & $11,5 \%$ & $<0,001^{*}$ \\
\hline Relato & 3,3 & $6,4 \%$ & \\
\hline
\end{tabular}




\begin{tabular}{cccc}
\hline Cliente permanece em silêncio & 2,3 & $4,4 \%$ & $<0,001^{*}$ \\
\hline Solicitação & 1,0 & $1,9 \%$ & $<0,001^{*}$ \\
\hline Reprovação & 0,7 & $1,3 \%$ & $<0,001^{*}$ \\
\hline Auto-orientações & 0,7 & $1,3 \%$ & $<0,001^{*}$ \\
\hline
\end{tabular}

Legenda:

* p-valores considerados estatisticamente significativos perante o nível de significância adotado.

Esta tabela foi organizada em ordem decrescente, dos resultados mais prevalecentes para os menos prevalecentes. A coluna p-valor mostra a comparação de cada nível de categoria sempre em relação aos mais prevalecentes.

Nos episódios de orientação, os consequentes mais comuns foram: concordância; oposição e nova orientação. Os clientes dos diferentes terapeutas consequenciavam as orientações recebidas aprovando-as em média em 46,2\% das vezes. A categoria concordância apresenta diferenças significativas em relação às demais categorias de consequentes. Em média, em 26,9\% das vezes, os clientes consequenciavam as orientações recebidas reprovando-as e em média, em 11,5\% das vezes, os terapeutas consequenciavam seu próprio comportamento de orientar emitindo uma nova orientação. Quando o consequente da orientação era uma nova emissão de regras, verificou-se nos episódios de orientação a existência de cadeias comportamentais. Assim um consequente pode assumir a função de antecedente e uma nova cadeia comportamental pode ser formada. As demais categorias de consequente ao comportamento de orientar apareceram de forma discreta.

Tabela 45. Número médio $(\mathrm{N})$ de ocorrências de categorias de consequentes a emissão de orientação, frequência relativa percentil e p-valor de categorias de consequentes emitidas nas sessões dos terapeutas experientes e pouco experientes.

\begin{tabular}{cccccc}
\hline $\begin{array}{c}\text { Consequentes } \\
\text { encontrados nos episódios } \\
\text { de orientação }\end{array}$ & \multicolumn{2}{c}{ Terap. Exp. } & $\begin{array}{c}\text { Terap. Pouco } \\
\text { Experientes }\end{array}$ & p-valor \\
\cline { 2 - 7 } & $\mathrm{N}$ & $\%$ & $\mathrm{~N}$ & $\%$ & \\
\hline Solicitação & 2 & $3,2 \%$ & 0,5 & $1,1 \%$ & 0,455 \\
\hline Relato & 4 & $6,5 \%$ & 3 & $6,4 \%$ & 0,988 \\
\hline Concordância & 34 & $54,8 \%$ & 19 & $40,4 \%$ & 0,136 \\
\hline Oposição & 13 & $21,0 \%$ & 14,5 & $30,9 \%$ & 0,239 \\
\hline Reprovação & 0 & $0,0 \%$ & 1 & $2,1 \%$ & 0,249 \\
\hline $\begin{array}{c}\text { Cliente permanece em } \\
\text { silêncio }\end{array}$ & 0 & $0,0 \%$ & 3,5 & $7,4 \%$ & $0,029 *$ \\
\hline
\end{tabular}




\begin{tabular}{llllll}
\hline Orientação & 8 & $12,9 \%$ & 5 & $10,6 \%$ & 0,718 \\
\hline Auto-orientações & 1 & $1,6 \%$ & 0,5 & $1,1 \%$ & 0,807 \\
\hline $\begin{array}{l}\text { Legenda: } \\
\text { * p-valores considerados estatisticamente significativos perante o nível de significância adotado. }\end{array}$
\end{tabular}

Nesta tabela observa-se que não há diferenças significativas entre as categorias de consequentes encontradas nas sessões dos terapeutas experientes e pouco experientes. A única exceção refere-se à categoria permanece em silêncio. Os clientes dos terapeutas pouco experientes consequenciam o comportamento de orientar de seus terapeutas permanecendo em silêncio significativamente em maior percentual $(7,4 \%)$ do que os clientes dos terapeutas experientes. Este resultado, no entanto, deve ser olhado com cautela, uma vez que a ocorrência média desta categoria é muito reduzida.

Os consequentes à emissão de auto-orientação também foram analisados. A Tabela 46 apresenta esses dados.

Tabela 46. Número médio $(\mathrm{N})$ de ocorrências de categorias de consequentes dos diferentes terapeutas (nove terapeutas) nos episódios de auto-orientação, frequência relativa percentil (apresentada em porcentagem) e p-valor

\begin{tabular}{|c|c|c|c|}
\hline \multirow{2}{*}{$\begin{array}{c}\text { Conseqüentes encontrados } \\
\text { nos episódios de auto- } \\
\text { orientação }\end{array}$} & \multicolumn{2}{|c|}{$\begin{array}{l}\text { Clientes dos } \\
\text { Terapeutas } \\
\end{array}$} & \multirow[t]{2}{*}{ p-valor } \\
\hline & $\mathrm{N}$ & $\%$ & \\
\hline Aprovação & 7,9 & $66,6 \%$ & \\
\hline Reprovação & 1,6 & $13,2 \%$ & $0,008 *$ \\
\hline Solicitação de reflexão & 0,6 & $5,3 \%$ & $0,002 *$ \\
\hline Orientação & 0,4 & $3,1 \%$ & $0,001 *$ \\
\hline Facilitação & 0,3 & $2,8 \%$ & $0,001 *$ \\
\hline $\begin{array}{c}\text { Outras verbalizações do } \\
\text { terapeuta }\end{array}$ & 0,3 & $2,5 \%$ & $0,001 *$ \\
\hline Relato & 0,2 & $1,9 \%$ & $<0,001 *$ \\
\hline Auto-orientações & 0,2 & $1,9 \%$ & $<0,001 *$ \\
\hline $\begin{array}{c}\text { Terapeuta permanece em } \\
\text { silêncio }\end{array}$ & 0,2 & $1,7 \%$ & $<0,001 *$ \\
\hline Interpretação & 0,1 & $0,8 \%$ & $<0,001 *$ \\
\hline
\end{tabular}

Esta tabela foi organizada em ordem decrescente, dos resultados mais prevalecentes para os menos prevalecentes. A coluna p-valor mostra a comparação de cada nível de categoria sempre em relação aos mais prevalecentes. 
Nos episódios de auto-orientação, o consequente mais comum foi aprovação e reprovação. Os terapeutas consequenciavam o comportamento de emitir autoorientações dos clientes em $66,9 \%$ das vezes aprovando-os. Esta categoria foi a mais prevalecente e é significante percentualmente em relação às demais categorias. Em $13,6 \%$ das vezes, os terapeutas consequenciavam as auto-orientações dos clientes reprovando-as. As demais categorias de consequente ao comportamento de autoorientar apareceram de forma discreta.

\subsection{Correlação entre perfil do cliente e orientação}

Para analisar uma possível relação entre perfil do cliente e orientação, listaramse em ordem decrescente os clientes que mais receberam orientação e auto-orientação. Simultaneamente os perfis dos clientes foram agrupados em três grandes grupos quanto à avaliação de sua cooperação e motivação, dos mais fáceis aos mais difíceis: (1) clientes considerados cooperativos, os considerados motivados e os considerados cooperativos e motivados; (2) clientes considerados motivados e resistentes; e (3) clientes considerados resistentes, os considerados desmotivados e os considerados resistentes e desmotivados.

Constatou-se que dos 27 clientes participantes desta pesquisa, 18 (67\%) foram considerados por seus terapeutas como cooperativos e motivados; dois $(7 \%)$ foram considerados motivados/resistentes e sete $(26 \%)$ foram considerados resistentes e desmotivados, conforme mostra a Tabela 47. 
Tabela 47. Número de orientação e auto-orientação e o perfil do cliente

\begin{tabular}{|c|c|c|c|c|c|}
\hline \multicolumn{3}{|c|}{$\begin{array}{l}\text { Número de Orientações e Perfil do } \\
\text { cliente }\end{array}$} & \multicolumn{3}{|c|}{\begin{tabular}{|c|} 
Número de Auto-orientações e Perfil do \\
cliente
\end{tabular}} \\
\hline $\begin{array}{c}\begin{array}{c}\text { Clientes } \\
\text { dos } \\
\text { Terapeutas }\end{array} \\
\end{array}$ & $\begin{array}{c}\mathbf{N}^{0} \text { de } \\
\mathbf{O}\end{array}$ & Perfil do cliente & $\begin{array}{c}\begin{array}{c}\text { Clientes } \\
\text { dos } \\
\text { Terapeutas }\end{array} \\
\end{array}$ & $\begin{array}{c}\mathbf{N}^{0} \text { de } \\
\text { AO }\end{array}$ & Perfil do cliente \\
\hline C2TEE & 49 & Cooperativo & C2TED & 20 & $\begin{array}{l}\text { Cooperativo e } \\
\text { motivado }\end{array}$ \\
\hline C1TEE & 32 & Cooperativo & C3TED & 12 & $\begin{array}{c}\text { Cooperativo e } \\
\text { motivado }\end{array}$ \\
\hline С2TPE2A & 31 & $\begin{array}{l}\text { Cooperativo e } \\
\text { motivado }\end{array}$ & C1TED & 11 & $\begin{array}{c}\text { Cooperativo e } \\
\text { motivado }\end{array}$ \\
\hline C2TPE2C & 24 & Cooperativo & C2TPE1C & 8 & Cooperativo \\
\hline C3TPE1A & 23 & $\begin{array}{l}\text { Cooperativo e } \\
\text { motivado }\end{array}$ & С3TPE2B & 5 & Motivado \\
\hline C1TED & 22 & $\begin{array}{c}\text { Cooperativo e } \\
\text { motivado }\end{array}$ & C1TEF & 4 & Motivado \\
\hline C1TEF & 22 & Motivado & C3TPE1A & 4 & $\begin{array}{c}\text { Cooperativo e } \\
\text { motivado }\end{array}$ \\
\hline C1TPE2C & 21 & Cooperativo & C2TEE & 3 & Cooperativo \\
\hline C3TEE & 18 & Cooperativo & C1TPE2C & 3 & Cooperativo \\
\hline C2TED & 17 & $\begin{array}{l}\text { Cooperativo e } \\
\text { motivado }\end{array}$ & C2TPE2C & 3 & Cooperativo \\
\hline C3TPE2C & 16 & Cooperativo & C2TPE1A & 2 & $\begin{array}{c}\text { Cooperativo e } \\
\text { motivado }\end{array}$ \\
\hline C2TPE1A & 14 & $\begin{array}{c}\text { Cooperativo e } \\
\text { motivado }\end{array}$ & C2TPE2A & 2 & $\begin{array}{c}\text { Cooperativo e } \\
\text { motivado }\end{array}$ \\
\hline C2TPE1C & 14 & Cooperativo & C3TPE1C & 2 & Cooperativo \\
\hline C3TPE2B & 13 & Motivado & C1TEE & 1 & Cooperativo \\
\hline C1TPE1C & 11 & Cooperativo & C3TEE & 1 & Cooperativo \\
\hline C3TPE1C & 11 & Cooperativo & C1TPE1C & 1 & Cooperativo \\
\hline C2TEF & 8 & $\begin{array}{c}\text { Cooperativo e } \\
\text { motivado }\end{array}$ & C3TPE2C & 1 & Cooperativo \\
\hline C3TED & 7 & $\begin{array}{l}\text { Cooperativo e } \\
\text { motivado }\end{array}$ & C2TEF & 0 & $\begin{array}{l}\text { Cooperativo e } \\
\text { motivado }\end{array}$ \\
\hline С2TPE2B & 25 & $\begin{array}{l}\text { Motivado/Resistent } \\
\text { e }\end{array}$ & C3TEF & 7 & $\begin{array}{c}\text { Motivado/Resistent } \\
\mathrm{e}\end{array}$ \\
\hline C3TEF & 9 & $\begin{array}{c}\text { Motivado/Resistent } \\
\mathrm{e}\end{array}$ & C2TPE2B & 5 & $\begin{array}{c}\text { Motivado/Resistent } \\
\mathrm{e} \\
\end{array}$ \\
\hline C1TPE1A & 18 & Desmotivado & C1TPE2B & 7 & Resistente \\
\hline C3TPE2A & 16 & Resistente & C1TPE1A & 5 & Desmotivado \\
\hline C3TPE1B & 12 & Desmotivado & C1TPE2A & 1 & Resistente \\
\hline C1TPE1B & 10 & Resistente & C1TPE1B & 1 & Resistente \\
\hline C1TPE2B & 10 & Resistente & C3TPE2A & 0 & Resistente \\
\hline C1TPE2A & 9 & Resistente & C2TPE1B & 0 & $\begin{array}{l}\text { Resistente e } \\
\text { desmotivado }\end{array}$ \\
\hline C2TPE1B & 3 & $\begin{array}{l}\text { Resistente e } \\
\text { desmotivado }\end{array}$ & C3TPE1B & 0 & Desmotivado \\
\hline
\end{tabular}


Após tal procedimento realizou-se o teste estatístico ANOVA. Para a realização desse o perfil motivado e resistente foi retirado da amostra, uma vez que o $\mathrm{N}$ amostral (dois clientes) era muito pequeno. A tabela a seguir mostra essa comparação.

Tabela 48. Comparação do número de orientação e auto-orientação e o perfil do cliente

\begin{tabular}{|c|c|c|c|c|}
\hline \multirow[b]{2}{*}{ O/AO } & \multicolumn{2}{|c|}{ Cooperativo/Motivado } & \multicolumn{2}{|c|}{ Resistente/Desmotivado } \\
\hline & $\begin{array}{c}\text { Auto- } \\
\text { Orientações }\end{array}$ & Orientações & $\begin{array}{c}\text { Auto- } \\
\text { Orientações }\end{array}$ & Orientações \\
\hline Média & 4,61 & 19,61 & 2,00 & 11,14 \\
\hline Mediana & 3 & 17,5 & 1 & 10 \\
\hline $\begin{array}{l}\text { Desvio } \\
\text { Padrão }\end{array}$ & 5,12 & 10,18 & 2,83 & 4,91 \\
\hline $\mathrm{CV}$ & $111 \%$ & $52 \%$ & $141 \%$ & $44 \%$ \\
\hline Min & 0 & 7 & 0 & 3 \\
\hline Max & 20 & 49 & 7 & 18 \\
\hline $\mathrm{N}$ & 18 & 18 & 7 & 7 \\
\hline IC & 2,37 & 4,70 & 2,10 & 3,64 \\
\hline p-valor & \multicolumn{2}{|c|}{$<0,001 *$} & \multicolumn{2}{|c|}{$0,001 *$} \\
\hline $\begin{array}{l}\text { Legenda: } \\
\text { * p-valores cons } \\
\mathrm{CV}=\text { coeficient } \\
\text { Min = valores } \mathrm{m} \\
\text { Max = valores } \mathrm{n} \\
\mathrm{N}=\mathrm{N} \text { amostral } \\
\text { IC = Intervalo d }\end{array}$ & $\begin{array}{l}\text { ados estatisticame } \\
\text { variação } \\
\text { nos } \\
\text { mos. } \\
\text { nfiança }\end{array}$ & significativos & o nível de sį & dotado. \\
\hline
\end{tabular}

A análise estatística indica que existe diferença estatisticamente significante de orientação e auto-orientação em cada um dos perfis. Assim, pode-se observar que clientes com o perfil cooperativo/motivado receberam em média $(19,61 \pm 4,70)$ mais orientações do que os clientes com o perfil resistente/desmotivado $(11,14 \pm 3,64)$. $\mathrm{O}$ mesmo pode ser dito em relação à emissão de auto-orientação. Clientes com o perfil cooperativo/motivado emitiram em média $(4,61 \pm 2,37)$ mais auto-orientações que clientes com o perfil resistente/desmotivado $(2,00 \pm 2,10)$. Esses dados estão de acordo com a literatura. Numa revisão de Beutler et al. (2002) sobre 20 estudos que verificaram os efeitos diferenciais da diretividade do terapeuta, tendo em vista a resistência dos clientes, foi constatado que $80 \%$ desses estudos demonstraram que intervenções 
diretivas funcionaram melhor com clientes com baixo nível de resistência, enquanto intervenções não diretivas funcionaram melhor com clientes com graus mais altos de resistência, sugerindo que os efeitos da resistência podem ser circundados pelo uso de intervenções não-diretivas e autodirecionadas. Tais pesquisas indicaram uma forte correlação entre a resistência do cliente e um resultado negativo da terapia e/ou abandono da mesma, e entre a resistência do cliente e comportamentos diretivos do terapeuta (Ablon \& Jones, 2002; Beutler, Moleiro \& Talebi, 2002; Bischoff \& Tracey, 1995), ou seja, estes dados sugerem que o uso de estratégias diretivas, tal como a orientação, não está vinculado apenas à linha teórica e à preferência do terapeuta. Os resultados encontrados sugerem que os terapeutas foram modelados pelos comportamentos do cliente no momento da emissão da orientação.

Foram também verificadas possíveis relações entre subtipos de orientação e de auto-orientação e perfis de clientes. Esta análise foi feita só para as terapias dos terapeutas pouco experientes já que dentre os terapeutas experientes praticamente todos foram considerados motivados ou cooperativos, com exceção do C3TEF que além de motivado foi considerado resistente. Mais uma vez o teste estatístico utilizado foi o ANOVA. Veja a tabela a seguir: 
Tabela 49. Perfis dos clientes dos terapeutas pouco experientes e subtipos de orientação e auto-orientação

\begin{tabular}{|c|c|c|c|c|c|c|c|c|c|c|}
\hline & Perfil & Média & Mediana & $\begin{array}{l}\text { Desvio } \\
\text { Padrão }\end{array}$ & $\mathbf{C V}$ & Min & Max & $\mathbf{N}$ & IC & $\begin{array}{c}\text { p- } \\
\text { valor }\end{array}$ \\
\hline \multirow{2}{*}{ OAE } & Cooperativo/Motivado & 7,00 & 6,5 & 4,67 & $67 \%$ & 1 & 16 & 10 & 2,89 & \multirow{2}{*}{0,433} \\
\hline & Resistente/Desmotivado & 5,38 & 4,5 & 3,66 & $68 \%$ & 1 & 11 & 8 & 2,54 & \\
\hline \multirow{2}{*}{$\mathrm{OAG}$} & Cooperativo/Motivado & 3,80 & 2,5 & 3,71 & $98 \%$ & 0 & 12 & 10 & 2,30 & \multirow{2}{*}{0,770} \\
\hline & Resistente/Desmotivado & 4,25 & 4,5 & 2,38 & $56 \%$ & 1 & 7 & 8 & 1,65 & \\
\hline \multirow{2}{*}{$\mathrm{OE}$} & Cooperativo/Motivado & 5,20 & 5,5 & 2,78 & $53 \%$ & 1 & 11 & 10 & 1,72 & \multirow{2}{*}{0,151} \\
\hline & Resistente/Desmotivado & 3,13 & 2 & 3,04 & $97 \%$ & 0 & 9 & 8 & 2,11 & \\
\hline \multirow{2}{*}{$\mathrm{OT}$} & Cooperativo/Motivado & 1,80 & 1 & 2,57 & $143 \%$ & 0 & 8 & 10 & 1,59 & \multirow{2}{*}{0,151} \\
\hline & Resistente/Desmotivado & 0,38 & 0 & 0,74 & $198 \%$ & 0 & 2 & 8 & 0,52 & \\
\hline \multirow{2}{*}{$\mathrm{AOAE}$} & Cooperativo/Motivado & 1,10 & 1 & 1,10 & $100 \%$ & 0 & 3 & 10 & 0,68 & \multirow{2}{*}{0,881} \\
\hline & Resistente/Desmotivado & 1,00 & 0,5 & 1,69 & $169 \%$ & 0 & 5 & 8 & 1,17 & \\
\hline \multirow{2}{*}{$\mathrm{AOAG}$} & Cooperativo/Motivado & 1,00 & 1 & 0,82 & $82 \%$ & 0 & 2 & 10 & 0,51 & \multirow{2}{*}{0,640} \\
\hline & Resistente/Desmotivado & 0,75 & 0 & 1,39 & $185 \%$ & 0 & 4 & 8 & 0,96 & \\
\hline \multirow{2}{*}{$\mathrm{AOE}$} & Cooperativo/Motivado & 0,20 & 0 & 0,63 & $316 \%$ & 0 & 2 & 10 & 0,39 & \multirow{2}{*}{0,769} \\
\hline & Resistente/Desmotivado & 0,13 & 0 & 0,35 & $283 \%$ & 0 & 1 & 8 & 0,24 & \\
\hline \multicolumn{11}{|c|}{$\begin{array}{l}\text { Legenda: } \\
* \text { p-valores considerados estat } \\
\text { CV = coeficiente de variação } \\
\text { Min = valores mínimos } \\
\text { Max = valores máximos. } \\
\mathrm{N}=\mathrm{N} \text { amostral } \\
\text { IC = Intervalo de confiança }\end{array}$} \\
\hline
\end{tabular}

Os resultados da análise estatística indicam que os subtipos de orientação e autoorientação emitidos não são influenciados pelos diferentes perfis de clientes, ou seja, não houve diferenças estatísticas ao analisar os subtipos de orientação e auto-orientação emitidos quando clientes foram considerados cooperativos/motivados ou quando foram considerados resistentes/desmotivados.

\subsection{Correlação entre escolaridade e auto-orientação; queixa e orientação, idade, tempo de terapia, situação financeira e emissão de auto-orientação}

Para analisar as possíveis correlações entre escolaridade e auto-orientação, queixa e orientação, perfil do cliente e auto-orientação, utilizou-se a técnica estatística de correlação de Pearson, o que pode ser observado na Tabela 50. 
Tabela 50. Correlação entre escolaridade, queixa, idade do cliente, tempo de terapia e situação financeira com o número de orientações e auto-orientações nas sessões dos terapeutas em geral, e separadamente nas sessões dos terapeutas experientes e pouco experientes.

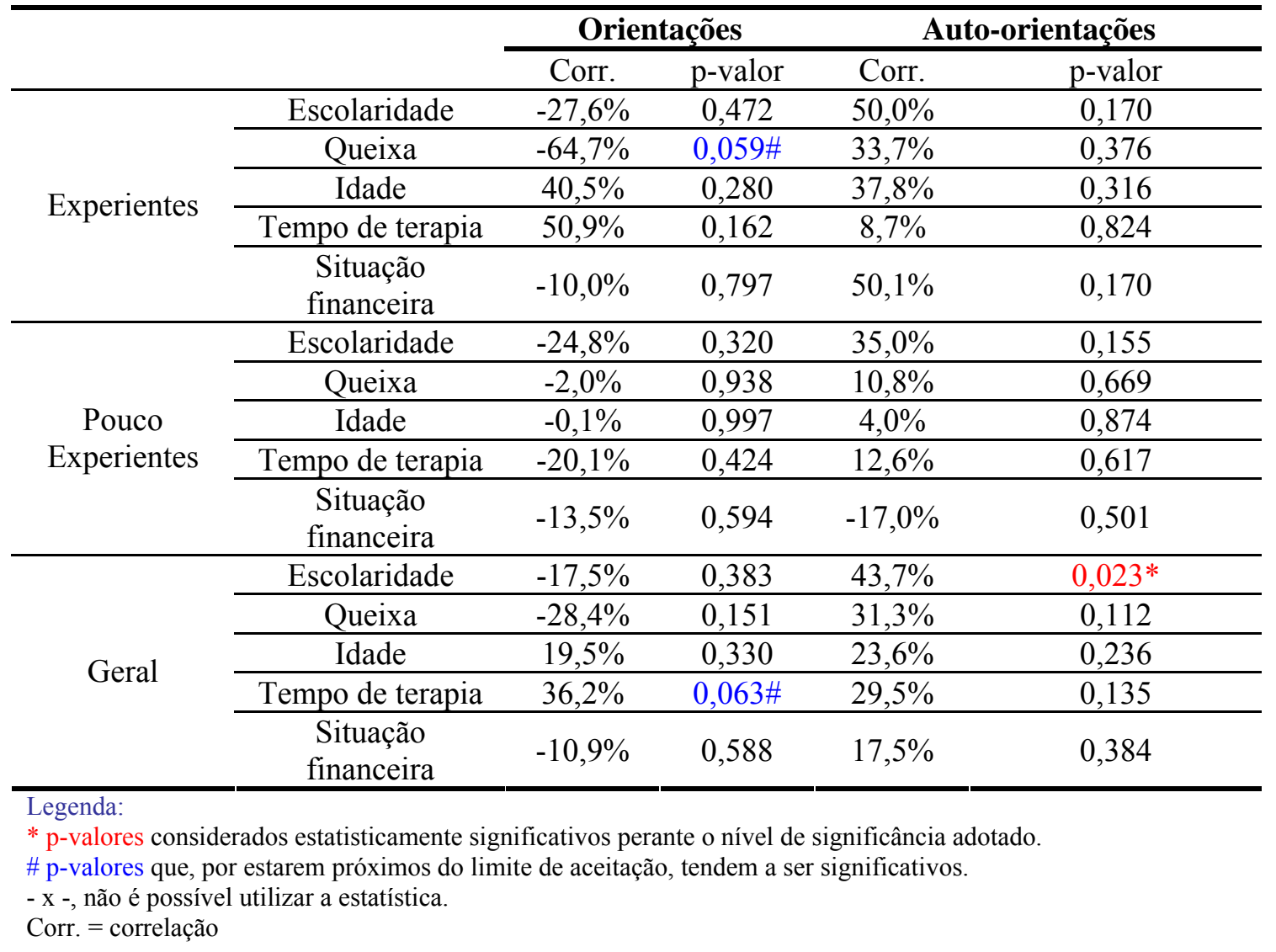

De maneira geral, a única correlação estatisticamente significativa encontrada foi entre escolaridade e emissão de auto-orientação, sendo esta correlação positiva e regular, ou seja, quanto maior a escolaridade do cliente maior o número de emissão de auto-orientação. Queixa, idade, tempo de terapia e situação financeira não foram correlacionadas significativamente nem à emissão de orientação nem à emissão de autoorientação.

Verificou-se também se havia correlação entre escolaridade, queixa, idade tempo de terapia e situação financeira nas sessões dos terapeutas experientes e pouco experientes. Os resultados encontrados apontam que não há diferenças significativas destas correlações nas sessões dos terapeutas experientes e pouco experientes. 


\subsection{Concordância entre pesquisador e juiz}

Nove sessões foram entregues ao juiz. Dessas nove sessões uma foi utilizada para treino e as oito restantes para a concordância.

Neste estudo dez pontos foram considerados para a análise de concordância: 1 . Identificação de temas discutidos na sessão; 2. Identificação de orientações; 3. Identificação de subtipos de orientações, 4. Identificação de auto-orientações; 5. Identificação de subtipos de auto-orientações; 6. Identificação de número de episódios de orientação/auto-orientação; 7. Identificação dos trechos dos episódios de orientação; 8. Média de concordância de perguntas e respostas encontradas nos episódios I; 9. Média concordância de perguntas e respostas encontradas nos episódios II e 10. Média de concordância de perguntas e respostas encontradas nos episódios III.

A partir dos dez pontos listados acima, realizou-se a análise de concordância por meio do teste estatístico ANOVA, como mostra a tabela a seguir. 
Tabela 51. Comparação da concordância e discordância entre pesquisador e juiz nos diferentes pontos analisados. Esta tabela apresenta os dez pontos de comparação entre pesquisador e juiz, assim como a média, mediana, desvio padrão, N (da amostra), intervalo de confiança (IC) e p-valor

\begin{tabular}{|c|c|c|c|c|c|c|c|}
\hline \multicolumn{2}{|c|}{ Inter pesquisador e juiz } & Média & Mediana & $\begin{array}{l}\text { Desvio } \\
\text { Padrão }\end{array}$ & $\mathbf{N}$ & IC & p-valor \\
\hline \multirow{2}{*}{$\begin{array}{l}\text { Identificação dos } \\
\text { temas }\end{array}$} & Concord. & $89,6 \%$ & $100 \%$ & $19,7 \%$ & 8 & $13,7 \%$ & \multirow{2}{*}{$<0,001^{*}$} \\
\hline & Discord. & $10,4 \%$ & $0 \%$ & $19,7 \%$ & 8 & $13,7 \%$ & \\
\hline \multirow{2}{*}{$\begin{array}{l}\text { Identificação de } \\
\text { orientações }\end{array}$} & Concord. & $84,6 \%$ & $90 \%$ & $18,6 \%$ & 8 & $12,9 \%$ & \multirow{2}{*}{$<0,001 *$} \\
\hline & Discord. & $15,5 \%$ & $10 \%$ & $18,6 \%$ & 8 & $12,9 \%$ & \\
\hline \multirow{2}{*}{$\begin{array}{l}\text { Identificação de } \\
\text { subtipos de } \\
\text { orientações }\end{array}$} & Concord. & $92,4 \%$ & $100 \%$ & $12,8 \%$ & 8 & $8,8 \%$ & \multirow{2}{*}{$<0,001 *$} \\
\hline & Discord. & $7,7 \%$ & $0 \%$ & $12,8 \%$ & 8 & $8,8 \%$ & \\
\hline \multirow{2}{*}{$\begin{array}{l}\text { Identificação de } \\
\text { auto-orientações }\end{array}$} & Concord. & $81,3 \%$ & $100 \%$ & $37,2 \%$ & 8 & $25,8 \%$ & \multirow{2}{*}{$0,005^{*}$} \\
\hline & Discord. & $18,8 \%$ & $0 \%$ & $37,2 \%$ & 8 & $25,8 \%$ & \\
\hline \multirow{2}{*}{$\begin{array}{l}\text { Identificação } \\
\text { subtipos }\end{array}$} & Concord. & $81,3 \%$ & $100 \%$ & $37,2 \%$ & 8 & $25,8 \%$ & \multirow{2}{*}{$0,005^{*}$} \\
\hline & Discord. & $18,8 \%$ & $0 \%$ & $37,2 \%$ & 8 & $25,8 \%$ & \\
\hline \multirow{2}{*}{$\begin{array}{l}\text { Identificação do } \\
\text { número de } \\
\text { episódios de } \\
\text { O/AO }\end{array}$} & Concord. & $93,8 \%$ & $100 \%$ & $17,7 \%$ & 8 & $12,2 \%$ & \multirow{2}{*}{$<0,001 *$} \\
\hline & Discord. & $6,3 \%$ & $0 \%$ & $17,7 \%$ & 8 & $12,2 \%$ & \\
\hline \multirow{2}{*}{$\begin{array}{l}\text { Identificação } \\
\text { trechos de } \\
\text { episódios de } \\
\text { O/AO }\end{array}$} & Concord. & $77,1 \%$ & $100 \%$ & $36,7 \%$ & 8 & $25,4 \%$ & \multirow{2}{*}{$0,010^{*}$} \\
\hline & Discord. & $22,9 \%$ & $0 \%$ & $36,7 \%$ & 8 & $25,4 \%$ & \\
\hline \multirow{2}{*}{$\begin{array}{l}\text { Média de } \\
\text { concordância de } \\
\text { perguntas e } \\
\text { respostas } \\
\text { encontradas nos } \\
\text { episódio I }\end{array}$} & Concord. & $69,9 \%$ & $78 \%$ & $29,9 \%$ & 8 & $20,7 \%$ & \multirow{2}{*}{$0,018^{*}$} \\
\hline & Discord. & $30,1 \%$ & $22 \%$ & $29,9 \%$ & 8 & $20,7 \%$ & \\
\hline \multirow{2}{*}{$\begin{array}{l}\text { Média de } \\
\text { concordância de } \\
\text { perguntas e } \\
\text { respostas } \\
\text { encontradas nos } \\
\text { episódio II } \\
\end{array}$} & Concord. & $73,5 \%$ & $76 \%$ & $20,8 \%$ & 6 & $16,7 \%$ & \multirow{2}{*}{$0,003 *$} \\
\hline & Discord. & $26,5 \%$ & $24 \%$ & $20,8 \%$ & 6 & $16,7 \%$ & \\
\hline \multirow{2}{*}{$\begin{array}{l}\text { Média de } \\
\text { concordância de } \\
\text { perguntas e } \\
\text { respostas } \\
\text { encontradas nos } \\
\text { episódio III }\end{array}$} & Concord. & $74,7 \%$ & $75 \%$ & $19,2 \%$ & 2 & $26,6 \%$ & \multirow{2}{*}{0,124} \\
\hline & Discord. & $25,3 \%$ & $25 \%$ & $19,2 \%$ & 2 & $26,6 \%$ & \\
\hline
\end{tabular}

Observa-se nesta tabela que pesquisador e juiz apresentaram uma concordância de $89,6 \%$ quando o ponto analisado se referia à identificação dos temas. Em 84,6\% das vezes em que o ponto analisado se referia à identificação de orientações houve concordância entre pesquisador e juiz; já para a identificação de subtipo de orientação essa concordância foi superior, atingindo 92,4\%. Pesquisador e juiz apresentaram uma 
concordância de $81,3 \%$ ao identificarem as auto-orientações e seus subtipos nas sessões analisadas.

Quanto à identificação do número de episódios de orientação/auto-orientação, a concordância foi de $93,8 \%$. No entanto, a identificação da delimitação dos trechos teve uma concordância de $77,1 \%$. A diferença entre a concordância e discordância foi significativa, apesar de inferior aos demais pontos, e justifica-se pela dificuldade em se precisar a primeira fala e a última fala de um episódio de orientação/auto-orientação.

Juiz e pesquisador também foram avaliados quanto à média de concordância de presença de perguntas e respostas encontradas nos episódios de orientação. No caso das sessões analisadas o número máximo de episódios encontrados foi de três. Para o primeiro episódio em média pesquisador e juiz concordaram quanto à presença de perguntas e respostas em $69,9 \%$ das vezes. Para o segundo episódio, a média foi de 73,5\%. Nos dois casos a diferença entre concordância e discordância foi significativa. Somente no terceiro episódio, a diferença encontrada não foi significativa, apesar de juiz e pesquisador concordarem em 74,7\%. Tal resultado justifica-se pelo tamanho da amostra. Somente em duas sessões foi encontrado o terceiro episódio e como esta amostra é muito reduzida, não há possibilidade de se generalizar os dados. 


\section{Comparação Concordância e Discordância (pesquisador-juiz)}

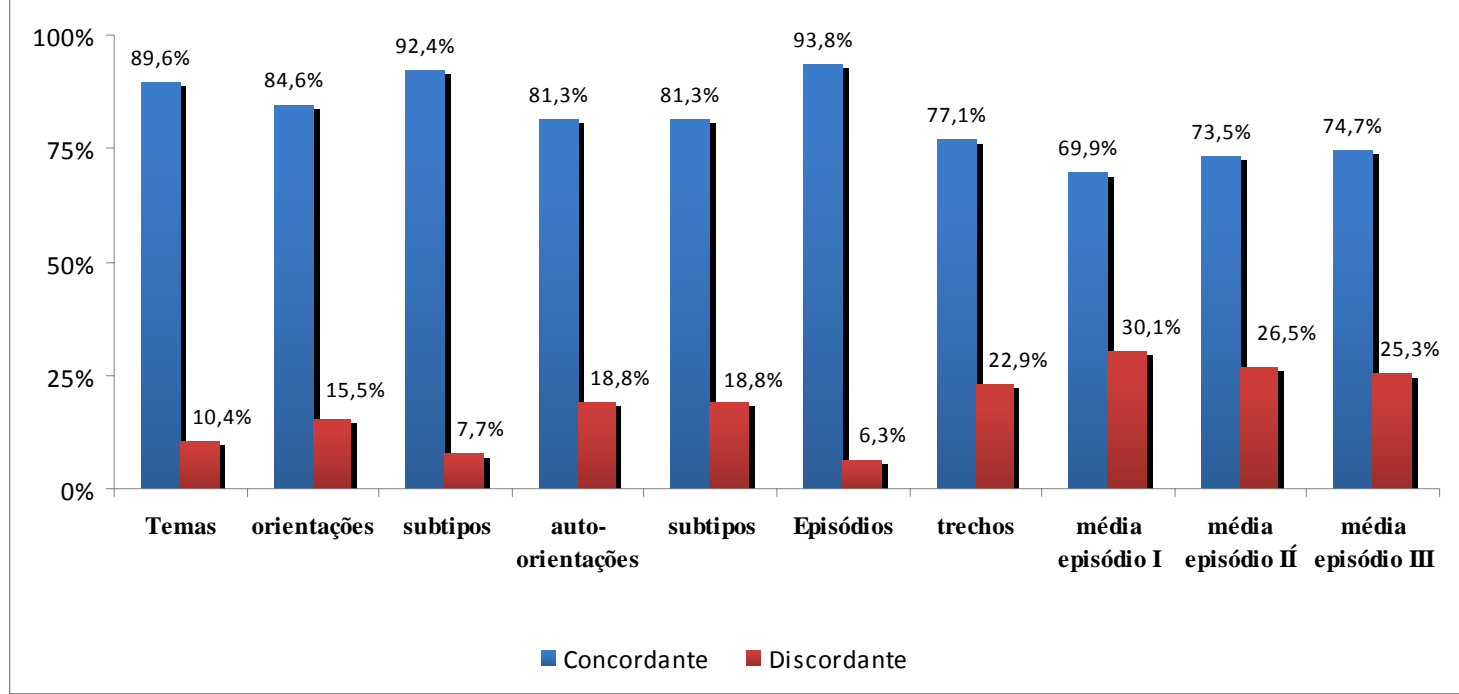

Figura 5. Comparação da concordância e discordância de pesquisador e juiz nas sessões analisadas

A figura acima indica que dez dos nove pontos analisados apresentaram concordância estatisticamente significativa, ou seja, houve diferenças significativas entre a concordância e a discordância. Somente para a média de perguntas e resposta encontradas nos episódio III, não foram obtidas diferenças significativas entre a concordância e a discordância. No entanto vale ressaltar que a amostra deste ponto de análise é extremamente baixa.

Conclui-se que, no geral, pesquisador e juiz apresentam um índice de concordância ótimo, o que nos sugere que a descrição de procedimentos feita pelo pesquisador é suficientemente clara para que possa ser utilizada por outros pesquisadores, além de demonstrar confiabilidade.

\subsection{Conclusões do estudo}

Nas pesquisas sobre o comportamento de orientar e de auto-orientar anteriores a esta pesquisa não foram encontradas variáveis responsáveis por sua emissão. A 
determinação da utilização da estratégia de orientação ora parecia ser o cliente, ora o terapeuta, ora nenhum deles, ora o tema abordado e possivelmente uma complexa combinação destas e de outras variáveis. O estudo detalhado das orientações e autoorientações de 81 sessões de terapia analítico-comportamental permitiu que se encontrassem regularidades não encontradas antes.

Quanto ao comportamento de orientar e de auto-orientar

O terapeuta que emitiu o maior número de orientações foi o experiente TEE, com 99 orientações em suas nove sessões; o terapeuta que emitiu o menor número de orientação foi o pouco experiente TPE1B com 25 orientações em nove sessões. Os outros sete terapeutas, experientes e pouco experientes emitiram de 40 a 60 orientações aproximadamente nas nove sessões realizadas por cada um.

O alto número de orientações do TEE não é característico de experiência e sim de um estilo pessoal mais diretivo. Se fosse a experiência, o número mais alto de orientações apareceria nas terapias dos outros terapeutas experientes. Não houve, tampouco, nenhuma característica de seus clientes que pudesse ser responsável por essa frequência mais alta. Já o baixo número de orientações do TPE1B parece estar relacionado ao perfil dos clientes com quem esse terapeuta trabalhava (dor crônica). Clientes com dores crônicas parecem aceitar menos estratégias diretivas. Tal afirmação encontra respaldo na literatura. Autores como Murta (1999), Teixeira (1994) e Kanner (1998) apontam que clientes com dores crônicas são mais hostis, belicosos, raivosos e irritadiços. Nardi (2004) afirma ainda que clientes com dores crônicas tendem a ser mais resistentes. Nardi (2004) e Scarpelli (2007) sugerem que trabalhos com clientes com dores crônicas deveriam ter ação mais discreta e menos diretiva, o que requer do terapeuta muita habilidade. 
Quanto à auto-orientação apenas os clientes do terapeuta experiente TED apresentaram um número mais elevado de emissões (43), o que parece estar relacionado a alguma característica do trabalho deste terapeuta. Os clientes de todos os outros terapeutas, independente de experiência, apresentaram poucas auto-orientações.

O número de orientações diminuiu para menos da metade quando foram contadas apenas orientações com conteúdos e funções diferentes, indicando que os terapeutas tendem a 'repetir' funcionalmente a orientação. Para as auto-orientações houve diminuição de um quarto ao se contar aquelas com conteúdo e função diferentes.

Quanto aos subtipos de orientação houve diferenças entre os terapeutas, indicando estilos de trabalho um pouco diferentes. A abordagem analíticocomportamental permite a existência de perfis variados de intervenção e essa variabilidade não está relacionada à experiência clínica. Quatro terapeutas (TED, TPE1A, TPE2A e TPE1C) apresentaram frequência relativa percentil mais baixas (em torno de 30\%) de orientação para ação específica. Os outros cinco terapeutas apresentaram frequência relativa percentil de orientação para ação específica superior a 40\%, destacando-se o TEE, que quase só emitiu este tipo de orientação (73\%).

A orientação para ação genérica foi menos emitida pelos terapeutas TEE, TEF, TPE1C e TPE2C que apresentaram frequência relativa percentil inferior a $20 \%$ para este subtipo de orientação. Os demais terapeutas apresentaram frequência relativa percentil de orientação genérica superior, destacando-se o TPE1A (38\%).

A orientação para encobertos ocorreu com maior frequência relativa percentil para os terapeutas TED, TEF, TPE2A e TPE1C. E as orientações para tarefa foram só emitidas pelos terapeutas pouco experientes.

Apesar das diferenças individuais, o conjunto dos terapeutas apresentou regularidades: utilizaram mais orientações para ação específica e orientações para ação 
genérica e a emissão de orientações para encobertos foi encontrada de forma significativa nas sessões de quatro dos terapeutas. As orientações para tarefa só ocorreram nas sessões dos terapeutas pouco experientes. Os clientes dos diferentes terapeutas também utilizaram percentualmente mais auto-orientações para ação específica e auto-orientações para ação genérica e houve baixa ocorrência de autoorientações para encobertos. Nenhum cliente emitiu auto-orientação para tarefa.

Quando a quantificação das orientações e auto-orientações passou a ser feita por episódios, análises similares e complementares foram feitas. Episódios de orientação/auto-orientação foram identificados nas 81 sessões, entretanto estes ocuparam apenas uma parte da sessão: um terço das sessões dos terapeutas experientes, em média, foi ocupado por episódios de orientação e um quarto das sessões dos terapeutas pouco experientes, em média, foi dedicado a episódios de orientação. E nesses episódios havia diversos tipos de intervenção do terapeuta além da orientação. Tais dados apontam na direção de que a orientação é apenas uma das diversas estratégias utilizadas pelos terapeutas. Nos episódios de auto-orientação essa parcela foi ainda menor sugerindo que os clientes emitem predominantemente outros comportamentos que não a emissão de autorregras.

Quanto aos temas

Temas, conteúdos ou assuntos discutidos em sessão são abordados em pesquisas sobre interação terapêutica (por exemplo, Baptistussi, 2001; Barbosa, 2006; Eells, Kendjelic, \& Lucas, 1998; Garcia, 2001; Goldberg, Hobson, Maguire, Margison, Osborn \& Moss, 1984; Yano, 2003 e Zamignani \& Andery, 2005). E é através da análise de categorias temáticas que perguntas de pesquisas (como por exemplo: caracterização do processo terapêutico, avaliação dos resultados do processo terapêutico 
e avaliação da atuação do terapeuta) são respondidas. Um dos objetivos desta pesquisa foi avaliar se existia relação entre a presença de orientação e o tema da sessão.

Os resultados encontrados indicaram que existe pouca relação entre o tema da sessão e a presença de orientação/auto-orientação. Apenas verificou-se haver uma probabilidade maior de haver orientação quando o tema em questão era sobre problemas fisiológicos. Enquanto para os outros temas (relacionamento interpessoal, queixas psiquiátricas e psicológicas, trabalho/estudo e ou carreira, problemas fisiológicos) em $80 \%$ das ocasiões em que eram abordados ocorria alguma orientação ou autoorientação, a probabilidade da orientação era maior ao se conversar sobre problemas fisiológicos, alcançando 94\%. A conclusão mais importante a que se chegou foi a de que terapeutas podem orientar sobre todos os temas abordados em sessão.

Sobre a análise dos temas merece ainda destaque a prevalência do grupo temático relacionamento interpessoal, que compôs metade dos temas discutidos no conjunto das 81 sessões analisadas.

O tema que mais propiciou auto-orientação foi trabalho/estudo e ou carreira. As auto-orientações ocorreram em aproximadamente metade das vezes em que o tema foi abordado no conjunto das sessões de todos os terapeutas. Quando o tema abordado era outro, auto-orientações ocorriam em aproximadamente um terço das vezes.

Ao falar sobre relacionamento interpessoal houve proporcionalmente maior emissão de regras genéricas (orientação para ação genérica e orientação para encobertos) do que específicas (orientação para ação específica e orientação para tarefa), mas a análise por frequência média de orientação por terapeuta indicou que os terapeutas experientes emitiram mais orientação para ação específica do que os terapeutas pouco experientes. Situação similar foi observada com os clientes dos 
terapeutas experientes, que emitiram mais autorregras específicas do que genéricas quando o assunto tratado em sessão era relacionamento interpessoal.

Com relação à variável 'temas' encontrou-se uma importante diferença entre terapeutas experientes e pouco experientes. Mais temas foram abordados nas sessões conduzidas pelos terapeutas experientes (variação de oito a 41 temas) do que nas sessões conduzidas pelos terapeutas pouco experientes (variação de quatro a 14 temas).

Análise similar provém da constatação de que nos episódios de orientação os terapeutas experientes apresentaram mais falas do que nos episódios dos terapeutas pouco experientes, indicando que o terapeuta experiente utiliza mais estratégias e conversa sobre mais temas antes ou após emitir a orientação do que os terapeutas pouco experientes.

Quanto às perguntas feitas pelo terapeuta nos episódios de orientação/auto-orientação

Em intervenções clínicas, realizar perguntas é uma estratégia comumente utilizada (Skinner, 1953/1967; Stiles \& Sultan, 1979; Fontaine \& Ylieff, 1981; Elliot et al., 1982; Hill et al.,1983; Skinner, 1984; Stiles et al., 1988; Hill et al., 1988; Wielenska, 1989; Schindler, Hohenberger-Sieber, \& Hahlweg, 1989; Verhulst \& van de Vijver, 1990; Skinner, 1989/1991; Kaimer et al. 1991; Skinner, 1974/1993; Keijsers,1994; Keijsers et al. 1995; Zamignani, 1996b; de Rose, 1997; de Rose 1999; Banaco, Zamignani \& Kovac 1999; Zamignani 2000; Silveira \& Kerbauy, 2000; Guilhardi \& Queiroz, 2001; Kohlenberg \& Tsai 2001; Delitti, 2001;Vanderberge, 2002; Guilhardi, 2004; Meyer, 2009).

Terapeutas podem atingir diferentes objetivos ao realizarem perguntas durante as intervenções clínicas. Dentre eles destacam-se: coleta de dados, promoção de autoconhecimento, promoção de boa relação terapêutica (ao demonstrar interesse através de perguntas), bloqueio de esquiva, identificação de variáveis estabelecedoras, 
mantenedoras do comportamento, explicitação de consequências do comportamento e realização de análise funcional. Vanderberge (2002) explicita que é por meio da realização de perguntas que se encontram variáveis que controlam o comportamento segundo o raciocínio do paradigma operante.

Um dos objetivos desta pesquisa foi verificar se havia relação entre a sequência de perguntas feitas pelos terapeutas e as respostas dos clientes com a subsequente orientação/auto-orientação.

Através da leitura das sessões desta amostra, observou-se que em $74 \%$ dos episódios de orientação/auto-orientação os terapeutas realizaram as seguintes perguntas aos clientes e obtiveram respostas: (a) Quando ocorreu a situação relatada pelo cliente? (b) Por que ocorreu aquela situação (a que o cliente atribui a situação relatada)? (c) Como o cliente lidou com a situação-problema? (e) $\mathrm{O}$ que o cliente sentiu diante daquela situação? E não emitiram as perguntas ou obtiveram respostas: (d) Qual é a avaliação do cliente sobre a forma como lidou com a situação? (f) Passada a situação o cliente é capaz de verbalizar o que deveria fazer em situações similares ou se emitiu a reação pretendida? A alta ocorrência desta sequência indica que os terapeutas emitem orientações após verificarem que os clientes não sabem dizer o que fazer diante da situação relatada.

A constatação de que orientações são emitidas após a verificação de que clientes não sabiam o que fazer diante da situação relatada é apoiada pela literatura comportamental, uma vez que a emissão de regras apresenta uma série de vantagens como a de produzir mudanças comportamentais rápidas sem a necessidade de exposição geralmente longa às consequências descritas, além de facilitar a aquisição de novos comportamentos, principalmente quando as contingências são complexas, imprecisas e aversivas. Terapeutas não comportamentais (Corey, 1983; Miranda \& Miranda, 1993) 
também indicam a utilização de regras quando clientes não têm domínio do assunto abordado, quando se encontram incapacitados de fazer opções (não sabem o que fazer) ou quando se encontram em perigo de prejudicar-se ou prejudicar os outros.

Verificou-se também que a auto-orientação estava de alguma forma vinculada à presença das seguintes perguntas que proporcionam 'reflexão' seguidas por respostas dos clientes: (d) Qual é a avaliação do cliente sobre a forma como lidou com a situação? (e) O que o cliente sentiu diante daquela situação? (f) Passada a situação o cliente é capaz de verbalizar o que deveria fazer em situações similares ou emitiu a reação pretendida? Quando ocorriam duas das perguntas proporcionava-se mais 'reflexão', havia maior porcentagem de auto-orientação. Essas perguntas levariam a uma avaliação da situação, dos sentimentos e do que pode ser feito a partir daí. Assim, quando é solicitada mais reflexão maior é a probabilidade de auto-orientação.

Em resposta à pergunta "Quando ocorreu a situação relatada pelo cliente?" constatou-se que a maioria das orientações e das auto-orientações era dada para problemas do cotidiano e não para problemas que vinham ocorrendo há mais tempo, ou seja, para problemas crônicos intervenções baseadas em orientação foram pouco usadas.

Em resposta à pergunta "Por que ocorreu aquela situação?" (a que o cliente atribui a situação relatada) verificou-se que os clientes não se consideram iniciadores ou responsáveis pelas situações problemáticas descritas e que culminaram em orientação e auto-orientação. A orientação parece, então, ter a função de indicar que a pessoa podia ter participação na ocorrência do evento.

Em resposta à pergunta "Como o cliente lidou com a situação-problema?" encontrou-se como resposta mais provável a esquiva do tipo não enfrentamento, o que parece compatível com a análise do cliente de não assumir a responsabilidade da situação problemática ter ocorrido. 
Na quase totalidade dos episódios de orientação os clientes não sabiam avaliar se a forma como lidaram com a situação era adequada ou não. Assim, os clientes não se responsabilizam pela situação geradora do problema, não a enfrentam e dizem que não sabem avaliar se consideram sua resposta adequada frente a essa situação.

Além disso, os clientes não emitiram a reação pretendida ou não sabiam dizer o que deveriam fazer em situações similares, tornando compreensível o uso da orientação. Há vantagens e desvantagens em orientar nessas situações. Como apontando acima, entre as vantagens destaca-se a rapidez na mudança e aquisição de novos comportamentos quando contingências são complexas, imprecisas e aversivas. No entanto, emissão de regras por parte do terapeuta pode gerar ou manter comportamentos de dependência do cliente. Esta seria uma desvantagem, pois de acordo com Skinner, "todo o problema pode ser resolvido mediante a aplicação de uma regra...", mas "os terapeutas precisam ir um passo à frente e ensinar seus clientes a construir suas próprias regras. Isso significa ensinar-lhes algo sobre análise do comportamento.”

Inversamente, em mais da metade dos episódios de auto-orientação, os clientes sabiam dizer o que deveriam fazer em situações similares ou emitiram a reação pretendida. Saber o que se deve fazer faz parte da própria definição de auto-orientação.

Nos relatos de situações problemáticas que evoluíram para uma orientação do terapeuta, o sentimento mais citado foi o de medo, seguido do sentimento de tristeza. Medo é o sentimento que acompanha respostas de não enfrentamento da situação temida. Culpa e vergonha, sentimentos indicativos de que a pessoa se sente responsável pela situação, ocorreram em poucos episódios de orientação.

Nos episódios de auto-orientação os sentimentos mais frequentemente relatados foram os de raiva e os de tristeza. Não houve a mesma prevalência do medo que nos episódios de orientação. Apesar de os sentimentos relatados terem sido negativos tanto 
nas orientações quanto nas auto-orientações, a diferença de prevalência dos sentimentos indica que possivelmente existem variáveis controladoras diferentes para as respostas que geram orientação e auto-orientação.

Quanto aos elos de antecedentes do comportamento de orientar e de se auto-orientar

Os episódios de orientação/auto-orientação iniciavam-se quase sempre com o relato de uma situação vivenciada ao terapeuta. Em pouquíssimas situações isso não ocorreu, e em tais casos o episódio foi iniciado com uma intervenção do terapeuta.

A maioria dos terapeutas realizou outras intervenções antes de orientar ou antes de o cliente se auto-orientar dentro dos episódios de orientação/auto-orientação. As intervenções dos terapeutas que antecediam a emissão da orientação/auto-orientação eram predominantemente solicitação de reflexão e interpretação. É como se frente ao relato de não saber o que fazer e não se responsabilizar pela situação, o terapeuta fornecesse condições para que o cliente mudasse esta resposta por meio de solicitação de análise (solicitação de reflexão) ou fornecimento de análise (interpretação).

O estabelecimento de relações feito pelos clientes, o relato de situações vivenciadas assim como a oposição e a concordância nas verbalizações dos terapeutas funcionavam como antecedente à emissão de orientação/auto-orientação. Ao comparar os antecedentes à emissão de orientação nas sessões dos terapeutas experientes e pouco experientes não foram encontradas diferenças estatisticamente significativas. Já no caso da auto-orientação, a comparação dos antecedentes encontrados nas sessões dos terapeutas experientes e pouco experientes indicou que os clientes dos terapeutas experientes (especialmente do TED) estabeleciam significativamente mais relações antes de emitir auto-orientação do que os clientes dos terapeutas pouco experientes. Tais dados sugerem que uma forma de atuação experiente é a de esperar que clientes estabeleçam relações modelando então a resposta de emissão de auto-orientação. 
Uma das sequências mais curtas de eventos antecedentes à emissão de orientação/auto-orientação era o relato de uma situação pelo cliente. Em seguida vinha a sequência relato do cliente e o estabelecimento de relações entre os eventos ocorridos pelo terapeuta. Sequência antecedente com um elo adicional era o relato do cliente, a solicitação de reflexão pelo terapeuta e o estabelecimento de relações entre os eventos ocorridos pelo cliente. Após uma interpretação do terapeuta foi bastante comum tanto a oposição quanto a concordância do cliente.

Quanto aos consequentes do comportamento de orientar e de se auto-orientar

Após uma orientação os clientes concordavam com ela em quase metade das ocasiões. Em um quarto dessas ocasiões os clientes se opunham a ela, e em um sexto das ocasiões o terapeuta emitia uma nova orientação. Há, portanto, indicações de que o comportamento de orientar é bastante reforçado pelo cliente, pelo menos de forma imediata.

Dois terços das auto-orientações foram seguidos de aprovação do terapeuta, mas ocorreram também $13 \%$ de reprovações. O número mais baixo de auto-orientações não parece ocorrer por falta de reforçamento social na interação terapêutica. O mais provável é que não são criadas oportunidades suficientes para que autorregras sejam formuladas em sessão.

Quanto a características do cliente

Os clientes considerados 'motivados; cooperativos; motivados e cooperativos' foram os que mais receberam orientações quando comparados aos clientes com os perfis ‘desmotivados e resistentes'. Este resultado está de acordo com pesquisas que indicaram uma forte correlação entre a resistência do cliente e um resultado negativo da terapia e/ou abandono da mesma, e entre a resistência do cliente e comportamentos diretivos do 
terapeuta. Aparentemente os terapeutas foram modelados pelos comportamentos do cliente no momento da emissão da orientação.

A escolaridade dos clientes parece ser uma variável importante. Houve uma correlação estatisticamente significativa entre escolaridade e emissão de autoorientação, sendo esta correlação positiva e regular. Ou seja, quanto maior a escolaridade do cliente maior o número de emissão de auto-orientação, o que nos sugere que para que ocorra emissão de auto-orientação, é necessário que haja um maior desenvolvimento de repertório verbal (incluindo abstrações).

Outras variáveis do cliente, como queixa, idade, tempo de terapia e situação financeira não foram correlacionadas a maior recebimento de orientação ou maior emissão de auto-orientação.

Quanto à concordância entre juiz e pesquisador

Nove sessões (10\% da amostra) foram entregues a um juiz. Uma sessão foi utilizada para o treino de categorização, e as oito restantes para a concordância. Juiz e pesquisador concordaram sobre quais eram os temas discutidos nas sessões analisadas em $89,6 \%$ das vezes. Houve uma concordância de $84,6 \%$ quanto às orientações emitidas nas sessões e de $81,3 \%$ quanto às auto-orientações emitidas. Já quanto aos subtipos de orientação esta concordância foi de $92,4 \%$ e no caso da auto-orientação foi de $81,3 \%$.

Juiz e pesquisador concordaram quanto ao número de episódios de orientação e auto-orientação encontrados nas sessões em 93,8\% das vezes. No entanto, a identificação dos trechos teve uma concordância de 77,1\%. Quanto à média de concordância das perguntas e respostas presentes nos diferentes episódios de orientação, houve uma concordância de $69,9 \%$ para o primeiro episódio, $73,5 \%$ para o segundo e $74,7 \%$ para o terceiro. 
Os índices de concordância entre pesquisador e juiz são satisfatórios e permitem inferir que a descrição de procedimentos é clara e que os resultados encontrados na presente pesquisa apresentam confiabilidade.

\section{Pesquisas futuras}

Apesar de terem sido detectadas diferenças de atuação do terapeuta em terapias de diferentes abordagens (ver, por exemplo, Garfield, 1995), é possível que existam práticas comuns a uma cultura terapêutica, que surgem da solução de problemas clínicos. Pesquisas deveriam procurar responder se terapeutas comportamentais (tanto os denominados analítico-comportamentais quanto os cognitivo-comportamentais) utilizam a formulação de novas regras como mecanismo básico de mudança e se há diferenças quando estas são enunciadas pelo terapeuta ou pelo cliente (autorregras). Pesquisas deveriam também responder se regras e autorregras são realmente menos utilizadas por terapeutas de outras abordagens teóricas.

Outras pesquisas deveriam ser conduzidas para comparar o processo de manutenção das mudanças obtidas quando comportamentos foram instalados por procedimentos diferentes. Contingências naturais do comportamento instruído passam a modelar sua forma de emissão? Esse comportamento se extingue na ausência de reforçamento social?

Outra questão a ser investigada refere-se ao efeito, na clínica, do emprego de orientações genéricas e específicas tanto com relação à insensibilidade às contingências naturais do comportamento (ou, em outras palavras, ao controle social ou ao controle direto pelas contingências), quanto ao seu seguimento ou não. É importante, também, procurar responder a questionamentos sobre que processos comportamentais são responsáveis pelas mudanças obtidas por meio da psicoterapia: alteração do controle por regras, modelagem na relação terapêutica, ambas, e, em caso positivo, em que 
proporção. E se os resultados obtidos diferem em sua manutenção e generalização.

Certamente, a cada pesquisa realizada, novas perguntas surgirão. 


\section{Referências}

Ablon, J. S., \& Jones, E. E. (1999). Psychotherapy process in the National Institute of Mental Health Treatment of Depression Collaborative Research Program. Journal of Consulting and Clinical Psychology, 67, 64-75.

Ablon, J. S., \& Jones, E. E. (2002). Psychotherapy process in the NIMH collaborative study of depression [manuscrito não publicado].

Abreu-Rodrigues, J., \& Sanabio-Heck, E. T. (2004). Instruções e auto-instruções: Contribuições da pesquisa básica. In C. N. de Abreu \& H. J. Guilhardi (Orgs.), Terapia comportamental e cognitivo-comportamental: Práticas clínicas (pp. 152-168). São Paulo: Editora Roca.

Abreu-Rodrigues, J., \& Sanabio, E. T. (2001). Eventos privados em uma psicoterapia externalista: Causa, efeito ou nenhuma das alternativas? In H. J. Guilhardi, M. B. B. P. Madi, P. P. Queiroz \& M. C. Scoz (Orgs.), Sobre comportamento e cognição: Vol. 7. Expondo a variabilidade (pp. 206-216). Santo André: ESETec.

Alexander, J. F., Barton, C., Schiavo, R., \& Parsons, B. (1976). Behavioral intervention with families of delinquents: Therapist characteristics and outcome. Journal of Consulting and Clinical Psychology, 44, 656-664.

Almásy, C. (2004). Efeitos da conseqüência na sessão terapêutica. Dissertação de mestrado, Pontifícia Universidade Católica de São Paulo, São Paulo, Brasil.

Amorim, C. F. R. B. (2001). O que se diz e o que se faz: Um estudo sobre interações entre comportamento verbal e comportamento não verbal. Dissertação de mestrado, Pontifícia Universidade Católica de São Paulo, São Paulo, Brasil

Anderson, C. M., Hawkins, R. P., Freeman, K. A., \& Scotti, J. R. (2000). Private events: Do they belong in a science of human behavior? The Behavior Analyst, 23, 1-10.

Anderson, C. M., Hawkins, R. P., \& Scotti, J. R. (1997). Private events in behavior analysis: Conceptual basis and clinical relevance. Behavior Therapy, 28, 157-179.

Azevedo, Y. L. (2001). Verbalizações sobre eventos privados em terapia analíticocomportamental: Uma análise das intervenções do terapeuta. Dissertação de mestrado, Universidade Federal do Pará, Belém, Brasil.

Banaco, R. A., Zamignani, D. R, \& Kovac, R. (1999). O estudo de eventos privados através de relatos verbais de terapeutas. In R. Banaco (Org.), Sobre comportamento e cognição: Vol. 1. Aspectos teóricos, metodológicos e de formação em análise do comportamento e terapia cognitivista (pp. 401-414). Santo André: ESETec.

Baptistussi, M. C. (2001). Comportamentos do terapeuta na sessão que favorecem a redução de efeitos supressivos sobre comportamentos punidos do cliente. Dissertação de mestrado, Pontifícia Universidade Católica de São Paulo, São Paulo, Brasil.

Barbera, T. J., \& Waldron, H. B. (1994). Sequential analysis as a method of feedback for family therapy process. The American Journal of Family Therapy, 22, 156-164.

Barbosa, D. R. (2001) Relação entre mudanças de peso e competência social em dois adolescentes obesos durante intervenção clínica comportamental. Dissertação de mestrado, Universidade de São Paulo, São Paulo, Brasil. 
Barbosa, J. I. C. (2006). Análise das funções de verbalizações de terapeuta e cliente sobre sentimentos, emoções e estados motivacionais na terapia analítico-comportamental. Tese de doutoramento, Universidade Federal do Pará, Belém, Brasil.

Barlow, D. H., O’Brien, G. T., \& Last, C. G. (1984). Couples treatment of agorafobia. Behavior Therapy, 15, 41-58.

Batista, J. R. (2006). Avaliação de um procedimento de treino para categorização de verbalizações de terapeutas. Trabalho de conclusão de curso de Psicologia, Universidade Federal do Pará, Belém, Brasil.

Baum, W. M. (1999). Compreender o behaviorismo: Ciência, comportamento e cultura (M. T. A. Silva, M. A. Matos \& G. Y. Tomanari, Trads.). Porto Alegre: Artmed (Trabalho original publicado em 1994).

Beck, A., \& Freeman, A. (1993). Terapia cognitiva dos transtornos de personalidade (A. E. Fillman, Trad.). Porto Alegre: Artes Médicas (Trabalho original publicado em 1990).

Beckham, E. E. (1989). Improvement after evaluation in psychotherapy of depression: Evidence of a placebo effect? Journal of Clinical Psychology, 45, 945-950.

Bennun, I., Hahweg, K., Schindler, L., \& Langlotz, M. (1986). Therapist's and client' perception in behaviour therapy: The development and cross-cultural analysis of an assessment instrument. British Journal of Clinical Psychology, 25, 275-283.

Bennun, I., \& Schindler, L. (1988). Therapist and patient factors in the behavioural treatment of phobic patients. British Journal of Clinical Psychology, 27, 145-150.

Bergin, A. E. (1997). Neglect of the therapist and human dimensions of change: A commentary. Clinical Psychology: Science and Practice, 4, 83-89.

Beutler, L. E., \& Clarkin, J. (1990). Systematic treatment selection: Toward targeted therapeutic interventions. New York: Brunner/Mazel.

Beutler, L. E., Moleiro, C., \& Talebi, H. (2002). Resistance in psychotherapy: What conclusions are supported by research? Journal of Clinical Psychology, 58, 207-217.

Beutler, L. E., \& Hamblin, D. L. (1986). Individualized outcome measures of internal changes: Methodological considerations. Journal of Consulting and Clinical Psychology, 54, 48-53.

Beutler, L. E. (1997). The psychotherapist as a neglected variable in psychotherapy: An illustration by reference to the role of therapist experience and training. Clinical Psychology: Science and Practice, 4, 44-52.

Beutler, L. E. (1981). Convergence in counseling and psychotherapy: A current look. Clinical Psychology Review, 1, 79-109.

Bischoff, M. M., \& Tracey, T. J. C. (1995). Client resistance as predicted by therapist behavior: A study of sequential dependence. Journal of Counseling Psychology, 42, 487-495.

Blaauw, E., \& Emmelkamp, P. M. G. (1991). De therapeutische relatie: Eeen onderzoeknaar de waarde van de Therapist Client Rating Scale (TCRS). Gedragstherapie, 24, 183-194. 
Blatt, S. J, Sanislow, C. A., Zurroff, D. C., \& Pilkonis, P. A. (1996). Characteristics of effective therapists: Further analysis of data from the National Institute of Mental Health Treatment of Depression Collaborative Research Program. Journal of Consulting and Clinical Psychology, 64, 1276-1284.

Blatt, S. J., Quinlan, D. M., Pilkonis, P. A., \& Shea, M. T. (1995). Impact of perfectionism and need for approval on the brief treatment of depression: The National Institute of Mental Health Treatment of Depression Collaborative Research Program revisited. Journal of Consulting and Clinical Psychology, 63, 125-132.

Bolsoni-Silva, A. T., Carrara, M., \& Marturano, E. M. (2008) Intervenção em grupo para pais: $\mathrm{O}$ que atentar quanto à intervenção e habilidades terapêuticas. In M. R. Cavalcante (Org.), Análise do Comportamento: Avaliação e intervenção (pp.102-135). São Paulo: Roca

Botomé, S. P., \& Souza, D. G. (1982). Linguagem: Uma classe de comportamentos com múltiplas funções. [Texto escrito para uso interno da disciplina Psicologia Geral oferecida para o curso de Enfermagem da Universidade Federal de São Carlos, São Carlos.]

Boyd, J. H. (1986). Use of mental health services for the treatment of panic disorder. American Journal of Psychiatry, 143, 1569-1574.

Brandão, F. S. (2003). O manejo das emoções por terapeutas comportamentais. Dissertação de mestrado, Universidade de São Paulo, São Paulo, Brasil.

Brandão, G. G. (2002). Análise de verbalizações de terapeuta e cliente em terapia analíticocomportamental: Desenvolvimento de categorias de registro. Trabalho de conclusão de curso de Psicologia, Universidade Federal do Pará, Belém, Brasil.

Burns, D. D., \& Nolen-Hoeksema, S. (1991). Coping styles, homework compliance, and the effectiveness of cognitive-behavioral therapy. Journal of Consulting and Clinical Psychology, 59, 305-311.

Burns, D. D., \& Nolen-Hoeksema, S. (1992). Therapeutic empathy and recovery from depression in cognitive behavior therapy: A structural equation model. Journal of Consulting and Clinical Psychology, 60, 441-449.

Buskist, W. F., \& Miller Jr., H. L. (1986). Interaction between rules and contingencies in the control of human fixed-interval performance. The Psychological Record, 36, 109116.

Butler, T., Giordano, S., \& Neren, S. (1985). Gender and sex-role attributes as predictors of utilization of natural support systems during personal stress events. Sex roles, 13, 515-524.

Cahill, S. P., Carrigan, M. H., \& Evans, I. M. (1998). The relation between behavior theory and behavior therapy: Challenges and promises. In J. J. Plaud \& G. H. Eifert (Eds.), From Behavior Theory to Behavior Therapy (pp. 294-319). Boston: Allyn and Bacon.

Canaan, S. (2002). A interpretação na terapia comportamental: Um estudo exploratório com um terapeuta em treinamento. Tese de doutoramento, Universidade de Brasília, Brasília, Brasil. 
Catania, A. C. (1999). Aprendizagem: Comportamento, linguagem e cognição (A. Schmidt, D. G. de Souza, F. C. Capovilla, J. C. C. de Rose, M. J. D. dos Reis, A. A. da Costa, . . . A. Gadotti, Trads.). Porto Alegre: Artmed (Trabalho original publicado em 1998).

Catania, A. C., Matthews, B. A., \& Shimoff, E. (1982). Instructed versus shaped human verbal behavior: Interactions with nonverbal responding. Journal of the Experimental Analysis of Behavior, 38, 233-248.

Cautilli, J., \& Santilli Connor, L. (2000). Assisting the client/consultee to do what is needed: A functional analysis of resistance and other forms of avoidance. The Behavior Analyst Today, 1(3), 37-45.

Cerutti, D. T. (1991). Discriminative versus reinforcing properties of schedules as determinants of schedule insensitivity in humans. The Psychological Record, 41, 51-67.

Chamberlain, P., \& Ray, J. (1988). The Therapy Process Code: A multidimensional system for observing therapist interactions in family treatment. In R. J. Prinz (Ed.), Advances in behavioral assessment of children and families (pp. 189-217). Greenwich. CT: JAI.

Chamberlain, P., Patterson, G. R., Reid, J. B., Kavanaugh, K., \& Forgatch, M. S. (1984) Observation of client resistance. Behavior Therapy, 5, 144-155.

Chequer, M. A. A. (2002). Estudo metodológico da medida de fidedignidade entre juízes na categorização de respostas verbais-vocais de terapeuta e cliente em duas condições de trabalho. Dissertação de mestrado, Pontifícia Universidade Católica de São Paulo, São Paulo, Brasil.

Clarkin, J. F., \& Levy, K. N. (2004). The influence of client variables on psychotherapy. In Lambert, M. J. (Ed.), Bergin and Garfield's handbook of psychotherapy and behavior change (pp. 194-226). New York: Wiley \& Sons.

Colombini, F. A. (2007). Terapia comportamental: Como o terapeuta trabalha com o seu cliente? Discussões de sua prática. Trabalho de conclusão de curso de Psicologia, Universidade Presbiteriana Mackenzie, São Paulo, Brasil.

Corey, G. (1983). Técnicas de aconselhamento e psicoterapia. Rio de Janeiro: Campus.

Costa, N. (2002). Terapia analítico-comportamental: Dos fundamentos filosóficos à relação com o modelo cognitivista. Santo André: ESETec.

Craske, M. G., \& Barlow, D. H. (2006). Mastery of your anxiety and panic: Therapist guide (4th ed.). New York: Oxford University Press.

Critchfield, T. (1993). Signal-detection properties of verbal self-reports. Journal of the Experimental Analysis of Behavior, 60, 495-514.

Critchfield, T., \& Perone, M. (1990). Verbal self-reports of delayed matching-to-sample by humans. Journal of the Experimental Analysis of Behavior, 53, 321-344.

Critchfield, T., \& Perone, M. (1993). Verbal self-reports about matching-to-sample: Effects of the number of elements in a compound sample stimulus. Journal of the Experimental Analysis of Behavior, 59, 193-214. 
Danforth, J. S., Chase, P. N., Dolan, M., \& Joyce, J. H. (1990). The establishment of stimulus control by instructions and by differential reinforcement. Journal of the Experimental Analysis of Behavior, 54, 97-112.

Danna, M. F., Matos, M. A. (1999). Ensinando observação: Uma introdução (4 ${ }^{a}$ ed.). São Paulo: Edicon.

Danzinger, P. R., \& Welfel, E. R. (2000). Age, gender, and health bias in counselors: An empirical analysis. Journal of Mental Health Counseling, 22, 135-149.

de Beurs, E. (1993). The assessment and treatment of panic disorder and agoraphobia. Amsterdam: Thesis Publishers.

de Haan, E., van Oppen, P., van Balkom, A. J. L. M., Spinhoven, K.A.L., \& van Dyck, R. (1997). Prediction of outcome and early versus late improvement in OCD patients treated with cognitive behaviour therapy and pharmacotherapy. Acta Psychiatrica Scandinavica, 96, 354-361.

Del Prette, G. (2006). Terapia analítico-comportamental infantil: Relações entre o brincar e comportamentos da terapeuta e da criança. Dissertação de mestrado, Universidade de São Paulo, São Paulo, Brasil.

Delitti, M. (2001). Análise funcional: O comportamento do cliente como foco da análise funcional. In M. Delitti (Org.), Sobre Comportamento e cognição: Vol. 2. A prática da análise do comportamento e da terapia cognitivo-comportamental (pp. 35-42). Santo André: ESETec.

Delitti, M., \& Meyer, S. B. (1995). O uso de encobertos na prática da terapia comportamental. In B. Rangé (Org.), Psicoterapia comportamental e cognitiva de transtornos psiquiátricos (pp. 269-274). Campinas: Editorial Psy.

Dixon, M. R., \& Hayes, L. J. (1998). Effects of differing instructional histories on the resurgence of rule-following. The Psychological Record, 48, 275-292.

Donadone, J., \& Meyer, S. (2005). Orientação e auto-orientação em atendimentos de terapeutas analítico-comportamentais experientes e pouco-experientes. Revista Brasileira de Terapia Comportamental e Cognitiva, 7, 219-229.

Donadone, J. C. (2004). O uso da orientação em intervenções clínicas por terapeutas comportamentais experientes e pouco experientes. Dissertação de mestrado, Universidade de São Paulo, São Paulo, Brasil.

Dunkle, J. H., \& Friedlander, M. L. (1996). Contribution of therapist experience and personal characteristics to the working alliance. Journal of Counseling Psychology, 43, 456460 .

Edelman, R. E., \& Chambless, D. L. (1993). Compliance during sessions and homework in exposure-based treatment of agorafobia. Behaviour Research and Therapy, 31, 767773.

Eells, T. D., Kendjelic, E. M., \& Lucas, C. P (1998). What's in a case formulation? Development and use a content coding manual. Journal of Psychotherapy Practice and Research, 7, 144-153. 
Elliot, R., Barker, C. B., Caskey, N., \& Pistrang, N. (1982). Differential helpfulness of counselor verbal responses modes. Journal of Counseling Psychology, 29, 354-361.

Fals-Stewart, W., \& Lucente, S. (1993). An MCMI-cluster typology of obsessive-compulsive: A measure of personality characteristics and its relationship to treatment participation, compliance and outcome in behavior therapy. Journal of Psychiatric Research, 27, 139-154.

Fernandes, E. M., \& Maia, A. (2001). Grounded Theory. In E. M. Fernandes \& L. S. Almeida (Eds.), Métodos e técnicas de avaliação: Contributos para a prática e investigação piscológica (pp. 49-76). Braga: CEEP Edições.

Ferster, C. B., \& Boren, M. C. P. (1968). Behavior principles. New York: Appleton Century Crofts.

Fiorini, H. J. (1995). Teorias e técnicas de psicoterapia. Rio de Janeiro: Francisco Alves.

Fiorot, M., Boswell, P., \& Murray, E. J. (1990). Personality and response to psychotherapy in depressed elderly women. Behavior, Health, \& Aging, 1, 51-63.

Follette, W. C., Naugle, A. E., \& Callaghan, G. M. (1996). A radical behavioral understanding of the therapeutic relationship in effecting change. Behavior Therapy, 27, 623-641.

Fontaine, O., \& Ylieff , M. (1981). Analyse fonctionnelle et raisonnement experimental. Journal de Thérapie Comportamentale, 3, 119-130.

Frank, J. D., \& Frank, J. B. (1993). Directive individual psychotherapies. In J. D. Frank \& J. B. Frank (Eds.), Persuasion and healing: A comparative study of psychotherapy (pp. 212-241). Baltimore: The John Hopkins University Press.

Galizio, M. (1979). Contingency-shaped and rule-governed behavior: Instructional control of human loss avoidance. Journal of the Experimental Analysis of Behavior, 31, 53-70.

Garcia, M. R. (2001). Uma tentativa de identificação de respostas de esquiva e da utilização do procedimento de bloqueio de esquiva através da análise de uma relação terapêutica. Dissertação de mestrado, Pontifícia Universidade Católica de São Paulo, São Paulo, Brasil.

Garfield, S. L. (1995). Psychotherapy: An eclectic-integrative approach. New York: John Wiley \& Sons.

Garfield, S. L. (1994). Research on client variables in psychotherapy. In S. L. Garfield \& A. E. Bergin (Eds.), Handbook of psychotherapy and behavior change (4th ed., pp. 72113). New York: John Wiley \& Sons.

Glaser, B., \& Strauss, A. (1967). The discovery of grounded theory: Strategies for qualitative research. Chicago: Aldine.

Gold, J., \& Dole, A. A. (1989). Professional psychotherapists vs. non-psychotherapists: Thought processes, verbal behavior and client's satisfaction. Psychological Reports, 65, 611620.

Goldberg, D. P., Hobson, R. F., Maguire, G. P., Margison, F. R., Osborn, M., \& Moss, S. (1984). The clarification and assessment of a method of psychotherapy. British Journal of Psychiatry, 144, 567-580. 
Greenberg, L. S., \& Pinsof, W. M. (1986). Process research: Current trends and future perspectives. In L. S. Greenberg \& W. M. Pinsof, The psychotherapeutic process: A research handbook (pp. 3-20). New York: Guilford Press.

Guilhardi, H. J., \& Queiroz, P. B. P. S. (2001). A análise funcional no contexto terapêutico: O comportamento do terapeuta como foco de análise. In M. Delitti (Org.) Sobre Comportamento e Cognição: Vol. 2. A prática da análise do comportamento e da terapia cognitivo-comportamental (pp. 43-93). Santo André: ESETec.

Guilhardi, H. J. (2002). A resistência do cliente a mudanças. In H. J. Guilhardi, M. B. B. P. Madi, P. P. Queiroz \& M. C. Scoz (Orgs.), Sobre comportamento e cognição: Vol. 9. Contribuições para a construção da teoria do comportamento (pp. 133-156). Santo André: ESETec.

Guilhardi, H. J. (2004). Considerações sobre o papel do terapeuta ao lidar com sentimentos do cliente. In M. Z. S. Brandão, F. C. S. Conte, F. S. Brandão, Y. K. Ingberman, V. L. M. Silva \& S. M. Oliani (Orgs.). Sobre comportamento e cognição: Vol. 13. Contingências e metacontingências: Contextos sócio-culturais e o comportamento do terapeuta (pp. 229-249). Santo André: ESETec.

Hacney, H., \& Nye, R. (1977). Aconselhamento: Estratégias e objetivos. São Paulo: Epu.

Harwood, M. D. (2003). Effect of therapist process variables on treatment outcome for parentchild interaction therapy (PCIT). Master's degree dissertation, University of Florida, Tallahasee, USA.

Harwood, M. D., \& Eyberg, G. (2004). Therapist verbal behavior in treatment: Relation to successful completion of parent-children interaction therapy, Journal of Clinical Child and Adolescent Psychology, 33, 601-612.

Hayes, S. C., \& Follette, W. C. (1992). Can functional analysis provide a substitute for syndrome classification? Behavior Assessment, 14, 345-365.

Hayes, S. C., \& Ju, W. (1998). The applied implications or rule-governed behavior. In W. O’Donohue (Ed.), Learning and behavior therapy (pp. 374-391). Boston: Allyn and Bacon.

Hayes, S. C., Kohlenberg, B. S., \& Melancon, S. M. (1989). Avoiding and altering rule-control as a strategy of clinical intervention. In S. C. Hayes (Ed.), Rule-governed behavior: Cognition, contingencies, and instructional control (pp. 359-385). New York: Plenum Press.

Hayes, S. C., Strosahl, K., \& Wilson, K. G. (1999). Acceptance and commitment therapy: An experiential approach to behavior change. New York: Guilford Press.

Hayes, S. C., Zettle, R. D., \& Rosenfarb, R. (1989). Rule-following. In S. C. Hayes (Ed.), Rulegoverned behavior: Cognition, contingencies, and instructional control (pp. 191220). New York: Plenum Press.

Hayes, S. C., Brownstein, A. J., Zettle, R. D., Rosenfarb, R., \& Korn, Z. (1986). Rule-governed behavior and sensitivity to changing consequences of responding. Journal of the Experimental Analysis of Behavior, 45, 237-256. 
Haynes, S. N., \& O'Brien, W. O. (1990). Functional analysis in behavior therapy. Clinical Psychology Review, 10, 649-668.

Heppner, P. P., \& Heesacker, M. (1982). Interpersonal influence process in real life counseling: Investigating client's perceptions, counselor experience level, and counselor power over time. Journal of Counseling Psychology, 29, 215-223.

Hersoug, A.G., Hoglend, O.H., Lippe, A., Monsen, J. (2009). Therapist characteristics influencing the quality of alliance in long-term psychotherapy. Clinical Psychology and Psychotherapy,16, 100-110.

Hill, C. E. (1978). The development of a system for classifying counselor responses. Journal of Counseling Psychology, 25, 461-468.

Hill, C. E. (2001). Helping skills: The empirical foundation. Washington: American Psychological Association.

Hill, C. E. (2004). Web form E: Helping skills system [Documento PDF]. Recuperado de APA Books: http://forms.apa.org/books/supp/hill/pdf/formE.pdf

Hill, C. E., Carter, J. A., \& O'Farrell, M. K. (1983). A case study of the process and outcome of time-limited counseling. Journal of Counseling Psychology, 30, 3-18.

Hill, C. E., Corbett, M. M., Kanitz, B., Rios, P., Lightsey, R., \& Gomez, M. (1992). Client behavior in counseling and therapy sessions: Development of a pantheoretical measure. Journal of Counseling Psychology, 39, 539-549.

Hill, C. E., Helms, J. E., Tichenor, V., Spiegel, S. B., O’Grady, K. E., \& Perry, E. S. (1988). Effects of therapist response in brief psychotherapy. Journal of Counseling Psychology, 35, 222-233.

Hoberman, H. M., Lewinsohn, P. M., \& Tilson, M. (1988). Group treatment of depression: Individual predictors of outcome. Journal of Consulting and Clinical Psychology, 56, 393-398.

Hoogduim, C. A. L., \& Duivenvoorden, H. J. (1988). A decision model in the treatment of obsessive-compulsive neuroses. British Journal of Psychiatry, 152, 516-521.

Horwitz, A. (1977). The pathways into psychiatric treatment: Some differences between men and women. Journal of Health and Social Behavior, 18, 169-178.

Hupert, J. D., Bufka, L. F., Barlow, D. H., Gorman, J. M., Shear, M. K., \& Woods, S. W. (2001). Therapists, therapists variables, and CBT outcome for panic disorder: Results from a multicenter trial. Journal of Consulting and Clinical Psychology, 69, 747-755.

Jahn, D. L., \& Lichstein, K. L. (1980). The resistive client: A neglected phenomenon in behavior therapy. Behavior Modification, 4, 303-320.

Johnston, J. M., \& Pennypacker, H. S. (1993). Strategies and tactics of behavioral research. (2nd ed.). Hillsdale: L. Erlbaum Associates.

Jonas, A. L. (1997). O que é auto-regra? In R. A. Banaco (Org.), Sobre comportamento e cognição: Vol. 1. Aspectos teóricos, metodológicos e de formação em análise do comportamento e terapia cognitivista (pp. 144-147). Santo André: ARBytes. 
Kaimer, P., Reinecker, H., \& Schindler, L. (1989). Interaktionsmuster von Klient un Therapeut bei zwei unterschiedlich erfolgreich behandelten Fãllen. Zeitschrift fur Klinische Psychologie, 18, 80-92

Kanfer, F. H., \& Grimm, L. G. (1980). Managing clinical change: A process model of therapy. Behavior Modification, 4, 419-444.

Kanner, R. (1998). Segredos em clínica de dor. Porto Alegre: Artmed.

Keijsers, G. P., Schaap, C. P., Hoogduin, C. A., \& Lammers, M. W. (1995). Patient-therapist interaction in the behavioral treatment of panic disorder with agoraphobia. Behavior Modification, 19(4), 491-517.

Keijsers, G. P., Schaap, C. P. D. R., Hoogduim, C. A. L. Hoogsteyns, B., \& de Keemp, E. C. M. (1999). Preliminary results on a new instrument to assess patient motivation for treatment in cognitive-behaviour therapy. Behavioural and Cognitive Psychotherapy, 27, 165-179.

Keijsers, G. P. J., Hoogduim, C. A. L., \& Schaap, C. P. D. R. (1994). Predictors of treatment outcome in the behavioral treatment of obsessive-compulsive disorder. British Journal of Psychiatry, 165(6), 781-786.

Keijsers, G. P. J., Hoogduin, C. A. L., \& Schaap, C. P. D. R. (1991). Motivae voor Psychotherapie: De ontwikkeling van een predictie-instrument. Gedragstherapie, 24, 195-208.

Keijsers, G. P. J., Schaap, C. P. D. R., \& Hoogduin, C. A. L. (2000). The impact of interpersonal patient and therapist behavior on outcome in cognitive-behavior therapy: A review of empirical studies. Behavior Modification, 24, 264-297.

Kelly, T. A. (1990). The role of values in psychotherapy: A critical review of process and outcome effects. Clinical Psychology Review, 10, 171-186.

Kerbauy, R. R. (1999). Pesquisa em terapia comportamental. In R. R. Kerbauy (Org.), Sobre comportamento e cognição: Vol. 4. Psicologia comportamental e cognitiva: Da reflexão teórica à diversidade na aplicação (pp. 61-68) Santo André: ESETec.

Kessler, R. C., Brown, R. L., \& Broman, C. L. (1981). Sex differences in psychiatric helpseeking: Evidence from four large-scale surveys. Journal of Health and Social behavior, 22, 49-64.

Kohlenberg, R. J., \& Tsai, M. (2001). Psicoterapia analítica funcional (F. Conte, M. Delliti, M. Z. Brandão, P. R. Derdyk, R. R. Kerbauy, R. C. Wielenska, R. A. Banaco \& R. Starling, Trads.). Santo André, SP: ESETec (Trabalho original publicado em 1991).

Kohlenberg, R. J., Tsai, M., \& Dougher, M. J. (1993). The dimensions of clinical behavior analysis. The Behavior Analyst, 16, 271-282.

Korman, L. M., \& Greenberg. L. S. (1996). Emotion and therapeutic change. In J. Panksepp (Ed.), Advances in biological psychiatry (Vol. 2, pp. 1-22). Greenwich, CT: JAI Press. 
Kornblith, S. J., Rehm, L. P., O'Hara, M. W., \& Lamparski, D. M. (1983). The contribution of self-reinforcement training and behavioral assignments to the efficacy of self-control therapy for depression. Cognitive Therapy and Research, 7, 499-528.

Kovac, R. (2001). Uma comparação entre duas propostas metodológicas para a análise de registros de uma interação verbal em uma situação aplicada: O setting clínico. Dissertação de mestrado, Pontifícia Universidade Católica de São Paulo, São Paulo, Brasil.

LaCrosse, M. B. (1980). Perceived counselor social influence and counseling outcomes: Validality of the Counselor Rating Form. Journal of Counseling Psychology, 27, 320-327.

Lambert, M. J., \& Anderson, E. M. (1996). Assessment for the time-limited psychotherapies. In L. J. Disckstein, M. B. Riba \& J. M. Oldham (Eds.), Review of Psychiatry (Vol. 15, pp. 23-42). Washington: American Psychiatric Press.

Lambert, M. J., \& Bergin, A. E. (1992). Achievements and limitations of psychotherapy research. In D. K. Freedheim, H. J. Freudenberger, J.W.S. Kessler, S.B. Messer, D.R. Peterson, H.H.Strupp, \& P.L. Wachtel. (Eds.), History of psychotherapy: A century of change. Washington: American Psychological Association.

Lambert, M. J., \& Okiishi, J. C. (1997). The effects of the individual psychotherapist and implications for the future research. Clinical Psychology: Science and Practice, 4, 66-75.

Lax, T., Basoglu, M., \& Marks, I. M. (1992). Expectancy and compliance as predictors of outcome in obsessive-compulsive disorder. Behavioural Psychotherapy, 20, 257266.

Leaf, P. J., Livingston, M. M., Tischler, G. L. Weissman, M. M., Holzer, C. E., \& Myers, J. K. (1985). Contact with health professionals for the treatment of psychiatric and emotional problems. Medical Care, 23, 1322-1337.

LeFrancois, J. R., Chase, P. N., \& Joyce, J. H. (1988). The effects of a variety of instructions on human fixed-interval performance. Journal of the Experimental Analysis of Behavior, 49, 383-393.

Lichtenberg, J. W., \& Heider-Barke, K. H. (1981). Investigation of transational communication relationship patterns in counseling. Journal of Counseling Psychology, 23, 310-315.

Liddle, B. J. (1995). Sexual orientation bias among advanced graduate students of counseling and counseling psychology. Counselor Education \& Supervision, 34, 321-331.

Lima, J. B. (2005). A avaliação de um sistema para categorização de verbalizações de terapeutas. Trabalho de conclusão de curso de Psicologia, Universidade Federal do Pará, Belém, Brasil.

Loduca, A. (1999). Atuação do psicólogo em um serviço multidisciplinar de tratamento da dor crônica: Experiência da Irmandade Santa Casa de Misericórdia de São Paulo. In M. M. M. J. Carvalho (Ed.), Dor: Um estudo multidisciplinar (pp. 175-195). São Paulo: Summus. 
Luborsky, L. (1997). The core conflictual relationship theme: A basic case formulation method. In T. D. Eells (Ed.) Handbook of psychotherapy case formulation (pp. 58-83). New York: Guilford Press.

Luborsky, L., McLellan, A. T., Diguer, L., Woody, G., \& Seligman, D. A. (1997). The psychotherapist matters: Comparison of outcomes across twenty-two therapists and seven patient samples. Clinical Psychology: Science and Practice, 4, 53-63.

Luborsky, L., Crits-Christoph, P., Mintz, J., \& Auerbach, A. (1988). Who will benefit from psychotherapy? Predicting therapeutic outcomes. New York: Basic Books.

Maciel, J. M. (2004). Terapia analítico-comportamental e ansiedade: Análise da interação verbal terapeuta-cliente. Dissertação de mestrado, Universidade Federal do Pará, Belém, Brasil.

Madden, G. J., Chase, P. N., \& Joyce, J. H. (1998). Making sense of sensitivity in the human operant literature. The Behavior Analyst, 21, 1-12.

Malerbi, F. E. K. (2000). Adesão ao tratamento. In R. R. Kerbauy (Org.), Sobre comportamento e cognição: Vol. 5. Conceitos, pesquisa e aplicação, a ênfase no ensinar, na emoção e no questionamento clínico (pp. 148-155). Santo André: ESETec.

Margotto, A. (1998). Identificando Mudanças na Interação Verbal em Situação Clínica. Dissertação de mestrado, Universidade de São Paulo, São Paulo, Brasil.

Martinez-Sanchez, H., \& Ribes-Iñesta, E. (1996). Interactions of contingencies and instructional history on conditional discrimination. The Psychological Record, 46, 301-318.

Martins, P. (1999). Atuação de Terapeutas Estagiários com Relação a falas sobre eventos privados em sessões de psicoterapia comportamental. Dissertação de mestrado, Universidade Federal do Pará, Belém, Brasil.

Mathews, A. M., Johnston, D. W., Shaw, P. M., \& Gelder, M. G. (1974). Process variables and the prediction of outcome in behavior therapy. British Journal of Psychiatric, 125, 256-264.

Mathews, A. M., Johnston, D. W., Lancashire, M., Munby, M., Shaw, P. M., \& Gelder, M. G. (1976). Imaginal flooding and exposure to real phobic situations: Treatment outcome with agoraphobic patients. British Journal of Psyquiatry, 129, 362-371.

Matos, M. A. (1999). Análise funcional do comportamento. Estudos de Psicologia (Campinas), $16(3), 8-18$.

Matos, M. A. (2001). Comportamento governado por regras. Revista Brasileira de Terapia Comportamental e Cognitiva, 3(2), 51-66.

Mawson, D., Marks, I. M., \& Ramn, L. (1982). Clomipramine and exposure for chronic obsessive-compulsive rituals: III. Two years follow-up and further findings. British Journal of Psychiatric, 140, 11-18.

Medeiros, M. L. A. (2001). Eventos privados e terapia analítico-comportamental: Uma análise de verbalizações de terapeuta e cliente. Dissertação de mestrado, Universidade Federal do Pará, Belém, Brasil. 
Meyer, S. B., \& Donadone, J. (2002). O emprego da orientação por terapeutas comportamentais. Revista Brasileira de Terapia Comportamental e Cognitiva, 4, 79-90.

Meyer, S. B., \& Vermes, J. S. (2001). Relação terapêutica. In B. Rangé (Org.), Psicoterapias cognitivo-comportamentais: Um diálogo com a psiquiatria (pp. 101-110). Porto Alegre: Artmed.

Meyer, S. B. (2001). A relação terapeuta-cliente é o principal meio de intervenção terapêutica? In H. J. Guilhardi, M. B. B. P. Madi, P. P. Queiroz \& M. C. Scoz (Orgs.), Sobre comportamento e cognição: Vol. 8. Expondo a variabilidade (pp. 95-98). Santo André: ESETec.

Meyer, S. B. (2003). Análise funcional do comportamento. In C. E. Costa, J. C. Luzia \& H. H. N. Sant'Anna (Orgs.), Primeiros passos em análise do comportamento e cognição (pp. 75-91). Santo André: ESETec.

Meyer, S. B. (2004). Regras e auto-regras no laboratório e na clínica. In J. Abreu-Rodrigues \& M. R. Ribeiro (Orgs). Análise do Comportamento (pp. 211-227). Porto Alegre: Artmed.

Meyer, S. B. (2005). Regras e auto-regras no laboratório e na clínica. In J. Abreu-Rodrigues e M. M. Ribeiro (Orgs), Análise do comportamento: pesquisa, teoria e aplicação, (pp. 211-229). Porto Alegre: Artmed.

Meyer, S. B. (2009). Análise de 'solicitação de informação' e 'recomendação' em banco de dados de terapias comportamentais. Tese de livre docência, Universidade de São Paulo, São Paulo, Brasil.

Millenson, J. R. (1975). Princípios de Análise do Comportamento. (A. A. Souza \& D. Rezende, Trads.). Brasília: Coordenada. (Trabalho original publicado em 1967).

Miller, W. R., \& Rollnick, S. (1993). Motivational interviewing: Preparing people to change addictive behavior. New York: Guilford.

Miranda, C. F., \& Miranda, M. L. (1993). Construindo a relação de ajuda. Belo Horizonte: Crescer.

Moore, J. (1984). On behaviorism, knowledge and causal explanation. The Psychological Record, 34, 73-97.

Murta, S. G. (1999). Avaliação e manejo da dor crônica. In M. M. M. J. Carvalho (Ed.) Dor: Um estudo multidisciplinar (pp. 175-195). São Paulo: Summus.

Nardi, R. (2004). Proposta de interpretação da interação terapeuta-cliente: Análise comportamental da esquiva através do comportamento verbal de terapeuta e cliente em um caso de dor crônica. Dissertação de mestrado, Universidade de São Paulo, São Paulo, Brasil.

Neimeyer, R. A., \& Freitas, G. (1990). The role of homework and skill acquisition in the outcome of group cognitive therapy for depression. Behavior Therapy, 21, 281-292.

Nelson, R. A., \& Borbovec, T. D. (1989). Relationship of client participation to psychotherapy. Journal of Behavior Therapy and Experimental Psychiatry, 20, 155-162. 
Neno, S. (2003). Análise funcional: Definição e aplicação na terapia analítico-comportamental. Revista Brasileira de Terapia Comportamental e Cognitiva, 5, 151-165.

Newman, B., Buffington, D. M., \& Hemmes, N. S. (1995). The effects of schedules of reinforcement on instructions following. The Psychological Record, 45, 463-476.

Novaki, P. (2003). Influência da experiência e de modelo na descrição de intervenções terapêuticas. Dissertação de mestrado, Universidade de São Paulo, São Paulo, Brasil.

Oliveira, S. C. (2002). A interpretação na terapia comportamental: Um estudo exploratório com uma terapeuta em treinamento. Dissertação de mestrado, Universidade de Brasília, Brasília, Brasil.

Oliveira-Silva, M. C., \& Tourinho, E. Z. (2006). A avaliação de duas condições de treino de categorizadores de verbalizações de terapeutas. Revista Brasileira de Terapia Comportamental e Cognitiva, 8, 39-57.

Orlinsky, D. E, Grawe, K., \& Parks, B. K. (1994). Process and outcome in psychotherapy: Noch einmal. In A. E. Bergin \& S. L. Garfield (Eds.), Handbook of psychotherapy and behavior change (4th ed., pp. 270-376). New York: Wiley.

Orlinsky, D. E., \& Howard, K. I. (1986). Process and outcome in psychotherapy. In S.L. Garfield \& A. E. Bergin (Eds.) Handbook of psychotherapy and behavior change (3rd ed., pp. 311-381). New York: John Wiley.

Otto, T. L., Torgrud, L. J., \& Holborn, S. W. (1999). An operant blocking interpretation of instructed insensitivity to schedule contingencies. The Psychological Record, 49, 663-684.

Owens, R. G., \& Ashcroft, J. B. (1982). Functional analysis in applied psychology. British Journal of Clinical Psychology, 21, 181-189.

Passos, M. L. R. F. (2003). Análise funcional do comportamento verbal em Verbal Behavior (1957) de B. F. Skinner. Revista Brasileira de Terapia Comportamental e Cognitiva, 5, 195-213.

Patterson, G. R., \& Chamberlain, P. (1994). A functional analysis of resistance during parent training therapy. Clinical Psychology: Science and Practice, 1, 53-70.

Patterson, G. R., \& Forgatch, M. S. (1985). Therapist behavior as a determinant for client noncompliance: A paradox for the behavior modifier. Journal of Consulting and Clinical Psychology, 6, 846-851.

Persons, J. B., Burns, D. D., \& Perloff, J. M. (1988). Predictors of dropout and outcome in cognitive therapy for depression in a private practice setting. Cognitive Therapy and Research, 12, 557-575.

Prado, O. Z. (2002). Terapia via internet e relação terapêutica. Dissertação de mestrado, Universidade de São Paulo, São Paulo, Brasil.

Propst, A., Paris, J., \& Rosberger, Z. (1994). Do therapist experience, diagnosis and functional level predict outcome in short-term psychotherapy. Canadian Journal of Psychiatry, 39(3), 168-176. 
Propst, L. R., Ostrom, R., Watkins, P., Deant, T., \& Mashburn, D. (1992). Comparative efficacy of religious and non-religious cognitive-behavioral therapy for the treatment of clinical depression in religious Individual. Journal of Consulting and Clinical Psychology, 60, 94-103.

Raia, C. P., Shillingford, S. W., Miller Jr, H. L., \& Baier, P. S. (2000). Interaction of procedural factors in human performance on yoked schedules. Journal of the Experimental Analysis of Behavior, 74, 265-281.

Rangé, B. (1995). Relação terapêutica. In B. Rangé (Org.), Psicoterapia comportamental e cognitiva de transtornos psiquiátricos (pp. 43-61). Campinas: Workshops.

Raue, P. J., \& Goldfried, M. R. (1994). The therapeutic alliance in cognitive-behavior therapy. In A. O. Horvath \& L. Greenberg (Orgs.), The working alliance: Theory, research, and practice (pp. 131-152). New York: John Wiley \& Sons.

Richards, P. S., \& Bergin, A. E. (Eds.). (2000). Handbook of psychotherapy and religious diversity. Washington: American Psychological Association Press.

Rocha, G. V. M. (2008). Psicoterapia analítico-comportamental com adolescentes infratores de alto-risco: Modificação de padrões anti-sociais e diminuição da reincidência criminal. Tese de doutorado. Universidade de São Paulo. São Paulo.

de Rose, J. C. C. (1999). O relato verbal segundo a perspectiva da análise do comportamento: Contribuições conceituais e experimentais. In R. A. Banaco (Org.). Sobre Comportamento e Cognição: Vol. 1. Aspectos teóricos e metodológicos e de formação em análise do comportamento e terapia cognitivista. (2 $2^{\mathrm{a}}$ ed., pp. 148-166). Santo André: ESETec.

Rosenbaum, R. L., \& Horowitz, M. J. (1983). Motivation for psychotherapy: A factorial and conceptual analysis. Psychotherapy: Theory, Research, and Practice, 20, 346-354.

Rosenfarb, I. S. (1992). A behavior analytic interpretation of the therapeutic relationship. The Psychological Record, 42, 341-354.

Rosenfarb, I. S., Newland, M. C., Brannon, S. E., \& Howey, D. S. (1992). Effects of selfgenerated rules on the development of schedule-controlled behavior. Journal of the Experimental Analysis of Behavior, 58, 107-121.

Russel, R. L., \& Stiles, W. B. (1979). Categories for classifying language in psychotherapy. Psychological Bulletin, 86(2), 404-419.

Russell, R. L., \& Trull, T. J. (1986). Sequential analyses of language variables in psychotherapy process research. Journal of Consulting and Clinical Psychology, 54, 16-21.

Ryan, V.L., \& Gizynski, M. N. (1971). Behavior therapy in retrospect: Patients' feelings about their behavior therapies. Journal of Consulting and Clinical Psychology, 37, 1-9.

Samson, D. M., \& McDonnell, A. A. (1990). Functional analysis and challenging behaviours. Behavioural Psychotherapy, 18, 259-271.

Sanabio, E. T. (2000). Punição de relato verbal: Uma contribuição para a análise do comportamento verbal. Dissertação de mestrado, Universidade de Brasília, Brasília, Brasil. 
Santos, J. V., \& Souza, C. B. A. (2007). Categorização de verbalizações do processo terapêutico e o operante intraverbal. Revista Brasileira de Psicoterapia e Medicina Comportamental, 9(2), 261-275.

Scarpelli, P. (2007). Manejo Comportamental da dor em disfunção temporomandibular. Projeto de doutoramento, Universidade de São Paulo, São Paulo, Brasil.

Schefft, B. K., \& Kanfer, F. H. (1987). The utility of a process model in therapy: A comparative study of treatment effects. Behavior Therapy, 2, 113-134.

Schindler, L., Hohenberger-Sieber, E., \& Hahlweg, K. (1989). Observing client-therapist interaction in behaviour therapy: Development and first application of an observational system. British Journal of Clinical Psychology, 28, 213-226.

Schindler, L., Revenstorf, D., Hahlweg, K., \& Brengelman, J. C. (1983). Therapeutenverhalten in der Verhaltenstherapie: Entwicklung eines Instrumentes zur Beurteilung durch den Klienten. Partnerberatung, 2, 149-157.

Shaffer, N. D. (1982). Multidimensional measures of therapist behavior and outcome prediction. Professional Psychology: Research and Practice, 14, 656-669.

Shafranske, E. P., \& Malony, H. N. (1996). Religion and the clinical practice of Psychology: A case for inclusion. In E.P. Shafranske (Ed.), Religion and the clinical practice of psychology (pp. 561-586). Washington: American Psychological Association.

Shaver, P., Scwarlz, J. Kirson, D., \& O’Connor, C. (1987). Emotion knowledge: Further exploration of a protype approach. Journal of Personality and Social Psychology, 52, 1061-1086.

Shinohara, H. (2000). Relação terapêutica: O que sabemos sobre ela? In R. R. Kerbauy (Org.), Sobre comportamento e cognição: Vol. 5. Conceitos, pesquisa e aplicação, a ênfase no ensinar, na emoção e no questionamento clínico (pp. 229-233). Santo André: ESETec.

Silva, A. S. (2001). Investigação dos efeitos do reforçamento na sessão terapêutica sobre os relatos de eventos privados, relatos de relações entre eventos privados e variáveis externas e relatos de relações entre eventos ambientais e respostas abertas. Dissertação de mestrado, Pontifícia Universidade Católica de São Paulo, São Paulo, Brasil.

Silveira, F. F. (2009). Análise da interação terapêutica em uma intervenção em grupo. Dissertação de mestrado, Universidade Estadual Paulista Júlio de Mesquita Filho, Bauru, Brasil.

Silveira, J. M., \& Kerbauy, R. R. (2000). A interação terapeuta-cliente: Uma investigação com base na queixa clínica. In R. R. Kerbauy (Org.), Sobre Comportamento e Cognição: Vol. 5. Conceitos, pesquisa e aplicação, a ênfase no ensinar, na emoção e no questionamento clínico (pp. 209-216) Santo André: ESETec.

Simonassi, L. E. (1999). Cognição: Contato com contingências e regras. Revista Brasileira de Terapia Comportamental e Cognitiva, 1, 83-93.

Simpsom, D. D., \& Joe, G. W. (1993). Motivation as a predictor of early dropout from drug abuse treatment. Psychotherapy, 2, 357-368. 
Skinner, B.F. (1992). Verbal Behavior. Acton: Copley. (Trabalho original publicado em 1957).

Skinner, B. F. (1974). Ciência e comportamento humano. (J. C. Todorov \& R. Azzi, Trads.). São Paulo: Edart. (Trabalho original publicado em 1953).

Skinner, B. F. (1982). Sobre o behaviorismo (M. P. Vilalobos, Trad.). São Paulo: Cultrix (Trabalho original publicado em 1974).

Skinner, B. F. (1984). Coming to terms with private events. The Behavioral and Brain Sciences, 7, 572-581.

Skinner, B. F. (1993). Sobre o behaviorismo (M. P. Vilalobos, Trad.). São Paulo: Cultrix (Trabalho original publicado em 1974).

Starling, R. R. (1999). Observação direta e medidas do comportamento verbal nas investigações da enfermidade: Um estudo piloto. Revista Brasileira de Terapia Comportamental e Cognitiva, 1, 107-124.

Startup, M., \& Edmons, J. (1994). Compliance with homework assignments in cognitive behavioral psychotherapy for depression: Relation to outcome and methods of enhancement. Cognitive Therapy and Research, 18, 567-579.

Stiles, W. B. (1992). Describing talk: A taxonomy of verbal response modes. Newbury Pak: Sage.

Stiles, W. B. (1999). Signs and voices in psychotherapy. Psychotherapy research, 9(1), 1-21.

Stiles, W. B., \& Sultan, F. E. (1979). Verbal responses mode use by clients in psychotherapy. Journal of Consulting and Clinical Psychology, 47, 611-613.

Stiles, W. B., Shapiro, D. A., \& Firth-Cozens, J. A. (1988). Verbal responses mode use in contrasting psychotherapies: A within-subjects comparison. Journal of Consulting and Clinical Psychology, 56, 727-733.

Stiles, W.B., Startup, M., Hardy, G.E., Barkham, M., Rees, A., Shapiro, D.A., \& Reynolds, S. (1996). Therapist session intentions in cognitive-behavioral and psychodynamicinterpessoal psychotherapy. Journal of Cousenling Psychology, 43, 402-414.

Stoolmiller, M., Duncan, T., Bank, L., \& Patterson, G. R. (1993). Some problems and solutions in the study of change: Significant patterns in client resistance. Journal of Consulting \& Clinical Psychology, 61, 920-928.

Strupp, H. H., \& Anderson, T. (1997). On the limitations of therapy manuals. Clinical Psychology: Science and Practice, 4, 76-82.

Sturmey, P. (1996). Functional analysis in clinical psychology. New York: Wiley \& Sons.

Teixeira, J., Correa, C. F., \& Pimenta, C. A. M. (1994) Dor: Conceitos gerais. São Paulo: Limay.

Thompson, L.W., Gallagher, D., \& Czirr, R. (1988). Personality disorder in the treatment of late-life depression. Journal of Geriatric Psychiatry, 21(2), 133-146. 
Thornton, D., \& Silverman, J. (1998). Avaliação psicológica em pacientes com dor crônica. In R. Kanner (Ed.), Segredos em clínica de dor (pp. 51-59). Porto Alegre: Artmed.

Torgrud, L. J., \& Holborn, S.W. (1990). The effects of verbal performance descriptions on nonverbal operant responding. Journal of the Experimental Analysis of Behavior, 54, 273-291.

Tourinho, E. Z., Garcia, M. G., \& Souza, L. M. (2003). Avaliação ampliada de categorias para análise de verbalizações de terapeutas. Projeto de pesquisa, Universidade Federal do Pará, Belém, Brasil.

Tourinho, E. Z., Neno, S., Batista, J. R., Garcia, M. G., Brandão, G. G., Souza, L M., . . . Oliveira-Silva, M. (2007). Condições de treino e sistemas de categorização de verbalizações de terapeutas. Revista Brasileira de Terapia Comportamental e Cognitiva, 9, 317-336.

Tourinho, E. Z., Carvalho Neto, M. B., \& Nemo, S. (2004). A psicologia como campo de conhecimento e como profissão de ajuda. Estudos de Psicologia, 9, 17-24.

Tracey, T. J. (1985). Dominance an outcome: A sequential examination. Journal of Counseling psychology, 32, 119-122.

Ulian, A. L. (2007). Uma sistematização da prática do terapeuta analítico-comportamental: Subsídios para a formação. Tese de doutoramento, Universidade de São Paulo, São Paulo, Brasil.

Vanderberghe, L. (2002). A prática e as implicações da análise funcional. Revista Brasileira de terapia comportamental e cognitiva, 4, 35-45.

Verhulst, J. C. R. M., \& van de Vijver, F. J. R. (1990). Resistance during psychotherapy and behavior therapy. Behavior Modification, 14, 172-187.

Vermes, J. S. (2000). Uma avaliação dos comportamentos do terapeuta durante a sessão: Relatos verbais do terapeuta e do cliente. Pesquisa de iniciação científica, Pontifícia Universidade Católica de São Paulo, São Paulo, Brasil.

Veroff, J., Kulka, R. A., \& Douvan, E. (1981). Mental health in America: Patterns of helpseeking form 1957 to 1976. New York: Basic Books.

Ware, J. E., Manning, W. G., Duan, N., Wells, K. B., \& Newhouse, J. P. (1984). Health status and the use of outclient mental health services. American Psychologist, 39, 10901110 .

Wielenska, R. C. (1989). A investigação de alguns aspectos da relação terapeuta-cliente em sessões de supervisão. Dissertação de mestrado, Universidade de São Paulo, São Paulo, Brasil.

Wielenska, R. C. (2002). Adesão e mudança de comportamento: Efeitos das interações verbais terapeuta-cliente nas primeiras sessões. Tese de doutoramento, Universidade de São Paulo, São Paulo, Brasil.

Willians, K. E., \& Chambless, D. L. (1990). The relationship between therapist characteristic and outcome of in vivo exposure treatment for agorafobia. Behavior Therapy, 21, 111-116. 
Worthington, E. L., Kurusu, T. A., McCullough, M. E., \& Sandage, S. J. (1996). Empirical research on religion and psychotherapeutic process and outcomes, a 10-yerar review and research prospectus. Psychological Bulletin, 119, 448-487.

Wulfert, E., Greenway, D. E., Farkas, P., Hayes, S.C., \& Dougher, M. J. (1994). Correlation between self-reported rigidity and rule-governed insensitivity to operant contingencies. Journal of Applied Behavior Analysis, 27, 659-671.

Yano, Y. (2003). Tratamento padronizado e individualizado no transtorno do pânico. Tese de doutoramento, Universidade de São Paulo, São Paulo, Brasil.

Yano, Y., Almeida, A. C., \& Meyer, S. B. (2008). Há indicadores de abandono de psicoterapia em sessões transcritas conduzidas por terapeutas-estagiários? [Trabalho apresentado no XVII Encontro da Associação Brasileira de Psicoterapia e Medicina Comportamental].

Yokopenic, P. A., Clark, V. A., \& Aneshensel, C. S. (1983). Depression, problem recognition, and professional consultation. Journal of Nervous and Mental Disease, 171, 15-23.

Zamignani, D. R., \& Andery, M. A. P. A. (2005). Interação entre terapeutas comportamentais e clientes diagnosticados com transtorno obsessivo-compulsivo. Psicologia Teoria e Pesquisa, 21(1), 109-119.

Zamignani, D. R. (2000). O caso clínico e a pessoa do terapeuta: Desafios a serem enfrentados. In R. R. Kerbauy (Org.). Sobre Comportamento e cognição: Vol. 5. Conceitos, pesquisa e aplicação, a ênfase no ensinar, na emoção e no questionamento clínico (pp. 229-240) Santo André: ESETec.

Zamignani, D. R. (2001). Uma tentativa de caracterização da prática clínica do analista do comportamento no atendimento de clientes com e sem o diagnóstico de transtorno obsessivo-compulsivo. Dissertação de mestrado, Pontifícia Universidade Católica de São Paulo, São Paulo, Brasil.

Zamignani, D. R. (2007). O desenvolvimento de um sistema multidimensional para a categorização de comportamentos na interação terapêutica. Tese de doutoramento, Universidade de São Paulo, São Paulo, Brasil.

Zettle, R. D., \& Hayes, S. C. (1982). Rule-governed behavior: A potential theoretical framework for cognitive-behavior therapy. In P. C. Kendall (Org.), Advances in cognitive-behavioral research and therapy (pp. 73-118). New York: Academic Press.

Zuroff, D. C., Blatt, S. J., Sotsky, S. M., Krupnick, J. L., Martin, D. J., Sanislow, C. A., \& Simmers, S. (2000). Relation of therapeutic alliance and perfectionism to outcome in brief outpatient treatment of depression. Journal of Consulting and Clinical Psychology, 68, 114-124. 
ANEXOS 


\section{ANEXO I}

(CD auto-explicativo e banco de dados IACON) 



\section{ANEXO II}

(Termo de consentimento do cliente) 


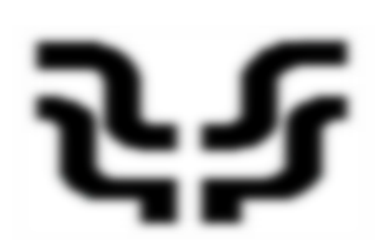

Universidade de São Paulo

Instituto de Psicologia Clínica

Departamento de psicologia Clínica

Av. Prof. Mello de Moraes, 1721, Bloco F

Cidade Universitária - São Paulo/SP

CEP: 05508-900

\section{CONSENTIMENTO INFORMADO}

$\mathrm{Eu}$, cliente do terapeuta , aceito participar do projeto

de pesquisa desenvolvido pela psicóloga Juliana Cristina Donadone, mestranda pelo Departamento de Psicologia Clínica do Instituto de Psicologia da Universidade de São Paulo e orientado pela Prof. ${ }^{a}$ Dr. ${ }^{a}$ Sonia Beatriz Meyer, docente e pesquisadora do mesmo departamento.

O objetivo geral das pesquisas coordenadas pela Prof. ${ }^{a}$ Dr. ${ }^{a}$ Sonia Beatriz Meyer é o de identificar as principais formas de atuação do psicólogo clínico na sua relação com seu cliente. Categorias de análise das falas do terapeuta e do cliente serão usadas baseadas na transcrição das sessões de psicoterapia gravadas em áudio e/ou vídeo. Diversas pesquisas poderão ser derivadas dos dados fornecidos, sempre dentro do objetivo geral proposto.

Serão gravadas no mínimo três sessões de psicoterapia de cada cliente e estas posteriormente poderão ser analisadas para elaboração de trabalho de pesquisa a ser desenvolvida pelo grupo de pesquisa coordenado pela Prof. ${ }^{a}$ Dra. Sonia Beatriz Meyer, da Universidade de São Paulo.

Apenas o grupo de pesquisa terá acesso às gravações, garantindo o sigilo absoluto sobre a identidade do cliente. Os resultados da pesquisa serão organizados de modo a não permitir que a identificação do cliente seja tornada pública nas apresentações em congresso e na elaboração de trabalhos escritos, publicados ou não que poderão ocorrer.

A participação neste projeto de pesquisa envolverá de minha parte:

a) o presente consentimento informado, em três vias, sendo que uma delas ficará em meu poder, outra com o terapeuta e outra com a pesquisadora. 
b) Autorizar a gravação das sessões através de recursos audiovisual no âmbito exclusivo desse protocolo de pesquisa. As gravações em fita de vídeo ou áudio serão de no mínimo três sessões de terapia e ficarão em poder do terapeuta que posteriormente encaminhará ao pesquisador.

Declaro estar ciente de que: a) receberei resposta ou esclarecimento a qualquer dúvida acerca dos procedimentos, riscos, benefícios e outros assuntos relacionados com a pesquisa; b) que tenho a liberdade de retirar meu consentimento informado e deixar de participar do estudo a qualquer momento sem penalização alguma; c) os dados indicativos de minha identidade não serão revelados; d) os nomes próprios (pessoas, lugares, instituições) serão alterados por nomes fictícios; e) poderei também apagar trechos da sessão que meu terapeuta e eu julgarmos que não devam ser vistos por outras pessoas envolvidas no projeto sem prejuízo da continuidade do meu atendimento.

Declaro finalmente concordar com os termos de consentimento sem restrições.

Assinatura do terapeuta:

Nome por extenso do terapeuta:

Data:

Assinatura do Cliente:

Nome do cliente:

Data:

Assinatura do pesquisador: 


\section{ANEXO III \\ (Termo de consentimento do terapeuta)}




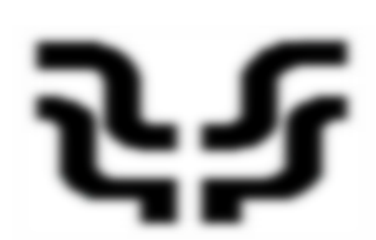

Universidade de São Paulo

Instituto de Psicologia Clínica

Departamento de psicologia Clínica

Av. Prof. Mello de Moraes, 1721, Bloco F

Cidade Universitária - São Paulo/SP

CEP: 05508-900

\section{CONSENTIMENTO INFORMADO}

$\mathrm{Eu}$, terapeuta do

cliente , aceito participar do projeto de pesquisa desenvolvido pela psicóloga Juliana Cristina Donadone, mestranda pelo Departamento de Psicologia Clínica do Instituto de Psicologia da Universidade de São Paulo e orientado pela Prof. ${ }^{a}$ Dr. ${ }^{\text {a }}$ Sonia Beatriz Meyer, docente e pesquisadora do mesmo departamento.

O objetivo geral das pesquisas coordenadas pela Prof. ${ }^{a}$ Dr. ${ }^{a}$ Sonia Beatriz Meyer é o de identificar as principais formas de atuação do psicólogo clínico na sua relação com seu cliente. Categorias de análise das falas do terapeuta e do cliente serão usadas baseadas na transcrição de sessões de psicoterapia gravas em áudio e/ou vídeo. Diversas pesquisas poderão ser derivadas dos dados fornecidos, sempre dentro do objetivo geral proposto.

Serão gravadas no mínimo três sessões de psicoterapia de cada cliente estas posteriormente poderão ser analisadas para elaboração de trabalho de pesquisa a ser desenvolvidas pelo grupo de pesquisa coordenado pela Prof. ${ }^{a}$ Dr. ${ }^{a}$ Sonia Beatriz Meyer, da Universidade de São Paulo.

Apenas o grupo de pesquisa terá acesso às gravações, garantindo o sigilo absoluto sobre a identidade do cliente. Os resultados da pesquisa serão organizados de modo a não permitir que a identificação do cliente seja tornada pública nas apresentações em congresso e na elaboração de trabalhos escritos, publicados ou não que poderão ocorrer.

A participação neste projeto de pesquisa envolverá de minha parte:

a) O presente consentimento informado, em três vias, sendo que uma delas ficará em meu poder, outra com o cliente e outra com a pesquisadora. 
b) Autorizar a gravação das sessões através de recursos audiovisual no âmbito exclusivo desse protocolo de pesquisa. As gravações em fita de vídeo ou áudio serão de no mínimo três sessões de terapia e ficarão em meu poder posteriormente sendo encaminhada ao pesquisador.

Declaro estar ciente de que: a) receberei resposta ou esclarecimento a qualquer dúvida acerca dos procedimentos, riscos, benefícios e outros assuntos relacionados com a pesquisa; b) que tenho a liberdade de retirar meu consentimento informado e deixar de participar do estudo a qualquer momento sem penalização alguma; c) os dados indicativos de minha identidade não serão revelados, a não ser que eu queira; d) os nomes próprios (pessoas, lugares, instituições) serão alterados para nomes fictícios; e) poderei também apagar trechos da sessão que meu cliente e eu julgarmos que não devam ser vistos por outras pessoas envolvidas no projeto sem prejuízo da continuidade do meu atendimento.

Declaro, finalmente, concordar com os termos de consentimento sem restrições.

Assinatura do terapeuta:

Nome por extenso do terapeuta:

Data:

Assinatura do Cliente:

Nome do cliente:

Data:

Assinatura do pesquisador: 


\section{ANEXO IV}

(Questionário entregue aos terapeutas) 


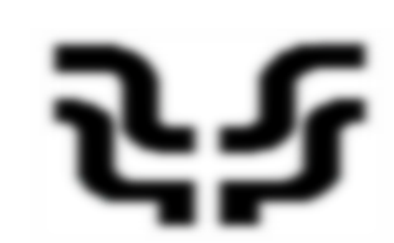

Universidade de São Paulo

Instituto de Psicologia Clínica

Departamento de psicologia Clínica

Av. Prof. Mello de Moraes, 1721, Bloco F

Cidade Universitária - São Paulo/SP

CEP: 05508-900

\section{INFORMAÇÕES A RESPEITO DO TERAPEUTA E CLIENTES}

\section{Informações - Terapeuta:}

1. Nome do terapeuta:

2. Em que estabelecimento realizou a graduação:

3. Abordagem teórica:

4. Cursos de aprimoramento, especialização e pós-graduação realizados:

5. Participa de eventos, congressos, cursos, grupos de estudo atualmente? Quais?

6. Número de anos de experiência como terapeuta e número de casos atendidos até o presente momento (favor especificar os tipos de caso - adulto/criança): 
7. Quais as maiores dificuldades encontradas nos casos atendidos?

8. Gostaria que seu nome aparecesse na pesquisa como terapeuta-participante?

\section{Informações dos Clientes}

\section{Cliente 1:}

(Estes dados não serão apresentados em publicações ou comunicações científicas)

Primeiro nome:

Estado civil:

Idade:

Data de nascimento:

Naturalidade:

Sexo:

Escolaridade:

Profissão:

Cargo:

Tempo nesta atividade:

Renda familiar:

Motivo de procura de terapia:

Diagnóstico:

Tempo de terapia:

Este cliente é:

Cooperativo

Resistente

Motivado

Desmotivado

Outros: 


\section{Cliente 2:}

(Estes dados não serão apresentados em publicações ou comunicações científicas)

Primeiro nome:

Estado civil:

Idade:

Data de nascimento:

Naturalidade:

Sexo:

Escolaridade:

Profissão:

Cargo:

Tempo nesta atividade:

Renda familiar:

Motivo de procura de terapia:

Diagnóstico:

Tempo de terapia:

Este cliente é:

Cooperativo

$\square$ Resistente

Motivado

Desmotivado

Outros:

\section{Cliente 3:}

(Estes dados não serão apresentados em publicações ou comunicações científicas)

Primeiro nome:

Estado civil:

Idade:

Data de nascimento:

Naturalidade:

Sexo:

Escolaridade:

Profissão:

Cargo: 
Tempo nesta atividade:

Renda familiar:

Motivo de procura de terapia:

Diagnóstico:

Tempo de terapia:

Este cliente é:

Cooperativo

$\square$ Resistente

$\square$ Motivado

Desmotivado

$\square$ Outros: 


\section{ANEXO V}

(Material de instrução para juiz e modelo de folha de resposta) 


\section{$\underline{\text { Material para Juiz }}$}

Você receberá algumas sessões de psicoterapia. Siga os passos apontados abaixo e anote suas respostas na folha de resposta.

\section{Passos para teste de concordância}

(1) Leia a sessão atentamente.

(2) Após a leitura da sessão, selecione os temas abordados durante a sessão.

Para facilitar esta seleção use a adaptação do modelo de grupo temático de Zamignani (2007) que se encontra no quadro abaixo.

Quadro 1 - Grupos temáticos

\begin{tabular}{|c|c|c|}
\hline & & Descrição das Categorias \\
\hline \multirow{5}{*}{ 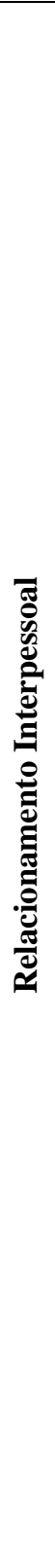 } & 1.1 Relacionamentos com cônjuge/ parceiro & $\begin{array}{l}\text { O assunto corrente diz respeito aos } \\
\text { relacionamentos do cliente fora da sessão, } \\
\text { que se refira a envolvimento afetivo amoroso } \\
\text { com um parceiro/parceira, ou a busca de um } \\
\text { parceiro/parceira, independentemente de } \\
\text { haver correspondência por parte da outra } \\
\text { pessoa. Podem envolver questões de } \\
\text { relacionamento tais como: dificuldades de } \\
\text { convivência, queixas, reclamações ou } \\
\text { acusações, bem como qualquer tipo de } \\
\text { interação - amigável ou não - com pessoas } \\
\text { com as quais haja interesse amoroso por parte } \\
\text { do cliente, ou com o (a) namorado (a), } \\
\text { cônjuge ou companheiro (a). }\end{array}$ \\
\hline & 1.2 Relacionamentos com filhos/ enteados & $\begin{array}{l}\text { O assunto corrente diz respeito aos } \\
\text { relacionamentos do cliente fora da sessão } \\
\text { com um filho ou enteado. Podem envolver } \\
\text { questões de relacionamento tais como: } \\
\text { dificuldades de convivência, queixas, } \\
\text { reclamações ou acusações, orientação de } \\
\text { pais, bem como o relato de qualquer tipo de } \\
\text { interação - amigável ou não. }\end{array}$ \\
\hline & $\begin{array}{lllll}1.3 & \text { Relacionamentos } & \text { com } & \text { pais } & \text { ou } \\
\text { padrasto/madrasta } & & & \end{array}$ & $\begin{array}{l}\text { O assunto corrente diz respeito aos } \\
\text { relacionamentos do cliente fora da sessão, } \\
\text { com pais ou padrastos. Podem envolver } \\
\text { questões de relacionamento tais como: } \\
\text { dificuldades de convivência, queixas, } \\
\text { reclamações ou acusações, bem como } \\
\text { qualquer tipo de interação - amigável ou não. }\end{array}$ \\
\hline & 1.4 Relacionamentos com outros familiares & $\begin{array}{l}\text { O assunto corrente diz respeito aos } \\
\text { relacionamentos do cliente com familiares. } \\
\text { Podem envolver dificuldades de convivência, } \\
\text { queixas, reclamações ou acusações, bem } \\
\text { como qualquer tipo de interação - amigável } \\
\text { ou não - com familiares que não o } \\
\text { cônjuge/companheiro. }\end{array}$ \\
\hline & 1.5 Outros relacionamentos & $\begin{array}{l}\mathrm{O} \text { assunto corrente diz respeito aos } \\
\text { relacionamentos com amigos, colegas, }\end{array}$ \\
\hline
\end{tabular}




\begin{tabular}{|c|c|c|}
\hline & & $\begin{array}{l}\text { vizinhos. Podem envolver dificuldades de } \\
\text { convivência, queixas, reclamações ou } \\
\text { acusações, bem como qualquer tipo de } \\
\text { interação - amigável ou não - com pessoas } \\
\text { que não sejam familiares ou } \\
\text { cônjuge/companheiro. }\end{array}$ \\
\hline & 1.6 Questões gerais sobre relacionamentos & $\begin{array}{l}\mathrm{O} \text { assunto corrente diz respeito a } \\
\text { comportamentos e sentimentos decorrentes } \\
\text { da interação interpessoal. }\end{array}$ \\
\hline 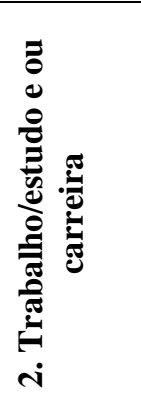 & 2. Trabalho/estudo e ou carreira & $\begin{array}{l}\text { O assunto corrente diz respeito a questões do } \\
\text { cliente relacionadas a trabalho, estudo ou } \\
\text { carreira, tanto no que se refere a projetos, } \\
\text { decisões, dúvidas, planejamento, problemas } \\
\text { de trabalho ou estudo, dificuldades de } \\
\text { relacionamento interpessoal que interferem } \\
\text { no trabalho ou estudo ou relacionamentos } \\
\text { com colegas de trabalho que têm implicações } \\
\text { diretas (implicações sugeridas no relato } \\
\text { presente do cliente) no trabalho ou estudo. }\end{array}$ \\
\hline 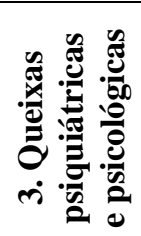 & 3. Queixas psiquiátricas e psicológicas & $\begin{array}{l}\text { O assunto corrente diz respeito a sintomas } \\
\text { relacionados a quadros psiquiátricos, e seus } \\
\text { tratamentos, médicos ou psicológicos, bem } \\
\text { como procedimentos tomados por pacientes, } \\
\text { familiares ou outros em situações de crise. }\end{array}$ \\
\hline 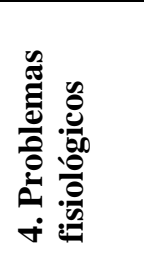 & 4. Problemas fisiológicos & $\begin{array}{l}\text { O assunto corrente diz respeito a problemas } \\
\text { fisiológicos como: desconforto físico, } \\
\text { descontentamento, desprazer, ou dor } \\
\text { relacionada a problemas de saúde - doenças } \\
\text { ou sintomas físicos, incluindo a descrição de } \\
\text { procedimentos médicos relacionados. }\end{array}$ \\
\hline 苞 & 5. Outros temas & $\begin{array}{l}\text { Essa categoria é utilizada quando não é } \\
\text { possível identificar o tema principal da } \\
\text { conversação ou quando o tema em curso não } \\
\text { se refere a nenhum dos anteriormente } \\
\text { previstos. }\end{array}$ \\
\hline
\end{tabular}

(3) Identifique a emissão de orientações na sessão. $O$ registro da identificação deverá ser anotado na folha de resposta. Para facilitar esta identificação, utilize o quadro abaixo que apresenta a definição de orientação e exemplos.

Quadro 2 - Definição de orientação e seus respectivos exemplos

\begin{tabular}{|l|l|}
\hline \multicolumn{1}{|c|}{ Definição } & \multicolumn{1}{|c|}{ Exemplo } \\
\hline $\begin{array}{l}\text { Por orientação para ação específica (OAE) } \\
\text { entendeu-se a orientação para que o cliente se } \\
\text { comportasse da forma indicada em seu cotidiano com }\end{array}$ & $\begin{array}{l}\text { EXer ir à festa do banco...” (OAE) } \\
\text { especificação da topografia do comportamento a ser } \\
\text { desenvolvido. }\end{array}$ \\
\hline
\end{tabular}


Por orientação para ação genérica (OAG)|EX1: “... Mas enfim, faça coisas que você entendeu-se a orientação para que o cliente se goste, tente estar sempre, cada vez mais comportasse da forma indicada em seu cotidiano, recheando a tua vida de coisas legais". (OAG) porém não indicando a ação que deveria ser executada, e sim qual o resultado a ser atingido com qualquer topografia de comportamento.

Por orientação para encobertos (OE) entendeu-se como uma recomendação para que o cliente refletisse sobre um tema proposto ou observasse suas ações e pensamentos.

Por orientação para tarefa (OT), entendeu-se a orientação para que o cliente executasse uma tarefa terapêutica.

EX1: "Não seria interessante você pensar nas implicações que teria contar ou não contar o que aconteceu para o seu noivo?’ (OE)

EX1: "Vamos tentar descobrir o que pode estar provocando as suas dores de cabeça. Para isso, anote durante a semana as coisas que aconteceram nos dias em que você sentir essas dores". (OT)

(4) Identifique a emissão de auto-orientações na sessão. O registro da identificação deverá ser anotado na folha de resposta. Para facilitar esta identificação, utilize o quadro abaixo que apresenta a definição de auto-orientação e exemplos.

Quadro 3 - Definição de auto-orientação e seus respectivos exemplos

\begin{tabular}{|c|c|}
\hline Definição & Exemplo \\
\hline $\begin{array}{l}\text { Por auto-orientação para ação específica (AOAE) } \\
\text { entendeu-se a auto-orientação feita pelo próprio } \\
\text { cliente para que se comportasse da forma indicada em } \\
\text { seu cotidiano com especificação da topografia do } \\
\text { comportamento a ser desenvolvido. }\end{array}$ & $\begin{array}{l}\text { EX1: “...vou fazer assim... Não vou responder } \\
\text { a emails, nem a mensagens dele esta semana, } e \\
\text { pior que eu sei que vai ser difícil, mas preciso } \\
\text { me posicionar”. (AOAE) }\end{array}$ \\
\hline $\begin{array}{l}\text { Por auto-orientação para ação genérica (AOAG) } \\
\text { entendeu-se a auto-orientação feita pelo próprio } \\
\text { cliente para que se comportasse da forma indicada em } \\
\text { seu cotidiano, porém não indicando a ação que } \\
\text { deveria ser executada, e sim qual o resultado a ser } \\
\text { atingido com qualquer topografia de comportamento. }\end{array}$ & $\begin{array}{l}\text { EX1: "Eu ainda não sei como exatamente vou } \\
\text { fazer, só sei que a partir de hoje vou assumir } \\
\text { as rédeas de minha vida, e começar a me } \\
\text { impor". (AOAG) }\end{array}$ \\
\hline $\begin{array}{l}\text { Por auto-orientação para encobertos (AOE) } \\
\text { entendeu-se como uma recomendação feita pelo } \\
\text { próprio cliente para que refletisse sobre um tema } \\
\text { proposto ou observasse suas ações e pensamentos. }\end{array}$ & $\begin{array}{l}\text { EX1: "Acho que vou pensar esta semana } \\
\text { seriamente sobre que rumo quero tomar em } \\
\text { minha vida, pois preciso definir algumas } \\
\text { coisas... (risos), depois te conto..." (AOE) }\end{array}$ \\
\hline $\begin{array}{l}\text { Por auto-orientação para tarefa (AOT) entendeu-se } \\
\text { a auto-orientação emitida pelo próprio cliente para } \\
\text { que executasse uma tarefa terapêutica. }\end{array}$ & $\begin{array}{l}\text { EX1: "Vou fazer assim... Toda vez que tiver } \\
\text { pesadelos, vou anotar... Não só o pesadelo, } \\
\text { mas o que eu fiz antes de dormir e o que } \\
\text { aconteceu depois. Vai ficar mais fácil pra mim } \\
\text { na hora que for te contar, tá bom?" (AOT) }\end{array}$ \\
\hline
\end{tabular}

(5) As orientações e auto-orientações não ocorrem a esmo. Para que elas ocorram é necessário que se identifique o contexto em que elas ocorrem. Nesta pesquisa chama-se esse contexto de episódio de orientação/auto-orientação.

Um Episódio de orientação/auto-orientação foi definido como um trecho da sessão em que o cliente ou terapeuta começam a abordar um tema até a última fala do cliente ou 
terapeuta sobre tal tema e a ocorrência de no mínimo uma orientação ou autoorientação.

Nesta etapa você deverá realizar os seguintes passos:

(a) A partir da orientação/auto-orientação categorizada, encontre o episódio de orientação/auto-orientação. Não se esqueça de utilizar a definição de episódio de orientação e auto-orientação que é composta pela soma de assunto tratado + emissão de $\mathrm{O} / \mathrm{AO}$.

(b) Anote na folha de resposta a fala de início do episódio de orientação e a fala de fim do episódio de orientação. Ex: Episódio I: fala inicial=T20; fala final=C120.

(c) Anote a fala e o subtipo de orientação ou auto-orientação encontrada neste episódio. Ex: T122 - OAE; C159 - AOAE

(d) Anote os temas discutidos ao longo do episódio analisado. Ex: no episódio I o tema discutido foi: Relacionamento Interpessoal.

(5.1) Nos episódios de orientação e auto-orientação, observou-se de forma assistemática que terapeutas faziam perguntas e que estas eram em algumas ocasiões respondidas pelos clientes. Sendo assim, nesta etapa você deverá realizar os seguintes passos:

(a) Releia os episódios de orientação/auto-orientação selecionados por você. A partir desta releitura verifique se há perguntas realizadas pelos terapeutas e respondidas pelos clientes. Neste trabalho só serão consideradas a díade perguntaresposta. Sendo assim, você só anotará as perguntas seguidas por respostas.

(b) Após a identificação das perguntas seguidas por respostas emitidas pelos clientes, verifique se no episódio de orientação/auto-orientação selecionado por você, há as seguintes perguntas feitas pelos terapeutas e respondidas pelo cliente:

(a) Quando ocorreu a situação relatada?

(b) Por que ocorreu aquela situação (a que o cliente atribui a situação relatada)?

(c) Como o cliente lidou com a situação-problema?

(d) Qual é a avaliação do cliente sobre a forma como lidou com a situação?

(e) O que o cliente sentiu naquela situação?

(f) Passada a situação o cliente é capaz de verbalizar o que deveria fazer em situações similares ou de emitir a reação pretendida?

Caso você encontre alguma dessas perguntas, mesmo que escritas de forma diferente, anote-as na folha de resposta.

(6) Esta etapa consiste na especificação das respostas as perguntas que ocorreram durante os episódios de orientação/auto-orientação.

Sendo assim; volte aos episódios de orientação e auto-orientação encontrada na sessão que você está analisando.

Quanto a pergunta: (a) Quando ocorreu a situação relatada? , as categorias de resposta do cliente eram:

(1) A situação relatada referia-se a algo que estava acontecendo na sessão;

(2) a situação relatada referia-se a algo que ocorreu na semana ou dias anterior; e

(3) a situação relatada referia-se a um tempo atrás [meses, anos]

Observe as possibilidades de categorias de respostas dos clientes acima e anote na folha de resposta a categoria que melhor se encaixe no episódio de orientação/autoorientação analisado por você. 
Quanto a pergunta: (b) Por que ocorreu aquela situação (a que o cliente atribui a situação relatada)? Observe as possibilidades de categorias de respostas dos clientes no quadro abaixo e anote na folha de resposta a categoria que melhor se encaixe no episódio de orientação/auto-orientação analisado por você.

Quadro 4 - Categorias de resposta a pergunta: "Porque ocorreu a situação?"

\section{Categorias de respostas a pergunta: "Por que ocorreu a situação?”. \\ 1. Sabe dizer o porquê de a situação ter ocorrido (descreve contingências).}

2. Não sabe dizer o porquê de a situação ter ocorrido, mas avalia seu comportamento como 'inadequado'.

3. A orientação ou a análise do terapeuta foi seguida ou deixou de ser seguida.

4. Responsabiliza a situação ao comportamento de outra pessoa.
Ex1: "É muito fácil te responder porque tudo isso que estou te contando aconteceu... Na tentativa de compensar meu sofrimento com a separação, gastei desenfreadamente... Comprava tudo o que via e queria... Meu lado menina minada aflorou, gastei e gasto ainda hoje o que tenho e o que não tenho... Assumo o que faço e não vou por a culpa no W...".

EX1: "Só sei que quando eu vi já tinha transado com uma garota de programa sem camisinha, mesmo sabendo que isso é errado", EX2: "Em um segundo tava tudo bem, no segundo seguinte tinha pegado minha mãe pelo colarinho... Quase bati na minha própria mãe, que horror... mãe é sagrado... não se bate né...”;

EX1: "Se a situação está mais estável hoje é porque consegui falar. Só estou conseguindo me expressar graças as suas dicas. Se hoje sou elogiada no trabalho é porque você me aconselhou a falar o que pensava." EX2: " Porque estamos nessa situação... porque como já analisamos aqui não há diálogo... como sair dessa crise se marido e mulher não se conversam..."; EX3: " Hoje vejo que se tivesse colocado em prática o que discutimos aqui, não estaria me sentido um lixo. Porque eu deixei a encrenca crescer... a situação não chegou a esse pé do nada, né".

EX1: "Essa ansiedade toda é culpa do meu namorado. Ele tinha que me falar que odeia minha companheira de república... Agora quando ele fala que vem me visitar fico ansiosa uma semana antes... Se ele não tivesse falado nada, estaria bem..." EX2: "Fui chamada até a escola do meu filho, pois ele está sendo agressivo com seus coleguinhas, e pior que falar com meu marido não adianta... Essa agressividade do meu filho é culpa do meu marido que é sempre ausente... o menino precisa chamar a atenção... e eu que sou repreendida na escola... justo eu que não fiz anda de errado"; EX3: "Quando eu vi, eles estavam discutindo e eu estava bem no meio da briga... Também toda vez que eles bebem, discutem... Eu entrei nessa de gaiato... a polícia tinha que entender isso... não fiz nada $\mathrm{e}$ agora to sendo acusada"; 
Quanto à pergunta: (c) Como o cliente lidou com a situação-problema? Observe as possibilidades de categorias de respostas dos clientes no quadro abaixo e anote na folha de resposta a categoria que melhor se encaixe no episódio de orientação/autoorientação analisado por você.

Quadro 5 - Categorias de resposta a pergunta: "Como o cliente lidou com a situação-problema?"

\begin{tabular}{|c|c|}
\hline $\begin{array}{c}\text { Categorias de resposta à pergunta: } \\
\text { “Como o cliente lidou com a situação- } \\
\text { problema?”. }\end{array}$ & Exemplos \\
\hline $\begin{array}{l}\text { 1. Comportou-se de forma que considerou } \\
\text { 'apropriada', apesar de as consequências nem } \\
\text { sempre serem as esperadas. }\end{array}$ & $\begin{array}{l}\text { EX1: "Diante da ausência de recursos, fiz o } \\
\text { melhor que um médico pode fazer..E aliás acho } \\
\text { que fiz muito bem feito... Falei pra A. ou nos } \\
\text { adequamos ou paramos de atender em serviços } \\
\text { públicos... É assim que agi e pretendo continuar } \\
\text { agindo... Sem briga, sem estresse, fiz o que a } \\
\text { situação exigia que eu fizesse...". EX2: "Quando } \\
\text { ele veio me falar sobre sua ex-namorada, respondi: } \\
\text { não falo sobre sua ex e ponto"; EX3: "Eu sei que } \\
\text { fiz a melhor coisa, mas falar a verdade a meu chefe } \\
\text { só serviu para que eu tivesse fama de fofoqueira no } \\
\text { setor". }\end{array}$ \\
\hline 2. Seguiu a orientação do terapeuta. & $\begin{array}{l}\text { EX1: "Tô feliz essa semana, na hora que meu } \\
\text { namorado começou a falar besteira, lembrei da } \\
\text { terapia, respirei fundo e disse: F, isso eu não } \\
\text { discuto e saí..." }\end{array}$ \\
\hline $\begin{array}{l}\text { 3. Analisou a situação, ou seja, cliente levanta as } \\
\text { principais variáveis que mantêm determinada } \\
\text { situação. }\end{array}$ & $\begin{array}{l}\text { EX1: "Fiquei pensando por que não consigo me } \\
\text { livrar desta tristeza, e percebi que várias coisas } \\
\text { ajudam para que eu não consiga me livrar, por } \\
\text { exemplo, minha situação financeira, não saber } \\
\text { fazer diferente e (risos) a vantagem que tenho em } \\
\text { ser deprimida..." }\end{array}$ \\
\hline $\begin{array}{l}\text { 4. Cliente não lidou/enfrentou a situação, ou } \\
\text { seja, diante de uma situação, cliente esquiva-se } \\
\text { da mesma. }\end{array}$ & $\begin{array}{l}\text { EX1: "Não adianta dialogar com meu marido, não } \\
\text { acho que isso vai me levar a algum lugar..." EX2: } \\
\text { "Não sei lidar com essa doença (referindo-se ao } \\
\text { câncer da esposa), na hora que as crises dela } \\
\text { começam, saio pra caminhar e só volto a noite... É } \\
\text { o meu jeito e também acho que não ajudaria em } \\
\text { nada..." }\end{array}$ \\
\hline $\begin{array}{l}\text { 5. Não sabe dizer, ou seja, cliente não sabe dizer } \\
\text { como lidou (se comportou) em determinada } \\
\text { situação. }\end{array}$ & $\begin{array}{l}\text { EX1: "Não tenho a menor ideia do que fiz para } \\
\text { isso ter acontecido". EX2: "Sabe quando você não } \\
\text { tem a menor idéia de porque os outros te tratam } \\
\text { mal... Essa sou eu! Se fiz alguma coisa, juro que } \\
\text { não sei o que fiz... na verdade não sei porque tudo } \\
\text { isso ta rolando"" }\end{array}$ \\
\hline
\end{tabular}

Quanto a pergunta: (d) Qual é a avaliacão do cliente sobre a forma como lidou com a situação? Observe as possibilidades de categorias de respostas dos clientes no 
quadro abaixo e anote na folha de resposta a categoria que melhor se encaixe no episódio de orientação/auto-orientação analisado por você.

Quadro 6 - Categorias de resposta a pergunta: “Qual é a avaliação do cliente sobre a forma como lidou com a situação?”

\begin{tabular}{|l|l|}
\hline $\begin{array}{l}\text { Possíveis respostas à pergunta: “Qual é } \\
\text { a } \frac{\text { avaliação do cliente sobre a forma }}{\text { como lidou com a situação?” }}\end{array}$ & \multicolumn{1}{|c|}{ Exemplos } \\
\hline $\begin{array}{l}\text { 1) Considera seu comportamento adequado à } \\
\text { situação. }\end{array}$ & $\begin{array}{l}\text { EX1: “Tô bem satisfeita comigo mesma, fiz o que } \\
\text { deveria ser feito... Não dá pra eu ficar esperando a } \\
\text { vida inteira pra saber se ele vai deixar a mulher ou } \\
\text { não... agora quem não quer mais sou eu... E a vida } \\
\text { continua....”. }\end{array}$ \\
\hline $\begin{array}{l}\text { 2) Considera seu comportamento inadequado, } \\
\text { mas sabe descrever qual deveria ser a reação } \\
\text { adequada à situação. }\end{array}$ & $\begin{array}{l}\text { EX1: “Nunca deveria ter reagido à provocação } \\
\text { dele... Agora ele passou por bonzinho e eu por } \\
\text { descontrolada... Mas não vejo a hora de ter outra } \\
\text { oportunidade... Quando ele começar a me xingar } \\
\text { baixinho, vou virar e dizer na lata...Não adianta } \\
\text { que não vai conseguir me desestabilizar...”. }\end{array}$ \\
\hline $\begin{array}{l}\text { 3) Não saber dizer se o comportamento emitido } \\
\text { é considerado desejável ou não. }\end{array}$ & $\begin{array}{l}\text { EX1: “Tô te contando tudo isso, mas não tenho a } \\
\text { menor ideia se fiz a melhor coisa ou não... Só sei } \\
\text { que fiz (risos)...”. }\end{array}$ \\
\hline
\end{tabular}

Quanto a pergunta: (e) $O$ que o cliente sentiu naquela situação? Observe as possibilidades de categorias de respostas dos clientes no quadro abaixo (adaptação do esquema básico de palavras emocionais de Shaver et al., 1987, adaptado por Donadone \& Meyer, 2008) e anote na folha de resposta a categoria que melhor se encaixe no episódio de orientação/auto-orientação analisado por você.

Quadro 7 - Esquema básico de palavras emocionais (adaptado de Shaver et al. 1987 - readaptado por Donadone \& Meyer, 2008)

\begin{tabular}{|c|c|c|}
\hline$\underline{\text { Amor }}$ & $\underline{\text { Raiva }}$ & Alegria \\
\hline 22. Adoração & 39. Abominação & 43. Alegria \\
\hline 23. Afeição & 40. Agitação & 44. Alívio \\
\hline 24. Amar & 41. Amargura & 45. Animado \\
\hline 25. Apreciação & 42. Aversão & 46. Ânsia \\
\hline 26. Atração (atraído) & 43. Bravo & 47. Bem (estar bem) \\
\hline 27. Carinho & 44. Ciúmes & 48. Confiante \\
\hline 28. Compaixão & 45. Contrariado & 49. Contentamento \\
\hline 29. Desejo & 46. Desdenho & 50. Coragem \\
\hline 30. Empolgada (quanto ao outro) & 47. Desgostar (não gostar) & 51. Deleite \\
\hline 31. Estimular & 48. Desprezo & 52. Distração (prazer) \\
\hline 32. Gamado, louco de paixão & 49. Enganado & 53. Ditoso \\
\hline 33. Gostar & 50. Estressado (irritado) & 54. Diversão \\
\hline 34. Luxúria ou desejo ardente & 51. Exaltação & 55. Elação \\
\hline
\end{tabular}




\begin{tabular}{|c|c|c|}
\hline $\begin{array}{l}\text { 36. Prazeroso } \\
\text { 37. Proteção } \\
\text { 38. Segura (na relação/ quanto ao } \\
\text { relacionamento) } \\
\text { 39. Sentimentalidade } \\
\text { 40. Ser cuidado por } \\
\text { 41. Ternura } \\
\text { 42. Vontade }\end{array}$ & $\begin{array}{l}\text { 52. Exasperação } \\
\text { 53. Feroz } \\
\text { 54. Frustração } \\
\text { 55. Fúria } \\
\text { 56. } \text { Hostilidade } \\
\text { 57. Incomodado } \\
\text { 58. } \text { Incompreensão } \\
\text { 59. } \text { Indignação } \\
\text { 60. Inveja } \\
\text { 61. Ira } \\
\text { 62. Irritação } \\
\text { 63. Mágoa } \\
\text { (ressentimento) } \\
\text { 64. Nojo } \\
\text { 65. Ódio } \\
\text { 66. Raiva } \\
\text { 67. Rancor } \\
\text { 68. Repugnância } \\
\text { 69. Resmungar } \\
\text { 70. Ressentimento } \\
\text { 71. Ser rabugento } \\
\text { 72. Ser zangado } \\
\text { 73. Tormento } \\
\text { 74. Ultrajar } \\
\text { 75. Vingança } \\
\text { 76. Vigiado (controlado, } \\
\text { sufocado) }\end{array}$ & 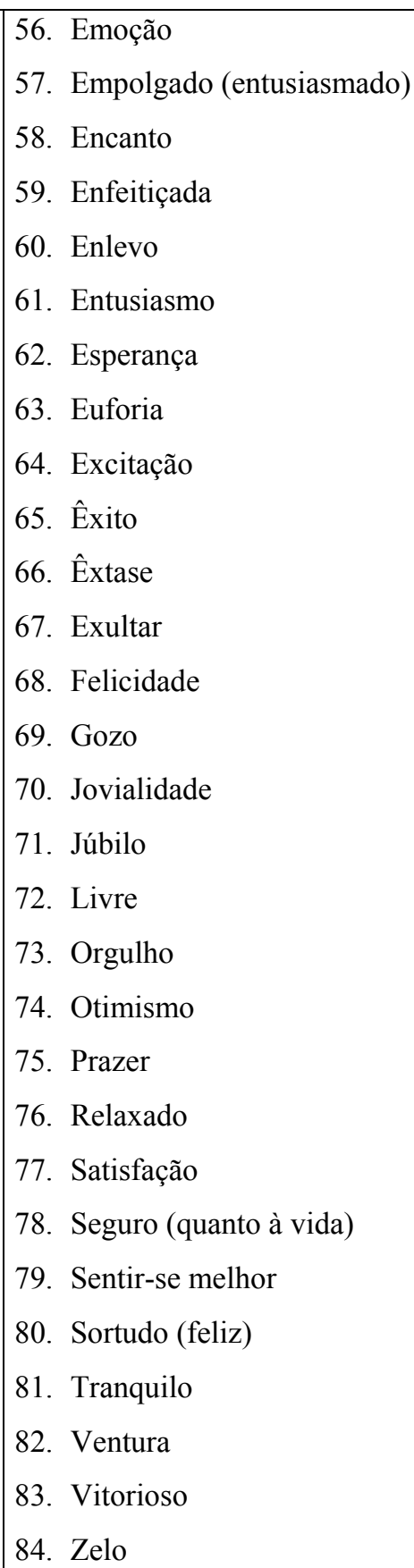 \\
\hline
\end{tabular}




\begin{tabular}{|l|l|l|}
\hline \multicolumn{1}{|c|}{ Tristeza } & \multicolumn{1}{|c|}{ Medo } & \multicolumn{1}{|c|}{ Culpa/vergonha } \\
\hline 44. Abatido & 25. Aflição & 13. Arrependimento \\
45. Agonia & 26. Alarmado & 14. Constrangido \\
46. Alienação & 27. Ansiedade & 15. Culpado \\
47. Angustia & 28. Apreensão & 16. Deslocado \\
48. Arrasado & 29. Assustado & 17. Embaraçado \\
49. Cansaço & 30. Choque & 18. Humilhado \\
50. Chateado & 31. Confuso & 19. Inferiorizado \\
51. Chocado & 32. Desgosto & 20. Inseguro \\
52. Compaixão & 33. Dúvidas & 21. Insultado \\
53. Depressão & 34. Estressado (temeroso) & 22. Remorso \\
54. Derrota & 35. Histeria & 23. Tímido \\
55. Desagrado & 36. Horror & 24. Vergonha \\
56. Desamparo & 37. Incapaz & \\
57. Desanimado & 38. Intranquilidade & \\
58. Desapontado & 39. Medo & \\
59. Desesperança & 40. Nervosismo & \\
60. Desespero & 41. Pânico & \\
61. Desgostoso & 42. Pavor & \\
62. Desgraçado & 43. Pesaroso & \\
63. Dó (lástima, comiseração, compaixão) & 44. Preocupado & \\
64. Doloroso (dor) & 45. Pressionado & \\
65. Esgotado & 46. Tensão & \\
66. Estar na escuridão/tristeza profunda & 47. Terror & \\
67. Fracassado & 48. Vigiado (intranquilo) & \\
68. Impotência & relatada) & \\
69. Indiferença & Sem Classificação & \\
70. Infelicidade & \\
71. Isolado & & \\
72. "Jogada às traças; deixada de lado" & \\
\hline
\end{tabular}




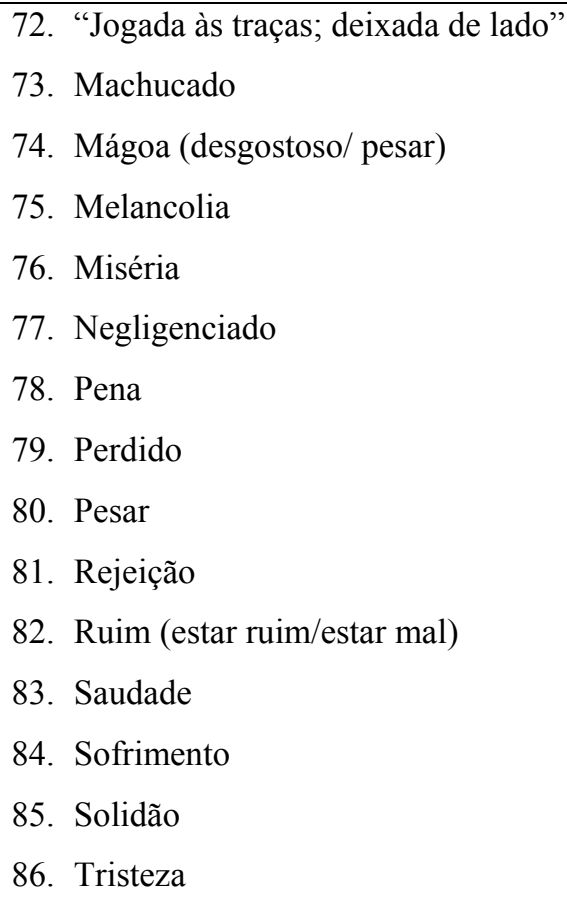

Quanto a pergunta: (f) Passada a situação o cliente é capaz de verbalizar o que deveria fazer em situações similares ou de emitir a reação pretendida? Observe as possibilidades de categorias de respostas dos clientes no quadro abaixo e anote na folha de resposta a categoria que melhor se encaixe no episódio de orientação/autoorientação analisado por você.

Quadro 8 - Categorias de resposta a pergunta: "Passada a situação o cliente é capaz de verbalizar o que deveria fazer em situações similares ou emitiu a reação pretendida?”

\begin{tabular}{|l|l|}
\hline $\begin{array}{c}\text { Categorias de respostas à pergunta: } \\
\text { "Passada a situação o cliente é capaz de } \\
\text { verbalizar o que deveria fazer em } \\
\text { situações similares ou emitiu a reação } \\
\text { pretendida?” }\end{array}$ & \multicolumn{1}{|c|}{ Exemplos } \\
\hline $\begin{array}{l}\text { 1) Sim, é capaz de verbalizar o que deveria } \\
\text { fazer em situações similares ou emitir a reação } \\
\text { pretendida }\end{array}$ & $\begin{array}{l}\text { EX1: "Agora eu aprendi... Ficar no pé de homem } \\
\text { não garante fidelidade, pelo contrário (risos)... Por } \\
\text { isso que não vejo a hora de arrumar um novo } \\
\text { namorado e colocar em prática tudo que aprendi } \\
\text { aqui... Nada de ligações altas horas, nem verificar } \\
\text { celular... Aprendi... E de agora em diante o que } \\
\text { tiver que ser será!". EX2: "Agora que vou ter } \\
\text { dinheiro de novo, sei que dinheiro não aceita } \\
\text { desaforo, vou economizar e fazer um fundo de } \\
\text { reserva para momentos difíceis. To feliz que a vida } \\
\text { ta me dando a chance de mostrar que sou capaz. } \\
\text { Agora é só ficar esperto". }\end{array}$ \\
\hline
\end{tabular}


2) Não saber dizer se emitiu o comportamento adequado à situação ou não sabe avaliar se em situações similares reagiria de outra forma
EX1: "Acho que se passasse por essa situação de novo, não saberia o que fazer de novo (risos)... É muito difícil agir diferente, afinal sou eu...". EX2: $\mathrm{Eu}$ nunca sei o que fazer quando alguém me ofende...Nunca tenho reação e acho que não saberia o que fazer se passasse por uma ofensa de novo...".

\section{Folha de Resposta}

Identificação da sessão:

Identificação do terapeuta:

Identificação do cliente:

(2) Os temas encontrados nesta sessão pertenciam aos grupos temáticos:

\begin{tabular}{|l|l|}
\hline 1.1 Relacionamentos com cônjuge/ parceiro & \\
\hline 1.2 Relacionamentos com filhos/ enteados & \\
\hline $\begin{array}{l}\text { 1.3 Relacionamentos com pais ou } \\
\text { padrasto/madrasta }\end{array}$ & \\
\hline 1.4 Relacionamentos com outros familiares & \\
\hline 1.5 Outros relacionamentos & \\
\hline 1.6 Questões gerais sobre relacionamentos & \\
\hline 2. Trabalho/estudo e ou carreira & \\
\hline 3. Queixas psiquiátricas e psicológicas & \\
\hline 4. Problemas fisiológicos & \\
\hline 5. Outros temas & \\
\hline
\end{tabular}

(3) as orientações encontradas nesta sessão ocorreram na fala T... e o subtipo de orientação foi...:

Fala: Ex1: T25 - OAE; Ex2: T45 - OE

\begin{tabular}{|l|l|}
\hline Fala & Categorização \\
\hline & \\
\hline & \\
\hline & \\
\hline & \\
\hline
\end{tabular}

(4) as auto-orientações encontradas nesta sessão ocorreram na fala T... e o subtipo de auto-orientação foi....:

Fala: Ex1: C25 - AOAE; Ex2: C112 - AOAG 


\begin{tabular}{|l|l|}
\hline Fala & Categorização \\
\hline & \\
\hline & \\
\hline & \\
\hline & \\
\hline
\end{tabular}

(5) Os episódios de orientação/auto-orientação encontrados nesta pesquisa foram:

\begin{tabular}{|c|c|c|c|}
\hline Episódios & Trecho & $\begin{array}{c}\text { Orientações ou } \\
\text { auto-orientações }\end{array}$ & $\begin{array}{c}\text { Temas discutidos no } \\
\text { episódio de orientação }\end{array}$ \\
\hline & & & \\
\hline & & & \\
\hline & & & \\
\hline
\end{tabular}

$(5,1)$ (a) Houve perguntas durante o episódio de orientação ou auto-orientação analisado?

Episódio I: $\square$ SIM $\square$ NÃO;

Episódio II: $\square$ SIM $\square$ NÃO;

Episódio III: $\square$ SIM $\square$ NÃO;

Episódio IV: $\square$ SIM $\square$ NÃO;

Episódio V: $\square$ SIM $\square$ NÃO;

\begin{tabular}{|c|c|}
\hline Episódios & Perguntas \\
\hline & \\
\hline & \\
\hline
\end{tabular}

(b) Nos episódios de orientação você encontra as perguntas apresentadas abaixo:

(a) Quando ocorreu a situação relatada?

(b) Por que ocorreu aquela situação (a que o cliente atribui a situação relatada)?

(c) Como o cliente lidou com a situação-problema?

(d) Qual é a avaliação do cliente sobre a forma como lidou com a situação?

(e) O que o cliente sentiu naquela situação?

(f) Passada a situação o cliente é capaz de verbalizar o que deveria fazer em situações similares ou de emitir a reação pretendida?

Caso você encontre alguma dessas perguntas, mesmo que escritas de forma diferente, marque $\mathrm{X}$ nas perguntas encontradas na tabela abaixo. Veja o exemplo:

\begin{tabular}{|l|l|l|l|l|l|}
\hline \multicolumn{1}{|c|}{ Perguntas } & Episódio I & Episódio II & Episódio III & Episódio IV & Episódio V \\
\hline $\begin{array}{l}\text { (a) Quando ocorreu a } \\
\text { situação relatada? }\end{array}$ & & & & & \\
\hline $\begin{array}{l}\text { (b) Por que ocorreu aquela } \\
\text { situação (a que o cliente } \\
\text { atribui a situação relatada)? }\end{array}$ & & & & & \\
\hline (c) Como o cliente lidou & & & & & \\
\hline
\end{tabular}




\begin{tabular}{|l|l|l|l|l|}
\hline com a situação-problema? & & & & \\
\hline $\begin{array}{l}\text { (d) Qual é a avaliação do } \\
\text { cliente sobre a forma como } \\
\text { lidou com a situação? }\end{array}$ & & & & \\
\hline $\begin{array}{l}\text { (e) O que o cliente sentiu } \\
\text { naquela situação? }\end{array}$ & & & & \\
\hline $\begin{array}{l}\text { (f) Passada a situação o } \\
\text { cliente é capaz de verbalizar } \\
\text { o que deveria fazer em } \\
\text { situações similares ou de } \\
\text { emitir a reação pretendida? }\end{array}$ & & & & \\
\hline
\end{tabular}

(6) Análise das categorias de resposta para cada pergunta realizada pelo terapeuta durante o episódio de orientação ou auto-orientação:

Para a pergunta: (a) Quando ocorreu a situação relatada? , anote no quadro abaixo, as respostas encontradas nos episódios de orientação/auto-orientação analisados.

\begin{tabular}{|c|l|l|l|l|l|}
\hline $\begin{array}{c}\text { Quando ocorreu a } \\
\text { situação relatada? }\end{array}$ & Episódio I & Episódio II & Episódio III & Episódio IV & Episódio V \\
\hline Na sessão & & & & & \\
\hline $\begin{array}{c}\text { Na semana ou dias } \\
\text { anteriores }\end{array}$ & & & & & \\
\hline $\begin{array}{c}\text { Há um tempo } \\
\text { (meses, anos) }\end{array}$ & & & & & \\
\hline
\end{tabular}

Para a pergunta: (b) Por que ocorreu aquela situação (a que o cliente atribui a situação relatada)? , anote as respostas encontradas nos episódios de orientação/autoorientação analisados.

\begin{tabular}{|l|l|l|l|l|l|}
\hline Porque ocorreu a situação relatada? & $\begin{array}{c}\text { Episódio } \\
\text { I }\end{array}$ & $\begin{array}{c}\text { Episódio } \\
\text { II }\end{array}$ & $\begin{array}{c}\text { Episódio } \\
\text { III }\end{array}$ & $\begin{array}{c}\text { Episódio } \\
\text { IV }\end{array}$ & $\begin{array}{c}\text { Episódio } \\
\text { V }\end{array}$ \\
\hline $\begin{array}{l}\text { 1. Sabe dizer o porquê de a situação ter } \\
\text { ocorrido (descreve contingências). }\end{array}$ & & & & & \\
\hline $\begin{array}{l}\text { 2. Não sabe dizer o porquê de a situação ter } \\
\text { ocorrido, mas avalia seu comportamento } \\
\text { como 'inadequado'. }\end{array}$ & & & & & \\
\hline $\begin{array}{l}\text { 3. A orientação ou a análise do terapeuta foi } \\
\text { seguida ou deixou de ser seguida. }\end{array}$ & & & & & \\
\hline $\begin{array}{l}\text { 4. Responsabiliza a situação ao } \\
\text { comportamento de outra pessoa. }\end{array}$ & & & & & \\
\hline $\begin{array}{l}\text { 5. Não sabe discriminar o porquê de a } \\
\text { situação ter ocorrido. }\end{array}$ & & & & \\
\hline
\end{tabular}

Para a pergunta: (c) Como o cliente lidou com a situação-problema?, anote as respostas encontradas nos episódios de orientação/auto-orientação analisados. 


\begin{tabular}{|c|c|c|c|c|c|}
\hline $\begin{array}{c}\text { Como o cliente lidou com a situação- } \\
\text { problema? }\end{array}$ & $\begin{array}{l}\text { Episódio } \\
\text { I }\end{array}$ & $\begin{array}{l}\text { Episódio } \\
\text { II }\end{array}$ & $\begin{array}{l}\text { Episódio } \\
\text { III }\end{array}$ & $\begin{array}{l}\text { Episódio } \\
\text { IV }\end{array}$ & $\begin{array}{l}\text { Episódio } \\
\text { V }\end{array}$ \\
\hline $\begin{array}{l}\text { 1. Comportou-se de forma que considerou } \\
\text { 'apropriada', apesar de as consequências } \\
\text { nem sempre serem as esperadas. }\end{array}$ & & & & & \\
\hline 2. Seguiu a orientação do terapeuta. & & & & & \\
\hline $\begin{array}{l}\text { 3. Analisou a situação, ou seja, cliente } \\
\text { levanta as principais variáveis que mantêm } \\
\text { determinada situação. }\end{array}$ & $\mathrm{x}$ & & & & \\
\hline $\begin{array}{l}\text { 4. Cliente não lidou/enfrentou a situação, ou } \\
\text { seja, diante de uma situação, cliente } \\
\text { esquiva-se da mesma. }\end{array}$ & & & & & \\
\hline $\begin{array}{l}\text { 5. Não sabe dizer, ou seja, cliente não sabe } \\
\text { dizer como lidou (se comportou) em } \\
\text { determinada situação. }\end{array}$ & & & & & \\
\hline
\end{tabular}

Para a pergunta: (d) Qual é a avaliação do cliente sobre a forma como lidou com a situação? , anote as respostas encontradas nos episódios de orientação/auto-orientação analisados.

\begin{tabular}{|l|l|l|l|l|l|}
\hline $\begin{array}{l}\text { “Qual é a avaliação do cliente sobre a } \\
\text { forma como lidou com a situação?” }\end{array}$ & $\begin{array}{c}\text { Episódio } \\
\text { I }\end{array}$ & $\begin{array}{c}\text { Episódio } \\
\text { II }\end{array}$ & $\begin{array}{c}\text { Episódio } \\
\text { III }\end{array}$ & $\begin{array}{c}\text { Episódio } \\
\text { IV }\end{array}$ & $\begin{array}{c}\text { Episódio } \\
\text { V }\end{array}$ \\
\hline $\begin{array}{l}\text { 1) Considera seu comportamento adequado } \\
\text { à situação. }\end{array}$ & & & & \\
\hline $\begin{array}{l}\text { 2) Considera seu comportamento } \\
\text { inadequado, mas sabe descrever qual } \\
\text { deveria ser a reação adequada à situação. }\end{array}$ & & & & & \\
\hline $\begin{array}{l}\text { 3) Não saber dizer se o comportamento } \\
\text { emitido é considerado desejável ou não. }\end{array}$ & & & & & \\
\hline
\end{tabular}

Para a pergunta: (e) $\boldsymbol{O}$ que o cliente sentiu naquela situação? , anote as respostas encontradas nos episódios de orientação/auto-orientação analisados.

\begin{tabular}{|l|c|c|c|c|c|}
\hline $\begin{array}{l}\text { “O que o cliente sentiu naquela } \\
\text { situação” }\end{array}$ & $\begin{array}{c}\text { Episódio } \\
\text { I }\end{array}$ & $\begin{array}{c}\text { Episódio } \\
\text { II }\end{array}$ & $\begin{array}{c}\text { Episódio } \\
\text { III }\end{array}$ & $\begin{array}{c}\text { Episódio } \\
\text { IV }\end{array}$ & $\begin{array}{c}\text { Episódio } \\
\text { V }\end{array}$ \\
\hline 1) Amor & & & & & \\
\hline 2) Raiva & & & & & \\
\hline 3) Alegria & & & & & \\
\hline 4) Tristeza & & & & & \\
\hline 5) Medo & & & & & \\
\hline 6) Culpa/vergonha & & & & & \\
\hline 7) sem classificação & & & & & \\
\hline
\end{tabular}


Para a pergunta: (f) Passada a situação o cliente é capaz de verbalizar o que deveria fazer em situações similares ou de emitir a reação pretendida? , anote as respostas encontradas nos episódios de orientação/auto-orientação analisados.

\begin{tabular}{|l|l|l|l|l|l|}
\hline $\begin{array}{l}\text { “Passada a situação o cliente é capaz } \\
\text { de verbalizar o que deveria fazer em } \\
\text { situações similares ou emitiu a reação } \\
\text { pretendida?” }\end{array}$ & $\begin{array}{c}\text { Episódio } \\
\text { I }\end{array}$ & $\begin{array}{c}\text { Episódio } \\
\text { II }\end{array}$ & $\begin{array}{c}\text { Episódio } \\
\text { III }\end{array}$ & $\begin{array}{c}\text { Episódio } \\
\text { IV }\end{array}$ & $\begin{array}{c}\text { Episódio } \\
\text { V }\end{array}$ \\
\hline $\begin{array}{l}\text { 1) Sim, é capaz de verbalizar o que deveria } \\
\text { fazer em situações similares ou emitir a } \\
\text { reação pretendida }\end{array}$ & & & & & \\
\hline $\begin{array}{l}\text { 2) Não saber dizer se emitiu o } \\
\text { comportamento adequado à situação ou não } \\
\text { sabe avaliar se em situações similares } \\
\text { reagiria de outra forma }\end{array}$ & & & & & \\
\hline $\begin{array}{l}\text { 3) Não saber dizer se o comportamento } \\
\text { emitido é considerado desejável ou não. }\end{array}$ & & & & & \\
\hline
\end{tabular}




\section{ANEXO VI \\ (Metodologia Estatística)}

\section{Testes Estatísticos}

O nível de significância definido para as análises estatísticas deste trabalho foi de 0,05 (5\%), ou seja, os resultados encontrados nestas análises foram construídos com 95\% de confiança estatística e admite-se erro estatístico de 5\%. 


\subsection{Igualdade de Duas Proporções}

O Teste de Igualdade de duas Proporções é um teste não paramétrico que compara se a proporção de respostas de duas determinadas variáveis e/ou seus níveis é estatisticamente significante. Assim trabalhou-se com as seguintes hipóteses:

$$
\left\{\begin{array}{l}
H_{0}: \mathrm{p}_{1}=p_{2} \\
H_{1}: \mathrm{p}_{1} \neq p_{2}
\end{array}\right.
$$

Para se realizar este teste devemos calcular $f_{1}=\frac{x_{1}}{n_{1}}, f_{2}=\frac{x_{2}}{n_{2}}$ e $\hat{p}=\frac{x_{1}+x_{2}}{n_{1}+n_{2}}$. Com isso pode-se agora calcular a estatística teste.

$$
Z_{c a l}=\frac{f_{1}-f_{2}}{\sqrt{\hat{p}(1-\hat{p})\left(\frac{1}{n_{1}}+\frac{1}{n_{2}}\right)}}
$$

Conclusões

- Se $-Z_{\frac{\alpha}{2}} \leq Z_{c a l} \leq Z_{\frac{\alpha}{2}}$, não se pode rejeitar $H_{0}$, isto é, a um determinado risco $\alpha$, diz-se que não existe diferença entre as proporções.

- Se $Z_{\text {cal }}>Z_{\frac{\alpha}{2}}$ ou $Z_{c a l}<-Z_{\frac{\alpha}{2}}$, rejeita-se $H_{0}$, concluindo-se, com risco $\alpha$, que há diferença entre as proporções.

\section{2 Índice de Concordância de Kappa}

O Índice de Concordância de Kappa é uma estatística utilizada para medir o grau de concordância entre duas variáveis e/ou resultados. A estatística Kappa parte dos seguintes pressupostos:

- Os casos a serem analisados são independentes.

- Os entrevistadores atuam de forma independente um do outro.

- As categorias analisadas são mutuamente exclusivas e exaustivas.

Assim, temos a seguinte configuração de uma tabela cruzada 


\section{Avaliador 1}

Qualidade

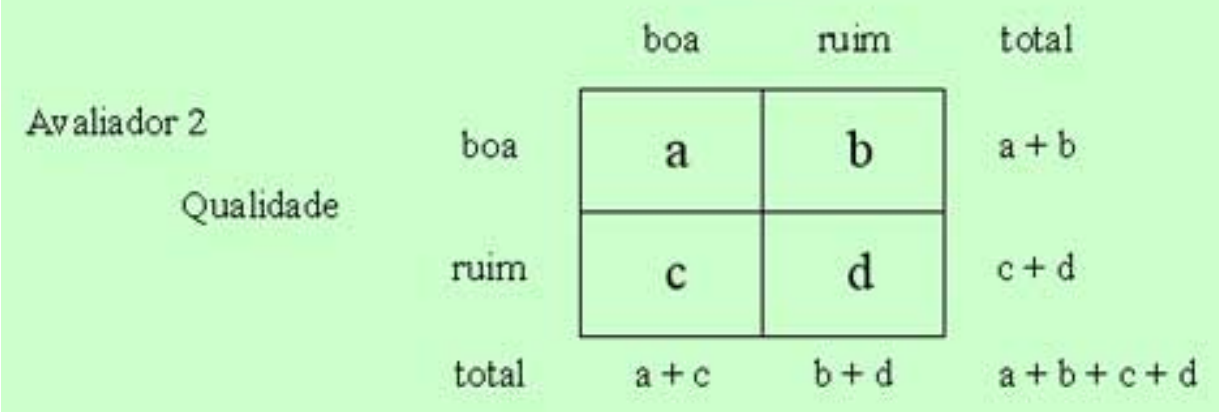

Figura 1: Tabela 2 x 2 comparando o resultado do questionário por dois observadores para quantificação da concordância entre observadores (Teste de Kappa)

\section{Interpretação das células:}

$a=$ concordância positivo/positivo entre observadores

$\mathrm{b}=$ concordância negativo/positivo entre observadores

$\mathrm{c}=$ concordância positivo/negativo entre observadores

$\mathrm{d}=$ concordância negativo/negativo entre observadores

\section{Fórmulas:}

$\mathrm{a}+\mathrm{d}=$ concordância observada (Ao)

$\mathrm{a}+\mathrm{b}+\mathrm{c}+\mathrm{d}=$ máxima concordância possível $(\mathrm{N})$

$(a+d) /(a+b+c+d)=$ percentagem global de concordância

$[(a+b)(a+c)] /(a+b+c+d)=$ concordância positiva esperada ao acaso (célula a)

$[(c+d)(b+d)] /(a+b+c+d)=$ concordância negativa esperada ao acaso (célula d)

Concordância positiva esperada ao acaso + concordância negativa esperada ao acaso $=$ concordância total esperada ao acaso (Ac)

$$
\text { Kappa }=\frac{A_{o}-A_{c}}{N-A_{c}}
$$

Figura 2: Fórmula para cálculo da concordância (Teste de Kappa) 
Divisão arbitrária para interpretação dos resultados: Kappa $<20 \%$ desprezível; 21 a 40\% mínimo; 41 a 60\% regular; 61 a $80 \%$ bom; acima de $81 \%$ ótimo.

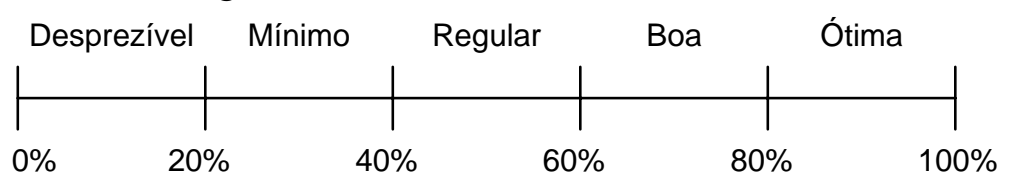

\subsection{ANOVA}

A ANOVA - Analysis of Variance é um teste paramétrico bastante usual, que faz uma comparação de médias utilizando a variância. No entanto deve-se atentar ao fato de que para a realização deste teste, algumas suposições a priori devem ser satisfeitas. Por ser um teste paramétrico, supomos que $\varepsilon_{i j} \sim N\left(0, \sigma^{2}\right)$, em linguagem de leigos, isso quer dizer que os erros para cada observação têm que ter uma distribuição normal com média zero e variância constante.

Para a utilização da técnica da ANOVA os dados têm de estar dispostos da seguinte maneira: 


\begin{tabular}{cccccc}
$\begin{array}{c}\text { Elemento } \\
\text { da } \\
\text { Amostra }\end{array}$ & 1 & 2 & 3 & & $\mathrm{~K}$ \\
\hline 1 & $x_{11}$ & $x_{21}$ & $x_{31}$ & $\cdots$ & $x_{k 1}$ \\
2 & $x_{12}$ & $x_{22}$ & $x_{32}$ & $\cdots$ & $x_{k 2}$ \\
$\vdots$ & $\vdots$ & $\vdots$ & $\vdots$ & & $\vdots$ \\
$n_{i}$ & $x_{1 n_{1}}$ & $x_{2 n_{2}}$ & $x_{3 n_{3}}$ & $\cdots$ & $x_{k n_{k}}$ \\
\hline$\sum$ & & & & & \\
\hline $\bar{x}_{i}$ & & & & & \\
\hline
\end{tabular}

Assim, realiza-se o seguinte teste nos dados amostrados:

$\left\{\begin{array}{l}\mathrm{H}_{0}: \mu_{\mathrm{A}}=\mu_{B}=\mu_{C}=\cdots=\mu_{N} \\ \mathrm{H}_{1}: \text { pelo menos uma diferente }\end{array}\right.$

Onde:

$\mu_{A}=$ média da variável A;

$\mu_{B}=$ média da variável $\mathrm{B}$;

$$
\begin{aligned}
& \mu_{C}=\text { média da variável } C \\
& \mu_{N}=\text { média da n-ésima (última) variável. }
\end{aligned}
$$

Com os dados dispostos da maneira anterior, deve-se calcular e montar a tabela abaixo que expressa de forma resumida e sucinta o teste realizado.

Tabela ANOVA

\begin{tabular}{ccccc}
\hline Fonte de & Soma de & Graus de & Quadrados & \multirow{2}{*}{ Teste F } \\
Variação & Quadrados & Liberdade & Médios &
\end{tabular}




\begin{tabular}{lccc}
\hline Entre Grupos & $Q_{e}$ & $k-1$ & $S_{e}^{2}=\frac{Q_{e}}{k-1}$ \\
\hline $\begin{array}{l}\text { Dentro dos } \\
\text { Grupos }\end{array}$ & $Q_{r}=Q_{t}-Q_{e}$ & $n-k$ & $S_{r}^{2}=\frac{Q_{t}-Q_{e}}{n-k}$ \\
\hline Total & $Q_{t}$ & $n-1$ & \\
\hline Onde: &
\end{tabular}

Onde:

$$
Q_{e}=\sum_{i}\left[\frac{\left(\sum_{j} x_{i j}\right)^{2}}{n_{i}}\right]-C \quad Q_{t}=\sum_{i=1}^{K} \sum_{j=1}^{n_{i}} x_{i j}^{2}-C \quad C=\frac{\left(\sum_{i=1}^{K} \sum_{j=1}^{n_{i}} x_{i j}\right)^{2}}{n}
$$

Assim se $F_{c a l}>F_{(k-1, n-k)}$, conclui-se pela hipótese nula, ou seja, a igualdade entre os grupos, caso contrário conclui-se pela hipótese alternativa $\left(H_{1}\right)$.

Para o entendimento deste teste, alguns conceitos estatísticos são necessários. São eles: mediana, desvio padrão, coeficiente de variação, valores mínimo e máximo e, intervalo de confiança.

Entende-se mediana como uma medida de posição. Ela divide a amostra ao meio e sempre é analisada em relação à média. Assim quanto mais próximo seu valor for da média, mais simétrica é a distribuição dos dados. Por outro lado, quando mais distante seu valor for da média, a distribuição dos dados mostra-se mais assimétrica e com grande variabilidade.

Já a variabilidade é medida pelo desvio-padrão. Assim quanto mais próximo (ou maior) for esse valor em relação à média, maior será a variabilidade. Muita variabilidade significa pouca homogeneidade dos dados.

Entende-se coeficiente de variação (CV) como uma estatística que avalia o quanto a variabilidade representa da média. Quanto mais baixo for esse índice, menor variabilidade e consequentemente mais homogeneidade dos resultados. 
Já valores ‘mínimo’ e ‘máximo’ são respectivamente o menor e o maior valor encontrados na amostra.

Por fim, o intervalo de confiança ora somado e ora subtraído da média mostra a variação da média segundo uma probabilidade estatística. O intervalo de confiança (IC) é mais confiável, pois há uma probabilidade estatística associada em seu cálculo.

\subsection{Correlação de Pearson}

Essa técnica serve para "medir" (mensurar) o quanto as variáveis estão interligadas, ou seja, o quanto uma está relacionada com a outra. Os resultados são dados em percentual, por isso, fica fácil de se entender. Vale lembrar que podemos ter valores positivos e negativos.

Quando a correlação for positiva significa que à medida que uma variável aumenta seu valor, a outra correlacionada a esta, também aumenta proporcionalmente. Porém se a correlação for negativa implica que as variáveis são inversamente proporcionais, ou seja, à medida que uma cresce a outra decresce, ou vice versa.

A metodologia desta técnica se dá da seguinte maneira:

$$
\begin{gathered}
\rho_{\mathrm{xy}}=\frac{E[X Y]-\mu_{x} \mu_{y}}{\sigma_{x} \sigma_{y}} \quad \operatorname{com} \quad-1 \leq \rho_{x y} \leq 1 \\
\text { Onde: } \quad E[X Y]=\sum_{i} \sum_{j} x_{i} \cdot y_{j} \cdot \rho\left(x_{i}, y_{i}\right)
\end{gathered}
$$

Quando são feitas diversas correlações ao mesmo tempo, colocam-se os resultados em uma única tabela, que é chamada de Matriz de Correlação.

Para determinamos o quão bom é uma correlação, utiliza-se a escala de classificações abaixo.

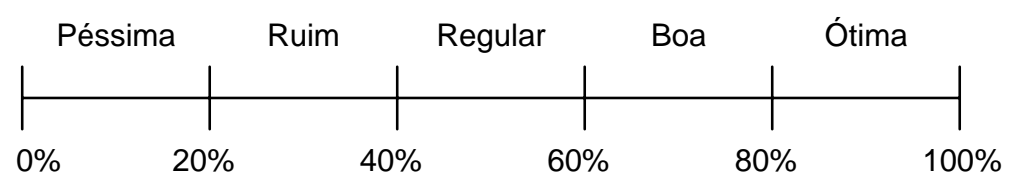




\subsection{Teste de Correlação}

O teste para o coeficiente de correlação é utilizado como no caso da média e variância, para testar o coeficiente de correlação entre duas variáveis. As hipóteses testadas são:

$$
\left\{\begin{array}{l}
H_{o}: \rho=0 \\
H_{1}: \rho \neq 0
\end{array}\right.
$$

Este teste pode ser feito através da variável $t_{0}=\rho \sqrt{\frac{n-2}{1-\rho^{2}}}$ que tem distribuição $\mathrm{t}$ de Student com $(n-2)$ graus de liberdade. Para realizar o teste procede-se como nos demais testes de hipóteses:

- Encontre na tabela t de Student com (n-2) graus de liberdade um valor $t_{\alpha / 2}$ tal que $p\left(t<-t_{\alpha / 2}\right)=\frac{\alpha}{2}$ e $p\left(t>t_{\alpha / 2}\right)=\frac{\alpha}{2}$.

- Calcule $t_{0}=\rho \sqrt{\frac{n-2}{1-\rho^{2}}}$ a partir dos dados da amostra.

- Se $t_{0}<-t_{\alpha / 2}$ ou $t_{0}>t_{\alpha / 2}$, rejeite $H_{0}$.

\subsection{Intervalo de Confiança para Média}

O intervalo de confiança para a Média é uma técnica utilizada quando se quer ver o quanto a média pode variar numa determinada probabilidade de confiança. Essa técnica é descrita da seguinte maneira:

$$
P\left(\bar{x}-Z_{\alpha / 2} \frac{\sigma}{\sqrt{n}} \leq \mu \leq \bar{x}+Z_{\alpha / 2} \frac{\sigma}{\sqrt{n}}\right)=1-\alpha
$$


Onde:

$\bar{X}=$ média amostral;

$Z_{\alpha / 2}=$ percentil da distribuição normal;

$\sigma=$ variância amostral (estatística não viciada da variância populacional);

$\mu=$ média populacional;

$\alpha=$ nível de significância.

\subsection{P-valor}

É importante lembrar que o resultado de cada comparação possui uma estatística chamada de p-valor. Esta estatística é que ajuda a concluir sobre o teste realizado. Caso esse valor seja maior que o nível de significância adotado (erro ou $\alpha$ ), conclui-se portanto que a $H_{0}$ (a hipótese nula) é a hipótese verdadeira, caso contrário fica-se com $H_{1}$, a hipótese alternativa.

\section{Legenda}

* p-valores considerados estatisticamente significativos perante o nível de significância adotado.

\# p-valores que, por estarem próximos do limite de aceitação, são considerados que tendem a ser significativos.

- X -, quando não foi possível utilizar a estatística, nós colocamos estes símbolos.

\section{Softwares}

Nesta analise estatística foram utilizados os softwares: SPSS V16, Minitab 15 e Excel Office 2007. 


\section{Bibliografia}

- JAIRO, SIMON DA FONSECA \& GILBERTO DE ANDRADE MARTINS, Curso de Estatística, 6a Edição, Editora Atlas - São Paulo 1996, 320 pp.

- MURRAY, R. SPIEGEL, Estatística Coleção Schaum, $3^{\text {a }}$ Edição, Editora Afiliada, São Paulo 1993, 640 pp.

- Vieira, Sônia, Bio Estatística Tópicos Avançados, 2ª Edição, Editora Campus, Rio de Janeiro 2004, 212 pp.

- VIEIRA, Sônia. (1991). Introdução à Bioestatística. Rio de Janeiro: Campus.

- MAROCO, João, Análise Estatística com utilização do SPSS, $2^{\mathrm{a}}$ Edição, Editora Silabo, Lisboa 2003, 508 pp. 